UNIVERSIDADE DE BRASÍLIA

FACULDADE DE CIÊNCIAS DA SAÚDE

PROGRAMA DE PÓS-GRADUAÇÃO EM ENFERMAGEM

ALAÍDE FRANCISCA DE CASTRO

PRÁTICAS DE PRECAUÇÕES EM UNIDADE DE TERAPIA INTENSIVA DE UM HOSPITAL DE ENSINO DO DISTRITO FEDERAL

BRASÍLIA

2016 
UNIVERSIDADE DE BRASÍLIA

FACULDADE DE CIÊNCIAS DA SAÚDE

PROGRAMA DE PÓS-GRADUAÇÃO EM ENFERMAGEM

ALAÍDE FRANCISCA DE CASTRO

\section{PRÁTICAS DE PRECAUÇÕES EM UNIDADE DE TERAPIA INTENSIVA DE UM HOSPITAL DE ENSINO DO DISTRITO FEDERAL}

Dissertação apresentada como requisito parcial para a obtenção do Título de Mestre em Enfermagem pelo Programa de PósGraduação em Enfermagem da Universidade de Brasília.

Área de Concentração: Cuidado, Gestão e Tecnologias em Saúde e Enfermagem.

Linha de Pesquisa: Gestão de Sistemas e de Serviços em Saúde e Enfermagem.

Orientadora: Prof. ${ }^{a}$ Dr. ${ }^{a}$ Maria Cristina Soares Rodrigues

BRASÍLIA 
Ficha catalográfica elaborada automaticamente, com os dados fornecidos pelo(a) autor(a)

Castro, Alaide Francisca de
Práticas de precauços em Unidade de Terapia
Intensiva de um hospital de ensino do Distrito
Federal / Alaide Francisca de Castro; orientador
Maria Cristina Soares Rodrigues. -- Brasilia, 2016.
$153 \mathrm{p.}$
Dissertação (Mestrado - Mestrado em Enfermagem) --
Universidade de Brasilia, 2016.
1. Higiene das Măos. 2. Precauçōes Universais. 3.
Unidades de Terapia Intensiva. 4. Infecção
Hospitalar. 5. Segurança do Paciente. I. Rodrigues,
Maria Cristina Soares, orient. II. Titulo.


ALAÍDE FRANCISCA DE CASTRO

\title{
PRÁTICAS DE PRECAUÇÕES EM UNIDADE DE TERAPIA INTENSIVA DE UM HOSPITAL DE ENSINO DO DISTRITO FEDERAL
}

\begin{abstract}
Dissertação apresentada como requisito parcial para a obtenção do título de Mestre em Enfermagem pelo Programa de Pós-Graduação em Enfermagem da Universidade de Brasília.
\end{abstract}

Aprovado em 15 de junho de 2016.

BANCA EXAMINADORA

Professora Doutora Maria Cristina Soares Rodrigues - Presidente da Banca

Universidade de Brasília

Professora Doutora Marcia Cristina da Silva Magro - Membro Efetivo do Programa Universidade de Brasília

Professora Doutora Paula Regina de Souza Hermann - Membro Externo ao Programa Universidade de Brasília

Professora Doutora Maria do Socorro Nantua Evangelista - Suplente Universidade de Brasília 
Dedico este trabalho à minha família, especialmente à minha mãe, Maria José, que lutou uma vida inteira para educar seus filhos. 


\section{AGRADECIMENTOS}

A Deus, por estar sempre ao meu lado.

Aos meus pais, pela criação tranquila e amorosa.

Ao meu esposo, pela cumplicidade em todos os momentos.

À minha filha, pela alegria que me traz ao vê-la tão inteligente e bela.

Ao meu filho, pelos sorrisos inocentes e beijos carinhosos que me apaixonam cada vez mais.

Ao meu irmão, sempre estudioso, e, como primogênito da família, foi exemplo para as irmãs.

À minha irmã e maior amiga, pelo interesse em participar e dividir realizações profissionais e de vida.

À Prof. ${ }^{\mathrm{a}}$ Dr. ${ }^{\mathrm{a}}$ Maria Cristina Soares Rodrigues, minha orientadora, pela maestria com que me conduziu na realização deste trabalho.

À Prof. ${ }^{a}$ Dr. $^{\text {a }}$ Osiris Turnes, minha estimada colaboradora, pela generosidade e disponibilidade com que contribuiu na correção da redação deste trabalho.

Aos colegas de mestrado, que contribuíram com ricas e alegres discussões sobre os temas abordados em nossas maravilhosas e saudosas aulas.

A toda a equipe de profissionais da Unidade de Terapia Intensiva do hospital do estudo que contribuiu para a realização de mais um estudo.

À amiga Isabela, pelo apoio, atenção e conselhos nos momentos difíceis.

Aos demais colegas de trabalho do Hospital Universitário de Brasília, que há vários anos me ouvem falar sobre o tema e me trazem suas dificuldades e expectativas, e, assim, contribuíram para a realização do trabalho. 
"O certo é certo mesmo que ninguém esteja fazendo e o errado é errado mesmo que todos estejam fazendo”.

(Autor desconhecido) 


\section{RESUMO}

Castro, Alaíde Francisca de. Práticas de precauções em Unidade de Terapia Intensiva de um hospital de ensino do Distrito Federal. 2016. 153p. Dissertação (Mestrado) Departamento de Enfermagem, Faculdade de Ciências da Saúde, Universidade de Brasília, Brasília, 2016.

INTRODUÇÃO: Os serviços de saúde têm dedicado grandes esforços para melhorar a adesão às medidas de prevenção de infecções relacionadas à assistência à saúde. $\mathrm{Na}$ avaliação da adesão às precauções, são necessárias auditorias de indicadores clínicos de estrutura e processo. OBJETIVOS: Avaliar a infraestrutura e as práticas de precauções dos profissionais de saúde da Unidade de Terapia Intensiva (UTI) de um hospital de ensino do Distrito Federal. MÉTODOS: Estudo descritivo, observacional, transversal e exploratório. Foram aplicados três instrumentos: um questionário autoaplicável aos profissionais e dois questionários estruturados para auditorias por meio de observações que avaliaram a adesão à higiene das mãos e registraram as condições físicas, a disponibilidade de insumos para as práticas de precauções, o uso de Equipamentos de Proteção Individual (EPI) e as indicações de precauções. Foi aplicado teste $\chi^{2}$ de independência e apresentado o nível descritivo. RESULTADOS: A estrutura física e os recursos materiais eram limitados quanto ao tipo das torneiras de alguns lavatórios e à indisponibilidade das preparações alcoólicas no ponto de assistência e antissépticos degermantes. O reabastecimento dos dispensadores de produtos era falho e o fornecimento de EPI foi irregular. Os profissionais da UTI eram capacitados, mas não havia médico diarista. A média da adesão à higiene das mãos foi de $65,31 \%$, sendo majoritariamente realizada com a higiene simples. Existiu diferença significativa da adesão entre as categorias profissionais $\left(\mathcal{X}^{2} 16,13\right.$ e $\left.p<0,01\right)$, com maior taxa entre os médicos $(77,94 \%)$, seguida dos fisioterapeutas $(73,84 \%)$, enfermeiros $(72,11 \%)$ e técnicos de enfermagem $(57,70 \%)$. Foi evidenciada significância da menor adesão dos técnicos de enfermagem durante os períodos da tarde e noite e não existiu diferença entre os dias da semana. Os momentos anteriores ao contato com o paciente e antes da realização de procedimentos assépticos apresentaram menor adesão $\left(\chi^{2} 130,33\right.$ e $\left.p<0,01\right)$. Quase todos pacientes foram submetidos às precauções de contato ao serem admitidos na UTI e $35 \%$ dessas indicações foram desnecessárias. Quanto ao uso de EPI para procedimentos assistenciais, existiu alta adesão ao uso de luvas, avental e máscara e muito baixa adesão ao uso de óculos de proteção. O não uso de EPI, quando não indicado, mostrou menor taxa de acerto ao não uso de luvas, porém, em números absolutos, a máscara foi o EPI mais usado desnecessariamente. A média da taxa de acerto do uso de EPI foi $72,72 \%\left(\chi^{2} 226,07\right)$ e do não uso, quando não indicado, foi de $68,01 \%$ ( $\left.\mathcal{X}^{2} 175,69\right)$, ambas com diferença significativa entre os EPI $(p<0,01)$. Entre as categorias profissionais, se evidenciou diferença entre fisioterapeutas do noturno devido ao não uso dos óculos em aspiração traqueal $\left(\mathcal{X}^{2} 6,14\right)$. CONCLUSÃO: Os resultados mostraram limitada infraestrutura, o que refletiu na baixa adesão à fricção antisséptica. Encontrou-se boa adesão ao uso de luvas, avental e máscara e baixa adesão ao uso de óculos de proteção. Identificou-se frequente uso desnecessário de máscaras e das precauções de contato admissionais. Auditorias por observação direta são limitadas devido ao efeito Hawthorne, mas fornecem um retrato do comportamento e da qualidade das práticas.

Palavras chave: Higiene das Mãos, Isolamento de Pacientes, Unidades de Terapia Intensiva, Infecção Hospitalar, Precauções Universais, Segurança do Paciente. 


\begin{abstract}
Castro, Alaíde Francisca de. Practices of precautions in a Intensive Care Unit of a teaching hospital of the Federal District. 2016. 153p. Dissertation (Master Degree) Department of Nursing, Faculty of Health Sciences, University of Brasília, Brasília, 2016.

INTRODUCTION: Health services have dedicated large efforts to improve the adherence to preventive measures against infections related to health care. When evaluating the adherence to the precautions, there is a need for audits of clinical indicators of structure and process. OBJECTIVES: Evaluate the infrastructure and practices of health professionals precautions in Intensive Care Unit (ICU) of a teaching hospital of the Federal District. METHODS: This is a descriptive, observational, cross-sectional and exploratory study. Three instruments were applied: a self-administered questionnaire to professionals and two structured questionnaires for audits by means of observations that evaluated the adherence to hand hygiene and recorded the physical conditions, the availability of inputs for the practices of precautions, the use of Personal Protective Equipment (PPE) and the indications of precautions. It was applied $\chi^{2}$ test of independence and presented the descriptive level. RESULTS: The physical structure and the material resources were limited with regard to the type of faucets of some sinks and to the unavailability of alcoholic preparations at the point of care and antiseptics to eliminate germs. The replenishment of product dispensers was flawed and the supply of PPE was irregular. The ICU professionals were empowered, but there was no diarist physician. The average of adherence to hand hygiene was $65.31 \%$, and it was mostly conducted with simple hygiene. There was a significant difference in the adherence among the professional categories $\left(\chi^{2} 16.13\right.$ and $\left.p<0.01\right)$, with a higher rate among physicians $(77.94 \%)$, followed by physiotherapists $(73.84 \%)$, nurses $(72.11 \%)$ and nursing technicians $(57.70 \%)$. It was found a significance of the lower adherence of nursing technicians during the afternoon and eveningnight shifts and there was no difference among the days of the week. The moments before the contact with the patient and before the accomplishment of aseptic procedures showed a lower adherence $\left(\chi^{2} 130.33\right.$ and $\left.p<0.01\right)$. Almost all patients were submitted to contact precautions when they were admitted to ICU and $35 \%$ of those indications were unnecessary. Concerning the use of PPE for health care procedures, there was a high adherence to the use of gloves, apron and mask and a very low adherence to the use of safety glasses. The non-use of PPE, when not indicated, showed a lower success rate in relation to the non-use of gloves, but, in absolute numbers, the mask was the PPE most used unnecessarily. The average of the success rate of the use of PPE was $72.72 \%\left(\chi^{2} 226.07\right)$ and of the non-use, when not indicated, was $68.01 \%\left(\chi^{2} 175.69\right)$, both with significant difference among PPE $(p<0.01)$. Among the professional categories, it was found a difference among the physiotherapists of the night shift due to the non-use of safety glasses in tracheal aspiration $\left(\chi^{2} 6.14\right)$. CONCLUSION: The results have shown a limited infrastructure, which resulted in the low adherence to antiseptic friction. It was found a good adherence to the use of gloves, apron and mask and a low adherence to the use of safety glasses. It was identified a frequent unnecessary use of masks and of the precautions of contact related to admission. Audits by direct observation are limited due to the Hawthorne effect, but they provide a portrait of the behavior and of the quality of the practices.
\end{abstract}

Keywords: Hand Hygiene, Patient Isolation, Intensive Care Units, Cross Infection, Universal Precautions, Patient Safety. 


\section{RESUMEN}

Castro, Alaíde Francisca de. Prácticas de precauciones en la Unidad de Cuidados Intensivos de un hospital de enseñanza del Distrito Federal. 2016. 153p. Disertación (Maestría) - Departamento de Enfermería, Facultad de Ciencias de la Salud, Universidad de Brasília, Brasília, 2016.

INTRODUCCIÓN: Los servicios de salud han dedicado grandes esfuerzos para mejorar la adhesión a las medidas de prevención de infecciones relacionadas con la asistencia a la salud. En la evaluación la adhesión a las precauciones, es necesario tener auditorías de indicadores clínicos de estructura y proceso. OBJETIVOS: Evaluar la infraestructura y las prácticas de los profesionales de las precauciones de salud en la Unidad de Cuidados Intensivos (UCI) de un hospital de enseñanza del Distrito Federal. MÉTODOS: Estudio descriptivo, observacional, transversal y exploratorio. Se aplicaron tres instrumentos: un cuestionario autoaplicable para los profesionales y dos cuestionarios estructurados para auditorías por medio de observaciones que evaluaron la adhesión a la higiene de manos y registraron las condiciones físicas, la disponibilidad de insumos para las prácticas de precauciones, el uso de Equipos de Protección Personal (EPP) y las indicaciones de precauciones. Se aplicó la prueba de $\chi^{2}$ de independencia y presentó el nivel descriptivo. RESULTADOS: La estructura física y los recursos materiales eran limitados en cuanto al tipo de los grifos de algunos lavabos y a la indisponibilidad de las preparaciones alcohólicas en el punto de asistencia y antisépticos eliminadores de gérmenes. El reabastecimiento de los dispensadores de productos era defectuoso y el suministro de EPP fue irregular. Los profesionales de la UCI eran calificados, pero no había médico diarista. El promedio de la adhesión a la higiene de las manos fue del $65,31 \%$ y, mayoritariamente, efectuada con la higiene simple. Existió una diferencia significativa en la adhesión entre las categorías profesionales $\left(\chi^{2} 16,13\right.$ y $\left.p<0,01\right)$, con una mayor tasa entre los médicos $(77,94 \%)$, seguida por los fisioterapeutas $(73,84 \%)$, enfermeros $(72,11 \%)$ y técnicos de enfermería $(57,70 \%)$. Se evidenció una significación de la menor adhesión de los técnicos de enfermería durante los períodos de la tarde y de la noche y no existió diferencia entre los días de la semana. Los momentos previos al contacto con el paciente y antes de la ejecución de procedimientos asépticos presentaron una menor adhesión $\left(\chi^{2} 130,33\right.$ y $\left.p<0,01\right)$. Casi todos los pacientes fueron sometidos a las precauciones de contacto cuando fueron admitidos en la UCI y el 35\% de esas indicaciones fueron innecesarias. En cuanto al uso de EPP para los procedimientos asistenciales, existió una alta adhesión al uso de guantes, delantal y mascarilla y una muy baja adhesión al uso de gafas de protección. El no uso de EPP, cuando no hay indicación, mostró una menor tasa de acierto con respeto al no uso de guantes, pero, en números absolutos, la mascarilla fue el EPP más usado innecesariamente. El promedio de la tasa de acierto del uso de EPP fue del $72,72 \%$ $\left(\mathcal{X}^{2} 226,07\right)$ y del no uso, cuando no hay indicación, fue del $68,01 \%\left(\mathcal{X}^{2} 175,69\right)$, ambas con una diferencia significativa entre los EPP $(p<0,01)$. Entre las categorías profesionales, se evidenció una diferencia significativa entre los fisioterapeutas del turno nocturno debido al no uso de gafas en la aspiración traqueal $\left(\chi^{2} 6,14\right)$. CONCLUSIÓN: Los resultados mostraron una infraestructura limitada, lo que resultó en una baja adhesión a la fricción antiséptica. Se encontró una buena adhesión al uso de guantes, delantal y mascarilla y una baja adhesión al uso de gafas de protección. Se identificó un frecuente uso innecesario de mascarillas y de las precauciones de contacto de admisión. Auditorías por observación directa son limitadas debido al efecto Hawthorne, pero suministran un cuadro del comportamiento y de la calidad de las prácticas. 
Palabras clave: Higiene de las Manos, Aislamiento de Pacientes, Unidades de Cuidados Intensivos, Infección Hospitalaria, Precauciones Universales, Seguridad del Paciente 


\section{LISTA DE FIGURAS}

FIGURA 1 - CADEIA EPIDEMIOLÓGICA DAS INFECÇÕES E INTERVENÇÕES PARA A QUEBRA DA CADEIA.

FIGURA 2 - ESTRUTURA FÍSICA INTERNA DA ÁREA DE INTERNAÇÃO, LOCALIZAÇÃO DOS LEITOS ATIVOS, PIAS, CUBAS E DISPENSADORES DE PREPARAÇÕES ALCOÓLICAS PARA HIGIENE DAS MÃOS, NA UTI DO HOSPITAL DE ENSINO. BRASÍLIA, DF, BRASIL, 2015. 73

FIGURA 3 - TAXA DE ADESÃO A HIGIENIZAÇÃO DAS MÃOS POR CATEGORIAS DOS PROFISSIONAIS QUE TRABALHAM NA ASSISTÊNCIA DIRETA AOS PACIENTES, NA UTI DO HOSPITAL DE ENSINO. BRASÍLIA, DF, BRASIL, 2015.

FIGURA 4 - TAXA DE ADESÃO AO TIPO DE HIGIENE DAS MÃOS DOS PROFISSIONAIS QUE ATUAM NA ASSISTENNCIA DIRETA AOS PACIENTES, NA UTI DO HOSPITAL DE ENSINO, POR CATEGORIAS. BRASÍLIA, DF, BRASIL, 2015. 79

FIGURA 5 - TAXA DE ADESÃO A HIGIENIZAÇÃO DAS MÃOS POR INDICAÇÕES (5 MOMENTOS) DOS PROFISSIONAIS QUE ATUAM NA ASSISTÊNCIA DIRETA AOS PACIENTES, NA UTI DO HOSPITAL DE ENSINO. BRASÍLIA, DF, BRASIL, 2015. 80

FIGURA 6 - TIPO DE HIGIENE DAS MÃOS POR INDICAÇÃO DOS PROFISSIONAIS QUE ATUAM NA ASSISTÊNCIA DIRETA AOS PACIENTES, NA UTI DO HOSPITAL DE ENSINO. BRASÍLIA, DF, BRASIL, 2015.

FIGURA 7 - PERCENTUAL DE USO CORRETO DO EPI NOS PROCEDIMENTOS DE ADMINISTRAÇÃO DE DIETA, ASPIRAÇÃO DE TRAQUEIA, BANHO NO LEITO, COLETA DE SANGUE, CUIDADOS COM ESTOMIAS, CURATIVOS, CURATIVOS DE CATETERES, AFERIÇÕES DE DÉBITOS DE DIETAS, INSTALAÇÃO DE DRENOS DE TÓRAX, ESVAZIAMENTO 
DE BOLSAS DE DIURESE, REALIZAÇÃO DE EXAME FÍSICO E GLICEMIA CAPILAR PELOS PROFISSIONAIS QUE ATUAM NA ASSISTÊNCIA DIRETA AOS PACIENTES, NA UTI DO HOSPITAL DE ENSINO. BRASÍLIA, DF, BRASIL, 2015. 89

FIGURA 8 - PERCENTUAL DE USO CORRETO DO EPI NOS PROCEDIMENTOS DE HIGIENE ORAL, INSTALAÇÃO DE CATETER PERIFÉRICO, INSTALAÇÃO DE CATETER VENOSO CENTRAL, INSTALAÇÃO DE SONDA NASOGÁSTRICA OU NASOENTÉRICA, INSTALAÇÃO DE SONDA VESICAL, MANUSEIO DE EQUIPAMENTOS, ADMINISTRAÇÃO DE MEDICAÇÃO ENDOVENOSA, MUDANÇA DE DECÚBITO, TRANSPORTE, TROCA DE EQUIPO, TROCA DE FRALDA E OUTROS PELOS PROFISSIONAIS QUE ATUAM NA ASSISTÊNCIA DIRETA AOS PACIENTES, NA UTI DO HOSPITAL DE ENSINO. BRASÍLIA, DF, BRASIL, 2015 ..................................................................90 


\section{LISTA DE TABELAS}

TABELA 1 - NÚMERO E PROPORÇÃO DOS PROFISSIONAIS QUE ATUAM NA ASSISTÊNCIA DIRETA AOS PACIENTES, NA UTI DE UM HOSPITAL DE ENSINO, POR GÊNERO. BRASÍLIA, DF, BRASIL, 2015. 68

TABELA 2 - NÚMERO E PROPORÇÃO DOS PROFISSIONAIS QUE ATUAM NA ASSISTÊNCIA DIRETA AOS PACIENTES, NA UTI DO HOSPITAL DE ENSINO, POR FAIXA ETÁRIA. BRASÍLIA, DF, BRASIL, 2015. 69

TABELA 3 - TEMPO EM ANOS DE ATUAÇÃO DOS PROFISSIONAIS QUE TRABALHAM NA ASSISTÊNCIA DIRETA AOS PACIENTES, NA UTI DO HOSPITAL DE ENSINO, POR CATEGORIA. BRASÍLIA, DF, BRASIL, 2015. 69

TABELA 4 - CARGA HORÁRIA SEMANAL DE TRABALHO DOS PROFISSIONAIS QUE ATUAM NA ASSISTÊNCIA DIRETA AOS PACIENTES, NA UTI DO HOSPITAL DE ENSINO. BRASÍLIA, DF, BRASIL, 2015. 70

TABELA 5 - PERCENTUAL DE PROFISSIONAIS QUE ATUAM NA ASSISTÊNCIA DIRETA AOS PACIENTES, NA UTI DO HOSPITAL DE ENSINO, QUE RECEBERAM CAPACITAÇÃO SOBRE HIGIENE DAS MÃOS, USO DE EPI E TIPOS DE PRECAUÇÕES NA FORMAÇÃO POR CATEGORIA PROFISSIONAL. BRASÍLIA, DF, BRASIL, 2015. 70

TABELA 6 - PERCENTUAL DE PROFISSIONAIS QUE ATUAM NA ASSISTÊNCIA DIRETA AOS PACIENTES, NA UTI DO HOSPITAL DE ENSINO, QUE RECEBERAM TREINAMENTO EM SERVIÇO SOBRE HIGIENE DAS MÃOS, USO DE EPI E TIPOS DE PRECAUÇÕES, POR CATEGORIA PROFISSIONAL. BRASÍLIA, DF, BRASIL, 2015.

TABELA 7 - FREQUÊNCIA DE INSUMOS DISPONÍVEIS PARA HIGIENE DAS MÃOS, POR SESSÃO DE OBSERVAÇÃO E PERCENTUAL ACUMULADO, NA UTI DO HOSPITAL DE ENSINO. BRASÍLIA, DF, BRASIL, 2015 
TABELA 8 - DISPONIBILIDADE DO EPI NA UTI DO HOSPITAL DE ENSINO, POR 36 SESSÕES DE OBSERVAÇÕES. BRASÍLIA, DF, BRASIL, 2015. 76

TABELA 9 - QUANTITATIVO DE PROFISSIONAIS COM ADORNO NAS MÃOS POR SESSÃO DE OBSERVAÇÃO, NA UTI DO HOSPITAL DE ENSINO. BRASÍLIA, DF, BRASIL, 2015. 76

TABELA 10 - FREQUÊNCIA DE PROFISSIONAIS COM ADORNO NAS MÃOS, NA UTI DO HOSPITAL DE ENSINO, POR 36 SESSÕES DE OBSERVAÇÕES. BRASÍLIA, DF, BRASIL, 2015. 76

TABELA 11 - FREQUÊNCIA DE PLANTONISTA POR CATEGORIA PROFISSIONAL PRESENTES POR SESSÃO, EM 36 OBSERVAÇÕES E PERCENTUAL ACUMULADO, NA UTI DO HOSPITAL DE ENSINO. BRASÍLIA, DF, BRASIL, 2015. 77

TABELA 12 - FREQUÊNCIA DE SESSÕES, DENTRE AS 36 OBSERVADAS, EM QUE O NÚMERO DE PLANTONISTAS ATENDEU ÀS EXIGÊNCIAS DA REGULAMENTAÇÃO SANITÁRIA NACIONAL, NA UTI DO HOSPITAL DE ENSINO, POR CATEGORIA PROFISSIONAL. BRASÍLIA, DF, BRASIL, 2015. 78

TABELA 13 - NÚMERO DE OPORTUNIDADES PARA A HIGIENIZAÇÃO DAS MÃOS OBSERVADAS E TAXA DE ADESÃO POR CATEGORIAS DOS PROFISSIONAIS QUE TRABALHAM NA ASSISTÊNCIA DIRETA AOS PACIENTES, NA UTI DO HOSPITAL DE ENSINO. BRASÍLIA, DF, BRASIL, 2015. 78

TABELA 14 - TAXA DE ADESÃO A HIGIENIZAÇÃO DAS MÃOS POR INDICAÇÕES (5 MOMENTOS) DOS PROFISSIONAIS QUE ATUAM NA ASSISTÊNCIA DIRETA AOS PACIENTES, NA UTI DO HOSPITAL DE ENSINO. BRASÍLIA, DF, BRASIL, 2015. 80

TABELA 15 - TESTE QUI-QUADRADO DE INDEPENDÊNCIA DAS OBSERVAÇÕES DE ADESÃO À HIGIENE DAS MÃOS DOS PROFISSIONAIS QUE ATUAM NA ASSISTÊNCIA DIRETA AOS PACIENTES, NA UTI DO HOSPITAL DE ENSINO. BRASÍLIA, DF, BRASIL, 2015. 
TABELA 16 - TESTE QUI-QUADRADO DE INDEPENDÊNCIA DAS OBSERVAÇÕES DE ADESÃO À HIGIENE DAS MÃOS DOS PROFISSIONAIS POR TURNO DE TRABALHO DOS PROFISSIONAIS QUE ATUAM NA ASSISTÊNCIA DIRETA AOS PACIENTES, NA UTI DO HOSPITAL DE ENSINO. BRASÍLIA, DF, BRASIL, 2015. 83

TABELA 17 - TESTE QUI-QUADRADO DE INDEPENDÊNCIA DAS OBSERVAÇÕES DE ADESÃO À HIGIENE DAS MÃOS POR TURNO DE TRABALHO DOS PROFISSIONAIS QUE ATUAM NA ASSISTÊNCIA DIRETA AOS PACIENTES, NA UTI DO HOSPITAL DE ENSINO. BRASÍLIA, DF, BRASIL, 2015. 84

TABELA 18 - FREQUÊNCIA DE ADEQUAÇÃO E INADEQUAÇÃO DAS INDICAÇÕIES DE PRECAUÇÕES NA UTI DO HOSPITAL DE ENSINO. BRASÍLIA, DF, BRASIL, 2015. . .84

TABELA 19 - NÚMERO DE OBSERVAÇÕES DE PROCEDIMENTOS ASSISTENCIAIS, POR CATEGORIA DE PROFISSIONAIS QUE ATUAM NA ASSISTÊNCIA DIRETA AOS PACIENTES, NA UTI DO HOSPITAL DE ENSINO. BRASÍLIA, DF, BRASIL, 2015. . .85

TABELA 20 - FREQUÊNCIA DA INDICAÇÃO DO EPI E DO USO DURANTE OS PROCEDIMENTOS PELOS PROFISSIONAIS QUE ATUAM NA ASSISTÊNCIA DIRETA AOS PACIENTES, NA UTI DO HOSPITAL DE ENSINO. BRASÍLIA, DF, BRASIL, 2015. 86

TABELA 21 - FREQUÊNCIA E TAXA DE USO CORRETO DOS 4 EPI (AVENTAL, LUVAS, MÁSCARA E ÓCULOS) POR PROCEDIMENTOS REALIZADOS PELOS PROFISSIONAIS QUE ATUAM NA ASSISTÊNCIA DIRETA AOS PACIENTES, NA UTI DO HOSPITAL DE ENSINO. BRASÍLIA, DF, BRASIL, 2015. 87

TABELA 22 - TESTE QUI-QUADRADO DE INDEPENDÊNCIA DO USO DO EPI ENTRE OS TIPOS DE EPI, PROFISSIONAIS E TURNOS DE TRABALHO, NA UTI DO HOSPITAL DE ENSINO. BRASÍLIA, DF, BRASIL, 2015. 
TABELA 23 - TESTE QUI-QUADRADO DE INDEPENDÊNCIA DO USO DE EPI ENTRE OS PROFISSIONAIS POR TURNO DE TRABALHO, NA UTI DO HOSPITAL DE ENSINO. BRASÍLIA, DF, BRASIL, 2015 ..........................92

TABELA 24 - TESTE QUI-QUADRADO DE INDEPENDÊNCIA DO USO DE EPI ENTRE OS TURNOS DE TRABALHO POR PROFISSIONAIS, NA UTI DO HOSPITAL DE ENSINO. BRASÍLIA, DF, BRASIL, 2015 ...................93 


\section{LISTA DE SIGLAS}

ABIH - Associação Brasileira dos Profissionais em Controle e Epidemiologia Hospitalar

AHA - American Hospital Association

AIDS - Síndrome da Imunodeficiência Adquirida

ANVISA - Agência Nacional de Vigilância Sanitária

APECIH - Associação Paulista de Epidemiologia e Controle de Infecção Relacionada à Assistência à Saúde

APIC - Association for Professionals in Infection Control and Epidemiology

CCIH - Comissão de Controle de Infecção Hospitalar

CCIRAS - Comissão de Controle de Infecções Relacionadas à Assistência à Saúde

CDC - Centers for Disease Control and Prevention

CDI - Clostridium difficile

CEP $\quad-$ Comitê de Ética em Pesquisa

CNS - Conselho Nacional de Saúde

CVE/SP - Centro de Vigilância Epidemiológica/São Paulo

DF $\quad-$ Distrito Federal

EBSERH - Empresa Brasileira de Serviços Hospitalares

ECDC - European Center for Disease Prevention and Control

ESCMID - European Society of Clinical Microbiology and Infectious Diseases 


\begin{tabular}{|c|c|}
\hline EPI & - Equipamento de Proteção Individual \\
\hline EUA & - Estados Unidos da América \\
\hline HIV & - Vírus da Imunodeficiência Humana \\
\hline HM & - Higiene das Mãos \\
\hline HUB & - Hospital Universitário de Brasília \\
\hline IDSA & - Infectious Diseases Society of America \\
\hline IHI & - Institute for Healthcare Improvement \\
\hline IRAS & - Infecções Relacionadas à Assistência à Saúde \\
\hline MRSA & - Staphytlococcus aureus resistente a meticilina \\
\hline MS & - Ministério da Saúde \\
\hline MTE & - Ministério do Trabalho e Emprego \\
\hline NR & - Norma Regulamentadora \\
\hline NSP & - Núcleo de Segurança do Paciente \\
\hline OMS & - Organização Mundial da Saúde \\
\hline OPAS & - Organização Panamericana da Saúde \\
\hline PCIH & - Programa de Controle de Infecção Hospitalar \\
\hline PCIRAS & $\begin{array}{l}\text { - Programa de Controle de Infecções Relacionadas à Assistência à } \\
\text { Saúde }\end{array}$ \\
\hline PIBIC & - Programa de Iniciação Científica \\
\hline PIDS & - Pediatric Infectious Diseases Society \\
\hline PNSP & - Programa Nacional de Segurança do Paciente \\
\hline
\end{tabular}




$\begin{array}{ll}\text { POP } & - \text { Procedimento Operacional Padrão } \\ \text { PVPI } & - \text { Polivinilpirrolidona Iodo } \\ \text { RN } & - \text { Recém-nascido } \\ \text { RDC } & - \text { Resolução da Diretoria Colegiada } \\ \text { SCCM } & - \text { Society for Critical Care Medicine } \\ \text { SHEA } & - \text { Society for Healthcare Epidemiology of America } \\ \text { SHM } & - \text { Society for Hospital Medicine } \\ \text { SIS } & - \text { Surgical Infection Society } \\ \text { TCLE } & - \text { Termo de Consentimento Livre e Esclarecido } \\ \text { UTI } & - \text { Unidade de Terapia Intensiva } \\ \text { WHO } & - \text { World Health Organization } \\ \text { VRE } & - \text { Enterococcus resistente a vancomicina }\end{array}$




\section{LISTA DE SÍMBOLOS}

$$
\begin{array}{ll}
\chi^{2} & \text { - Qui-quadrado } \\
\Sigma & - \text { Somatória } \\
\sim & \text { - Proporcional } \\
\alpha & \text { - Alfa } \\
< & \text { - Menor que } \\
\leq & - \text { Menor ou igual } \\
> & \text { - Maior que } \\
\% & \quad-\text { Por cento } \\
\% & \quad-\text { Por mil }
\end{array}
$$




\section{SUMÁRIO}

APRESENTAÇÃ 0 .................................................................................................................24

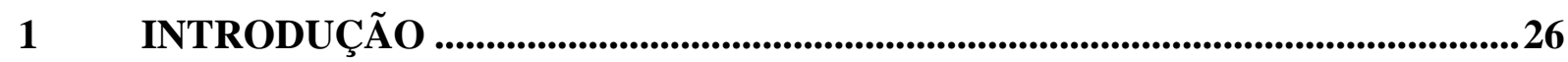

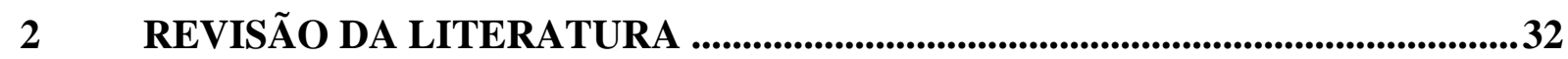

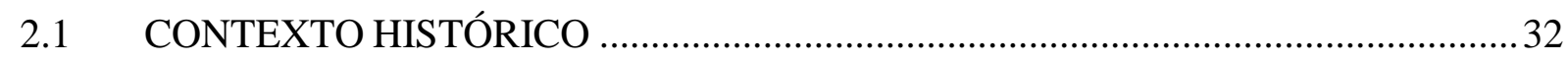

2.2 A PREVENÇÃO DA TRANSMISSÃO DAS INFECÇÕES ……………………........36

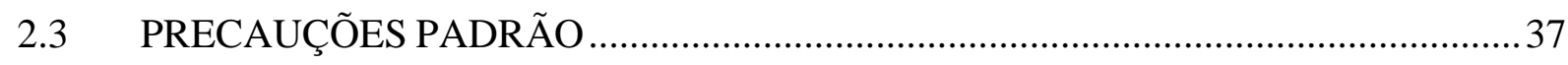

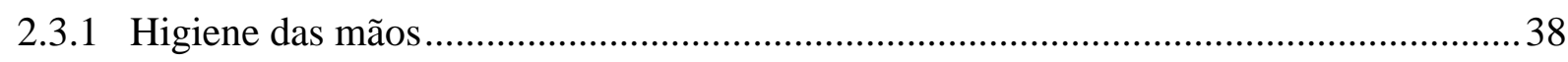

2.3.2 Uso adequado dos Equipamentos de Proteção Individual................................................ 43

2.3.3 Acomodação de pacientes em local de acordo com o risco ........................................... 44

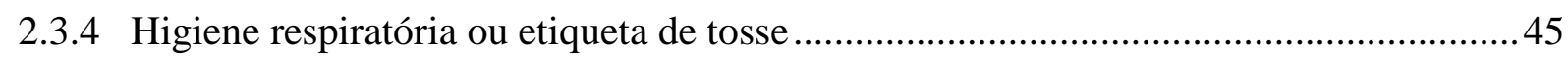

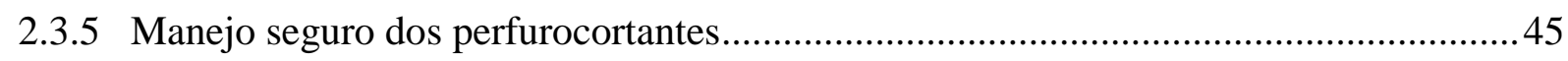

2.3.6 Manuseio/recolha/coleta seguros de roupas e resíduos .................................................. 45

2.3.7 Limpeza e desinfecção de superfícies, artigos e equipamentos usados...........................46

2.3.8 Práticas seguras de injeção ...................................................................................4

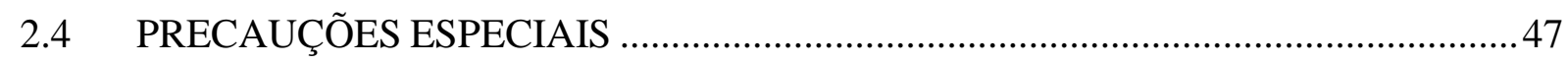

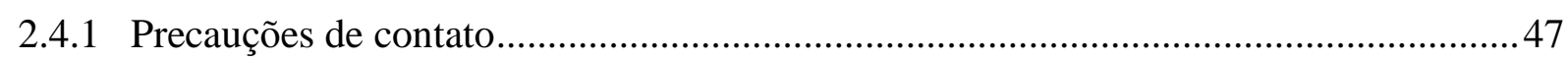

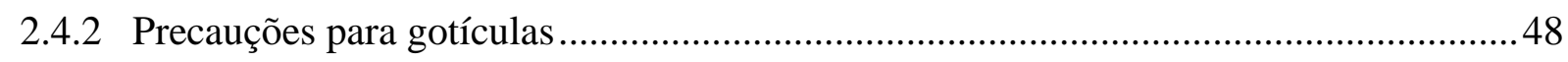

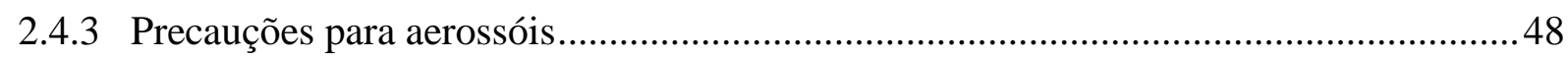

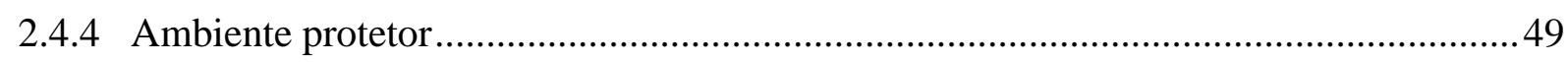

2.5 PRECAUÇÕES EM UNIDADE DE TERAPIA INTENSIVA .....................................49

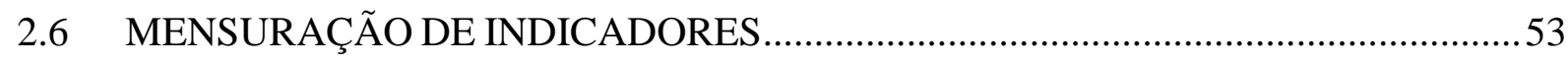

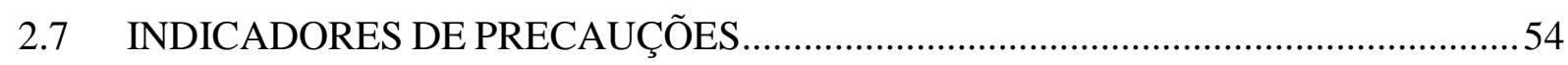

$3 \quad$ OBJETIVOS ……..........................................................................................................58

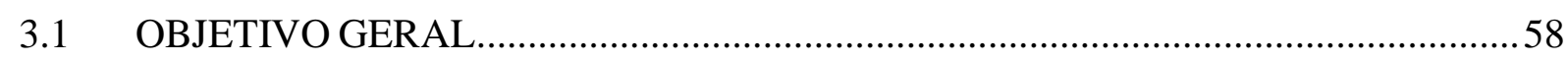

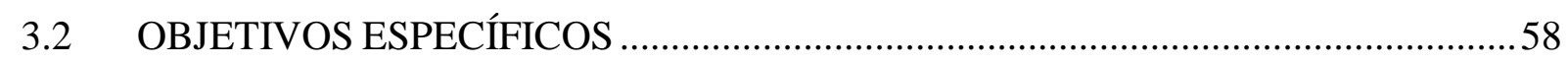

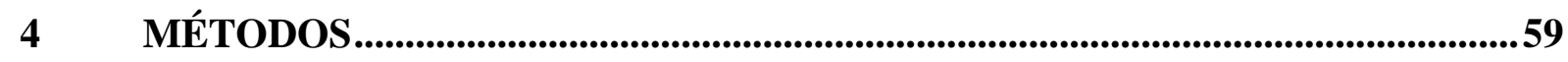

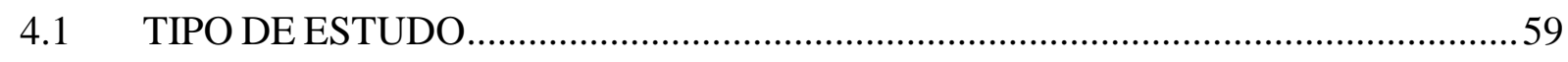

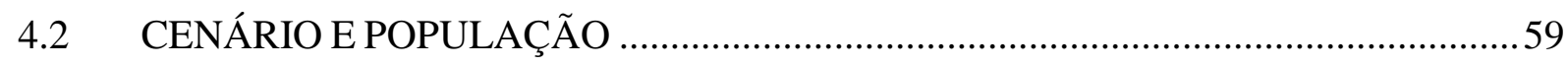


4.3 CRITÉRIOS DE INCLUSÃO E EXCLUSÃO 60

4.4 RISCOS IDENTIFICADOS PARA OS PARTICIPANTES E FORMAS DE MINIMIZAÇÃO 60

4.5 PROCEDIMENTOS E INSTRUMENTO DE COLETA DE DADOS ...........................60

4.5.1 Etapa 1: aproximação da equipe de pesquisa com o campo . .62

4.5.2 Etapa 2: aplicação do questionário para caracterização dos profissionais participantes do estudo. .62

4.5.3 Etapa 3: treinamento do observador . .63

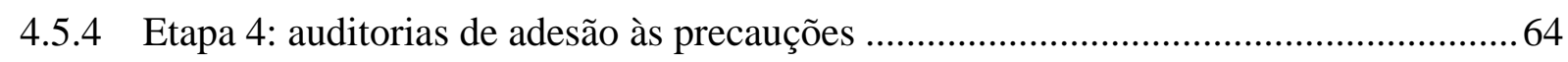

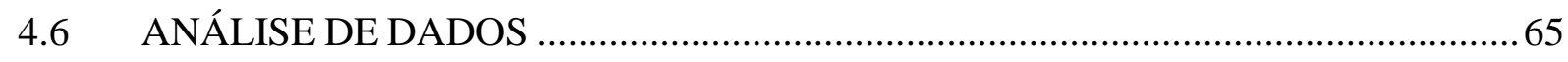

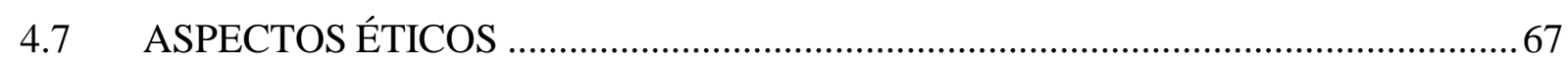

$5 \quad$ RESULTADOS ...................................................................................................................68

5.1 CARACTERÍSTICAS DOS PROFISSIONAIS QUE ATUAM NA UTI ......................68

5.2 INFRAESTRUTURAS DISPONÍVEIS PARA EXECUÇÃO DAS PRÁTICAS DE

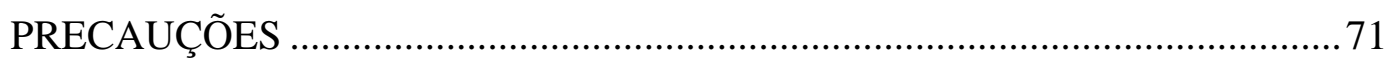

5.3 ADESÃO ÀS PRÁTICAS DE HIGIENE DAS MÃOS …………………………….....78

1.4 AVALIAÇÃO DA ADEQUAÇÃO DAS INDICAÇÕES DE PRECAUÇÕES ............84

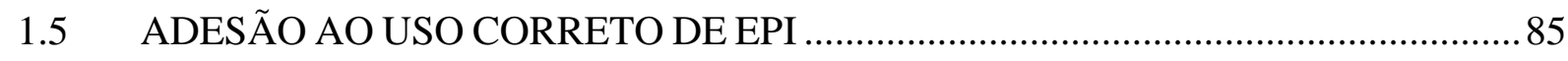

6 DISCUSSÃO …...............................................................................................94

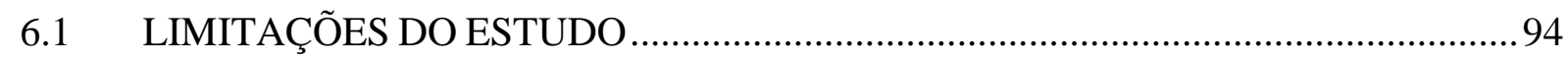

6.2 CARACTERÍSTICAS DOS PROFISSIONAIS QUE ATUAM NA UTI .......................94

6.3 INFRAESTRUTURA DISPONÍVEL PARA EXECUÇÃO DAS PRÁTICAS DE

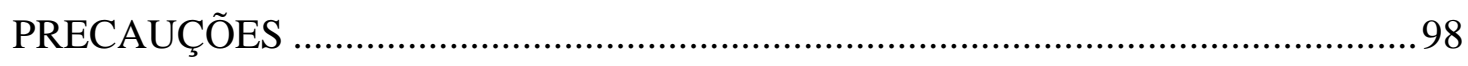

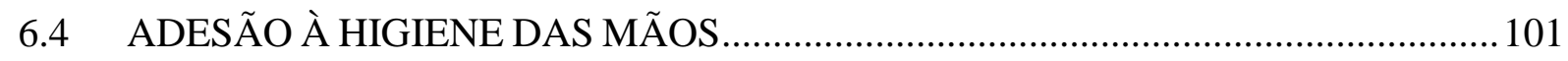

6.5 ADEQUAÇÃO DAS INDICAÇÕES DE PRECAUÇÕES.........................................104

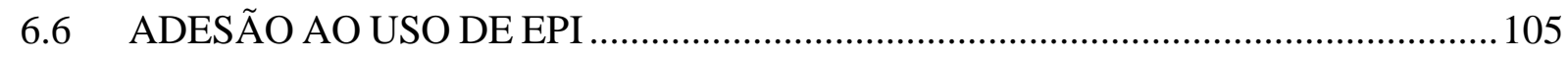

6.7 RECOMENDAÇÕES AO LOCAL DO ESTUDO …………………......................110

7 CONCLUSÃO....................................................................................114

REFERÊNCIAS........................................................................................................117

APÊNDICE A - TERMO DE CONSENTIMENTO LIVRE E ESCLARECIDO 
APÊNDICE B - QUESTIONÁRIO DE PESQUISA: PERFIL DOS PROFISSIONAIS

APÊNDICE C - INSTRUMENTO DE COLETA DE DADOS 2: AVALIAÇÃO DE ESTRUTURA, PRECAUÇÕES E USO DE EPI

APÊNDICE D - EPI INDICADO PARA OS PROCEDIMENTOS POR TIPO DE PRECAUÇÃO 138

APÊNDICE E - AUTORIZAÇÃO E CONCORDÂNCIA DA INSTITUIÇÃO 139 ANEXOS A - TÉCNICA DE HIGIENE SIMPLES DAS MÃOS DA OMS........140 ANEXO B - TÉCNICA DE FRICÇÃO ANTISSÉPTICA DAS MÃOS DA OMS

ANEXO C - TÉCNICA DE ANTISSEPSIA CIRÚRGICA DAS MÃOS DA ANVISA

ANEXO D - PIRÂMIDE DE ORIENTAÇÕES AO USO DE LUVAS DA OMS

ANEXO E - TÉCNICA DE COLOCAÇÃO E RETIRADA DE LUVAS DA OMS 144

ANEXO F - PLANTA FÍSICA DA UTI 145

ANEXO G - INSTRUMENTO DE COLETA DE DADOS 1: AVALIAÇÃO DE HIGIENE DAS MÃOS DA OMS 146 ANEXO H - APROVAÇÃO DO COMITÊ DE ÉTICA DA FACULDADE DE CIÊNCIAS DA SAÚDE, DA UNIVERSIDADE DE BRASÍLIA 


\section{APRESENTAÇÃO}

Boas práticas assistenciais e medidas de prevenção das infecções relacionadas à assistência à saúde são consideradas fundamentais na atividade do cuidado. As dificuldades que se apresentam nos diferentes cenários são variadas e, assim, faz-se necessário estudo individualizado da realidade local de cada serviço de saúde.

A autora exerce atividade profissional em enfermagem e controle de infecções desde que finalizou a graduação no início deste século. Em seu cotidiano de trabalho, vivencia as dificuldades, limites e desafios que se impõem ao cumprimento das efetivas ações que envolvem a segurança do paciente e dos profissionais de saúde, na prevenção da transmissão cruzada de microrganismos entre eles.

Desenvolveu este estudo na busca de respostas para as questões que envolvem a realidade da prática da higiene das mãos e uso dos Equipamentos de Proteção Individual (EPIs) na instituição em que trabalha, para identificar formas de mensuração da adesão aplicáveis à realidade local, coletar indicadores de processo de forma padronizada e fornecer dados para o planejamento de ações de melhoria. Além disso, o estudo também produziu ferramentas para a coleta sistematizada da adesão às precauções que podem ser usadas por outros profissionais que atuam em controle das Infecções Relacionadas à Assistência à Saúde (IRAS).

Este trabalho está dividido em oito capítulos que objetivam apresentar e discutir dados referentes à complexa realidade do cumprimento das boas práticas das precauções padrão, na assistência à saúde de pacientes críticos, em um hospital de ensino no Distrito Federal (DF).

No primeiro capítulo, abordam-se as inter-relações entre as IRAS e a segurança do paciente às precauções. Apresentam-se aspectos relacionados à magnitude do problema e alternativas de melhorias que vêm sendo desenvolvidas internacional e nacionalmente. E finaliza-se com a apresentação do contexto no hospital cenário do estudo.

No segundo capítulo, expõe-se a revisão da literatura subdividida em oito subitens que são: 1) contexto histórico das práticas de precauções; 2) a prevenção da transmissão das infecções e a cadeia epidemiológica; 3) precauções padrão; 4) precauções especiais; 5) precauções em Unidades de Terapia Intensiva (UTI); 6) mensuração de indicadores; 7) indicadores de precauções; e 8) adesão às precauções. 
No terceiro capítulo, apresentam-se os objetivos do estudo, estes relacionados à avaliação da adesão às precauções em UTI.

No quarto capítulo, relata-se o método detalhado subdividido em sete subitens. Tratase de um trabalho de natureza quantitativa, do tipo descritivo, exploratório e transversal em que se aplicaram três instrumentos em forma de questionários para coleta de dados sobre caraterísticas dos profissionais que atuavam na assistência direta aos pacientes, adesão à higiene das mãos, uso de EPI, adequação das indicações de precauções e infraestrutura disponíveis para as práticas de precauções na UTI de um hospital de ensino no DF.

No quinto capítulo, estão os resultados das variáveis referentes às características dos profissionais. Os resultados da adesão à higiene das mãos são apresentados em percentual de adesão à higiene das mãos entre todos os profissionais, percentual de adesão por categoria profissional, percentual de uso das técnicas de higiene simples e fricção antisséptica e percentual de adesão aos cinco momentos indicados para a higiene das mãos.

As disponibilidades de insumos para a execução das práticas de precauções são mostradas em proporção de adequação da disponibilidade de preparação alcoólica por dispensador disponível na unidade, sabonete líquido e papel toalha por pia, avental, luvas, máscara e óculos, disponíveis por sessão de observação.

Os resultados da avaliação do quantitativo de profissionais para a execução dos cuidados são apresentados em percentual de plantões com número adequado de profissionais por categoria.

Os resultados da adesão ao uso de EPI são mostrados em percentual de adequação ao uso de EPI (luvas, avental, máscara e óculos) entre todos os profissionais e o percentual de adequação ao uso dos EPIs por categoria profissional, estratificados por tipo de procedimento realizado.

Os resultados da avaliação das indicações de precauções são mostrados em percentual de adequação das precauções padrão, de contato ou respiratórios (gotículas ou aerossóis).

O sexto capítulo traz a discussão dos achados do estudo, compara-os aos de outros trabalhos nacionais e internacionais, discute as limitações das auditorias observacionais devido ao efeito Hawthorne e se finaliza com recomendações para as melhorias da prática de precauções no local do estudo.

A conclusão está no sétimo capítulo e as referências no oitavo.

Apêndices e Anexos trazem os instrumentos usados e demais documentos necessários ao trabalho. 


\section{INTRODUÇÃO}

As Infecções Relacionadas à Assistência à Saúde (IRAS) são adquiridas durante o processo de cuidado em hospital ou outro local destinado à assistência à saúde, não estavam presentes ou em incubação na admissão do paciente e podem se manifestar durante a internação ou após a alta hospitalar. Além disso, incluem as infecções ocupacionais adquiridas pelos profissionais de saúde. (WHO, 2011; PINA, FERREIRA, UVA, 2014).

As IRAS constituem um grande problema para a segurança dos pacientes, pois seu impacto pode resultar em internação prolongada, incapacidades em longo prazo, aumento de resistência microbiana aos antimicrobianos, aumento da mortalidade, além do ônus financeiro adicional para o sistema de saúde, pacientes e familiares. (WHO, 2011; PINA, FERREIRA, UVA, 2014).

Atualmente, estima-se que a cada 100 pacientes internados, pelo menos sete em países desenvolvidos e 10 em países em desenvolvimento irão adquirir IRAS. Na Europa, a prevalência é de 5,7\% de taxas de IRAS em cerca de quatro milhões de pessoas, ocasionando aproximadamente 37.000 mortes, com um impacto financeiro de sete bilhões de euros. Nos Estados Unidos da América (EUA), ocorrem cerca de dois milhões de casos e 80.000 mortes por ano, com custo estimado entre 4,5 e 5,7 milhões de dólares. (WHO, 2011; ECDC, 2013).

No Brasil, por muitos anos as informações que se apresentavam em relação aos indicadores de IRAS não eram comparáveis entre si devido à inexistência de uniformidade dos critérios usados para diagnóstico e da metodologia de vigilância. Após a publicação dos Critérios Nacionais de IRAS pela Agência Nacional de Vigilância Sanitária (Anvisa), no ano de 2009 e a coleta padronizada desses dados em nível nacional, começam-se a obter informações acerca da ocorrência das infecções primárias da corrente sanguínea em Unidades de Terapia Intensiva (UTI) e, mais recentemente, da ocorrência de infecções de sítio cirúrgico em cesarianas. (ANVISA, 2013a, 2015a).

Segundo o último boletim epidemiológico do Sistema Nacional de Vigilância Sanitária, a densidade de incidência de infecções primárias da corrente sanguínea laboratorial e clínica, nos pacientes em uso de cateter venoso central, em UTI de atenção a adultos, vem decrescendo desde o ano de 2011, quando foi iniciado o monitoramento, e no ano de 2014 as densidades foram 5,1 e 1,5\%o, respectivamente. A ocorrência das infecções do sítio cirúrgico em cesarianas teve o monitoramento nacional iniciado no ano de 2014, que apontou para taxa de 1,1\%; no entanto, a dificuldade na metodologia de vigilância pós-alta e identificação dos 
casos pode ser um fator importante para a subnotificação do mesmo. Todos os boletins nacionais não trazem informações sobre mortalidade atribuída às IRAS ou custos para o sistema, e alertam para as limitações na análise dos dados devido à possibilidade de subnotificações e de sistemas de vigilância não adequados. (ANVISA, 2012a, 2013b, 2014, 2015a).

No Distrito Federal (DF), o monitoramento das IRAS é mais antigo, porém limitava-se aos dados dos serviços públicos da rede de saúde do DF e foi ampliado para os demais hospitais junto com o sistema nacional, no ano de 2011. O relatório dos indicadores do ano de 2014 mostra boa adesão às notificações por parte dos hospitais locais, com indicadores muito variáveis entre si e taxas similares aos dados nacionais. No ano de 2014, a média geral de IRAS nas UTI do DF foi de 4,4\%o de infecção primária da corrente sanguínea laboratorial; 1,6 \%o de infecção primária da corrente sanguínea clínica; 7,1 \%o de pneumonia associada à ventilação mecânica e 3,2 \% de infecção do trato urinário. (DF, 2015a).

Dada a magnitude da ocorrência desses eventos e os danos provocados por eles, cientistas, governos, profissionais, gestores - e mais recentemente os pacientes - estão com foco de atuação cada vez maior para minimizar a ocorrência dos mesmos. Dessa forma, as estratégias eficazes de prevenção - desde as já conhecidas há muito tempo, como a higiene das mãos, até as mais modernas, que envolvem tecnologias complexas com produtos que inibem o crescimento de microrganismos - são amplamente estudadas em todo o mundo, objeto de políticas de governo e investimentos na área. (WHO, 2006; SRIGLEY et al., 2015).

Nas últimas duas décadas, diante da evolução acentuada da qualidade e segurança em todas as atividades econômicas, principalmente na indústria, na aviação e na produção de energia nuclear, a área da saúde também despertou para isso. Além das IRAS, outras complicações evitáveis - como erros que envolvem uso de medicamentos, cirurgias, diagnósticos, falhas de comunicação que decorrem em cuidados equivocados, dentre outros despertaram a atenção do mundo após sucessivos relatórios e estudos sobre a magnitude desses graves problemas que comprometem a qualidade e a segurança dos sistemas de saúde. (KOHN, CORRIGAN, DONALDSON, 1999).

A Organização Mundial da Saúde (OMS), em 2004, demonstrando preocupação com a situação, criou a World Alliance for Patient Safety, cujos objetivos, entre outros, eram a organização dos conceitos e as definições sobre segurança do paciente e propor medidas para reduzir os riscos e mitigar os eventos adversos. (WHO, 2006). A segurança do paciente é definida pela OMS como a redução, ao mínimo aceitável, do risco de dano desnecessário associado ao cuidado em saúde. (MENDES, 2014). 
Para o alcance da segurança do paciente, a OMS propôs os denominados desafios globais: reduzir a infecção associada ao cuidado em saúde, por meio de estratégia para melhorar a higiene das mãos; promover uma cirurgia mais segura, pela adoção de uma lista de verificação antes, durante e após o ato cirúrgico; e o combate à resistência microbiana. (WHO, 2006).

No Brasil, a Anvisa regulamenta em várias resoluções de sua Diretoria Colegiada, a estrutura física e as boas práticas de funcionamento mínimas que devem ser obedecidas pelos estabelecimentos de saúde com vistas à minimização dos riscos inerentes à assistência (ANVISA, 2004, 2010a, 2010b, 2011, 2013c). Desde o ano de 1997, a Lei n. ${ }^{\circ} 9.431$ obriga os hospitais a manter um Programa de Prevenção de Infecções Hospitalares (PCIH). (BRASIL, 1997). A Portaria n. ${ }^{o}$ 2.616, de 12 de maio de 1998, regulamenta a Lei n. ${ }^{\circ}$ 9.431, e expede diretrizes e normas para a prevenção e controle de infecções hospitalares. (MINISTÉRIO DA SAÚDE (MS), 1998).

Nesse contexto, o Ministério da Saúde (MS) instituiu, recentemente, o Programa Nacional de Segurança do Paciente (PNSP), por meio da Portaria MS/GM n. ${ }^{\circ}$ 529, de $1 .^{\circ}$ de abril de 2013, com o objetivo geral de contribuir para a qualificação do cuidado em saúde, em todos os estabelecimentos de saúde do território nacional. (MS, 2013a).

O PNSP dá ênfase à promoção da cultura de segurança e à gestão de riscos. Define cultura de segurança a partir de cinco características operacionalizadas pela gestão de segurança da organização: 1) cultura na qual todos os trabalhadores, incluindo profissionais envolvidos no cuidado e gestores, assumem responsabilidade pela sua própria segurança, pela segurança de seus colegas, pacientes e familiares; 2) cultura que prioriza a segurança acima de metas financeiras e operacionais; 3) cultura que encoraja e recompensa a identificação, a notificação e a resolução dos problemas relacionados à segurança; 4) cultura que, a partir da ocorrência de incidentes, promove o aprendizado organizacional; e 5) cultura que proporciona recursos, estrutura e responsabilização para a manutenção efetiva da segurança. (MS, 2013a).

Para o MS (2013a), a gestão de risco é a aplicação sistêmica e contínua de iniciativas, procedimentos, condutas e recursos na avaliação e controle de riscos e eventos adversos que afetam a segurança, a saúde humana, a integridade profissional, o meio ambiente e a imagem institucional.

No âmbito da segurança do paciente, a não realização de higiene das mãos pelo profissional de saúde em procedimento assistencial é considerada uma violação. Segundo a OMS, violação é a divergência deliberada de um procedimento cirúrgico, um padrão ou regra. 
São, de forma habitual, intencionais, apesar de raramente maliciosas; e, em determinado contexto, podem se tornar rotineiras ou automáticas. (MENDES, 2014).

Dentre os eventos adversos que afetam a segurança do paciente, estão as IRAS. Diferentes estudos internacionais e nacionais identificaram que esse é o evento adverso mais frequente na atenção à saúde. (ARANAZ-ANDRÉS et al., 2011; MENDES et al., 2013). Por esse motivo, o PNSP engloba ações que visam propor e validar protocolos, guias e manuais voltados à segurança do paciente em prevenção das IRAS. (MS, 2013a).

$\mathrm{Na}$ ocorrência de IRAS, a segurança do paciente e a qualidade dos serviços de saúde são ligadas em vários aspectos porque praticamente em todos os cuidados assistenciais estão presentes os riscos de transmissão dessas infecções. As IRAS em serviços de saúde podem ocorrer por diferentes motivos: falta de infraestrutura para o PCIH, como apoio da liderança ineficiente ou ausente, profissionais insuficientes em vários níveis; falta de treinamento dos trabalhadores da saúde sobre medidas preventivas de infecção ou carência de materiais e equipamentos; emergência de microrganismos multirresistentes, em parte, devido ao uso inapropriado de antimicrobianos; e aumento do número de pacientes imunocomprometidos. (KAWAGOE, GONÇALVES, 2013).

A higiene das mãos para prevenir IRAS e o combate à resistência microbiana foram desafios propostos pela OMS para o alcance da segurança do paciente. Para tanto, diferentes estudos na área apontam para a necessidade de um Programa de Controle de Infecções Relacionadas à Assistência à Saúde (PCIRAS) que contemple o monitoramento de diferentes indicadores, além dos indicadores de resultados, que são as taxas de IRAS.

O Hospital Universitário de Brasília (HUB) é um Hospital de Ensino localizado no Distrito Federal, com 257 leitos, que atende às diversas especialidades médicas clínicas e cirúrgicas. Em sua estrutura organizacional está o Setor de Vigilância em Saúde, que executa as atividades deliberadas pelas comissões assessoras diretamente envolvidas com a segurança do paciente e a prevenção e controle das IRAS, que são o Núcleo de Segurança do Paciente (NSP) e a Comissão de Controle de Infecção Relacionada à Assistência à Saúde (CCIRAS), conforme definido nas diretrizes da Empresa Brasileira de Serviços Hospitalares (EBSERH), que administra o hospital. (EBSERH, 2014).

Como parte integrante do Plano de Segurança do Paciente, o Programa de Controle de Infecção Relacionada à Assistência à Saúde (PCIRAS) do HUB contempla atividades relacionadas à coleta dos indicadores de resultados e diferentes formas para divulgação das práticas de prevenção e controle das IRAS no hospital. No entanto, avaliações de estrutura e 
de processos para conhecer as outras dimensões da qualidade envolvidas na atividade assistencial faziam-se necessárias para o desenvolvimento desse programa. (HUB, 2014a).

Quatro documentos institucionais reúnem recomendações detalhadas e ilustrativas sobre precauções: os procedimentos operacionais do hospital e um protocolo que orientam a higiene das mãos, o uso de EPI, as precauções especiais e a indicação de precauções de contato admissionais para pacientes suspeitos de colonização ou infecção por microrganismos multirresistentes. (HUB, 2013a, 2014b, 2014c, 2015a).

As divulgações internas desses documentos são realizadas no desenvolvimento do PCIRAS em capacitações e atualizações profissionais, campanhas semestrais, palestras e cursos para estudantes, além de orientações oferecidas em visitas às unidades de internação e em sistema interno de intranet. (HUB, 2014a).

O hospital possui uma UTI de pacientes adultos com 10 leitos, onde as taxas e densidades de incidência de IRAS são monitoradas em vigilância epidemiológica ativa e visita conjunta com a CCIRAS. O último relatório dos indicadores de resultados de IRAS elaborado pela comissão, com dados de janeiro a setembro de 2015, apresentou altas taxas e densidades de incidências de IRAS na UTI. O relatório comparou esses indicadores com os anteriores da unidade e concluiu que essas taxas não tinham aumentado nos últimos anos. Também apontou que a presença de pacientes colonizados ou infectados com microrganismos multirresistentes é comum nessa unidade, assim como nos demais hospitais do DF. (HUB, 2015b).

A análise do fenômeno das IRAS não pode ser realizada somente com parâmetros de indicadores de resultados que são as taxas e densidades de incidências de infecções, porque as questões que envolvem o perfil do paciente atendido podem influenciar diretamente nos resultados desses indicadores. A gravidade dos pacientes, a necessidade do uso prolongado dos procedimentos invasivos como ventilação mecânica, cateteres vasculares e vesicais, por exemplo, além do uso de imunossupressores e da forte influência da pressão de colonização nas UTI, podem influenciar diretamente no risco aumentado de IRAS e de transmissão cruzada de microrganismos. Assim, analisados individualmente, os indicadores de resultado não são suficientes para avaliar qualidade da assistência prestada.

No monitoramento de indicadores são necessários esforços adicionais para coleta de informações precisas ao que o fenômeno deseja medir. A coleta sistematizada de informações referentes ao processo de trabalho e à estrutura física devem ser implementadas para um completo diagnóstico situacional. Assim, surgiu a questão que norteou a realização desta 
pesquisa: qual é a estrutura disponível e a adesão às práticas de precauções na UTI do hospital?

Desenvolveu-se este estudo para, com o rigor da metodologia científica, obter-se uma avaliação detalhada da prática das precauções, além de avaliar a viabilidade técnica da metodologia de coleta desses indicadores no serviço, que poderão orientar as estratégias institucionais de monitoramento dos mesmos, a fim de que os gestores das áreas possam usálos para guiar a elaboração do PCIRAS na busca da qualidade e segurança do paciente. 


\section{REVISÃO DA LITERATURA}

\subsection{CONTEXTO HISTÓRICO}

A busca por explicações sobre as doenças que acometem o homem acompanha sua própria história, e, na antiguidade, durante muito tempo as infecções foram encaradas como castigos. A medicina tinha caráter mágico e religioso, sabia-se que as infecções podiam ser transmitidas de uma pessoa para outra, mas a sua presença era atribuída aos espíritos, aos deuses, à influência dos planetas ou às impurezas do ar. As pessoas doentes eram afastadas porque traziam o medo da morte. Isso aconteceu com os doentes de hanseníase, que foram isolados em leprosários, e com os doentes da peste negra, obrigados a permanecerem em suas casas e a usar sinal distintivo. (SILVA et al., 2000).

Até a primeira metade do século XIX, os hospitais urbanos eram construídos em amplas enfermarias, sem separação entre os doentes, com condições de higiene precárias; eram comuns a transmissão cruzada de infecções e a alta mortalidade. (SILVA et al, 2000).

Em meados do século XIX, antes da invenção dos microscópios, o médico Ignaz Semmelweis comprovou com estudos epidemiológicos a eficácia da higiene das mãos para a prevenção da febre puerperal. Infelizmente, à época, seus pares não se convenceram de que as mãos que cuidam poderiam causar doenças malignas, desacreditaram o médico, que morreu em um sanatório. (SILVA et al., 2000; PINA, FERREIRA, UVA, 2014).

O mesmo não aconteceu com sua contemporânea, a enfermeira Florence Nightingale, que com um grupo de senhoras foi cuidar de soldados feridos de guerra em hospital na Crimeia, onde a maioria dos homens morria por doenças diarreicas e não dos próprios ferimentos da guerra. Florence correlacionou as infecções hospitalares aos cuidados prestados no hospital e à necessidade de medidas de higiene ambiental, higiene dos alimentos e separação de pessoas mais doentes para prevenção das infecções, e obteve grande sucesso na redução da mortalidade hospitalar. (SILVA et al, 2000; PINA, FERREIRA, UVA, 2014).

Outro médico que marcou a história das IRAS foi Joseph Lister, que introduziu conceitos de antissepsia cirúrgica com o uso do ácido carbólico, e conseguiu reduzir infecções e mortalidade pós-cirúrgicas. Posteriormente, Louis Pasteur elaborou a Teoria Microbiana da Infecção, que só pode ser demonstrada com os postulados de Koch, já final do século XIX. (SILVA et al., 2000; PINA, FERREIRA, UVA, 2014). 
Surgiram, em 1877, nos EUA, as primeiras recomendações publicadas sobre isolamento que orientavam a separação de doentes com doenças infecciosas em pavimento ou acomodações separadas. (LYNCH, 1949). Posteriormente, na Europa, da evolução dessas práticas surgiram, em 1910, as "barreiras de enfermagem”, que consistiam na distribuição dos pacientes em enfermarias de múltiplos leitos, utilização de aventais diferentes, lavagem das mãos com solução antissépticas e desinfecção dos materiais contaminados entre um paciente e outro. (GAGE, LANDON, SIDER, 1959).

Em 1880, em consonância com o pensamento da época, no Brasil, foi fundado o Hospital Emílio Ribas em São Paulo, sendo o primeiro hospital de isolamento para doenças infectocontagiosas. (APECIH, 1999).

Muita discussão ocorreu sobre a necessidade de hospitais exclusivos para o atendimento às doenças infecciosas e, a partir da década de 1950, estes começaram a ser fechados. Os pacientes começaram a ser admitidos em enfermarias de hospitais gerais ou encaminhados para tratamento ambulatorial, como foi o caso de muitos portadores de tuberculose pulmonar. (GARNER, 1996).

No século XX, aconteceu a descoberta da Penicilina e o desenvolvimento de muitos antimicrobianos capazes de tratar as infecções. Porém, os microrganismos tornaram-se capazes de resistir ao uso desses medicamentos, e com isso as medidas de prevenção tornaram-se, novamente, a principal alternativa para controlar a ocorrência dessas IRAS. (SILVA et al., 2000; OMS, 2012; PINA, FERREIRA, UVA, 2014).

As orientações aos hospitais para precauções e isolamentos nos EUA começaram a ser publicadas mais detalhadamente pelos Centers for Disease Control (CDC) de Atlanta, em 1970, introduzindo o conceito de isolamentos por categorias com uma segunda edição em 1975. Apresentavam as seguintes categorias de isolamento: estrito, respiratório, de proteção, entérico, precauções com sangue e materiais descartáveis. (NATIONAL COMMUNICABLE DISEASE CENTER, 1970; CDC, 1975). Essas recomendações não foram eficientes, porque os isolamentos eram definidos de acordo com as características epidemiológicas da doença e não valorizavam as vias de transmissão. (SCHAFFNER, 1980).

Diante de um contexto de epidemias de infecções nosocomiais causadas por microrganismos resistentes e com o aprofundamento no conhecimento das enfermidades, de seus mecanismos de transmissão e a descrição de novas síndromes, os CDC, em 1983, revisaram seu guia. As categorias de isolamentos passaram a ser divididas em: estrito, de contato, precauções respiratórias, para pacientes com tuberculose, entérico, precauções com secreções e drenos e precauções com sangue e fluídos corporais. Foi retirado o isolamento de 
proteção - também conhecido como isolamento reverso -, atendendo aos resultados dos estudos que comprovaram a ausência de impacto dessa estratégia para prevenção de infecção no paciente imunodeprimido, uma vez que a principal fonte de microrganismos dessas infecções é a microbiota endógena. (GARNER, SIMMONS, 1983).

Essa nova forma de atuação, que enfatizava a tomada de decisão pelo profissional de saúde, levou à necessidade de maior treinamento e de sistema hospitalar informatizado e com melhor acurácia diagnóstica, porque as doenças não usuais em hospitais, atrasos ou erros de diagnósticos poderiam colocar em risco outros pacientes e profissionais de saúde. (SILVA et al., 2000).

A preocupação com a segurança dos profissionais e não somente com transmissão cruzada de infecções teve seu marco no início da década de 1980, com o advento da epidemia da Aids, quando as estratégias de biossegurança foram incorporadas aos guias. Surgiu, em 1985, um conjunto de procedimentos a serem aplicadas nos cuidados de todos os pacientes, uma vez que nem sempre é reconhecido o indivíduo portador de uma infecção veiculada pelo sangue. Essas medidas foram denominadas precauções universais e enfocavam a prevenção da transmissão de patógenos pelo sangue e fluídos corpóreos, para aplicação em todas as atividades assistenciais aos pacientes, independentemente do local e do diagnóstico infeccioso, em adição ao sistema tradicional de isolamento. (CDC, 1985).

A Universidade Católica da Califórnia, em San Diego, e o Departamento de Controle de Infecções do Centro Médico Harborview, em Seattle, propuseram, em 1987, o isolamento de substâncias corpóreas, como alternativa aos sistemas de isolamento por diagnóstico. (LYNCH et al., 1987). No início da década de 1990, surgiu a necessidade de uma nova política de isolamento, pois havia grande variação nas interpretações e até mesmo certa confusão sobre o assunto. (SILVA et al., 2000).

Para reorganizar, simplificar as regras e uniformizar condutas, em 1995, os CDC publicaram um novo guia que sintetizava as recomendações das precauções universais e do isolamento de substâncias corporais. As categorias de precauções foram divididas em duas padrão e adicionais -, sendo estas subdivididas, por sua vez, em contato, gotículas e aerossóis. Essa nova estratégia tinha a vantagem de ser baseada na compreensão das diferentes formas de transmissão de agentes infecciosos e priorizava também a biossegurança. (GARNER, 1996).

Já no início deste século, novas situações tornaram o controle das infecções mais problemático e, em 2007, os CDC atualizaram seu guia de diretrizes para precauções e 
isolamentos, Preventing Transmission of Infectious Agents in Healthcare Settings. (SIEGEL et al., 2007). Os principais tópicos revisados foram:

- Mudança do termo infecção hospitalar por IRAS, em decorrência da alteração dos locais de cuidados de pacientes agudos, que passaram a ser realizados tanto em hospitais como fora dele;

- A preocupação com o bioterrorismo e o aparecimento de patógenos emergentes (por exemplo, Síndrome Respiratória Aguda Grave), novos problemas relacionados aos patógenos conhecidos (por exemplo, Staphylococcus aureus resistente a oxacilina comunitário), desenvolvimento de novas terapias (por exemplo, terapia genética);

- Ampliar as precauções padrão com as recomendações da etiqueta de tosse, práticas seguras de injeção, incluindo uso de máscara em procedimentos prolongados envolvendo punções do canal espinhal;

- Criação de outra nova categoria de precauções especiais ou isolamentos, o ambiente protetor, devido ao acúmulo das evidências de que o controle ambiental reduz o risco de infecções fúngicas filamentosas graves em pacientes que foram submetidos a transplante alogênico de células tronco na medula;

- Recomendações para o envolvimento formal da administração das instituições no apoio e desenvolvimento dos programas de controle de infecção e diretrizes específicas para a vigilância e controle dos microrganismos multirresistentes.

Com a epidemia do vírus Ebola na África, ocorrida no ano de 2014, devido à alta mortalidade atribuída à doença e à grande possibilidade de os profissionais se infectarem, os CDC publicaram um guia de recomendações específico para manejo desses pacientes, que orienta o uso de EPI para total proteção do corpo, no manejo desses pacientes, mas não alterou as recomendações anteriores do guia de 2007 para as precauções nas outras doenças.

As recomendações de precauções e isolamentos do CDC têm guiado a prática das precauções no Brasil. (APECIH, 1999). São exemplos do uso dessas orientações as várias edições do Guia de Utilização de Anti-infecciosos e Recomendações para a Prevenção de Infecções Hospitalares, do Hospital das Clínicas da Faculdade de Medicina, da Universidade de São Paulo. (LEVIN et al., 2009, 2011; DE OLIVEIRA et al., 2014) e do Manual de Recomendações de Prevenção e Controle das Infecções em Estabelecimentos de Saúde da Secretaria de Estado de Saúde do Distrito Federal. (DF, 2005, 2014). O Guideline for Isolation Precautions: Preventing Transmission of Infections Agents in Healthcare Settings, 
do CDC, de 2007, é a principal referência utilizada nas recomendações dos protocolos dos serviços de saúde brasileiros.

\subsection{A PREVENÇÃO DA TRANSMISSÃO DAS INFECÇÕES}

A prevenção e o controle das IRAS são possíveis e esforços devem ocorrer para o desenvolvimento de novas estratégias e iniciativas, na busca contínua de melhoria da qualidade assistencial e segurança do paciente. A maioria das IRAS é endêmica e recomendações de medidas para preveni-las estão publicadas por organizações internacionais, como os CDC, de Atlanta, o European Center for Disease Prevention and Control (ECDC), da União Europeia, e nacionais, como a Anvisa. (SIEGEL et al., 2007; UNIÃO EUROPEIA, 2009; KAWAGOE, GONÇALVES, 2013; ANVISA, 2013c).

O bloqueio da transmissão de microrganismos de pacientes colonizados/infectados para pacientes susceptíveis e para profissionais de saúde é um dos fatores mais importantes no controle das IRAS. (CUNHA, JOHNSON, 2009). Esse tem sido o principal foco de estudo dos profissionais que lidam com o controle de infecções e segurança dos profissionais de saúde. (PINA, FERREIRA, UVA, 2014).

Para compreensão das medidas de prevenção, faz-se necessário o entendimento sobre a cadeia epidemiológica da transmissão dos agentes infecciosos. As medidas de prevenção são barreiras para interromper os elos de transmissão dessa cadeia. A cadeia epidemiológica das infecções pode ser representada, de forma didática, por um modelo em círculo, onde cada elo representa um dos seis elementos, conforme simbolizado na Figura 1. Essa figura também apresenta as principais medidas de intervenção que devem ser aplicadas para a interrupção da cadeia. 
FIGURA 1 - CADEIA EPIDEMIOLÓGICA DAS INFECÇÕES E INTERVENÇÕES PARA A QUEBRA DA CADEIA

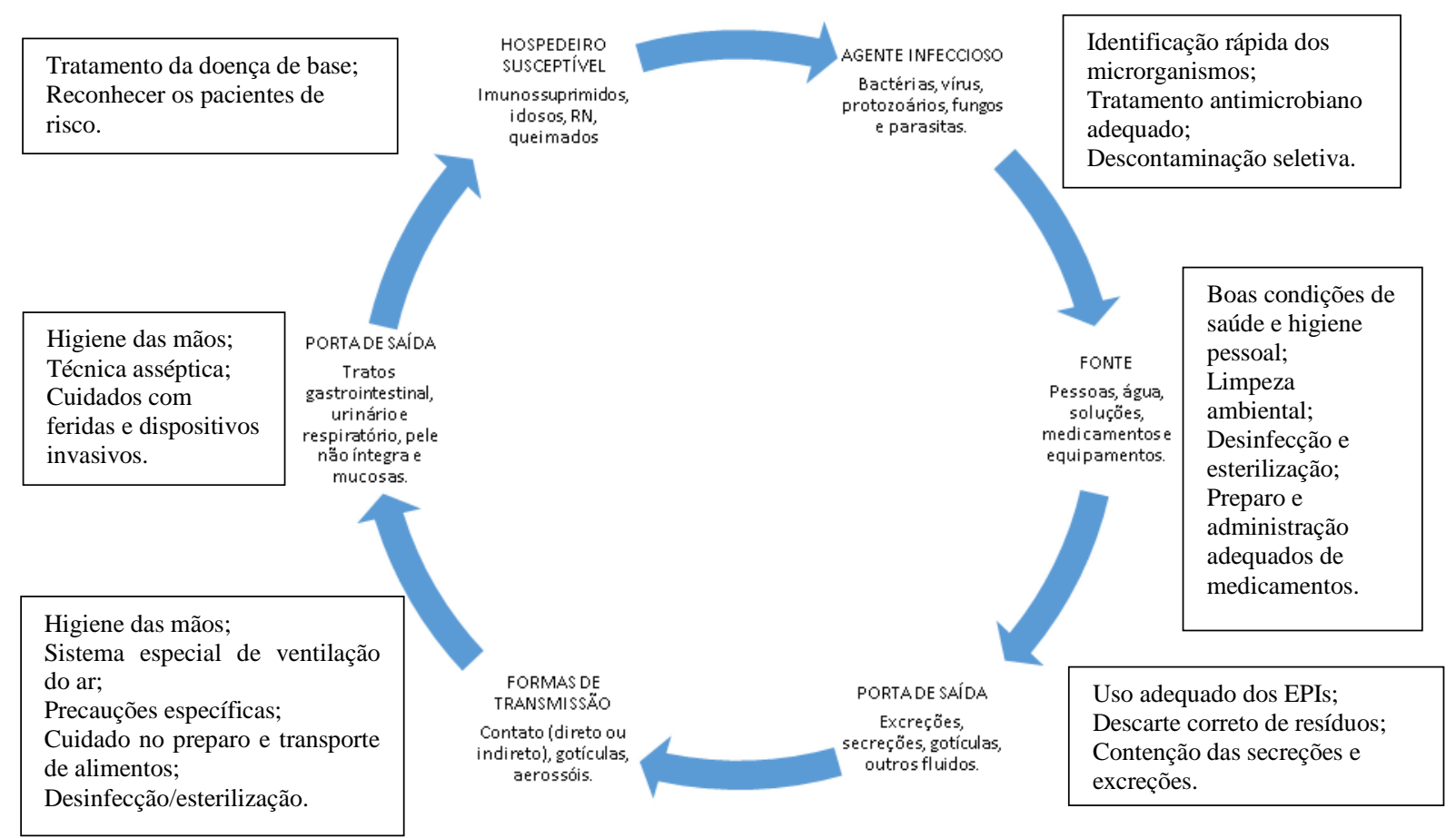

FONTE: Adaptado de KAWAGOE et al. (2012).

Para interromper essa cadeia e evitar a transmissão dos patógenos, as precauções devem ser aplicadas em vários pontos. Por exemplo, a higiene das mãos pode interromper o elo da forma de transmissão e não permitir o contato direto ou indireto com o microrganismo, e o uso correto dos EPIs pode interromper o elo da porta de saída, fonte ou forma de transmissão. (SIEGEL et al., 2007).

As IRAS podem ser causadas por microrganismos já presentes no paciente em sua pele e mucosas, conhecidos como microbiota endógena, ou por microrganismos de outros pacientes, transmitidos por profissionais de saúde ou pelo ambiente circulante, a microbiota exógena. Na maioria dos casos, as mãos dos profissionais são o principal veículo de transmissão desses microrganismos de um paciente para o outro, de um sítio anatômico para outro do corpo do mesmo paciente e do ambiente para o paciente e vice-versa. (SIEGEL et al., 2007; WHO, 2009).

As precauções dividem-se em precauções padrão e precauções especiais.

\subsection{PRECAUÇÕES PADRÃO}


As precauções padrão incluem um grupo de práticas de prevenção de infecções indicadas para assistência a todos os pacientes, em locais onde há prestação de cuidados à saúde, independentemente da suspeita ou confirmação de infecção. São elas: higiene das mãos, uso correto dos EPIs, a acomodação do paciente em local de acordo com o risco, higiene respiratória ou etiqueta de tosse, manejo seguro dos perfurocortantes, manuseio/recolha/coleta seguros das roupas e resíduos, limpeza e desinfecção de superfícies e artigos e práticas seguras de injeções. (SIEGEL et al., 2007).

\subsubsection{Higiene das mãos}

Desde Semmelweis, Florence, Lister, Pasteur e Koch, a higiene das mãos foi amplamente estudada e é apontada como a medida primária mais eficaz na prevenção de infecções. As várias publicações dos guias dos CDC enfatizavam a lavagem das mãos em hospitais com água e sabonete antes e após os cuidados com pacientes, ou lavagem com água e sabonete com antisséptico antes e após a realização de procedimentos invasivos. Em 1996, os CDC recomendavam que a lavagem das mãos fosse realizada com água e sabonete associado a antisséptico ou um agente não hidratado, após o contato com pacientes com patógenos multirresistentes. (ANVISA, 2009).

No ano de 2002, ocorreu a publicação de um novo guia dos CDC, que pela primeira vez trouxe a recomendação da fricção antisséptica das mãos com preparações alcoólicas como o método de escolha pelos profissionais de saúde e também substituiu o uso do termo lavagem das mãos por higiene das mãos, de forma mais abrangente. (CDC, 2002).

Apesar das robustas evidências científicas sobre as boas práticas da higiene das mãos na prevenção de transmissão de infecções e microrganismos, a adesão pelos profissionais de saúde ainda é muito baixa. Essa foi estudada em diferentes localidades do mundo, indicando que é menor que $40 \%$. Vários fatores influenciam na adesão, como estrutura física e produtos disponíveis para a prática, tipo de serviço, conhecimento das equipes sobre o assunto e grau de exigência da instituição na qual é exercida a atividade profissional. (WHO, 2006).

No Brasil, assim como em outros países subdesenvolvidos e em desenvolvimento, as publicações apontam taxas de adesão à higiene das mãos muito variáveis; em alguns serviços, a adesão encontrada foi muito baixa, chegando a 10\%. (PERUGINI, 2008; PÉREZ, ZAMBRAMO, AMADO, 2012; ROSENTHAL et al.; BATHKE et al.; YAWSON, HESSE, 2013). 
Segundo dados da OMS, equipes muito bem treinadas, em estabelecimentos de saúde com estrutura física e recursos adequados para prática, conseguem manter adesão maior que $60 \%$. Alguns serviços, principalmente em atendimento neonatal e pediátrico, podem alcançar taxas de adesão maiores que 80\%. (WHO, 2006; SONG et al., 2013).

A melhoria da adesão à higiene das mãos para prevenir infecções é um dos desafios da Aliança Mundial para Segurança do Paciente. O lema desse desafio é "Uma assistência limpa é uma assistência mais segura", sendo orientado o desenvolvimento de uma estratégia multimodal pelos serviços de saúde para o alcance dessa melhoria. (OPAS, ANVISA, 2008a, 2008b). A partir das recomendações dessa estratégia, o MS, dentro das atividades do PNSP, orienta, no Protocolo de Higiene das Mãos em Serviços de Saúde, o monitoramento e ações dessa prática a serem aplicados nos serviços de saúde do Brasil. (MS, 2013b).

$\mathrm{Na}$ atualidade, quatro técnicas diferentes são recomendadas para a higiene das mãos na assistência à saúde: higiene simples, fricção antisséptica com preparação alcoólica, higiene antisséptica e antissepsia cirúrgica. A indicação do tipo de higiene das mãos a ser efetuada depende do grau de invasão do procedimento que será realizado no paciente e da presença ou não de sujidade nas mãos. (OPAS, ANVISA, 2008a, 2008b; ANVISA, 2009, MS, 2013b).

A higiene simples das mãos é a tradicional lavagem com água e sabonete. As indicações para sua realização são: presença de sujeira visível ou contaminação nas mãos, como sangue, urina ou outros fluidos corporais; ao iniciar e terminar o período de trabalho; após ir ao banheiro; antes e após as refeições; quando a exposição a potenciais organismos formadores de esporos é fortemente suspeita ou comprovada; e também pode ser usada em todas as indicações para a utilização da fricção antisséptica com preparação alcoólica. (OPAS, ANVISA, 2008a, 2008b; ANVISA, 2009, MS, 2013b).

A técnica da higiene simples, da OMS, dura aproximadamente 40 a 60 segundos, é realizada com a fricção de água e sabonete líquido em todas as superfícies das mãos (palmas, dorsos, espaços interdigitais, unhas, pontas dos dedos e polegares), seguida de abundante enxágue em água limpa e posterior secagem com papel toalha, como descrito no Anexo A. (OPAS, ANVISA, 2008a, 2008b; ANVISA, 2009, MS, 2013b).

A fricção antisséptica das mãos com preparações alcoólicas é a técnica recomendada na maioria das atividades assistenciais quando as mãos não estão visivelmente sujas. São exemplos: antes e após tocar a pele do paciente para a realização de procedimentos não invasivos, como aferição de sinais vitais, conferência de pulseira, movimentação do paciente, entre outros; antes de inserir cateteres vesicais ou vasculares que não requeiram preparo cirúrgico; após risco de contato com fluidos corpóreos se as mãos não estiverem sujas; após 
remoção de luvas; ao mudar de sítio anatômico contaminado para outro limpo no mesmo paciente. (OPAS, ANVISA, 2008a, 2008b; ANVISA, 2009, MS, 2013b).

A técnica da fricção antisséptica dura entre 20 a 30 segundos, é realizada com a fricção de preparação alcoólica nas formas de gel, espuma ou líquida nas mãos, em quantidade suficiente para cobrir todas as superfícies (palmas, dorsos, espaços interdigitais, unhas, pontas dos dedos e polegares), friccionando o produto até secar como descrito no Anexo B. (OPAS, ANVISA, 2008a, 2008b; ANVISA, 2009; MS, 2013b).

A fricção antisséptica das mãos é considerada a técnica de escolha para a maioria das indicações assistenciais porque é mais rápida e mais eficaz na redução da carga microbiana das mãos quando comparada com a higiene simples, pode ser realizada no ponto de assistência porque o produto admite ser dispensado em várias apresentações e não danifica a pele dos profissionais de saúde quando usado produto alcoólico com adição de emolientes. (CDC, 2002; WHO, 2006, 2009).

A higiene antisséptica é a lavagem das mãos com água e sabonete associado a antisséptico, com técnica igual à higiene simples; porém, substituindo-se o sabonete comum, é indicada para os casos de cuidados em pacientes com precauções especiais para microrganismos multirresistentes e nas situações de surtos hospitalares, e também requer de 40 a 60 segundos. (ANVISA, 2009; MS, 2013b).

A antissepsia cirúrgica conhecida como degermação cirúrgica das mãos, deve ser realizada antes de qualquer procedimento cirúrgico, quer sejam cirurgias ou procedimentos, como inserção de cateteres vasculares centrais, drenagens de cavidades, pequenas suturas, procedimentos de cardiologia intervencionista e outros. A técnica, apresentada no Anexo C, consiste em molhar a escova com água, escovação dos leitos subungueais e pontas dos dedos com as cerdas da escova, que deve ser individual, descartável e impregnada com antisséptico. A seguir, friccionam-se os espaços interdigitais, demais áreas das mãos e os antebraços com a esponja da outra face da escova com as mãos mantidas acima do cotovelo, e seca-se com compressa estéril. A duração da primeira antissepsia do dia deve ser de cinco minutos e as subsequentes de dois a três minutos. (ANVISA, 2009; MS, 2013b).

A execução de qualquer uma das técnicas de higiene das mãos requer a retirada de adornos como alianças, anéis, pulseiras, relógios, unhas artificiais e outros. (WHO, 2006, 2009; OPAS, ANVISA, 2008a, 2008b; ANVISA, 2009; MS, 2013b).

São indicados cinco momentos durante as atividades assistenciais, em que é necessária a realização da higiene das mãos: (1) antes de tocar o paciente, (2) antes de realizar procedimento limpo/asséptico, (3) após risco de exposição a fluidos corporais ou excreções, 
(4) após tocar o paciente e (5) após tocar superfícies próximas ao paciente. O primeiro e o segundo momentos são destinados à proteção do paciente contra os microrganismos carreados pelas mãos dos profissionais de saúde. O terceiro, quarto e quinto momentos são destinados à proteção do profissional de saúde e redução da contaminação ambiental com microrganismos dos pacientes. (WHO, 2006, 2009; OPAS, ANVISA, 2008a, 2008b; ANVISA, 2009; MS, 2013b).

Os equipamentos e produtos necessários para a realização da higiene das mãos em serviços de saúde incluem pia e lavabo cirúrgico, dispensadores de sabonete e antisséptico, dispensadores de papel toalha e lixeira, sabonete líquido, antisséptico degermante e preparações alcoólicas. (ANVISA, 2009).

A Resolução da Diretoria Colegiada (RDC) n. ${ }^{\circ}$ 50, da Anvisa, de 21 de fevereiro de 2002, define normas mínimas que devem ser seguidas pelos hospitais em relação à disponibilidade desses itens. Segundo essa resolução, é obrigatória a presença de lavatórios ou pias para a higiene das mãos nos locais onde ocorram exames, tratamentos ou manuseio de pacientes, acamados ou não, ou o manuseio de amostras, medicamentos ou alimentos. (ANVISA, 2004).

As torneiras das pias e lavabos cirúrgicos devem possuir sistema de fechamento que dispense o contato das mãos. As torneiras dos lavabos cirúrgicos não podem possuir temporizador e podem ser acionadas com o cotovelo, joelho, pés ou sensores de células fotoelétricas. As pias e lavabos devem possuir sabonete líquido e recursos para secagem das mãos. Os antissépticos devem ser disponibilizados em áreas onde sejam executados procedimentos invasivos, contato com feridas, cateteres e drenos e nos locais de cuidados críticos. (ANVISA, 2004).

A localização desses produtos deve ser de fácil acesso e não estarem bloqueados com a presença de equipamentos ao seu redor. O número mínimo de pias e lavabos também é definido na RDC n. ${ }^{\circ}$ 50/2002; a UTI deve dispor de uma pia para cada cinco leitos de não isolamento. A RDC n. ${ }^{\circ}$ 7, da Anvisa, de 24 de fevereiro de 2010, que dispõe sobre requisitos mínimos para o funcionamento de UTI, também exige que as pias estejam disponíveis para uso da equipe e de visitantes, localizadas na entrada da unidade, no posto de enfermagem e em outros locais estratégicos definidos pela Comissão de Controle de Infecção Hospitalar (CCIH). (ANVISA, 2004, 2010a).

Os dispensadores de sabonete e de antissépticos devem possuir sistema de dispensação que não permita a contaminação do produto, de preferência em refil descartável, devem ser higienizados a cada troca de refil. Os dispensadores de papel-toalha devem ser fabricados em 
material antioxidante e possuir rotina de limpeza e reposição. (ANVISA, 2009). Junto aos lavatórios também deve ser disponibilizada uma lixeira que pode ou ter ou não tampa; se com tampa, deve possuir acionamento por pedal. (DF, 2014).

A água que abastece os lavatórios deve ser livre de contaminantes químicos e biológicos. Os reservatórios devem possuir tampa, rotina de limpeza e desinfecção e com avaliação de qualidade da água periodicamente, minimamente a cada semestre. (ANVISA, 2009).

Para secagem das mãos, as toalhas de tecido e os secadores elétricos são contraindicados devido ao risco de contaminação. Deve-se usar papel-toalha que possua boa absorção, composto de fibras $100 \%$ de celulose, que não soltem partículas, não possua fragrância, impurezas ou furos. (ANVISA, 2009).

O sabonete líquido deve ser cuidadosamente escolhido porque alguns produtos podem aumentar o ressecamento, causar irritação ou alergias na pele. $O$ produto deve ser preferencialmente acondicionado em refis descartáveis para evitar sua contaminação. $\mathrm{O}$ sabonete deve ser agradável ao uso, suave, de fácil enxágue, com leve ou sem fragrância. (ANVISA, 2009).

Alguns tipos de antissépticos degermantes disponíveis no mercado podem ser usados para a higiene das mãos, como gluconato de clorexidina, polivinilpirrolidona iodo (PVPI) e o triclosan. O gluconato de clorexidina, devido ao seu maior tempo de efeito residual, à coloração, que não deixa a pele manchada, e à rara ocorrência de alergias associadas ao produto, têm sido o mais utilizado. (ANVISA, 2009).

As preparações alcoólicas para a fricção das mãos nos serviços de saúde são motivo de regulamentação específica sobre o assunto, a RDC n. ${ }^{\circ}$ 42, da Anvisa, de 25 de outubro de 2010. Essas devem ser disponibilizadas em todos os pontos de assistência à saúde, em local de fácil acesso e ao alcance das mãos dos profissionais, de forma que estes não tenham que se deslocar do ponto de assistência. Para tanto, podem ser usadas nas formas líquida, gel ou espuma, e dispensadas em várias apresentações, como dispensadores fixos em paredes ou leitos, frascos móveis ou de bolso. (ANVISA, 2010b).

A concentração alcoólica das formulações líquidas deve ser entre $60 \%$ a $80 \%$ e a concentração final das formulações em gel, espuma e outras deve ser de 70\%. Ambas devem conter emolientes em sua fórmula para evitar o ressecamento das mãos. (ANVISA, 2010b).

Todos os produtos, como sabonete líquido, antissépticos degermantes ou preparações alcoólicas para higiene das mãos de profissionais de saúde, devem ser regularizados junto ao 
órgão sanitário competente e é proibido o uso de quaisquer desses produtos registrados na Anvisa como saneantes. (ANVISA, 2009, 2010b).

É recomendado que a avaliação e escolha dos produtos devam ser realizadas pela CCIH em conjunto com a Comissão de Farmácia e Terapêutica dos serviços de saúde, e a aceitação dos usuários deve ser sempre considerada nessa escolha. (ANVISA, 2009).

\subsubsection{Uso adequado dos Equipamentos de Proteção Individual}

As luvas devem ser usadas para reduzir o risco de contaminação das mãos de profissionais de saúde por sangue e por outros fluidos corporais, e reduzir o risco de disseminação de microrganismos no ambiente e de transmissão do profissional de saúde para o paciente e vice-versa, bem como de um paciente para outro. (SIEGEL et al., 2007; WHO 2009).

O uso de luvas está indicado durante todas as atividades de atendimento ao paciente que podem envolver a exposição a sangue e outros fluidos corporais, contato com membranas mucosas ou pele não intacta, durante as precauções de contato e situações de surto. (SIEGEL et al., 2007; WHO, 2009).

Nas precauções padrão devem-se calçar luvas antes de um procedimento asséptico, ao prever contato com sangue ou outro fluido corporal, independentemente da existência de condições que exijam técnica estéril, incluindo o contato com pele não intacta e membrana mucosa. E nas precauções de contato, devem-se calçar as luvas sempre que houver contato com o paciente e/ou suas imediações. (WHO, 2009).

A remoção ou retirada das luvas deve acontecer sempre que elas forem danificadas, imediatamente após término do procedimento em que ocorreu o risco de contato com fluidos corporais, pele não intacta ou membrana mucosa, após o contato com um paciente ou com um sítio anatômico contaminado de um paciente e em todas as indicações para a higiene das mãos. (WHO, 2009).

As luvas não fornecem proteção completa para as mãos porque podem conter pequenos furos e o profissional de saúde pode contaminar as mãos ao removê-las; por isso, após a retirada das mesmas deve-se obrigatoriamente realizar a higiene das mãos. (SIEGEL et al., 2007; WHO, 2009).

O impacto do uso de luvas na adesão à higiene das mãos ainda não é bem definido. Para a OMS, os estudos ainda apresentam resultados contraditórios, mas existe o alerta de que o uso de luvas durante todo o atendimento ao paciente por tempo prolongado, sem considerar 
as indicações para higiene das mãos e a troca das luvas, pode aumentar o risco de transmissão de microrganismos. (WHO, 2009).

O uso inadequado de luvas nas situações em que não há a indicação representa desperdício de recursos e pode também resultar em oportunidades perdidas de higiene das mãos, assim como o armazenamento incorreto das luvas e técnicas erradas de calçar e descalçar podem levar à transmissão de microrganismos. (WHO, 2009).

Atualmente, existem no mercado luvas estéreis e não estéreis de diferentes tipos. Para apoiar a tomada de decisão sobre quando usar luvas - se estéril ou não estéril e quando não as usar - foi elaborada pela OMS uma pirâmide que detalha o assunto, apresentada no Anexo D. A técnica para calçar e retirar luvas é apresentada no Anexo E.

Máscara cirúrgica e óculos de proteção devem ser usados nas precauções padrão para proteger as mucosas bucal, nasal e ocular do profissional de saúde sempre que existir o risco de respingo de sangue, fluidos corporais, secreções ou excreções durante os procedimentos. Esses itens devem ser individuais, retirados após o procedimento, seguido do descarte da máscara e da desinfecção dos óculos com álcool 70\%. (SIEGEL et al., 2007; SILVA et al., 2012).

O avental, também conhecido como capote, deve ser usado para proteção dos braços, tronco e roupas do profissional de saúde sempre que existir o risco de respingo de sangue, fluidos corporais, secreções ou excreções durante os procedimentos. Esses itens devem ser individuais e retirados após o procedimento. Avental de tecido deve ser higienizado em lavanderia hospitalar e avental descartável descartado após o uso. Avental impermeável é indicado nos procedimentos com risco de contato com grandes quantidades de sangue ou líquidos corporais, e deve ser submetido à desinfecção após o uso. Deve-se realizar a higiene das mãos após a retirada do avental. (SIEGEL et al., 2007; SILVA et al., 2012).

\subsubsection{Acomodação de pacientes em local de acordo com o risco}

Para escolha do local de acomodação do paciente, deve-se levar em consideração o potencial de transmissão dos agentes infecciosos que o paciente apresenta. Aqueles que representem um risco para a transmissão de microrganismos a outros - por exemplo, secreções, excreções incontidas ou drenagem da ferida; lactentes com suspeita de doença respiratória viral ou infecções gastrintestinais - devem ser internados em quarto individual e com banheiro, quando disponível. Na impossibilidade de quarto privativo, considerar a 
realização de coorte, por exemplo, pacientes com a mesma doença compartilhar a enfermaria. (SIEGEL et al., 2007).

\subsubsection{Higiene respiratória ou etiqueta de tosse}

Pacientes, acompanhantes ou visitantes que apresentem sintomas de doenças respiratórias, como coriza, tosse ou congestão nasal, que usem os serviços de saúde, até mesmo nas salas de espera de atendimentos ambulatoriais, devem ser orientados sobre a higiene respiratória. A estratégia deve ser intensificada durante os períodos de maior incidência dessas doenças e consiste em disponibilizar material educativo, cartazes e estrutura para a higiene das mãos após tossir ou espirrar, lenços descartáveis para conter as secreções, fornecimento de máscara cirúrgica e separação espacial de mais de um metro de áreas comuns. (SIEGEL et al., 2007).

\subsubsection{Manejo seguro dos perfurocortantes}

Atenção especial deve ser dispensada durante a manipulação de perfurocortantes. $\mathrm{O}$ manejo requer uso de EPI apropriado. Os artigos perfurocortantes descartáveis devem ser desprezados imediatamente após uso, próximo do local onde são gerados, em coletores especiais de paredes rígidas (resistentes à perfuração) e impermeáveis. As agulhas não devem ser reencapadas, entortadas, quebradas ou retiradas das seringas. (SIEGEL et al., 2007).

A Norma Regulamentadora (NR) n. ${ }^{\circ}$ 32, do Ministério do Trabalho e Emprego (MTE), determina que agulhas, cateteres, seringas e outros produtos convencionais devem ser substituídos por outros com dispositivos de segurança. (MTE, 2005).

Os coletores para descarte de material perfurocortante devem ser preenchidos até $2 / 3$ de sua capacidade total ou conforme limite indicado pelo fabricante, instalados/fixados em altura adequada, próximos ao local do procedimento, ou de maior fluxo de atendimento. $\mathrm{O}$ acondicionamento e transporte de perfurocortantes não descartáveis para a limpeza e esterilização devem ser em condições de segurança, dentro de recipientes resistentes à perfuração e com tampa. (DF, 2014).

2.3.6 Manuseio/recolha/coleta seguros de roupas e resíduos 
Utilizar os EPIs adequados ao manipular resíduos ou roupas sujas de uso hospitalar. Acondicionar a roupa suja em sacos impermeáveis, respeitando a sua capacidade de ocupação, evitando extravasamento e contaminação ambiental. Manipular as roupas sujas com técnica segura evitando agitação e propagação de partículas suspensas. (SIEGEL et al., 2007).

Os hampers para roupas e lixeiras abertos devem ser substituídos por contêiner e lixeiras com tampa. Deve-se utilizar saco plástico com identificação de roupas ou resíduos de acordo com a categoria a que pertencem. O transporte de roupas ou de resíduos deve ser realizado em carros de transporte fechados, identificados e específicos para essa finalidade. (DF, 2014).

2.3.7 Limpeza e desinfecção de superfícies, artigos e equipamentos usados

Rotina de limpeza e desinfecção de superfícies deve incluir todo o mobiliário, equipamentos e superfícies frequentemente tocadas. O piso e as paredes devem ser limpos com água e sabão. A desinfecção dessas superfícies deve ser realizada somente quando existir derramamento ou respingos, matéria orgânica como sangue, fluidos corporais ou excreções. (ANVISA, 2010c).

Artigos e equipamentos usados nos pacientes devem ser manipulados com o uso de EPI, transportados em saco plástico e sofrer limpeza, desinfecção ou esterilização de acordo com a criticidade do artigo. (SIEGEL et al., 2007).

\subsubsection{Práticas seguras de injeção}

Para procedimentos que envolvem o canal medular, como punção lombar, anestesia espinhal ou epidural, colocação de cateteres ou mielograma, devem-se utilizar avental estéril, luvas cirúrgicas, gorro, óculos e máscara cirúrgica. (SIEGEL et al., 2007; DF, 2014).

Não existe a necessidade de uso de máscara no preparo de medicamentos. (WHO, 2010).

Utilizar a técnica asséptica para o preparo e administração de medicamentos com a desinfecção da tampa dos frascos e dos gargalos das ampolas com álcool $70 \%$ antes de introduzir a agulha para a aspiração. Agulhas, seringas, extensores, torneirinhas, conectores, equipos e bolsas devem ser de uso único e não podem ser usadas em diferentes pacientes. 
Nunca administrar medicações diluídas de uma mesma seringa ou bolsa para múltiplos pacientes. (SIEGEL et al., 2007; SILVA et al., 2012).

Frascos de múltiplas doses devem ser evitados, e, se necessário, utilizar em um único paciente. Todos os medicamentos devem ser controlados pelo serviço de farmácia, forma de armazenamento, rotulagem, distribuição, fracionamento em múltiplas doses. Deve-se assegurar que todos os envolvidos no processo que abrange o uso de medicamentos foram capacitados, conhecem e seguem as normas de segurança. (SIEGEL et al., 2007; SILVA et al., 2012).

A segurança no uso de medicamentos também é uma das metas de segurança dos pacientes, estabelecidas pelo PNSP, a serem alcançadas pelos serviços de saúde. O MS criou o Protocolo de Segurança na Prescrição, Uso e Administração de Medicamentos com orientações de práticas para otimizar a segurança nas diferentes fases desse processo. (MS, 2013c).

\subsection{PRECAUÇÕES ESPECIAIS}

As precauções especiais incluem três categorias, baseadas na forma de transmissão do agente infeccioso, que são as precauções de contato, para gotículas e para aerossóis. São utilizadas quando a(s) via(s) de transmissão do agente infeccioso não é(são) interrompida(s) completamente pelo uso das precauções padrão. Na categoria das precauções especiais também estão incluídas outras duas, ou seja, o ambiente protetor e as precauções para prevenção de transmissão de microrganismos multirresistentes. As especiais devem ser sempre adicionadas às precauções padrão. (SIEGEL et al., 2007).

O ambiente protetor também é considerado uma categoria de precaução especial e está destinado aos pacientes que foram submetidos ao transplante halogênicos de medula, para prevenir a ocorrência de infecções pela disseminação de esporos fúngicos ambientais. (SIEGEL et al., 2007).

\subsubsection{Precauções de contato}

Devem ser adicionadas às precauções padrão quando da suspeita ou confirmação de pacientes com colonizados ou infectados por microrganismo que se transmite por contato direto ou indireto. Incluem a indicação de quarto privativo quando disponível ou coorte, higiene das mãos com antisséptico, uso de avental e luvas em todos os contatos com o 
paciente e seu ambiente, cuidados especiais com o seu transporte, artigos e equipamentos de uso exclusivo como estetoscópio, termômetro, esfigmomanômetro, limpeza e desinfecção das superfícies frequentes, visitas reduzidas e orientadas quanto à higiene das mãos. (SIEGEL et al., 2007).

\subsubsection{Precauções para gotículas}

Devem ser adicionadas às precauções padrão, quando da suspeita ou confirmação de diagnóstico de doença provocada por microrganismo que se transmite por meio da via respiratória por partículas maiores que cinco micras, que são geradas quando o paciente fala, tosse ou espirra. Incluem a indicação de quarto privativo e na impossibilidade, coorte de pacientes com a mesma doença com distância mínima de um metro entre os leitos, higiene das mãos com antisséptico, uso de máscara cirúrgica pelo profissional ao entrar no quarto, instruir paciente quanto à etiqueta de tosse, colocar máscara cirúrgica no paciente durante o transporte, visitas reduzidas, orientadas quanto à higiene das mãos e uso máscara cirúrgica. (SIEGEL et al., 2007).

\subsubsection{Precauções para aerossóis}

Devem ser adicionadas às precauções padrão, quando da suspeita ou confirmação de diagnóstico de doença provocada por microrganismo que se transmite por meio da via aérea, por partículas menores que cinco micras, que podem ficar suspensas no ar ou ressecadas no ambiente. Incluem o uso de quarto privativo dotado de sistema de ventilação especial, com pressão negativa em relação ao lado de fora e filtragem do ar que sai do quarto com filtros de alta eficiência, higiene das mãos com antisséptico, uso de máscara do tipo respirador com eficiência de filtração de $95 \%$ das partículas de até 0,3 micra de diâmetro pelo profissional de saúde, orientar o paciente quanto à etiqueta de tosse, colocar máscara cirúrgica no paciente durante o transporte, visitas reduzidas, orientadas quanto à higiene das mãos e uso máscara tipo respirador. (SIEGEL et al., 2007).

Precauções empíricas com a adição de precauções especiais às precauções padrão são indicadas quando há suspeita de doenças ou condições clínicas que indiquem necessidade de precauções especiais, mesmo antes da confirmação do diagnóstico ou quando o diagnóstico não foi possível. (SIEGEL et al., 2007). 


\subsubsection{Ambiente protetor}

Devem ser adicionados às precauções padrão em pacientes que foram submetidos ao transplante halogênico de medula para diminuir o risco de exposição aos agentes fúngicos ambientais. Incluem quarto com sistema de filtros de ar de alta eficiência para o ar interno, pressão positiva em relação à antecâmara e/ou corredor, de forma a garantir fluxo de ar sempre na direção do quarto para o corredor, vedação dos quartos incluindo portas, janelas e dispositivos elétricos, pelo menos 12 trocas de ar/hora, barreiras entre área de pacientes e áreas de reforma/construção; flores e vasos de plantas são proibidos. (SIEGEL et al., 2007).

\subsection{PRECAUÇÕES EM UNIDADE DE TERAPIA INTENSIVA}

O risco de transmissão de infecção está presente em todos os cenários do hospital. Entretanto, certos cenários e pacientes apresentam condições específicas que predispõem essa transmissão. Eles frequentemente são sentinelas da emergência de novos riscos de transmissão que podem ser específicos do local ou ocorrerem em outras situações. (SIEGEL et al., 2007; WHO, 2011).

Múltiplos fatores influenciam diferenças no risco de transmissão de infecções entre os vários tipos de serviços de saúde, incluindo características populacionais - por exemplo, maior susceptibilidade às infecções, tipo e prevalência de procedimentos invasivos -, intensidade dos cuidados, exposição a fontes ambientais, tempo de permanência e a frequência de interação entre pacientes ou residentes dos serviços uns com os outros e com os profissionais de saúde. Esses fatores, bem como as prioridades institucionais, metas e recursos, influenciam como os demais cenários de assistência à saúde e adaptam os guias de prevenção de transmissão ao encontro de suas necessidades específicas. (SIEGEL et al., 2007).

Unidades de Terapia Intensiva atendem pacientes que são imunossuprimidos pelo estado de sua doença ou modalidades de tratamento, bem como pacientes politraumatizados, com falência respiratória e outras condições de perigo de vida - por exemplo, infarto do miocárdio, insuficiência cardíaca congestiva, superdosagem de medicamentos, coma, sangramento gastrointestinal, insuficiência hepática, renal ou de múltiplos órgãos, e extremos de idade. (SIEGEL et al., 2007).

A população de pacientes de UTI tem maior susceptibilidade à colonização e infecção, especialmente com bactérias multirresistentes e Candida sp., devido à patologia de base, uso 
de medicamentos e tecnologias invasivas no seu cuidado - por exemplo, cateter venoso central e outros dispositivos intravasculares, ventilação mecânica, hemodiálise/diálise peritoneal, marca-passo, dispositivos implantáveis no ventrículo esquerdo -, a frequência de contato com os profissionais de saúde, duração prolongada da permanência e exposição a agentes antimicrobianos. (WENZEL, GENNINGS, 2005; SAN MIGUEL et al., 2005; EDWARDS et al., 2009).

Além disso, resultados adversos nesses pacientes são mais graves e associados com maior mortalidade. (KNAUS et al., 1993). Surtos associados com uma variedade de patógenos virais, bacterianos ou fúngicos, devido à fonte comum ou transmissão cruzada, são frequentes em UTIs para pacientes pediátricos e adultos. (PINA, FERREIRA, UVA, 2014; WENZEL, GENNINGS, 2005; VILLARINO et al., 1992; SANCHEZ et al., 1993; HUSNI et al., 1999).

Taxas de resistência a antimicrobianos são maiores nas UTIs do que em outras unidades hospitalares, devido ao alto consumo de antimicrobianos, ao elevado uso de dispositivos invasivos somados à gravidade dos pacientes ali hospitalizados. (GALES et al., 2012).

A resistência microbiana e a ocorrência de IRAS nas UTIs brasileiras são monitoradas pela Anvisa. Relatórios anuais com seus indicadores apontam taxas de infecções da corrente sanguínea por microrganismos multirresistentes muito altas e preocupantes. Assim, ações que visem prevenir ou restringir a sua disseminação devem ser implementadas de forma efetiva pelos serviços de saúde para controle desse cenário. (ANVISA, 2013c, 2015b).

No Distrito Federal, assim como os estados do Rio de Janeiro e Paraná, a incidência de microrganismos multirresistentes, principalmente nas UTIs, têm preocupado os serviços de saúde locais e os gestores da área da vigilância em saúde. Um "Plano de Enfrentamento da Resistência Bacteriana nas Áreas Críticas dos Hospitais Públicos do GDF” foi criado em 2015, que envolve o uso racional de antimicrobianos, vigilância epidemiológica das IRAS e, principalmente, a aplicação das medidas adequadas de precauções. (DF, 2015b).

Nas UTIs, devido à grande ocorrência de patógenos multirresistentes, é muito comum a presença de pacientes que necessitem de precauções de contato e também, como é muita alta a frequência de procedimentos invasivos nesses pacientes, as boas práticas de precauções são primordiais nos cuidados aos pacientes críticos. A higiene das mãos e o uso de EPI devem ser rigorosamente trabalhados com as equipes de saúde. A interrupção da cadeia epidemiológica de transmissão dos microrganismos para prevenir a transmissão cruzada é um dos doze passos apontados pelos CDC para prevenir a resistência microbiana. (SIEGEL et al., 2007). 
Devem ser implementados pelos serviços de saúde a educação dos profissionais, pacientes e visitantes que abordem a higiene das mãos, o uso correto de equipamentos de proteção individual, as barreiras de precauções especiais (isolamentos), a identificação precoce de microrganismos multirresistentes, a promoção de antibioticoprofilaxia apropriada e práticas rigorosas de limpeza. (PINA, FERREIRA, UVA, 2014; KAWAGOE, GONÇALVES, 2013).

Um compêndio atualizado de estratégias para prevenção de IRAS foi publicado recentemente nos EUA. O documento foi produto de um esforço colaborativo liderado pela Society for Healthcare Epidemiology of America (SHEA), a Infectious Diseases Society of America (IDSA), a American Hospital Association (AHA), a Association for Professionals in Infection Control and Epidemiology (APIC), a The Joint Commission, com importantes contribuições de representantes de várias organizações e sociedades, com experiência de conteúdo, incluindo os Centers for Disease Control and Prevention (CDC), o Institute for Healthcare Improvement (IHI), a Pediatric Infectious Diseases Society (PIDS), a Society for Critical Care Medicine (SCCM), a Society for Hospital Medicine (SHM) e a Surgical Infection Society (SIS). O documento traz recomendações com atualizações das categorias de evidências para as práticas de prevenção de IRAS, em que o reforço à higiene das mãos e as precauções de contato para prevenção de Staphytlococcus aureus resistente a meticilina (MRSA) e Clostridium difficile (CDI) são fortemente indicados. (YOKOE et al, 2014).

As estratégias para prevenir IRAS por meio da higiene das mãos, recomendadas para hospitais de pacientes agudos no documento supracitado, e suas respectivas categorias de evidências estão relacionadas abaixo:

1. Selecionar os produtos apropriados (qualidade de evidência: II).

2. Proporcionar um acesso conveniente ao equipamento de higiene das mãos e dos produtos, colocando-os estrategicamente e garantindo que eles são recarregados rotineiramente tantas vezes quanto necessário (qualidade das provas: III).

3. Envolver profissionais de assistência na escolha dos produtos (qualidade das provas: III).

4. Higienizar as mãos com preparações alcoólicas, em alternativa ao sabonete com ou sem antimicrobiano, para as indicações definidas (qualidade das provas: II).

5. Higienizar as mãos com sabonete com ou sem antimicrobiano quando as mãos estiverem visivelmente sujas (qualidade das provas: II). 
6. Avaliar os obstáculos da unidade ou específicos da instituição para a higiene das mãos dos profissionais de saúde da linha de frente, com a finalidade de intervenções de identificação que serão localmente relevantes (qualidade de evidência: III).

7. Implementar uma estratégia multimodal (ou "pacote") para melhorar a adesão à higiene das mãos para abordar diretamente as barreiras mais significativas da organização (qualidade das provas: II).

8. Educar, motivar e assegurar a competência dos profissionais de saúde sobre a higiene adequada das mãos (qualidade das provas: III).

9. Medir a adesão à higiene das mãos com observação direta (observadores humanos), medição do volume do produto, ou monitoramento automatizado (qualidade das provas: II).

10. Fornecer feedback para profissionais de saúde sobre o desempenho da higiene das mãos (qualidade das provas: III).

Abordagens especiais para práticas de higiene das mãos:

1. Durante surtos de norovírus, além de precauções de contato que exigem o uso de luvas, considere o uso preferencial de água e sabão depois de cuidar de pacientes com conhecida ou suspeita de infecção norovírus (qualidade das provas: III).

2. Durante os surtos de Clostridium difficile ou em ambientes com CDI hiperendêmica, além de precauções de contato que exigem o uso de luvas, considere o uso preferencial de água e sabão depois de cuidar de pacientes com suspeita ou diagnóstico CDI (qualidade das provas: III). (YOKOE et al., 2014).

Quanto às demais práticas que envolvem a prevenção e o monitoramento de microrganismos multirresistentes, o documento reforça a necessidade de monitoramento de vigilância para CDI e MRSA, em adição às precauções especiais de contato em quarto privativo, e várias outras intervenções para controle da contaminação ambiental e prevenção da disseminação e transmissão cruzada desses agentes. Deve-se implementar sistema de alerta de comunicação rápida em laboratório, área assistencial e profissional de controle de IRAS para casos positivos de colonização ou infecção, monitorar a qualidade da limpeza e desinfecção do ambiente e usar desinfetante ambiental apropriado para CDI (hipoclorito de sódio), dentre outras. (YOKOE et al., 2014).

A European Society of Clinical Microbiology and Infectious Diseases (ESCMID) conduziu uma revisão sistemática da literatura para reunir estudos e definir diretrizes com categorias de evidências sobre medidas de controle e prevenção de transmissão de bactérias Gram-negativas multidroga-resistentes em pacientes hospitalizados. A publicação foi posteriormente traduzida para o português do Brasil por parceria entre a ESCMID e a 
Associação Brasileira dos Profissionais em Controle e Epidemiologia Hospitalar (ABIH). O guia traz recomendações com categorias de evidências a partir das diferentes situações epidemiológicas de endemia ou epidemia que podem ocorrer no hospital para bactérias Gramnegativas multidroga-resistentes como: $P$. aeruginosa, $A$. baumannii, do gênero Enterobacteriaceae, Stenotrophomonas maltophilia e Burkholderia cepacia. Em geral, as recomendações incluem promoção da higiene das mãos, precauções de contato, culturas de triagem ativas, com destaque para necessidade de sistemas de alerta que possibilite a identificação de pacientes sabidamente colonizados na admissão, rigorosas práticas de limpeza ambiental, efetivo sistema de gestão do uso de antimicrobianos. Tais diretrizes são extremamente úteis, porque trazem recomendações específicas com as categorias de evidências encontradas separadamente por tipo de microrganismo. (TACCONELLI et al., 2014).

\subsection{MENSURAÇÃO DE INDICADORES}

A literatura e os órgãos governamentais em suas publicações recomendam que se façam avaliações periódicas dos processos que envolvem a prevenção e o controle das infecções. (ANVISA, 2013; SIEGEL et al., 2007).

Um bom programa de melhoria de qualidade deve incluir avalições de como a organização controla ou adere às políticas, documenta os resultados das auditorias observacionais, realiza a análise de causa-raiz, reporta as taxas de infecção às unidades ou ao médico individualmente, e compara as taxas (benchmark) com outros serviços ou com a média local/estadual/nacional. (KAWAGOE, GONÇALVES, 2013; JCI, 2010).

No desenvolvimento do $\mathrm{PCIH}$, as avaliações detalhadas da qualidade das práticas de assistência à saúde são necessárias. Nessa avaliação, é cada vez mais frequente a utilização de indicadores clínicos, aqui definidos como medidas quantitativas das características de um dado processo ou sistema, e podem incorporar as três dimensões de avaliação de qualidade em saúde: estrutura, processo e resultado. Esses indicadores podem ser expressos em taxas, razão ou evento. (SÃO PAULO, 2006; JCI, 2010; GOUVÊA, 2011).

Avaliações de resultado medem a frequência com que algo acontece, podendo ser específicas a um dado problema de saúde ou desfecho, por exemplo, mortalidade. Esse é o caso dos indicadores de IRAS. Esses indicadores mostram o desfecho negativo, ou seja, quando a infecção já ocorreu, assim, mostraram quais áreas precisam de atenção, mas não conseguem identificar as falhas no processo que poderiam ser corrigidas para evitar o efeito 
negativo, no caso, a IRAS. Esse tipo de indicador é muito influenciado pela gravidade das condições clínicas apresentadas pelos pacientes. (SÃO PAULO, 2006; GOUVÊA, 2011).

Avaliações estruturais se referem às características dos recursos físicos, materiais e humanos requeridos para assistência de qualidade, os quais incluem profissionais, sistemas de assistência, suporte financeiro, área física, equipamentos, acessibilidade, entre outros, e para tanto se devem ter parâmetros de avaliação claros. (SÃO PAULO, 2006; GOUVÊA, 2011).

Avaliações processuais se referem à análise da dinâmica dos processos, ou seja, entender como o trabalho, o cuidado ou o protocolo clínico, por exemplo, se realizam na prática. Também podem incluir a avaliação da estrutura e permite analisar o que, quem, com o que, como, por que. Esses indicadores são menos influenciados pelas características clínicas dos pacientes. (SÃO PAULO, 2006; GOUVÊA, 2011).

Os três tipos de avaliações se completam para se obter a um diagnóstico preciso da realidade. Os líderes ou gestores devem identificar indicadores para monitorar as estruturas, os processos e os resultados clínicos e administrativos da instituição, assim como as metas de segurança do paciente. (SÃO PAULO, 2006; UNIÃO EUROPÉIA, 2009; JCI, 2010; GOUVÊA, 2011).

\subsection{INDICADORES DE PRECAUÇÕES}

Estudos que buscam avaliar a higiene das mãos em serviços de saúde são amplamente publicados na literatura. Em geral são desenvolvidos com questionários autoaplicáveis, entrevistas, observação direta da prática, observação da prática via uso de câmeras de vídeo, mensuração do consumo; e os mais recentes envolvem o uso de tecnologias, como contadores automáticos de dispensação de produtos e sensores de presença e movimento conectados a sistemas informatizados para calcular as oportunidades e as ações de higiene das mãos. (MARRA et al., 2010; DE OLIVEIRA, DE PAULA, 2011; MACEDO et al., 2012; VAIDOTAS et al., 2015; SUNKESULA et al., 2015).

O método de mensuração da adesão à higiene das mãos, proposto na estratégia multimodal da OMS, é a observação direta da prática assistencial realizada por profissionais treinados usando-se de um formulário especialmente desenvolvido para esse fim. Nesse formulário são registrados os dados de identificação da unidade e das categorias e número de profissionais, as oportunidades de higiene das mãos a partir dos cinco momentos e a realização ou não das técnicas de higiene simples ou fricção antisséptica. Também são recomendadas as avaliações e adequações da estrutura física e de insumos, além da 
mensuração do consumo dos sabonetes líquidos e das preparações alcoólicas. (WHO, 2006, 2009; OPAS, ANVISA, 2008a, 2008b; ANVISA, 2009; MS, 2013b).

O Protocolo de Higiene das Mãos do MS, proposto dentro do PNSP, traz como obrigatórias a mensuração dos indicadores de consumo de sabonete líquido e preparações alcoólicas e, como recomendada, a mensuração do indicador de adesão à higiene das mãos. (MS, 2013b).

O consumo de sabonete ou de preparação alcoólica é obtido pelo volume de cada um desses produtos utilizados para cada 1.000 pacientes-dia. O percentual de adesão à higiene das mãos é calculado pela divisão do número de ações de higiene das mãos realizadas pelos profissionais de saúde, dividido pelo número de oportunidades ocorridas para a higiene das mãos, multiplicado por 100. (MS, 2013b).

Uma revisão da literatura para avaliar os métodos de mensuração da adesão à higiene das mãos aponta alguns pontos fortes e fracos dos métodos. Os questionários apresentam baixo custo e possibilitam que os profissionais pensem em sua aderência à higiene das mãos, mas apresentam como desvantagem as altas taxas de vieses, porque vários estudos mostraram que a adesão autorrelatada é maior que a adesão real. A observação direta que é considerada o padrão ouro pelo OMS permite avaliar a técnica utilizada e traçar características específicas das oportunidades de higiene das mãos. As desvantagens da observação direta apontadas nos estudos são o tempo necessário para a realização dessas observações, a necessidade de profissional capacitado e treinado, a não existência de método padronizado para as observações, o risco de viés quando se avalia turnos de trabalho e, principalmente, estar sujeita ao chamado efeito Hawthorne, que é a mudança de atitude ou comportamento do profissional de saúde por saber que está sendo observado. (OLIVEIRA, DE PAULA, 2011; WALKER et al., 2014).

A observação por câmera de vídeo não está sujeita ao viés de seleção ou ao efeito Hawthorne, mas apresenta alto custo e também pode ser passível de viés no momento de revisão das gravações. O cálculo indireto pelo consumo de suprimentos é de baixo custo e não apresenta o viés de seleção, porque avalia a unidade como um todo, mas suas desvantagens são muitas, como não permitir a avaliação da técnica e das oportunidades de higiene das mãos que não são cumpridas, além de não possuir validação de método. (OLIVEIRA, DE PAULA, 2011).

Outra revisão sistemática foi conduzida para avaliar a eficácia dos métodos automatizados que monitoram a adesão à higiene das mãos. Foram comparados resultados dos estudos experimentais e quase experimentais que avaliaram a melhoria da adesão à higiene 
das mãos usando-se de métodos de monitoramento eletrônico e os de monitoramento por vídeo. Todos os sete estudos apresentaram alto ou moderado risco de viés. Os autores concluíram que os dados foram insuficientes para recomendar sistema eletrônico ou sistema de vídeo, e que ambos aumentam a adesão à higiene das mãos. Além disso, sugerem que estudos futuros devem priorizar os testes de sistema de monitoramento por vídeo usando melhor desenho e que incluam grupo controle. (SRIGLEY et al., 2015).

Da mesma forma que a higiene das mãos, os estudos publicados que avaliam o uso de EPI e as recomendações de isolamentos utilizam-se de entrevistas e questionários que visam identificar o conhecimento e a prática autorrelatada dos profissionais. Dois modelos teóricos americanos foram desenvolvidos para avaliar a adesão às precauções, e os motivos que levaram ao não cumprimento das práticas: o Modelo de Sistemas de Trabalho que avalia fatores individuais e os ligados à instituição; e o Modelo de Adesão às Precauções Padrão que com uso de escalas tipo Likert, avalia os fatores individuais e sociodemográficos, fatores psicossociais (como medo, estresse relacionado ao trabalho e atitudes dos profissionais) e fatores organizacionais, que englobam clima de segurança organizacional, suporte da instituição e participação em treinamentos. (BREVIDELLI, CIANCIARULLO, 2009; MALAGUTI-TOFFANO et al., 2012).

A partir dos modelos americanos, no Brasil, Brevidelli e Cianciarullo (2009) validaram um questionário com perguntas e respostas em escalas do tipo Likert, que avalia os fatores psicossociais e organizacionais na adesão às precauções padrão para prevenir a exposição a material biológico em hospital. O uso do instrumento evidenciou que fatores individuais relativos ao trabalho e organizacionais explicaram 38,5\% do índice global de adesão às precauções padrão: associação significativa entre adesão e pertencer ao grupo profissional de médicos, ter recebido treinamento em precauções padrão no hospital, perceber menos intensamente os obstáculos para seguir as precauções padrão, perceber mais intensamente a carga de trabalho, o feedback das práticas de segurança e as ações gerenciais de apoio à segurança, e concluem que os programas de melhorias devem considerar tais fatores. (BREVIDELLI, CIANCIARULLO, 2009).

Uma nova avaliação com o uso desse instrumento foi repetida em 2012, quando se evidenciou que 59,4\% dos profissionais apresentaram escores médios altos para a adesão às precauções padrão, 38,3\% escores intermediários, e 2,3\% baixos. Porém, não houve diferenças estatisticamente significativas entre os escores e outras variáveis; no entanto, destacou-se a importância do resultado positivo encontrado pela valorização das ações de educação permanente pela instituição. (MALAGUTI-TOFFANO et al., 2012). 
As observações diretas em auditorias feitas por profissionais que atuam em controle de infecções ou em saúde e segurança do trabalho também são frequentemente usadas, e em geral mostram taxas de adesão menores que as autorrelatadas em pesquisas com uso de questionários. (SÃO PAULO, 2006; HOSOGLU et al., 2011; MALAGUTI-TOFFANO et al., 2012).

O Manual de Avaliação de Qualidade das Práticas de Controle de Infecção Hospitalar do Centro de Vigilância Epidemiológica do Estado de São Paulo (CVE/SP), elaborado em 2006 por um grupo de especialistas da área, define um método para a coleta de indicadores de adesão ao uso de EPI e recomendações de isolamentos, com instrumentos validados para coleta das informações pertinentes, e cálculo das taxas de adesão às técnicas e recomendações em geral, via observação direta em auditorias das práticas assistenciais. (SÃO PAULO, 2006).

A análise da adequação de estrutura física, recursos humanos e materiais deve levar em consideração a regulamentação sanitária brasileira, da ANVISA, que normatiza a elaboração de projetos físicos de estabelecimentos assistenciais de saúde pela Resolução RDC n. ${ }^{\circ} 50$, de 21 de fevereiro de 2002; a RDC n. ${ }^{\circ}$ 7, de 24 de fevereiro de 2010, que dispõe sobre os requisitos mínimos para funcionamento de UTI; a RDC n. ${ }^{\circ} 26$, de 11 de maio de 2012, que altera a RDC n. ${ }^{\circ}$; e a RDC n. ${ }^{\circ}$ 42, de 25 de outubro de 2010, que dispõe sobre a obrigatoriedade de disponibilização de preparação alcoólica para fricção antisséptica das mãos, pelos serviços de saúde do País. (ANVISA, 2004, 2010a, 2010b, 2012b).

Para análise de processo de trabalho, é necessária observação direta da realidade no momento em que está ocorrendo assistência à saúde. Esses tipos de avaliações fazem parte das atribuições dos profissionais que atuam no controle de infecções e também podem receber o nome de auditorias. Outras tecnologias mais complexas e que envolvem maior investimento podem também ser incorporadas, como o monitoramento por vídeos, sensores de presença e contadores de dispensação de produtos conectados a softwares de análises de dados, por exemplo; no entanto, essas não estão disponíveis na maioria dos serviços públicos de saúde no Brasil. 


\section{OBJETIVOS}

\subsection{OBJETIVO GERAL}

Avaliar a infraestrutura e as práticas de precauções dos profissionais de saúde da UTI de um hospital de ensino do Distrito Federal.

\subsection{OBJETIVOS ESPECÍFICOS}

Descrever características demográficas e profissionais da equipe de assistência direta ao paciente da UTI.

Identificar a infraestrutura disponível para executar as práticas de precauções.

Verificar a adequação das indicações de precauções.

Medir indicadores de processo de higiene das mãos.

Mensurar adesão ao uso de Equipamentos de Proteção Individual. 


\section{MÉTODOS}

\subsection{TIPO DE ESTUDO}

Trata-se de um estudo de natureza quantitativa, do tipo descritivo, com delineamento observacional, transversal e exploratório. Justifica-se como pesquisa observacional porque desempenha um papel passivo na observação dos eventos que ocorrem com os sujeitos do estudo; transversal, com observações feitas em curto período de tempo; e exploratório porque busca informações sobre o objeto e possíveis explicações sobre o fenômeno. (HULLEY et al., 2008).

\subsection{CENÁRIO E POPULAÇÃO}

A pesquisa foi realizada em um hospital de ensino, considerado de médio porte, com 257 leitos ativos, localizado na cidade de Brasília, Distrito Federal.

Os serviços oferecidos nas áreas de média e alta complexidade incluem várias especialidades médicas e cirúrgicas.

Elegeu-se como cenário de investigação a UTI Adulto, que possui 18 leitos; porém, somente 10 leitos estavam ativos e destinados ao atendimento de pacientes agudos clínicos e cirúrgicos à época da coleta de dados. A indisponibilidade de profissionais e de equipamentos era o fator que limitava a ativação dos demais leitos.

A estrutura física foi reconstruída e ampliada, sendo a nova unidade inaugurada em julho de 2014. A planta da UTI pode ser visualizada no Anexo F. (HUB, 2013b).

O quadro fixo de pessoal que prestava assistência direta aos pacientes internados nessa unidade no período da coleta de dados era composto por nove médicos, 10 enfermeiros, cinco fisioterapeutas, 31 técnicos e auxiliares de enfermagem, totalizando 55 colaboradores. Destes, 45 foram admitidos recentemente, a partir de fevereiro de 2014 e após a ampliação da UTI.

As escalas de trabalho eram distribuídas entre os plantões do turno da manhã (7h às 13h), tarde (13h às $19 \mathrm{~h})$ e noite (19h às $7 \mathrm{~h}$ ). Normalmente, o quadro mínimo de recursos humanos que compunha cada turno de trabalho era: um médico, um fisioterapeuta (entre $7 \mathrm{~h}$ e 24h), um enfermeiro assistencial para cada dez pacientes e um enfermeiro para atividades de supervisão de equipe no período diurno. A proporção de técnicos e auxiliares de enfermagem 
era mantida durante qualquer horário de trabalho em um para cada dois pacientes, mais um para serviços de apoio.

Como é comum no atendimento aos pacientes críticos e nos hospitais de ensino, estudantes de graduação, pós-graduação, residentes, profissionais de áreas de apoio como radiologia e laboratório, médicos de outras especialidades, nutricionistas, psicólogos e odontólogos também, eventualmente, prestavam assistência aos pacientes nessa unidade.

\subsection{CRITÉRIOS DE INCLUSÃO E EXCLUSÃO}

Foram incluídos na pesquisa os profissionais de saúde do quadro de pessoal fixo da UTI, envolvidos diretamente na assistência ao paciente, a saber: médico intensivista, enfermeiro, fisioterapeuta, técnico e auxiliar de enfermagem, que aceitaram ao convite para participar do estudo e assinaram o Termo de Consentimento Livre e Esclarecido (TCLE) (Apêndice A), em conformidade com a Resolução n. ${ }^{\circ}$ 466/12, do Conselho Nacional de Saúde (CNS).

Excluíram-se os profissionais que estavam em licença médica, férias ou outros afastamentos no período da coleta de dados.

\subsection{RISCOS IDENTIFICADOS PARA OS PARTICIPANTES E FORMAS DE MINIMIZAÇÃO}

A pesquisa pôde acarretar, aos participantes, risco mínimo, de natureza psíquica, decorrente de possível desconforto ou ansiedade ao responder perguntas que envolvessem informações de si, assim como a observação direta pela pesquisadora das práticas de trabalho, mas que poderia ser minimizado com esclarecimentos necessários antes e no decorrer da pesquisa referente ao seu objetivo e procedimentos de coleta de dados. No entanto, a reflexão dos participantes sobre o assunto é um grande benefício indireto desta pesquisa para seu local de trabalho, porque a abordagem do tema serve para divulgar e estimular a melhoria da adesão às práticas recomendadas.

\subsection{PROCEDIMENTOS E INSTRUMENTO DE COLETA DE DADOS}

A fonte de dados é primária e foram aplicados três instrumentos. O primeiro instrumento trata-se de um questionário estruturado e autoaplicável para coleta das variáveis 
referentes às características demográficas e profissionais dos participantes da pesquisa (Apêndice B). O segundo e o terceiro instrumentos são questionários preenchidos por observações diretas não participantes da adesão às precauções e avaliação quanto à disponibilidade de recursos para o cumprimento das mesmas.

A auditoria de adesão às práticas de precauções foi realizada com observação direta não participativa in loco na unidade, dos profissionais de saúde envolvidos na assistência direta prestada aos pacientes. As observações diretas não participativas foram feitas sem ocultar a presença do observador, realizado por um auxiliar de pesquisa. Dois questionários estruturados foram usados.

Para registro das observações da adesão à higiene das mãos, foi usado o formulário validado, tipo checklist, da Estratégia Multimodal para Melhoria da Higiene das Mãos, da OMS, constante do "Manual para observadores: estratégia multimodal da OMS para melhoria da higienização das mãos”, da Organização Pan-Americana da Saúde e Anvisa, apresentado no Anexo G. (OPAS, ANVISA, 2008b).

A supracitada estratégia foi criada pela OMS dentro do primeiro desafio global da Aliança Mundial para Segurança do Paciente denominado "Uma Assistência Limpa é uma Assistência mais Segura”. A metodologia multimodal para melhoria da adesão à higiene das mãos foi desenvolvida para ser usada pelos serviços de saúde com o objetivo de prevenir e controlar as IRAS. As ferramentas propostas e o instrumento de observação de adesão à higiene das mãos foram estudados e aplicadas em múltiplos centros em diferentes realidades de vários países. (WHO, 2006).

O detalhamento dos conceitos do método de observação de higiene das mãos da OMS, o conceito, o perfil e a tarefa dos observadores, a sua formação e validação do formulário de coleta de dados, o escopo, a seleção do pessoal observado, e a forma de tornar as sessões de observação acessíveis para uso universal são discutidos por SAX et al. (2009) e em mais recente publicação da OMS sobre a estratégia do ano de 2009. (SAX et al., 2009; WHO, 2009).

A aplicação do instrumento se deu conforme as orientações constantes do manual para observadores e do guia de implantação da Estratégia Multimodal da OMS para Melhoria da Higienização das Mãos. (OPAS, ANVISA, 2008a, 2008b).

As observações referentes à disponibilidade de insumos e de pessoal, presentes na unidade para execução das práticas, o uso de EPI pelos profissionais e a adequação do tipo de precaução indicada, foram registradas em outro questionário estruturado, tipo checklist, que 
foi construído e adaptado a partir dos indicadores validados, do Manual de Avaliação de Qualidade das Práticas de Controle de Infecção Hospitalar do CVE/SP. (SÃO PAULO, 2006).

O Manual de Avaliação de Manual de Avaliação de Qualidade das Práticas de Controle de Infecção Hospitalar do CVE/SP foi criado por um grupo especialistas na área à partir de um projeto de parceria multiprofissional e multi-institucional de política pública de saúde na área de controle de IRAS no ano de 2006. Três métodos foram utilizados para a validação científica dos indicadores constantes do manual: 1) fundamentação teóricocientífica; 2) ajuste e padronização; 3) validade de conteúdo. (SÃO PAULO, 2006).

O novo questionário que foi usado nesse trabalho foi testado anteriormente no hospital, em estudo piloto no ano de 2010 e realizado pela pesquisadora responsável. O instrumento foi adaptado às necessidades do estudo e à realidade da UTI (Apêndice C). (DE CASTRO, 2010).

A pesquisa ocorreu entre os meses de setembro e dezembro de 2015 e foi desenvolvida em quatro etapas a seguir descritas.

\subsubsection{Etapa 1: aproximação da equipe de pesquisa com o campo}

Antes do início da coleta de dados, o pesquisador responsável visitou 12 vezes a UTI do hospital nos diferentes turnos de trabalho para convidar os profissionais que atuavam na assistência direta aos pacientes a participarem do estudo.

Para não prejudicar a rotina de trabalho dos profissionais, ao entrar na UTI, o pesquisador responsável aproximava-se do profissional que, no momento, não estava prestando assistência ou executando outra atividade, para convidá-lo a participar do estudo. Alguns profissionais do noturno foram abordados ao chegarem na unidade, ou seja, antes de iniciar o turno de trabalho.

Todos os 52 participantes foram esclarecidos e, concordando em participar do estudo, leram e assinaram o Termo de Consentimento Livre e Esclarecido (TCLE) (Apêndice A), em conformidade com a Resolução n. ${ }^{\circ}$ 466/12, do Conselho Nacional de Saúde (CNS). Dentre os 55 profissionais atuantes na UTI durante o período de coleta de dados, um estava em licença maternidade e, portanto, não participou do estudo, e dois não foram localizados.

4.5.2 Etapa 2: aplicação do questionário para caracterização dos profissionais participantes do estudo 
A descrição das características dos profissionais foi obtida com a aplicação de um questionário estruturado autoaplicável (Apêndice B). Eles foram convidados pelo pesquisador responsável a responderem o questionário após concordarem em participar do estudo. Nesse instrumento há variáveis relacionadas ao gênero, idade, profissão, tempo de atuação na profissão, número de horas semanais trabalhadas, capacitação e treinamento em precauções.

\subsubsection{Etapa 3: treinamento do observador}

Um auxiliar de pesquisa foi selecionado para realizar a coleta de dados das observações não participantes. Assim, em relação à coleta de dados, o pesquisador principal foi cegado para evitar tendenciosidade. A coleta de dados por um auxiliar de pesquisa também foi planejada com o objetivo de reduzir o efeito Hawthorne nos profissionais da UTI. O pesquisador responsável frequentemente realizava atividades de orientações às boas práticas de prevenção e controle de infecções no hospital porque é membro da CCIRAS, sendo muito conhecido pelos profissionais que atuam na assistência direta aos pacientes da UTI e também aplicou o TCLE para o presente estudo. Portanto, na presença do pesquisador responsável, os profissionais da UTI poderiam ficar sob maior grau do efeito Hawthorne.

Esse auxiliar de pesquisa foi um acadêmico de enfermagem no último ano do curso, selecionado para participar do trabalho, por meio de um Programa de Iniciação Científica (PIBIC), da Universidade de Brasília.

O pesquisador responsável forneceu treinamento teórico e prático.

O treinamento teórico consistiu em fornecimento de material educativo referente ao tema para a leitura prévia, seguido de aulas expositivas, apresentação de vídeos de treinamento para observadores da estratégia multimodal e vídeo sobre uso de EPI.

O treinamento prático consistiu na realização de sessões de observação em conjunto com o pesquisador responsável em outra unidade de assistência do hospital, na sala vermelha da Unidade de Paciente Crítico, que tem estrutura física de localização dos leitos parecida com a da UTI. Durante as sessões conjuntas, o auxiliar de pesquisa e o pesquisador responsável realizaram observações das práticas assistenciais e registraram as observações nos instrumentos, separadamente. Essas sessões conjuntas de observações foram realizadas até que existiu a concordância total entre os itens preenchidos dos formulários pelos diferentes observadores. No total foram necessárias oito sessões conjuntas. 
4.5.4 Etapa 4: auditorias de adesão às precauções

Na UTI, o auxiliar de pesquisa foi apresentado aos profissionais como estudante de graduação em Enfermagem que estava desenvolvendo um trabalho de PIBIC para avaliar cuidados de enfermagem. Somente os gestores da unidade foram informados que o PIBIC era integrado a esse trabalho.

Ao entrar na UTI, o auxiliar de pesquisa vestia roupa privativa, assim como os demais estudantes de graduação e residentes de enfermagem que estão em atividade assistencial na unidade. Com uma prancheta, os formulários de coletada de dados e lápis, ele posicionava-se no posto de enfermagem, que é a área central da unidade, para iniciar a sessão de auditoria.

De forma aleatória, foram escolhidos para observação os profissionais que se aproximavam dos pacientes para prestarem a assistência durante o tempo determinado de observação, sendo observado no máximo dois profissionais concomitantemente. Para evitar que muitas observações fossem realizadas de um mesmo profissional e possibilitar que muitos fossem observados, verificaram-se cinco a 12 oportunidades para higiene das mãos e seis a 13 procedimentos por profissional. O número de observações foi distribuído proporcionalmente entre as diferentes categorias profissionais.

Durante os primeiros 30 minutos da sessão de auditoria, foram realizadas as observações da higiene das mãos com o preenchimento do formulário referente à sua adesão.

O preenchimento do questionário de adesão à higiene das mãos foi realizado conforme definido pela OMS na Estratégia Multimodal de Adesão à Higiene das Mãos. Foram registradas as datas, o horário de início e término das sessões, as categorias e números dos profissionais que estavam sendo observados, as oportunidades para higiene das mãos conforme os cinco momentos de indicações, as ações de fricção das mãos com preparações alcoólicas, higiene simples com água e sabonete ou não realização da higiene.

A seguir, empreenderam-se as observações das indicações de precauções e do uso de EPI nos procedimentos assistenciais. Os profissionais que iniciavam a realização de procedimentos eram observados, no máximo dois ao mesmo tempo. Primeiro era feito o registro do tipo de precaução que estava sinalizada no leito do paciente, o número do leito, a categoria do profissional, o tipo de procedimento que estava sendo realizado, os EPIs que estavam sendo usados. Ao término do procedimento, era avaliado se o uso do EPI estava ou não indicado, conforme as orientações gerais apresentadas no Apêndice $\mathrm{D}$, e o risco identificado no procedimento que foi executado. 
Finalizava-se a sessão de auditoria com a avaliação da disponibilidade de produtos para higiene das mãos nas pias e dispensadores de preparações alcoólicas, EPIs disponíveis para uso e número de profissionais presentes durante o turno de trabalho na unidade naquela sessão de observação.

As auditorias ocorreram durante os períodos matutino, vespertino e noturno, com duração máxima de duas horas. A divisão de horários se fez necessária para que grande parte dos profissionais fosse observada, visto que nas escalas de trabalho da unidade estes eram assim distribuídos e para que o fornecimento de insumos fosse também observado em todos os horários (ex. fornecimento de aventais). Durante o período de coleta de dados, as escalas de trabalho da unidade foram avaliadas para que as sessões de auditorias fossem agendadas a partir da distribuição dos profissionais nessas escalas e possibilitar a observação de um maior número de pessoas.

\subsection{ANÁLISE DE DADOS}

Os dados coletados foram lançados no programa EPIINFO, versão 3.5.1, e posteriormente os arquivos transportados para análise no aplicativo Excel da empresa Microsoft, versão n. ${ }^{0}$ 7. O EPIINFO foi usado porque organiza o lançamento das informações em máscaras numeradas sequencialmente e permite a conferência de vários dados de um único questionário na mesma tela. Apesar de possuir recursos de análise estatística, estes não foram usados nesse trabalho. O Excel foi usado porque facilita a criação de lista de dados, elaboração de relatórios e gráficos sofisticados.

Seguindo a metodologia da estatística descritiva, foram calculadas as frequências absolutas das respostas e seus desdobramentos, para cada um dos questionários aplicados. Posteriormente, foi aplicado o teste Qui-quadrado de independência, quando pertinente.

O teste Qui-quadrado $\left(\chi^{2}\right)$ pode ser usado para avaliar a relação entre duas variáveis qualitativas. É um teste não paramétrico, muito útil, pois não necessita da suposição de normalidade das variáveis para analisar o grau de associação entre elas; porém, esse teste é menos poderoso que o teste paramétrico. (BUSSAB, MORETTIN, 2010).

A estatística de Qui-quadrado é dada por:

$$
\chi_{o b s}^{2}=\sum_{i=1}^{k} \sum_{j=1}^{k} \frac{\left(O_{i j}-E_{i j}\right)^{2}}{E_{i j}} \sim \chi_{1 ;(1-\alpha) \%}^{2}
$$


Em que $O_{i j}$ e $E_{i j}$ são, respectivamente, as frequências observadas e esperadas da iésima linha e j-ésima coluna. Tal teste utiliza-se da Estatística do Qui-quadrado para testar a significância estatística da associação observada em uma tabela de contingência. (BUSSAB, MORETTIN, 2010).

$O$ teste é feito calculando-se as frequências das células que seriam esperadas $E_{i j}$ se não houvesse associação alguma entre as variáveis, dados os totais das linhas e colunas. Essas frequências esperadas $\left(E_{i j}\right)$ são comparadas com as frequências efetivamente observadas a partir dos dados amostrais. Quanto maiores forem as discrepâncias (diferenças) entre as frequências esperadas e as frequências observadas, maior o valor da estatística, o que indicaria que os dados amostrais trazem evidências de que há uma dissociação entre as duas variáveis em estudo. As hipóteses são:

\section{$\left\{H_{0}\right.$ : Independência de variáveis \\ $\left\{H_{1}\right.$ : Dependência de variáveis}

Se a hipótese de independência (não associação) for verdadeira, o valor da estatística de teste tende a ser próximo de zero. Infelizmente, o teste Qui-quadrado não permite concluir como se dá a relação, uma vez que ele testa apenas a hipótese geral de que as duas variáveis são independentes. (BUSSAB, MORETTIN, 2010).

Há restrições para aplicação do $\chi^{2}$ em tabelas de contingência, situações em que a correção de Yates (1934) se faz necessária. Esta correção deve ser usada quando:

- $n<40$;

- $20<n<40$ e $E_{i j} \leq 5$ para algum ij;

- $n>40$ e $E_{i j} \leq 5$ para algum $\mathrm{ij}$;

A estatística de Qui-quadrado com correção de Yates é dada por:

$$
\begin{aligned}
& \chi_{o b s}^{2}=\sum_{i=1}^{k} \sum_{j=1}^{k} \frac{\left(\left|O_{i j}-E_{i j}\right|-0,5\right)^{2}}{E_{i j}} \sim \chi_{1 ;(1-\alpha) \%}^{2} \\
& \sum_{i=1}^{k} \sum_{j=1}^{k} \frac{\left(\left|O_{i j}-E_{i j}\right|-0,5\right)^{2}}{E_{i j}} \sim \chi_{1 ;(1-\alpha) \%}^{2}
\end{aligned}
$$

Além do procedimento clássico de testes de hipóteses, pode-se adotar outro, que consiste em apresentar o nível descritivo (ou $p$-valor). Ao invés de construir a região crítica, indica-se o $p$-valor como a probabilidade de se observar valores da estatística, tão ou mais 
extremos do que o valor obtido a partir da amostra, sob a hipótese $\mathrm{H}_{0}$ ser verdadeira. Desse modo, define-se uma regra de decisão simples: $p$-valores inferiores ao nível de significância estabelecido implicarão a rejeição da hipótese nula. Ou seja, se o nível de significância for de 0,05, rejeita-se $H_{0}$ para $p$-valor < 0,05. (BUSSAB, MORETTIN, 2010).

A adesão à higiene das mãos foi calculada em percentual de adesão total, por categoria profissional, por turno de trabalho e aos cinco momentos. A adesão ao uso de EPI foi calculada em percentual total de uso quando indicado e não indicado, por tipo de EPI, por profissional, por turno de trabalho e percentual de acerto ao uso dos quatro EPI por procedimentos. Os dados serão apresentados em tabelas, gráficos de radar e colunas.

\subsection{ASPECTOS ÉTICOS}

Este trabalho foi aprovado pelo Comitê de Ética em Pesquisa, da Faculdade de Ciências da Saúde (CEP/FS) da Universidade de Brasília, com CAAE n. ${ }^{\text {o }}$ 44389815.8.0000.0030 (Anexo H).

Aos gestores da instituição foi solicitada a liberação e concordância (APÊNDICE E).

Aos participantes requisitou-se anuência por meio do preenchimento do Termo de Consentimento Livre e Esclarecido (APÊNDICE A).

Foram garantidos o sigilo e anonimato dos participantes do estudo, e todas as recomendações da legislação vigente envolvendo pesquisa com seres humanos foram respeitadas. (MS, 2012). 


\section{RESULTADOS}

A análise dos dados permitiu conhecer as condições da infraestrutura e avaliar a adesão às práticas de precauções da UTI em hospital de ensino do Distrito Federal.

Os resultados são apresentados em cinco partes: 1) descrição das características dos profissionais que atuam na assistência direta aos pacientes na UTI; 2) infraestrutura disponível para execução das práticas de precauções; 3) adesão às práticas de higiene das mãos; 4) avaliação da adequação das indicações de precauções; e 5) adesão ao uso correto de EPI pelos profissionais que prestam assistência direta aos pacientes.

\subsection{CARACTERÍSTICAS DOS PROFISSIONAIS QUE ATUAM NA UTI}

Participaram do estudo 52 profissionais que atuavam na assistência direta aos pacientes internados na UTI do hospital, de setembro a dezembro de 2015 , período em que foi realizada a coleta de dados do estudo.

Os técnicos de enfermagem representaram 55,77\% da equipe de assistência, os enfermeiros $36,53 \%$, os médicos $32,69 \%$ e os fisioterapeutas $15,38 \%$. A TABELA 1 apresenta a distribuição dos profissionais por categorias e gêneros. Quanto à faixa etária, apresentada em quatro classes, na TABELA 2, mostra que havia um predomínio de profissionais na faixa entre 30 e 40 anos.

\begin{tabular}{|c|c|c|c|c|c|}
\hline \multirow[b]{2}{*}{ Categoria profissional } & \multicolumn{2}{|c|}{ Feminino } & \multicolumn{2}{|c|}{ Masculino } & \multirow{2}{*}{$\begin{array}{r}\text { Total } \\
\mathrm{n} \\
\end{array}$} \\
\hline & $\mathrm{n}$ & $\%$ & $\mathrm{n}$ & $\%$ & \\
\hline Técnico de enfermagem & 23 & 79,31 & 6 & 20,69 & 29 \\
\hline Enfermeiro & 5 & 50,00 & 5 & 50,00 & 10 \\
\hline Fisioterapeuta & 2 & 50,00 & 2 & 50,00 & 4 \\
\hline Médico & 4 & 44,44 & 5 & 55,56 & 9 \\
\hline Total & 34 & 65,38 & 18 & 34,62 & 52 \\
\hline
\end{tabular}

FONTE: A autora (2016). 
TABELA 2 - DISTRIBUIÇÃO DOS PROFISSIONAIS QUE ATUAM NA ASSISTÊNCIA DIRETA AOS PACIENTES, NA UTI DO HOSPITAL DE ENSINO, POR FAIXA ETÁRIA. BRASÍLIA, DF, BRASIL, 2015

\begin{tabular}{lrr}
\hline Faixa etária & $\mathrm{n}$ & $\%$ \\
\hline 20 a 29 anos & 7 & 13,46 \\
30 a 40 anos & 29 & 55,77 \\
41 a 50 anos & 13 & 25,00 \\
51 ou mais & 3 & 5,77 \\
Total & 52 & 100,00 \\
\hline FONTE: A autora $(2016)$ & &
\end{tabular}

FONTE: A autora (2016).

O tempo de atuação na profissão distribuído por categorias é apresentado na TABELA 3. Entre os técnicos de enfermagem e os fisioterapeutas, a maioria tinha de 6 a 10 anos. Todos os médicos possuíam mais de 11 anos de atuação na profissão, e entre os enfermeiros o tempo encontrava-se distribuído de forma mais uniforme.

TABELA 3 - TEMPO EM ANOS DE ATUAÇÃO DOS PROFISSIONAIS QUE TRABALHAM NA ASSISTÊNCIA DIRETA AOS PACIENTES, NA UTI DO HOSPITAL DE ENSINO, POR CATEGORIA. BRASÍLIA, DF, BRASIL, 2015

\begin{tabular}{lccccccccccc}
\hline \multirow{2}{*}{ Categoria profissional } & \multicolumn{2}{c}{0 a 5 anos } & 6 a 10 anos & 11 a 15 anos & 16 a 20 anos & 21 ou mais & Total \\
\cline { 2 - 13 } & $\mathrm{n}$ & $\%$ & $\mathrm{n}$ & $\%$ & $\mathrm{~N}$ & $\%$ & $\mathrm{n}$ & $\%$ & $\mathrm{n}$ & $\%$ & $\mathrm{n}$ \\
\hline Técnico de enfermagem & 8 & 27,58 & 14 & 48,27 & 3 & 10,35 & 2 & 6,90 & 2 & 6,90 & 29 \\
Enfermeiro & 2 & 20,00 & 2 & 20,00 & 2 & 20,00 & 1 & 10,00 & 3 & 30,00 & 10 \\
Fisioterapeuta & 1 & 25,00 & 3 & 75,00 & 0 & 0,00 & 0 & 0,00 & 0 & 0,00 & 4 \\
Médico & 0 & 0,00 & 0 & 0,00 & 4 & 44,00 & 1 & 11,00 & 4 & 44,00 & 9 \\
Total & 11 & 21,16 & 19 & 36,54 & 9 & 17,30 & 4 & 7,70 & 9 & 17,30 & 52 \\
\hline
\end{tabular}

FONTE: A autora (2016).

A carga horária de trabalho semanal desses profissionais foi avaliada e segue apresentada na TABELA 4. Essa questão não avaliou somente a carga horária de trabalho na instituição. A pergunta feita ao profissional foi: Qual é a sua carga horária semanal total de trabalho? Somando-se todos os seus vínculos empregatícios.

Identifica-se que, na equipe, a maioria dos profissionais tem somente um vínculo empregatício. Destacam-se, nas duas primeiras categorias, principalmente os técnicos de enfermagem, pois 23 deles afirmaram trabalhar até 40h semanais e os outros seis, até $60 \mathrm{~h}$. 
TABELA 4 - CARGA HORÁRIA SEMANAL DE TRABALHO DOS PROFISSIONAIS QUE ATUAM NA ASSISTEENCIA DIRETA AOS PACIENTES, NA UTI DO HOSPITAL DE ENSINO.

BRASÍLIA, DF, BRASIL, 2015

\begin{tabular}{lrr}
\hline Carga horária semanal & $\mathrm{n}$ & $\%$ \\
\hline Até 40 horas & 31 & 59,62 \\
41 a 60 horas & 14 & 26,92 \\
61 a 80 horas & 7 & 13,46 \\
81 horas ou mais & 0 & 0,00 \\
Total & 52 & 100,00 \\
\hline FONTE: A autora (2016). & &
\end{tabular}

Adicionalmente, observou-se que os profissionais com maior carga horária de trabalho na unidade eram quatro enfermeiros, dois médicos e um fisioterapeuta, que afirmaram trabalhar de 61 a $80 \mathrm{~h}$ semanais.

Para identificar questões referentes à capacitação na formação profissional, os participantes foram questionados se haviam recebido capacitação sobre higiene das mãos, uso de EPI (avental, luvas, máscara e óculos de proteção) e tipos de precauções (padrão e isolamentos) durante os cursos de graduação (médicos, enfermeiros e fisioterapeutas) ou durante o curso de técnicos de enfermagem (técnicos de enfermagem).

Na TABELA 5, os resultados mostram que a grande maioria dos entrevistados afirmou ter recebido esse tipo de capacitação em seus cursos de formação. Destaca-se que, na totalidade, os técnicos de enfermagem e enfermeiros afirmaram ter recebido as capacitações sobre higiene das mãos, uso de EPI e tipos de precauções.

TABELA 5 - DISTRIBUIÇÃO DE PROFISSIONAIS QUE ATUAM NA ASSISTÊNCIA DIRETA AOS PACIENTES, NA UTI DO HOSPITAL DE ENSINO, QUE RECEBERAM CAPACITAÇÃO SOBRE HIGIENE DAS MÃOS, USO DE EPI E TIPOS DE PRECAUÇÕES NA FORMAÇÃO POR CATEGORIA PROFISSIONAL. BRASÍLIA, DF, BRASIL, 2015

\begin{tabular}{lrrrrrrr}
\hline & \multicolumn{2}{c}{ Higiene das Mãos } & Uso de EPI & \multicolumn{2}{c}{ Tipos de precauções } & Total \\
\cline { 2 - 8 } Categoria profissional & $\mathrm{n}$ & $\%$ & $\mathrm{n}$ & $\%$ & $\mathrm{n}$ & $\%$ & $\mathrm{n}$ \\
\hline Técnico de enfermagem & 29 & 100,00 & 29 & 100,00 & 29 & 100,00 & 29 \\
Enfermeiro & 10 & 100,00 & 10 & 100,00 & 10 & 100,00 & 10 \\
Fisioterapeuta & 3 & 75,00 & 3 & 75,00 & 4 & 100,00 & 4 \\
Médico & 8 & 88,88 & 7 & 77,77 & 7 & 77,77 & 9 \\
Total & & & & & & & 52 \\
\hline
\end{tabular}

FONTE: A autora (2016).

Para a TABELA 5 acima, o valor da estatística Qui-quadrado de independência observado foi de 0,097 com p-valor igual a 0,99. Ou seja, não há evidências de que as categorias profissionais difiram em relação à capacitação na formação profissional. 
Ter participado ou não de treinamento em serviço, no hospital cenário do estudo, sobre higiene das mãos, uso de EPI e tipos de precauções também foram questionados. As respostas encontram-se na TABELA 6. Destaca-se que menos da metade dos médicos afirmou ter recebido treinamento sobre higiene das mãos e somente $22 \%$ sobre precauções.

\section{TABELA 6 - DISTRIBUIÇÃO DE PROFISSIONAIS QUE ATUAM NA ASSISTÊNCIA DIRETA AOS PACIENTES, NA UTI DO HOSPITAL DE ENSINO, QUE RECEBERAM TREINAMENTO EM SERVIÇO SOBRE HIGIENE DAS MÃOS, USO DE EPI E TIPOS DE PRECAUÇÕES, POR CATEGORIA PROFISSIONAL. BRASÍLIA, DF, BRASIL, 2015}

\begin{tabular}{lrrrrrrr}
\hline & \multicolumn{1}{c}{ Higiene das Mãos } & Uso de EPI & \multicolumn{2}{c}{ Tipos de precauções } & Total \\
\cline { 2 - 8 } Categoria profissional & $\mathrm{n}$ & $\%$ & $\mathrm{n}$ & $\%$ & $\mathrm{n}$ & $\%$ & $\mathrm{n}$ \\
\hline Técnico de enfermagem & 27 & 93,10 & 25 & 93,10 & 27 & 93,10 & 29 \\
Enfermeiro & 9 & 90,00 & 7 & 70,00 & 7 & 70,00 & 10 \\
Fisioterapeuta & 4 & 100,00 & 3 & 75,00 & 3 & 75,00 & 4 \\
Médico & 4 & 44,44 & 3 & 33,33 & 2 & 22,22 & 9 \\
Total & & & & & & & 52 \\
\hline FONTE: A autora (2016). & & & & & & &
\end{tabular}

Questionou-se, também, a respeito do tempo transcorrido desde o último treinamento em serviço. Aproximadamente 70\% dos profissionais afirmaram que os treinamentos tinham acontecido durante o último ano.

\subsection{INFRAESTRUTURAS DISPONÍVEIS PARA EXECUÇÃO DAS PRÁTICAS DE PRECAUÇÕES}

A FIGURA 2 apresenta a planta física da parte interna da UTI onde estão localizados os 18 leitos, dos quais, somente 10 estavam ativos. Dos 10 leitos, nove eram leitos em forma de boxe, fechados na frente e laterais por cortinas ou paredes e um estava alocado em um quarto individual, totalmente fechado com paredes e com banheiro. A localização dos leitos ativos está sinalizada na FIGURA 2, os leitos estão numerados sequencialmente em algarismos arábicos.

A distribuição de lavatórios para higiene das mãos, da parte que se encontrava em funcionamento, da área interna da UTI, era composta por: quatro pias nas laterais do posto de enfermagem que ocupava o centro da unidade, duas cubas nas laterais da bancada de preparo de medicamentos, uma pia dentro de expurgo, uma pia dentro do quarto de isolamento e uma pia na área do banheiro do quarto do isolamento. No total, na área em funcionamento da UTI, existiam nove pias e duas cubas. A localização delas está identificada na FIGURA 2 com as letras $\mathrm{P}$ e $\mathrm{C}$, respectivamente. 
As torneiras das pias eram de acionamento por pressão, dispensando assim o contato das mãos para o acionamento. As torneiras das cubas eram de abertura e fechamento manual.

Todas as pias e cubas dispunham de dispensadores de sabonete líquido, do tipo que é reabastecido com refil descartável e papel toalha, exceto a pia da área interna do quarto individual, que não possuía tais dispensadores. As duas cubas também dispunham de almotolias com antisséptico gluconato de clorexidina.

As preparações alcoólicas eram fornecidas na forma de gel em dispensadores fixados nas paredes, do tipo que é reabastecido com refil descartável, totalizando cinco dispensadores distribuídos na parte interna da unidade. Na FIGURA 2, o local dos dispensadores de preparações alcoólicas está sinalizado com a letra A.

No leito de número 3, o dispensador de preparação alcoólica estava no ponto de assistência, fixado na parede lateral ao leito. Os demais dispensadores da unidade estavam fixados em pilastras, distribuídos no trajeto entre os leitos e o posto de enfermagem, todos localizados a mais de dois metros de distância dos leitos. 
FIGURA 2 - ESTRUTURA FÍSICA INTERNA DA ÁREA DE INTERNAÇÃO, LOCALIZAÇÃO DOS LEITOS ATIVOS, PIAS, CUBAS E DISPENSADORES DE PREPARAÇÕES ALCOÓLICAS PARA HIGIENE DAS MÃOS, NA UTI DO HOSPITAL DE ENSINO. BRASÍLIA, DF, BRASIL, 2015

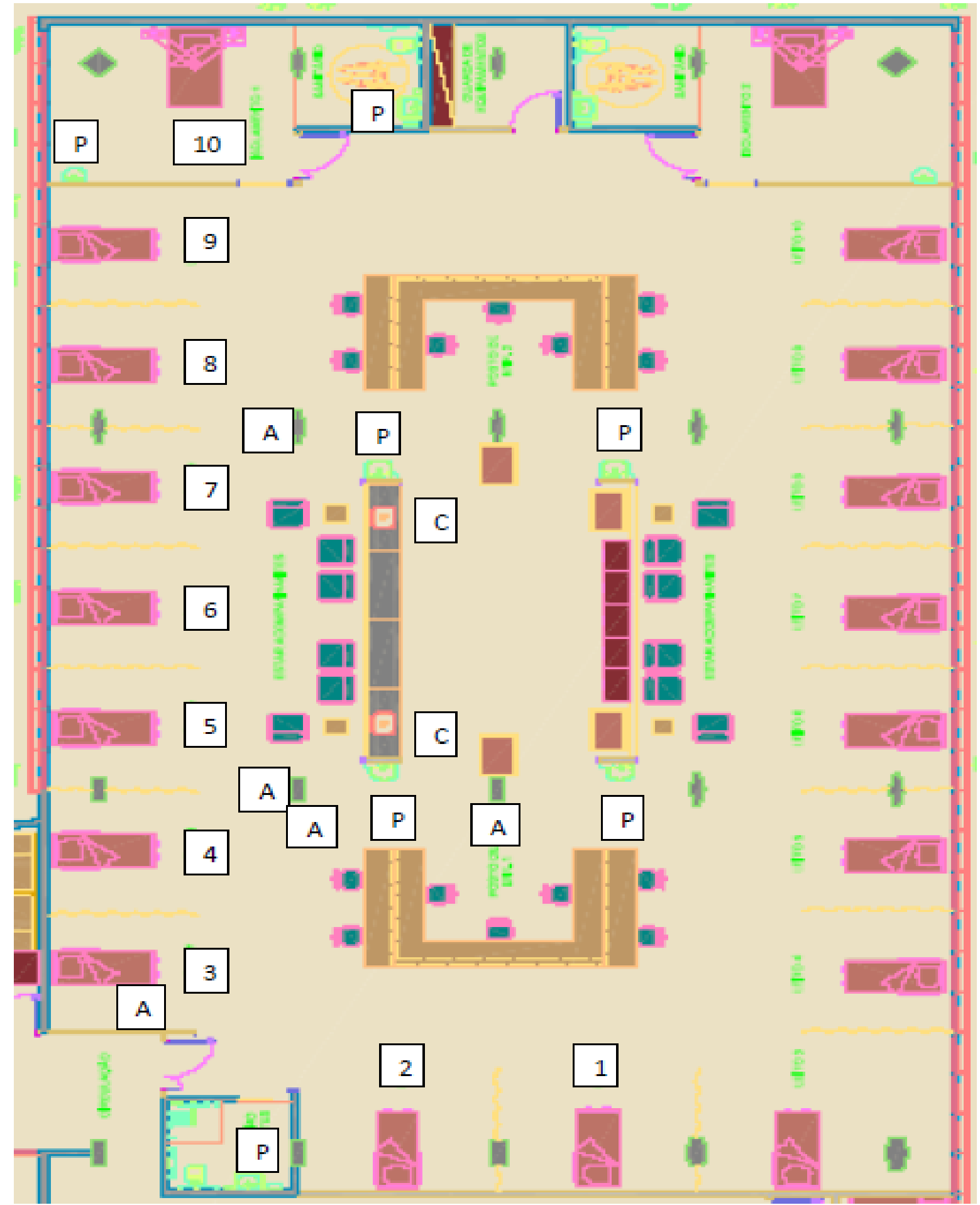

FONTE: Adaptado da Planta baixa com layout da UTI Adulto (HUB, 2013b).

LEGENDA: A - Local com dispensador de álcool em gel.

$\mathrm{P}$ - Pia para higiene das mãos.

C - Cuba para higiene das mãos.

Números 1 a 10 - números de identificação dos leitos ativos. 
Quanto à disponibilidade de material educativo e lembretes no local de trabalho sobre as precauções, na área interna da UTI foram identificados uma placa contendo instruções sobre a técnica da higiene simples das mãos, próxima à pia, e um cartaz com frase de incentivo à higiene das mãos. Não foram encontrados materiais educativos sobre as indicações (cinco momentos) da higiene das mãos fixados nas paredes ou murais. Encontravase afixado em uma pilastra um folder com orientações sobre as precauções padrão e adicionais.

Os quatro documentos institucionais, sendo o Protocolo de higiene das mãos, o POP de Precauções padrão, o POP de Precauções adicionais e o POP de Prevenção de microrganismos multirresistentes, que orientam as precauções e as rotinas de vigilância epidemiológica e pesquisa de microrganismos multirresistentes, estavam disponíveis na UTI para consulta, na forma impressa, em uma pasta que ficava acima do armário onde eram colocados os prontuários dos pacientes. Portanto, encontrava-se em lugar de fácil acesso para consulta. Esses documentos também se encontravam disponibilizados em forma eletrônica na rede de intranet do hospital e na área de prescrição estavam três computadores com acesso à rede.

A disponibilidade de produtos para higiene das mãos e o fornecimento de EPI foram avaliados em 36 sessões de observações em que a presença ou ausência desses itens na unidade foi registrada. Essas observações ocorreram no período de 05/10/2015 a 16/12/2015, em todos os turnos. Dos dez leitos, a média de ocupação foi de 6,41 leitos por sessão.

O abastecimento dos cinco dispensadores de preparações alcoólicas, dos oito dispensadores de sabonete líquido das pias e cubas e dos oito dispensadores de papel-toalha disponíveis na área interna na UTI, foi monitorado, e os resultados obtidos encontram-se na TABELA 7. Identificou-se que o abastecimento de sabonete líquido e preparações alcoólicas eram irregulares. 
TABELA 7 - FREQUÊNCIA DE INSUMOS DISPONÍVEIS PARA HIGIENE DAS MÃOS, POR SESSÃO DE OBSERVAÇÃO E PERCENTUAL ACUMULADO, NA UTI DO HOSPITAL DE ENSINO.

BRASÍLIA, DF, BRASIL, 2015

\begin{tabular}{crrr}
\hline $\begin{array}{l}\text { Frequência de insumo } \\
\text { disponível }\end{array}$ & $\mathrm{n}$ & $(\%)$ & $\begin{array}{r}\text { Acumulado } \\
\%\end{array}$ \\
\hline $\begin{array}{c}\text { Preparação alcoólica } \\
2\end{array}$ & 2 & 5,56 & 5,56 \\
3 & 4 & 11,11 & 16,67 \\
4 & 27 & 75,00 & 91,67 \\
5 & 3 & 8,33 & 100,00 \\
Sabão líquido & & & \\
6 & 3 & 8,33 & 8,33 \\
7 & 24 & 66,67 & 75,00 \\
8 & 9 & 25,00 & 100,00 \\
Papel-toalha & & & \\
7 & 30 & 83,33 & 83,33 \\
8 & 6 & 16,67 & 100,00 \\
\hline FONTE: A autora (2016). & & &
\end{tabular}

Dentre as 36 sessões de observação, constatou-se que faltaram máscaras em 5,55\%, e aventais e luvas em $2,77 \%$ das vezes. Somente os óculos estiveram disponíveis em todas as sessões.

Além disso, identificou-se, durante o período, que houve a falta de avental e luva em uma sessão, conforme apresentado na TABELA 8. Tal falta ocorreu nos primeiros 15 minutos da sessão de observação durante o período noturno. Passados esses 15 minutos, a UTI recebeu o fornecimento de avental e luva para o restante do período de trabalho. Ainda em relação aos aventais, foram identificados alguns pendurados próximo ao leito dos pacientes, o que sugere que tinham sido usados e estavam sendo guardados para serem usados novamente nos mesmos pacientes.

A TABELA 8 também mostra que a falta de máscaras foi identificada em duas sessões de observação. É importante destacar que não ocorreu falta total desse EPI na unidade porque, nas mesmas sessões em que não foram identificadas máscaras disponíveis para uso nos locais de guarda, também havia registros de procedimentos dos profissionais usando máscara. Segundo os registros do auxiliar de pesquisa, os profissionais utilizavam a mesma máscara durante todo o turno de trabalho, deixavam-na no pescoço e não a descartavam após os procedimentos. 
TABELA 8 - DISPONIBILIDADE DO EPI, NA UTI DO HOSPITAL DE ENSINO, POR 36 SESSÕES DE OBSERVAÇÕES. BRASÍLIA, DF, BRASIL, 2015

\begin{tabular}{lrrrr}
\hline \multirow{2}{*}{ EPI } & Disponível & Disponível & Falta & Falta \\
& $\mathrm{n}$ & $\%$ & $\mathrm{n}$ & $\%$ \\
\hline Avental & 35 & 97,22 & 1 & 2,88 \\
Luvas & 35 & 97,22 & 1 & 2,88 \\
Máscara & 34 & 94,44 & 2 & 5,66 \\
Óculos & 36 & 100,00 & 0 & 0,00 \\
\hline FONTE: A autora (2016). & & &
\end{tabular}

O uso de adornos nas mãos pelos profissionais de saúde interfere diretamente na qualidade da técnica da higiene das mãos. Para levantar o número de ocorrências desse quesito, conduziu-se a anotação da presença de qualquer tipo de adorno nas mãos, como anéis, alianças, pulseiras, relógios ou unhas postiças. Observou-se que o uso de adornos entre a equipe de saúde da UTI foi alto, entre todas as categorias profissionais, conforme dados das TABELAS 9 e 10.

TABELA 9 - QUANTITATIVO DE PROFISSIONAIS COM ADORNO NAS MÃOS, POR SESSÃO DE OBSERVAÇÃO, NA UTI DO HOSPITAL DE ENSINO. BRASÍLIA, DF, BRASIL, 2015

\begin{tabular}{lrrr}
\hline $\begin{array}{l}\text { Quantitativo de } \\
\text { profissionais com adorno }\end{array}$ & $\mathrm{n}$ & $\%$ & Acumulado \\
\hline Nenhum profissional & 4 & 11,11 & 11,11 \\
1 profissional & 5 & 13,88 & 24,99 \\
2 profissionais & 13 & 36,11 & 61,11 \\
3 profissionais & 9 & 25,00 & 86,11 \\
4 profissionais & 4 & 11,11 & 97,22 \\
5 profissionais & 1 & 2,77 & 100,00 \\
\hline FONTE. A autora $(2016)$ & & &
\end{tabular}

FONTE: A autora (2016).

Pode-se notar, pela TABELA 10, que, das 36 sessões, os médicos usaram adornos nas mãos em sete $(19,44 \%)$ sessões, os enfermeiros em 11 (30,55\%), os fisioterapeutas em 13 $(36,11 \%)$ e os técnicos de enfermagem em $23(63,88 \%)$. Em apenas quatro das sessões não houve plantonistas com adornos, o que representou somente $11,11 \%$.

TABELA 10 - FREQUÊNCIA DE PROFISSIONAIS COM ADORNO NAS MÃOS, NA UTI DO HOSPITAL DE ENSINO, POR 36 SESSÕES DE OBSERVAÇÕES. BRASÍLIA, DF, BRASIL, 2015

\begin{tabular}{lrr}
\hline Categoria profissional & $\mathrm{n}$ & $\%$ \\
\hline Médico & 7 & 19,44 \\
Enfermeiro & 11 & 30,55 \\
Fisioterapeuta & 13 & 36,11 \\
Técnico de enfermagem & 23 & 63,88 \\
\hline FONTE: A autora (2016). & &
\end{tabular}


A disponibilidade de recursos humanos para execução das práticas assistenciais foi avaliada considerando-se o número de leitos ocupados e o número de profissionais presentes por turno e por categoria profissional durante as sessões de observação. Os resultados encontrados estão apresentados na TABELA 11.

\section{TABELA 11 - FREQUÊNCIA DE PLANTONISTA POR CATEGORIA PROFISSIONAL PRESENTES POR SESSÃO, EM 36 OBSERVAÇÕES E PERCENTUAL ACUMULADO, NA UTI DO HOSPITAL DE ENSINO. BRASÍLIA, DF, BRASIL, 2015}

\begin{tabular}{lrrr}
\hline $\begin{array}{l}\text { Número de profissionais } \\
\text { presentes }\end{array}$ & $\mathrm{n}$ & $\%$ & $\begin{array}{r}\text { Acumulado } \\
\%\end{array}$ \\
\hline Médico & 31 & 86,11 & 86,11 \\
1 & 5 & 13,89 & 100,00 \\
2 & & & \\
Enfermeiro & 12 & 33,33 & 33,33 \\
1 & 18 & 50,00 & 83,33 \\
2 & 5 & 13,89 & 97,22 \\
3 & 1 & 2,78 & 100,00 \\
4 & & & \\
Fisioterapeuta & 1 & 2,78 & 2,78 \\
0 & 23 & 63,89 & 66,67 \\
1 & 12 & 33,33 & 100,00 \\
2 & & & \\
Técnico de enfermagem & 3 & 8,33 & 8,33 \\
4 & 20 & 55,55 & 63,89 \\
5 & 8 & 22,22 & 86,11 \\
6 & 5 & 13,89 & 100,00 \\
\hline 7 & & &
\end{tabular}

Na TABELA 12, observa-se que o número de profissionais presentes foi menor que o exigido pela RDC n. ${ }^{\circ} 7$ em uma sessão $(2,78 \%)$ para fisioterapeuta. Entre os médicos a questão é diferenciada. Segundo a RDC n. ${ }^{0}$ 7, seria necessária, para cada 10 leitos ou fração, durante os períodos matutino e vespertino, a permanência de um médico diarista ou rotineiro e um médico plantonista. Durante todo o período de coleta de dados, a presença de médicos diaristas não foi identificada, nos períodos matutino e vespertino na UTI. Entretanto, como em cinco sessões encontravam-se presentes dois médicos durante o turno, considerou-se que o segundo médico, nessas sessões, estava atuando na figura de diarista ou rotineiro, conforme dados da TABELA 12. 
TABELA 12 - FREQUÊNCIA DE SESSÕES, DENTRE AS 36 OBSERVADAS, EM QUE O NÚMERO DE PLANTONISTAS ATENDEU ÀS EXIGÊNCIAS DA REGULAMENTAÇÃO SANITÁRIA NACIONAL, NA UTI DO HOSPITAL DE ENSINO, POR CATEGORIA PROFISSIONAL. BRASÍLIA, DF, BRASIL, 2015

\begin{tabular}{|c|c|c|c|}
\hline Categoria profissional & Critério de avaliação & $\begin{array}{r}\mathrm{n} .^{\circ} \text { de sessões } \\
\text { atendidas }\end{array}$ & $\%$ \\
\hline Médico diarista & $\begin{array}{l}\text { Um médico para cada } 10 \text { leitos ou fração nos } \\
\text { períodos matutino e vespertino }\end{array}$ & 5 & 13,89 \\
\hline Médico plantonista & Um médico para cada 10 leitos ou fração & 36 & 100,00 \\
\hline Enfermeiro & Um enfermeiro para cada 10 leitos ou fração & 36 & 100,00 \\
\hline Fisioterapeuta & Um fisioterapeuta para cada 10 leitos ou fração & 35 & 97,22 \\
\hline Técnico de enfermagem & Um técnico de enfermagem para cada 2 leitos & 36 & 100,00 \\
\hline
\end{tabular}

FONTE: A autora (2016).

Além do número insuficiente de profissionais, em várias sessões ocorreu o contrário. Identificaram-se números maiores de profissionais do que o necessário, assim distribuídos: enfermeiros em 13 sessões (36,11\%), fisioterapeutas em 12 sessões $(33,33 \%)$ e técnicos de enfermagem em 32 sessões $(88,88 \%)$.

\subsection{ADESÃO ÀS PRÁTICAS DE HIGIENE DAS MÃOS}

Foram monitoradas 516 oportunidades de higiene das mãos, em 43 sessões. Ocorreram 337 ações de higiene das mãos, o que representa adesão média de 65,31\%. A TABELA 13 traz o número de oportunidades observadas e a taxa de adesão à higiene das mãos por categoria profissional, e a FIGURA 3 mostra a taxa de adesão com destaque para a linha da média. Ficou evidente que os técnicos de enfermagem tiveram adesão abaixo da média.

TABELA 13 - NÚMERO DE OPORTUNIDADES PARA A HIGIENIZAÇÃO DAS MÃOS OBSERVADAS E TAXA DE ADESÃO POR CATEGORIAS DOS PROFISSIONAIS QUE TRABALHAM NA ASSISTÊNCIA DIRETA AOS PACIENTES, NA UTI DO HOSPITAL DE ENSINO. BRASÍLIA, DF, BRASIL, 2015

\begin{tabular}{|c|c|c|c|}
\hline Categoria profissional & $\begin{array}{l}\mathrm{N}^{\mathrm{o}} \text { de oportunidades } \\
\text { observadas }(\mathrm{n})\end{array}$ & $\begin{array}{l}\mathrm{N}^{\circ} \text { de } \mathrm{HM} \\
\text { realizadas (n) }\end{array}$ & $\begin{array}{l}\text { Taxa de adesão } \\
\text { à HM }(\%)\end{array}$ \\
\hline Fisioterapeuta & 65 & 48 & 73,84 \\
\hline Médico & 68 & 53 & 77,94 \\
\hline Enfermeiro & 104 & 75 & 72,11 \\
\hline Técnico de enfermagem & 279 & 161 & 57,70 \\
\hline
\end{tabular}

FONTE: A autora (2016). 
FIGURA 3 - TAXA DE ADESÃO A HIGIENIZAÇÃO DAS MÃOS POR CATEGORIAS DOS PROFISSIONAIS QUE TRABALHAM NA ASSISTÊNCIA DIRETA AOS PACIENTES, NA UTI DO HOSPITAL DE ENSINO. BRASÍLIA, DF, BRASIL, 2015

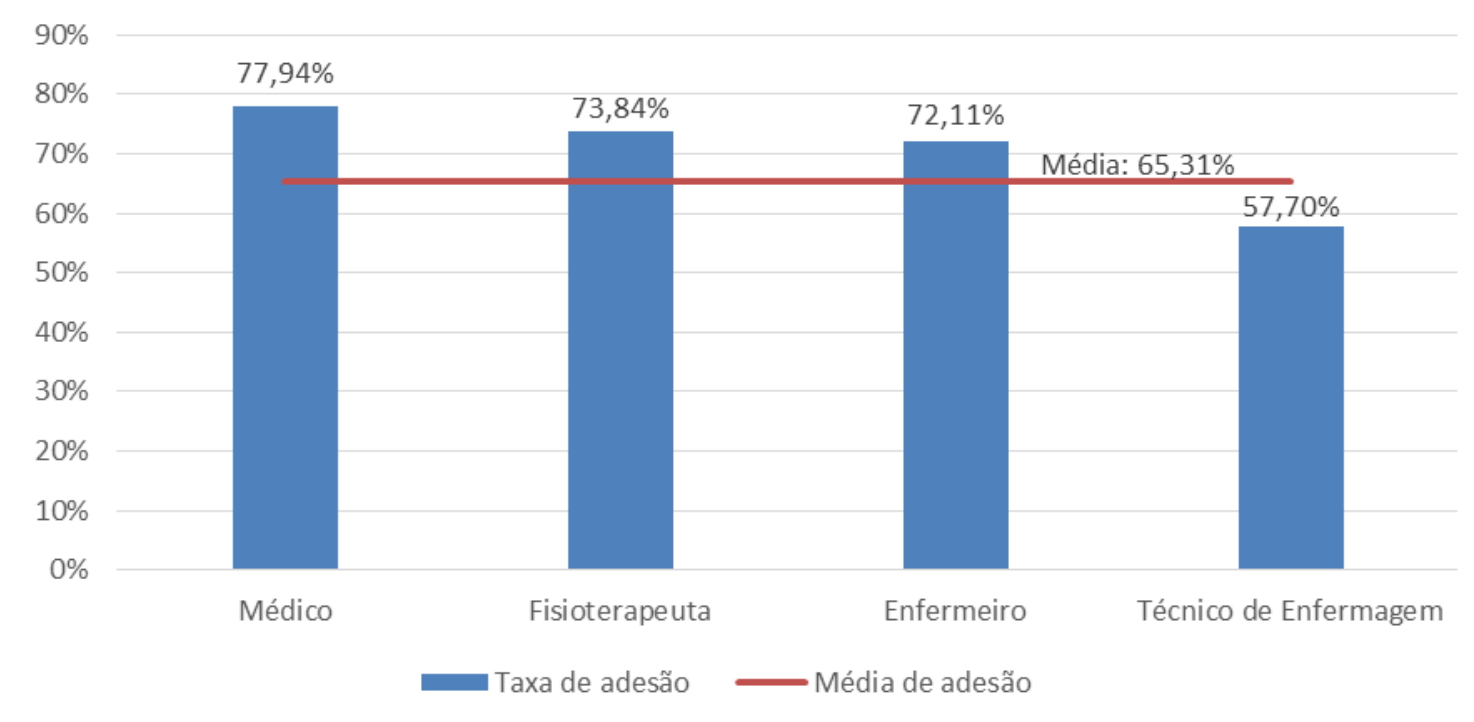

FONTE: A autora (2016).

A adesão e o tipo de higiene das mãos foram avaliados e estão apresentados na FIGURA 4. Predominantemente, a higiene das mãos foi realizada com água e sabonete. Ressalta-se que os médicos apresentaram a melhor adesão ao uso das preparações alcoólicas dentre todas as categorias profissionais.

FIGURA 4 - TAXA DE ADESÃO AO TIPO DE HIGIENE DAS MÃOS DOS PROFISSIONAIS QUE ATUAM NA ASSISTÊNCIA DIRETA AOS PACIENTES, NA UTI DO HOSPITAL DE ENSINO, POR CATEGORIAS. BRASÍLIA, DF, BRASIL, 2015

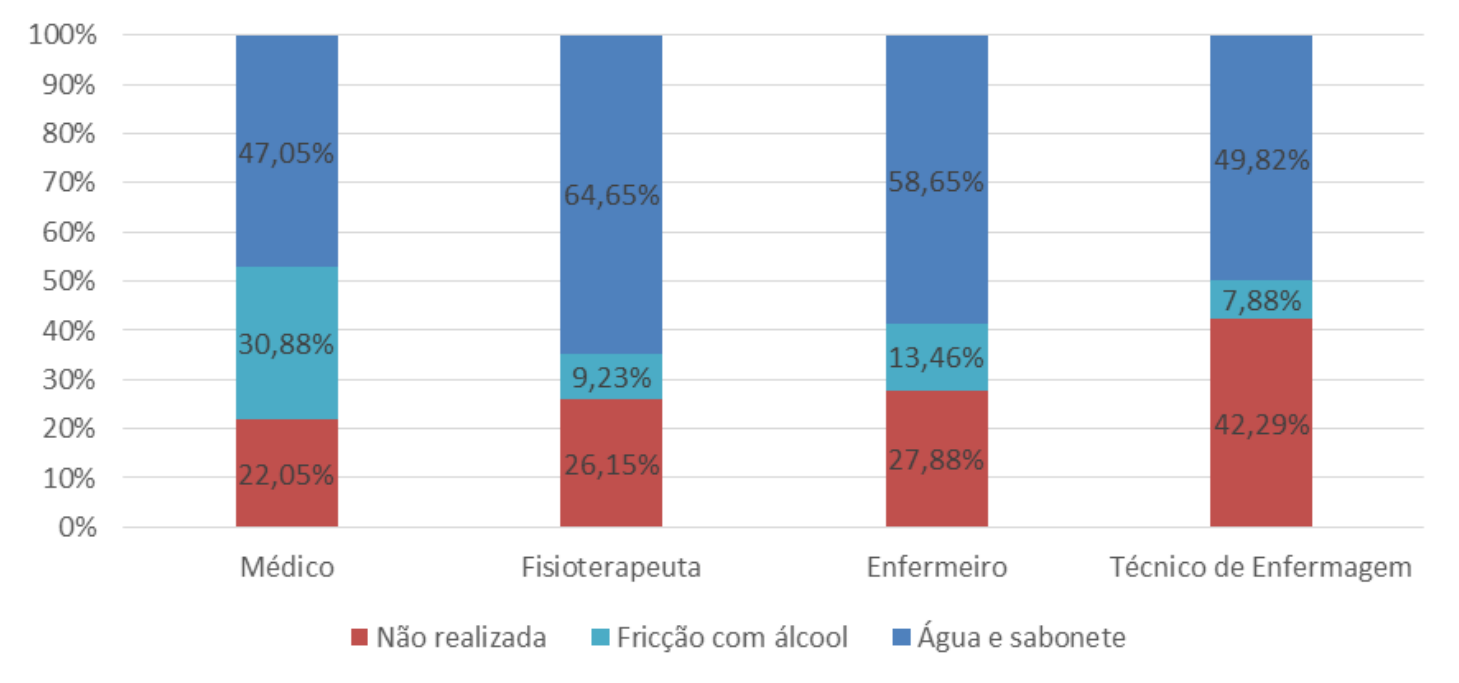

FONTE: A autora (2016). 
A taxa de adesão à higiene das mãos foi calculada com relação às indicações para concretizar a ação ou aos cinco momentos, considerados como oportunidades de fazer a higiene das mãos, que são: (1) antes do contato com o paciente; (2) antes de procedimento asséptico; (3) após risco de exposição ou contato com fluidos corporais; (4) após contato com paciente; e (5) após contato com ambiente ou unidade do paciente. Os momentos um e dois apresentaram menor taxa de adesão quando comparados aos momentos três, quatro e cinco. O número de oportunidades observadas e a taxa de adesão a cada um dos cinco momentos indicados para a necessária higiene das mãos são mostrados na TABELA 14. A seguir, na FIGURA 5, em que aparece a linha média de adesão, destaca-se a baixa adesão aos momentos um e dois.

TABELA 14 - TAXA DE ADESÃO A HIGIENIZAÇÃO DAS MÃOS POR INDICAÇÕES (5 MOMENTOS) DOS PROFISSIONAIS QUE ATUAM NA ASSISTÊNCIA DIRETA AOS PACIENTES, NA UTI DO HOSPITAL DE ENSINO. BRASÍLIA, DF, BRASIL, 2015

\begin{tabular}{lccc}
\hline Indicações para HM & $\begin{array}{c}\mathrm{N}^{\mathrm{o}} \text { de oportunidades } \\
\text { observadas (n) }\end{array}$ & $\begin{array}{c}\mathrm{N}^{\mathrm{o}} \text { de HM } \\
\text { realizadas (n) }\end{array}$ & $\begin{array}{c}\text { Taxa de adesão } \\
\text { à HM (\%) }\end{array}$ \\
\hline Antes do contato com o paciente & 117 & 47 & 40,17 \\
Antes de procedimento asséptico & 77 & 22 & 28,57 \\
Após risco/contato com fluidos biológicos & 148 & 129 & 87,16 \\
Após contato com paciente & 136 & 114 & 83,82 \\
Após contato com ambiente & 73 & 48 & 65,75 \\
\hline
\end{tabular}

FONTE: A autora (2016).

FIGURA 5 - TAXA DE ADESÃO A HIGIENIZAÇÃO DAS MÃOS POR INDICAÇÕES (5 MOMENTOS) DOS PROFISSIONAIS QUE ATUAM NA ASSISTÊNCIA DIRETA AOS PACIENTES, NA UTI DO HOSPITAL DE ENSINO. BRASÍLIA, DF, BRASIL, 2015

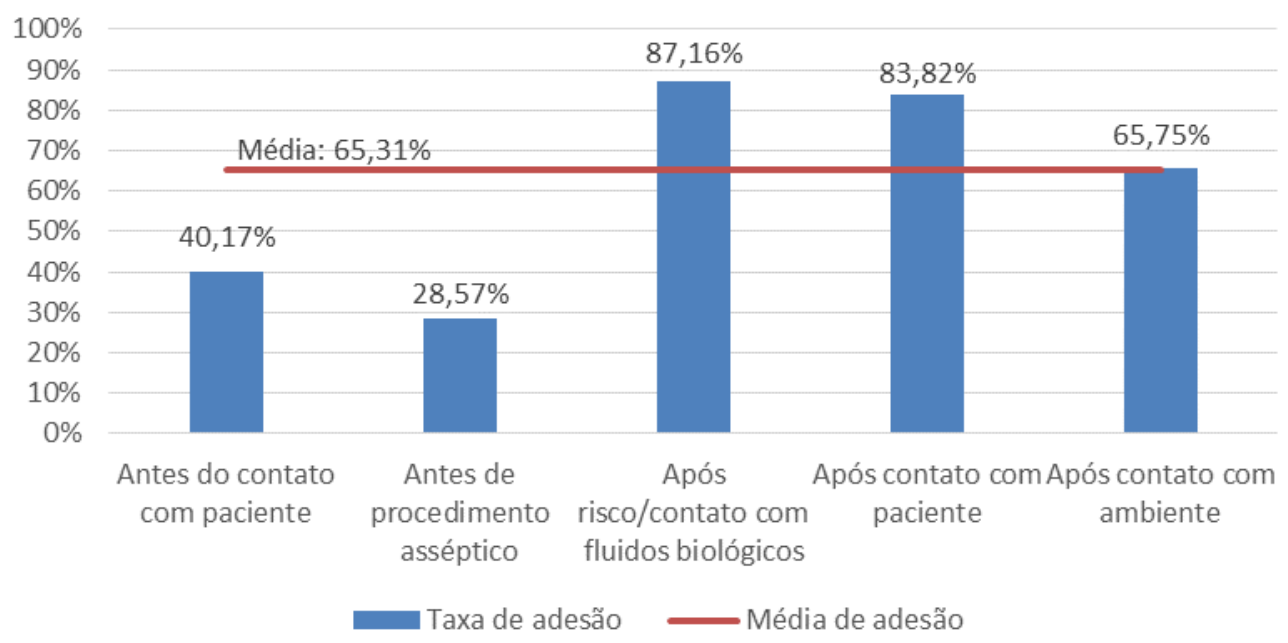

FONTE: A autora (2016). 
A frequência dos tipos de higiene das mãos que foram realizadas por indicações também foi calculada. Predominantemente, água e sabonete foram mais usados em todas as ações de higiene das mãos e as preparações alcoólicas foram mais usadas nos momentos um e quatro. Os dados estão apresentados na FIGURA 6.

\section{FIGURA 6 - TIPO DE HIGIENE DAS MÃOS POR INDICAÇÃO DOS PROFISSIONAIS QUE ATUAM NA ASSISTÊNCIA DIRETA AOS PACIENTES, NA UTI DO HOSPITAL DE ENSINO. \\ BRASÍLIA, DF, BRASIL, 2015}

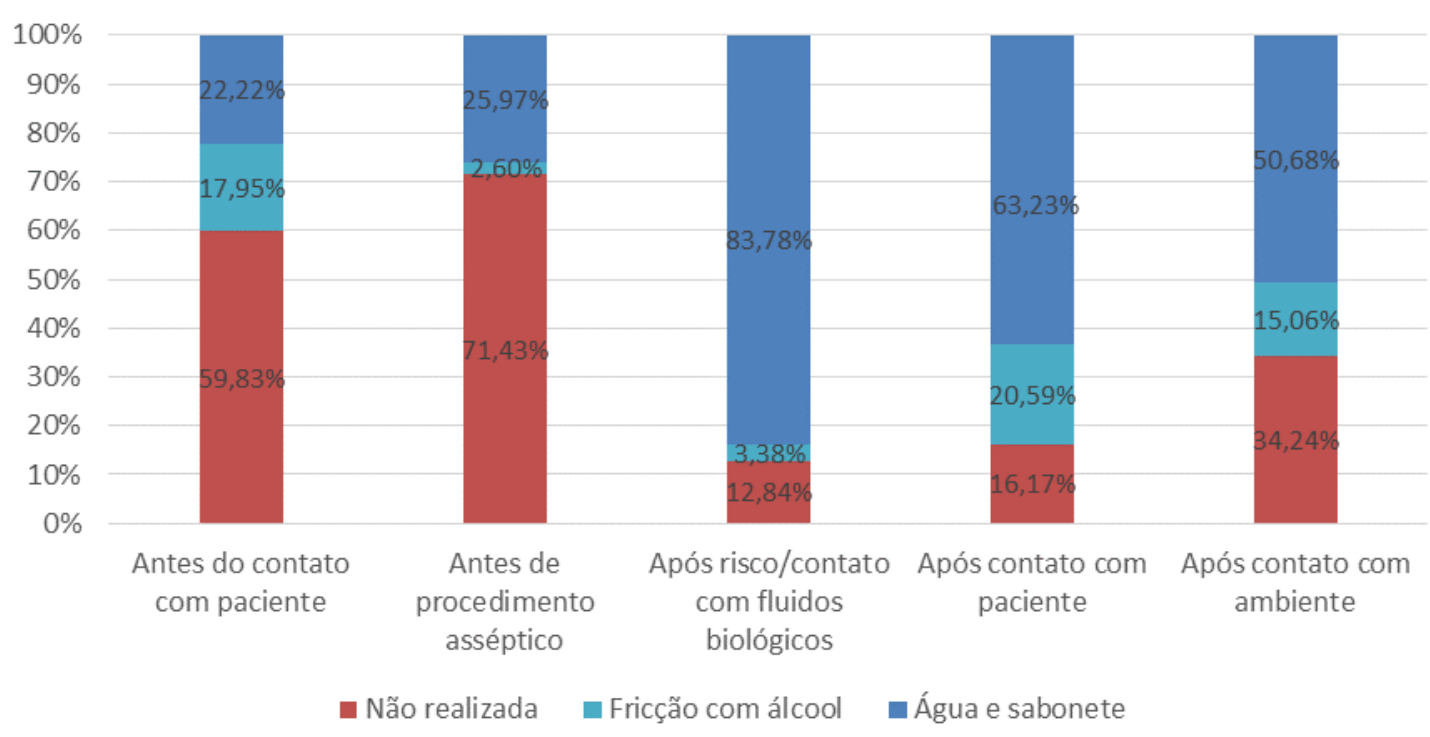

FONTE: A autora (2016).

O teste Qui-quadrado de independência foi aplicado e os resultados obtidos são mostrados na TABELA 15. Obteve-se $p<0,01$ em duas situações. Isso significa que se pode afirmar que existe dependência entre a taxa de adesão e as indicações (cinco momentos) de higiene das mãos. O mesmo pode ser afirmado em relação às categorias profissionais. Entretanto, com relação aos dias da semana e ao turno de serviço, a diferença não foi significativa. 


\begin{tabular}{|c|c|c|c|c|c|}
\hline Variáveis & $\begin{array}{c}\mathrm{N}^{\circ} \mathrm{de} \\
\text { oportunidades } \\
(\mathrm{n})\end{array}$ & $\begin{array}{c}\mathrm{N}^{\circ} \mathrm{de} \\
\mathrm{HM}(\mathrm{n})\end{array}$ & $\begin{array}{c}\text { Taxa de } \\
\text { adesão } \\
(\%)\end{array}$ & $\begin{array}{c}\text { Qui- } \\
\text { quadrado }\end{array}$ & $P$-valor \\
\hline \multicolumn{6}{|l|}{ Indicações (oportunidades) } \\
\hline Antes do contato com paciente & 117 & 47 & 40,17 & 130,33 & $<0,0001$ \\
\hline Antes de procedimento asséptico & 77 & 22 & 28,57 & & \\
\hline Após risco/contato com fluidos biológicos & 148 & 129 & 87,16 & & \\
\hline Após contato com paciente & 136 & 114 & 83,82 & & \\
\hline Após contato com ambiente & 73 & 48 & 65,75 & & \\
\hline \multicolumn{6}{|l|}{ Categoria profissional } \\
\hline Técnico de enfermagem & 279 & 161 & 57,70 & 16,13 & 0,0011 \\
\hline Enfermeiro & 104 & 75 & 72,11 & & \\
\hline Médico & 68 & 53 & 77,94 & & \\
\hline Fisioterapeuta & 65 & 48 & 73,84 & & \\
\hline \multicolumn{6}{|l|}{ Dias da semana } \\
\hline Segunda-feira & 103 & 65 & 63,10 & 3,82 & 0,2812 \\
\hline Terça-feira & 73 & 42 & 57,53 & & \\
\hline Quinta-feira & 225 & 156 & 69,33 & & \\
\hline Sexta-feira & 115 & 74 & 64,34 & & \\
\hline \multicolumn{6}{|l|}{ Turno } \\
\hline Manhã & 187 & 133 & 71,12 & 4,52 & 0,1043 \\
\hline Tarde & 209 & 128 & 61,24 & & \\
\hline Noite & 120 & 76 & 63,33 & & \\
\hline Total & 516 & 337 & 65,31 & & \\
\hline
\end{tabular}

FONTE: A autora (2016).

Como a adesão por categoria profissional tem taxas variadas e significativas para $\alpha=$ $1 \%$ e por turnos de trabalho não apresentou significância, optou-se por analisar separadamente a adesão de cada categoria profissional por turno de trabalho. Após aplicação do Teste Quiquadrado de independência com correção de Yates, verificou-se correlação significativa ao nível de 0,01 para os turnos da tarde e noite, devido à muito baixa adesão dos técnicos de enfermagem nesses turnos, conforme apresentado na TABELA 16. 
TABELA 16 - TESTE QUI-QUADRADO DE INDEPENDÊNCIA DAS OBSERVAÇÕES DE ADESÃO À HIGIENE DAS MÃOS DOS PROFISSIONAIS, POR TURNO DE TRABALHO, DOS PROFISSIONAIS QUE ATUAM NA ASSISTÊNCIA DIRETA AOS PACIENTES, NA UTI DO HOSPITAL DE ENSINO. BRASÍLIA, DF, BRASIL, 2015

\begin{tabular}{lccccc}
\hline $\begin{array}{l}\text { Categoria profissional por } \\
\text { turno }\end{array}$ & $\begin{array}{c}\mathrm{N}^{\circ} \text { de } \\
\text { oportunidades } \\
(\mathrm{n})\end{array}$ & $\begin{array}{c}\mathrm{N}^{\circ} \text { de } \mathrm{HM} \\
(\mathrm{n})\end{array}$ & $\begin{array}{c}\text { Taxa de adesão } \\
(\%)\end{array}$ & $\begin{array}{c}\text { Qui- } \\
\text { quadrado }\end{array}$ & $P$-valor \\
\hline Manhã & & & & & \\
$\quad$ Fisioterapeuta & 21 & 14 & 66,66 & 0,64 & 0,8867 \\
$\quad$ Médico & 34 & 23 & 67,65 & & \\
$\quad$ Enfermeiro & 24 & 18 & 75,00 & & \\
$\quad$ Técnico de enfermagem & 108 & 78 & 72,22 & & \\
Tarde & & & & & \\
$\quad$ Fisioterapeuta & 32 & 25 & 78,12 & $13,57^{*}$ & 0,0036 \\
$\quad$ Médico & 20 & 18 & 90,00 & & \\
$\quad$ Enfermeiro & 54 & 33 & 61,11 & & \\
$\quad$ Técnico de enfermagem & 103 & 52 & 50,48 & & \\
Noite & & & & & \\
$\quad$ Fisioterapeuta & 12 & 9 & 75,00 & $19,09^{*}$ & 0,0003 \\
$\quad$ Médico & 14 & 12 & 85,71 & & \\
$\quad$ Enfermeiro & 26 & 24 & 92,30 & & \\
$\quad$ Técnico de enfermagem & 68 & 31 & 45,59 & & \\
\hline
\end{tabular}

FONTE: A autora (2016).

NOTA: *Qui-quadrado com correção de Yates por conter células menores que 5

Para aumentar a sensibilidade e complementar as análises, o Teste Qui-quadrado de independência com correção de Yates foi novamente aplicado aos turnos de trabalho individualmente por categorias profissionais, cujos dados se encontram na TABELA 17. Nesse caso, pode-se afirmar que existe dependência $(p<0,05)$, entre os enfermeiros e os turnos de trabalho. 
TABELA 17 - TESTE QUI-QUADRADO DE INDEPENDÊNCIA DAS OBSERVAÇÕES DE ADESÃO À HIGIENE DAS MÃOS POR TURNO DE TRABALHO DOS PROFISSIONAIS QUE ATUAM NA ASSISTÊNCIA DIRETA AOS PACIENTES, NA UTI DO HOSPITAL DE ENSINO. BRASÍLIA, DF, BRASIL, 2015

\begin{tabular}{lccccc}
\hline $\begin{array}{l}\text { Turno por categoria } \\
\text { profissional }\end{array}$ & $\begin{array}{c}\mathrm{N}^{\mathbf{0}} \text { de } \\
\text { oportunidades } \\
(\mathrm{n})\end{array}$ & $\begin{array}{c}\mathrm{N}^{\mathrm{o}} \mathrm{de} \\
\mathrm{HM}(\mathrm{n})\end{array}$ & $\begin{array}{c}\text { Taxa de } \\
\text { adesão (\%) }\end{array}$ & $\begin{array}{c}\text { Qui- } \\
\text { quadrado }\end{array}$ & $P$-valor \\
\hline $\begin{array}{l}\text { Fisioterapeuta } \\
\text { Manhã }\end{array}$ & 21 & 14 & 66,66 & 0,87 & 0,6466 \\
Tarde & 32 & 25 & 78,12 & & \\
Noite & 12 & 9 & 75,00 & & \\
Médico & & & & & \\
Manhã & 34 & 23 & 67,65 & 4,28 & \\
Tarde & 20 & 18 & 90,00 & & \\
Noite & 14 & 12 & 85,71 & & \\
Enfermeiro & & & & & \\
Manhã & 24 & 18 & 75,00 & $7,05 *$ \\
Tarde & 54 & 33 & 61,11 & & \\
Noite & 26 & 24 & 92,30 & & \\
Técnico de enfermagem & & & & & \\
Manhã & 108 & 78 & 72,22 & 15,62 & \\
Tarde & 103 & 52 & 50,48 & & \\
Noite & 68 & 31 & 45,59 & & \\
\hline
\end{tabular}

FONTE: A autora (2016).

NOTA: *Qui-quadrado com correção de Yates por conter células menores que 5

$\mathrm{Na}$ avaliação da adesão à higiene das mãos, considerou-se a seguinte regra de decisão: 1) realizada - quando o profissional de saúde cumpriu todas as etapas da técnica da higiene das mãos de forma correta; 2) não realizada - em caso contrário. No entanto, a presença do adorno nas mãos do profissional de saúde não influenciou esse critério de decisão.

\subsection{AVALIAÇÃO DA ADEQUAÇÃO DAS INDICAÇÕES DE PRECAUÇÕES}

Foram realizadas 36 sessões de monitoramento, durante as quais ocorreram 445 oportunidades de observação de procedimentos assistenciais que envolvem o uso de EPI. O período de observação foi de 05/10/2015 a 16/12/2015 em todos os turnos. A ocupação dos leitos teve média de 6,41 leitos por sessão.

A TABELA 18 mostra os tipos de precauções a que os pacientes estavam submetidos durante as observações, e a avaliação quanto a ser adequado ou inadequado o tipo de precaução que estava sinalizada no leito do paciente com a placa de precauções padronizada na UTI. 
TABELA 18 - FREQUÊNCIA DE ADEQUAÇÃO E INADEQUAÇÃO DAS INDICAÇÕES DE PRECAUÇÕES NA UTI DO HOSPITAL DE ENSINO. BRASÍLIA, DF, BRASIL, 2015

\begin{tabular}{lcccccc}
\hline \multirow{2}{*}{ Tipo de } & \multicolumn{2}{c}{ Indicação adequada } & \multicolumn{2}{c}{ Indicação inadequada } & \multicolumn{2}{c}{ Total } \\
\cline { 2 - 7 } Precaução & $\mathrm{n}$ & $\%$ & $\mathrm{n}$ & $\%$ & $\mathrm{n}$ & $\%$ \\
\hline Contato & 194 & 48,87 & 203 & 51,13 & 397 & 89,21 \\
Padrão & 13 & 31,71 & 28 & 68,29 & 41 & 9,21 \\
Respiratória & 2 & 29,57 & 5 & 71,43 & 7 & 1,57 \\
Total & 209 & 46,96 & 236 & 53,03 & 445 & 100,00 \\
\hline FONTE: A autora (2016). & & & & & &
\end{tabular}

É importante destacar que o número total de pacientes admitidos na unidade no período foi 45 . Dos 45 pacientes, 43 foram colocados em precauções de contato, um em precauções padrão e um em precauções respiratórias para aerossóis. Segundo os critérios estabelecidos pela CCIRAS do hospital, constante nos POPs locais e de acordo com os registros da CCIRAS de monitoramento dos pacientes internados na UTI durante o período, deveriam ter sido submetidos às precauções de contato 27 pacientes, às precauções padrão 17 pacientes e um às precauções respiratórias. Essa medida resultou em um percentual de 35\% de pacientes que foram submetidos às precauções de contato desnecessariamente.

\subsection{ADESÃO AO USO CORRETO DE EPI}

Para estudar esse tipo de adesão, o número de observações foi distribuído proporcionalmente entre o número de profissionais das diferentes categorias para que todas pudessem ser representadas na mesma proporção.

No total foram realizadas 445 observações, o que supera o número inicialmente calculado, que era 384. Essa alteração ocorreu devido ao maior número de oportunidades que foram necessárias para que as diferentes categorias de profissionais fossem contempladas.

Os procedimentos assistenciais com as frequências e percentuais são apresentados na TABELA 19. 
TABELA 19 - NÚMERO DE OBSERVAÇÕES DE PROCEDIMENTOS ASSISTENCIAIS, POR CATEGORIA DE PROFISSIONAIS QUE ATUAM NA ASSISTÊNCIA DIRETA AOS PACIENTES, NA UTI DO HOSPITAL DE ENSINO. BRASÍLIA, DF, BRASIL, 2015

\begin{tabular}{lcc}
\hline Categoria profissional & $\mathrm{N}^{\mathrm{o}}$ de observações (n) & $\%$ \\
\hline Enfermeiro & 68 & 15,28 \\
Fisioterapeuta & 47 & 10,56 \\
Médico & 69 & 15,51 \\
Técnico de enfermagem & 261 & 58,65 \\
Total & 445 & 100,00 \\
\hline FONTE: A autora (2016). & &
\end{tabular}

A TABELA 20 mostra a frequência com que os EPIs foram indicados e a de uso desses equipamentos pelos profissionais. É importante destacar que, para avaliar se existiu a indicação ou não do uso do EPI, foi considerada a sinalização da placa que indicava o tipo de precaução a que o paciente estava submetido. Posteriormente, mesmo tendo sido identificado que o tipo de precaução sinalizado na placa do leito estava inadequado, conforme dados apresentados na TABELA 18, esse equívoco não foi usado para avaliar a necessidade do uso do EPI porque naquele momento a equipe seguia a indicação da placa.

TABELA 20 - FREQUÊNCIA DA INDICAÇÃO DO EPI E DO USO DURANTE OS PROCEDIMENTOS PELOS PROFISSIONAIS QUE ATUAM NA ASSISTÊNCIA DIRETA AOS PACIENTES, NA UTI DO HOSPITAL DE ENSINO. BRASÍLIA, DF, BRASIL, 2015

\begin{tabular}{lrrr}
\hline EPI & \multicolumn{1}{l}{$\begin{array}{l}\text { Usou } \\
\mathrm{n}(\%)\end{array}$} & $\begin{array}{c}\text { Não usou } \\
\mathrm{n}(\%)\end{array}$ & $\begin{array}{c}\text { Total } \\
\text { (n) }\end{array}$ \\
\hline Luvas & $410(94,91)$ & $22(5,09)$ & 432 \\
$\quad$ Indicado & $9(69,23)$ & $4(30,77)$ & 13 \\
$\quad$ Não indicado & & & \\
Avental & $267(91,43)$ & $25(8,56)$ & 292 \\
$\quad$ Indicado & $19(12,41)$ & $134(87,58)$ & 153 \\
$\quad$ Não indicado & & & \\
Máscara & $124(80,00)$ & $31(20,00)$ & 155 \\
$\quad$ Indicado & $123(42,41)$ & $167(57,58)$ & 290 \\
$\quad$ Não indicado & & & \\
Óculos & $14(24,56)$ & $43(75,43)$ & 57 \\
$\quad$ Indicado & $15(3,86)$ & $373(96,13)$ & 388 \\
$\quad$ Não indicado & & &
\end{tabular}

O uso correto dos EPIs, conforme a precaução a que o paciente estava submetido e o tipo de procedimento que estava sendo realizado, foi avaliado. Foi considerado uso correto 
quando o profissional usou corretamente todos os quatro EPIs (avental, luvas, máscara e óculos) nos procedimentos em que estavam indicados ou quando o profissional não usou os EPIs quando não estavam indicados. A TABELA 21 detalha a frequência e percentual dos acertos no uso de EPI entre os 445 procedimentos observados.

TABELA 21 - FREQUÊNCIA E TAXA DE USO CORRETO DOS 4 EPI (AVENTAL, LUVAS, MÁSCARA E ÓCULOS) POR PROCEDIMENTOS REALIZADOS PELOS PROFISSIONAIS QUE ATUAM NA ASSISTÊNCIA DIRETA AOS PACIENTES, NA UTI DO HOSPITAL DE ENSINO. BRASÍLIA, DF, BRASIL, 2015

\begin{tabular}{|c|c|c|c|}
\hline Procedimento & $\begin{array}{c}\text { N } \mathrm{N}^{\mathrm{o}} \mathrm{de} \\
\text { procedimentos } \\
\text { observados (n) }\end{array}$ & $\begin{array}{l}\mathrm{N}^{\circ} \text { de uso } \\
\text { correto de } \\
\text { EPI (n) }\end{array}$ & $\begin{array}{c}\text { Taxa de uso } \\
\text { correto de } \\
\text { EPI }(\%)\end{array}$ \\
\hline Exame físico & 55 & 24 & 43,64 \\
\hline Mudar decúbito & 46 & 11 & 23,91 \\
\hline Aspiração de traqueia & 43 & 10 & 23,26 \\
\hline Medição endovenosa & 42 & 25 & 59,52 \\
\hline Banho no leito & 40 & 31 & 77,50 \\
\hline Manuseio de equipamento & 39 & 22 & 56,41 \\
\hline Trocar fralda & 22 & 18 & 66,67 \\
\hline Administração de dieta & 22 & 8 & 31,82 \\
\hline Glicemia & 21 & 16 & 76,19 \\
\hline Curativo & 15 & 10 & 66,67 \\
\hline Cuidar de estomias & 11 & 7 & 63,64 \\
\hline Coletar sangue & 11 & 2 & 18,18 \\
\hline Troca de equipo & 10 & 6 & 27,27 \\
\hline Instalar cateter periférico & 9 & 2 & 22,22 \\
\hline Esvaziar bolsa de diurese & 8 & 3 & 37,50 \\
\hline Transporte & 7 & 4 & 40,00 \\
\hline Instalar CVC & 7 & 0 & 0,00 \\
\hline Curativo de cateter & 5 & 5 & 100,00 \\
\hline Débito de dieta & 1 & 1 & 100,00 \\
\hline Higiene oral & 1 & 1 & 100,00 \\
\hline Instalar SVD & 1 & 1 & 100,00 \\
\hline Instalar dreno de tórax & 1 & 0 & 0,00 \\
\hline Instalar SNG/NE & 1 & 0 & 0,00 \\
\hline Outros & 27 & 3 & 42,86 \\
\hline Total & 445 & 210 & 47,19 \\
\hline
\end{tabular}

FONTE: A autora (2016).

LEGENDA: CVC - cateter venoso central

SNG/NE - sonda nasogástrica ou nasoentérica

SVD - sonda vesical de demora

Para análise individualizada de cada procedimento e melhor visualização das informações quando aos acertos encontrados no uso de cada um dos quatro tipos de EPIs, as 
representações dos percentuais de uso corretos dos EPIs por procedimentos foram agrupadas nas FIGURAS 7 e 8.

Foi usado o gráfico do tipo radar para reunir em uma mesma figura a sinalização dos percentuais de acerto dos quatro EPIs avaliados em cada um dos procedimentos de forma simples. Nesse tipo de gráfico, a linha colorida em azul representa a taxa de acerto do EPI que está identificado pelo nome na ponta do quadrilátero. Nos procedimentos em que a linha colorida de azul se aproxima das pontas do quadrilátero os profissionais tiveram maior taxa de acerto de uso do EPI e nos procedimentos em que a linha azul se aproxima do centro do quadrilátero os profissionais tiveram menor taxa de acerto do EPI.

Na FIGURA 7, observa-se que durante o procedimento de administração de dieta enteral os profissionais: acertaram aproximadamente $60 \%$ quanto ao uso das luvas; acertaram cerca de $97 \%$ quanto ao uso ou não uso de avental (depende do tipo de precaução a que o paciente estava submetido); acertaram $70 \%$ quanto ao uso ou não uso da máscara (depende do tipo de precaução a que o paciente estava submetido); e acertaram 100\% quanto ao não uso de óculos de proteção. 
FIGURA 7 - PERCENTUAL DE USO CORRETO DO EPI NOS PROCEDIMENTOS DE ADMINISTRAÇÃO DE DIETA, ASPIRAÇÃO DE TRAQUEIA, BANHO NO LEITO, COLETA DE SANGUE, CUIDADOS COM ESTOMIAS, CURATIVOS, CURATIVOS DE CATETERES, AFERIÇÕES DE DÉBITOS DE DIETAS, INSTALAÇÃO DE DRENOS DE TÓRAX, ESVAZIAMENTO DE BOLSAS DE DIURESE, REALIZAÇÃO DE EXAME FÍSICO E GLICEMIA CAPILAR PELOS PROFISSIONAIS QUE ATUAM NA ASSISTÊNCIA DIRETA AOS PACIENTES, NA UTI DO HOSPITAL DE ENSINO. BRASÍLIA, DF, BRASIL, 2015
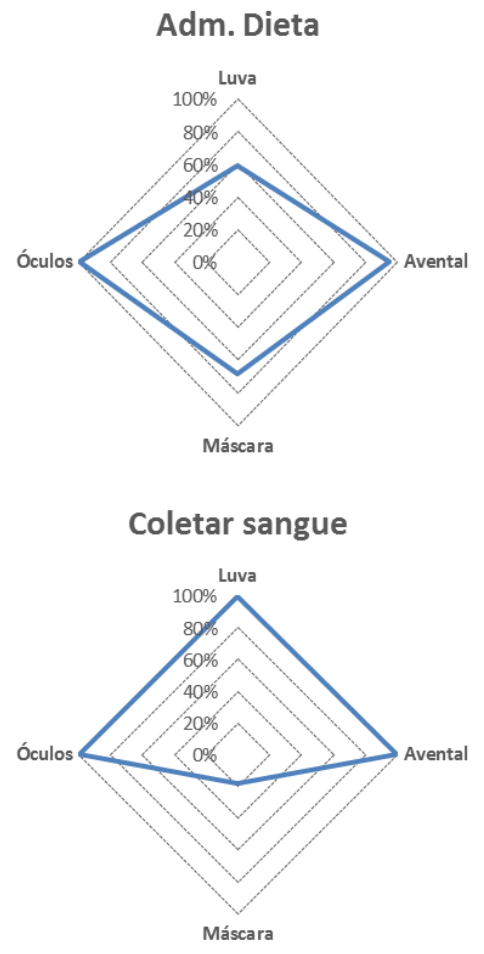

Curativo de cateter

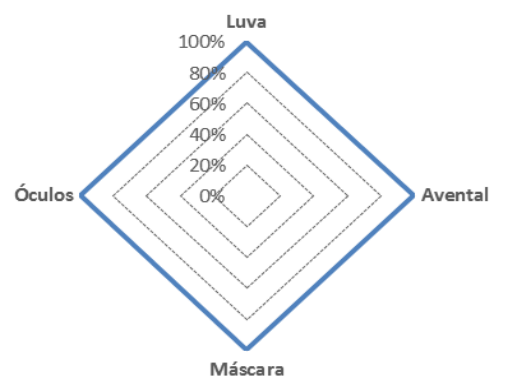

Esvaziar diurese

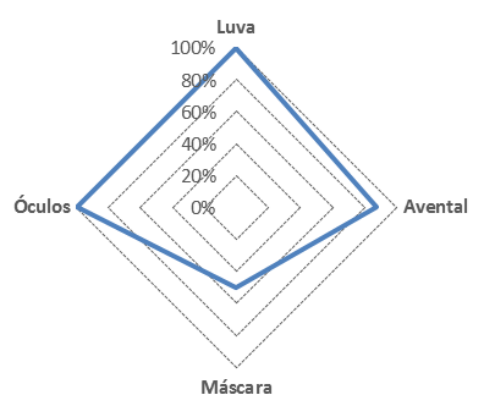

Aspiração de traqueia

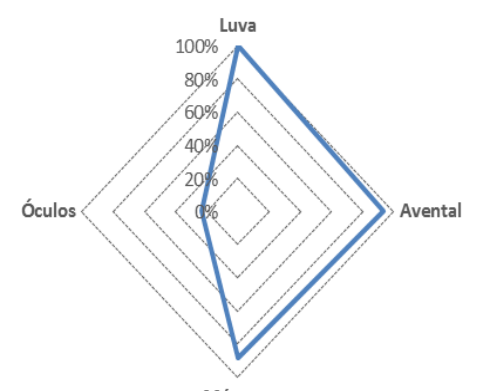

Máscara

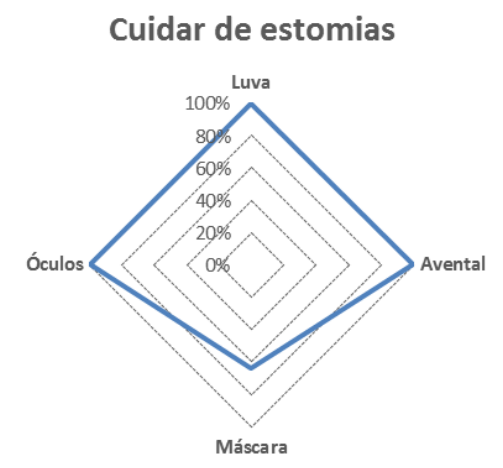

Débito de dieta

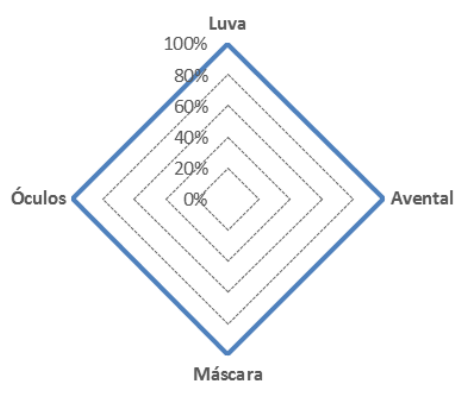

Exame físico

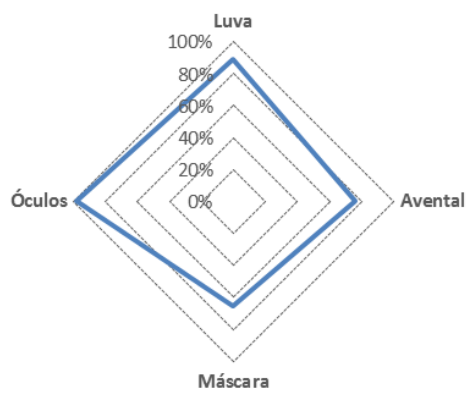

Máscara
Banho no leito
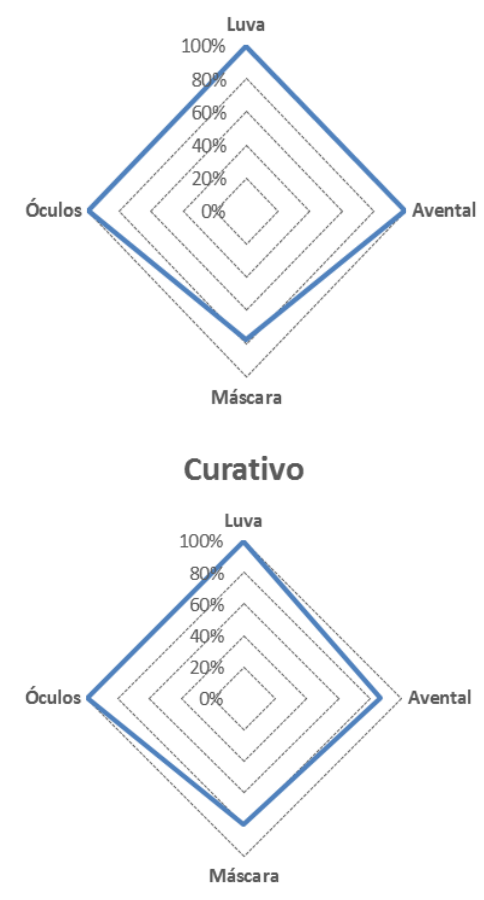

Dreno de tórax

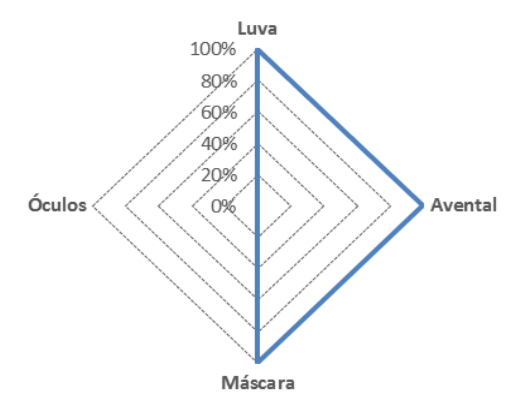

Glicemia

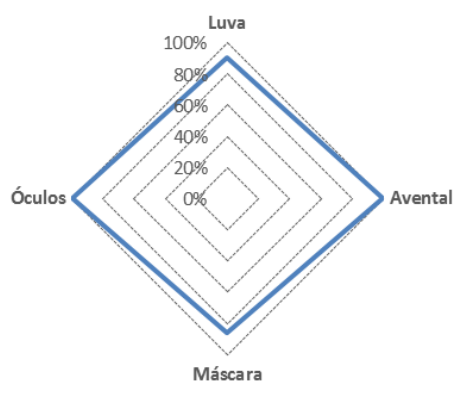

FONTE: A autora (2016). 
FIGURA 8 - PERCENTUAL DE USO CORRETO DO EPI NOS PROCEDIMENTOS DE HIGIENE ORAL, INSTALAÇÃO DE CATETER PERIFÉRICO, INSTALAÇÃO DE CATETER VENOSO CENTRAL, INSTALAÇÃO DE SONDA NASOGÁSTRIÇA OU NASOENTÉRICA, INSTALAÇÃO DE SONDA VESICAL, MANUSEIO DE EQUIPAMENTOS, ADMINISTRAÇÃO DE MEDICAÇÃO ENDOVENOSA, MUDANÇA DE DECÚBITO, TRANSPORTE, TROCA DE EQUIPO, TROCA DE FRALDA E OUTROS PELOS PROFISSIONAIS QUE ATUAM NA ASSISTÊNCIA DIRETA AOS PACIENTES, NA UTI DO HOSPITAL DE ENSINO. BRASÍLIA, DF, BRASIL, 2015

Higiene oral

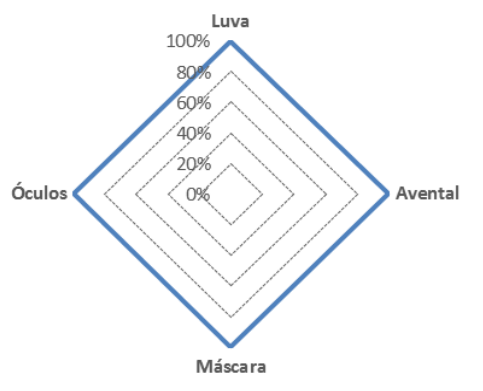

Instalar SNG/NE

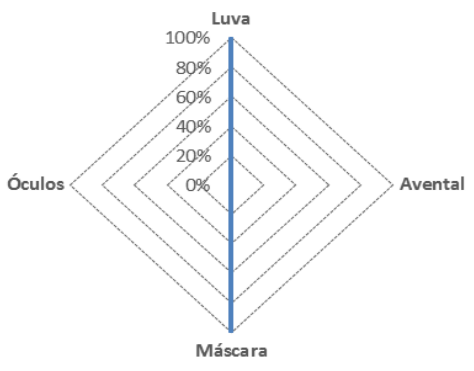

Medição endovenosa

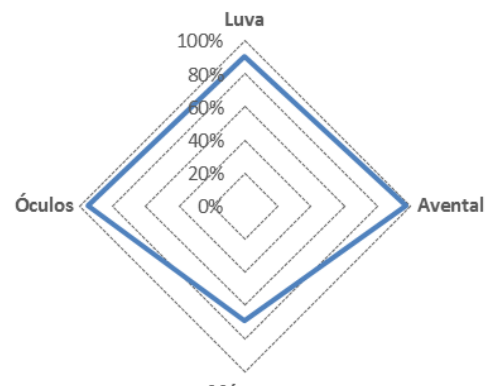

Máscara

Troca de equipo

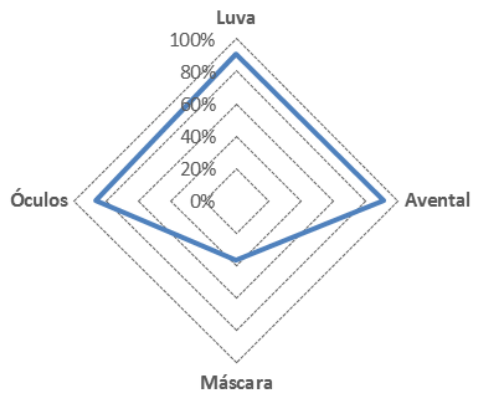

Instalar cat. Periférico

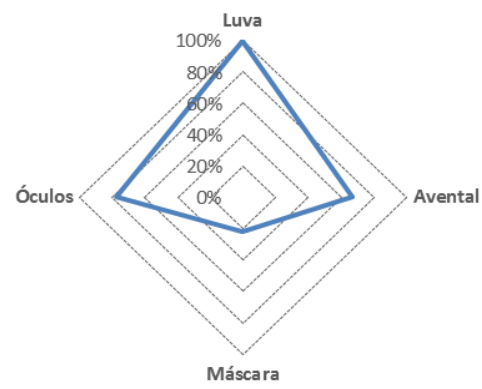

Instalar SVD

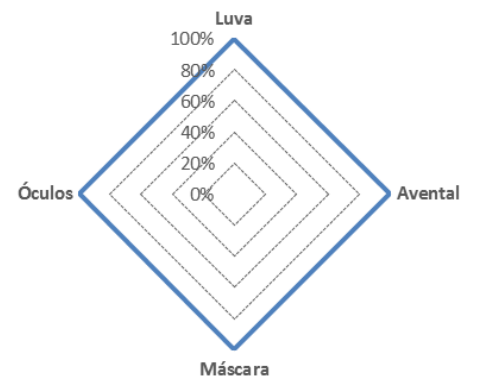

Mudar decúbito

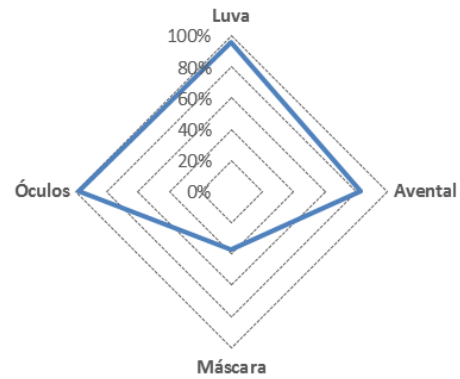

Máscara

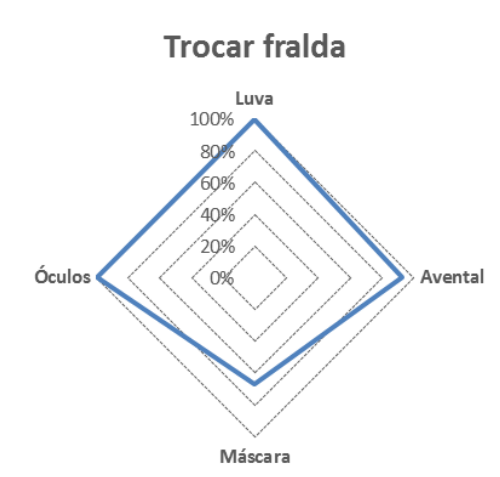

FONTE: A autora (2016).
Instalar CVC

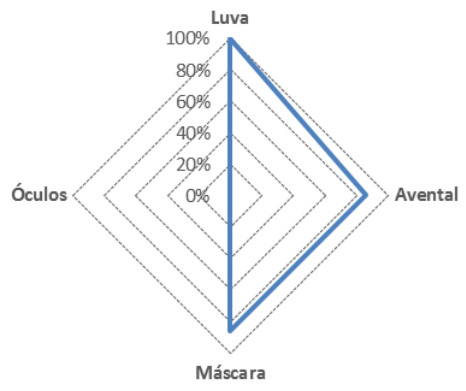

Manuseio de equip.

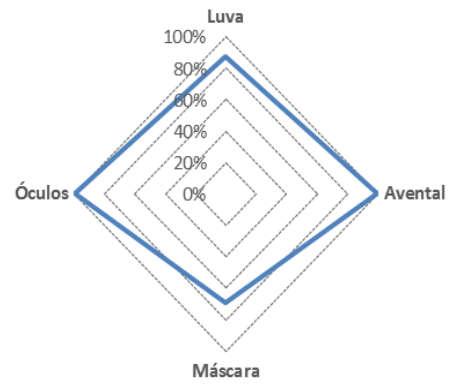

Transporte
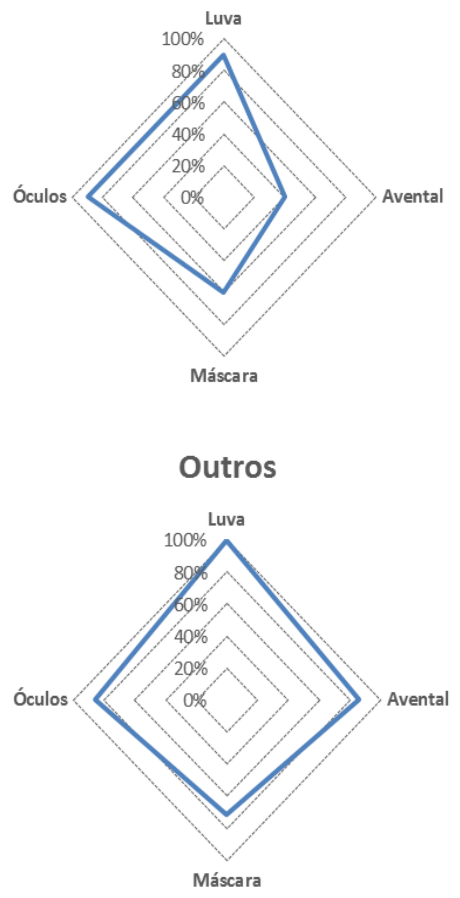
O teste Qui-Quadrado de independência foi aplicado para avaliar o uso de EPI quando indicado e quando não indicado. Constata-se pela TABELA 22, que a taxa de uso correto é significativamente diferente $(p<0,01)$ entre os EPI. Entretanto, as taxas entre os profissionais e o turno de serviço não diferem significativamente.

TABELA 22 - TESTE QUI-QUADRADO DE INDEPENDÊNCIA DO USO DO EPI ENTRE OS TIPOS DE EPI, PROFISSIONAIS E TURNOS DE TRABALHO, NA UTI DO HOSPITAL DE ENSINO. BRASÍLIA, DF, BRASIL, 2015

\begin{tabular}{|c|c|c|c|c|c|}
\hline Variáveis & $\begin{array}{c}\mathrm{N}^{\circ} \text { de } \\
\text { observações }\end{array}$ & $\begin{array}{c}\mathrm{N}^{\circ} \text { de uso } \\
\text { correto de EPI }\end{array}$ & $\begin{array}{l}\text { Taxa de uso } \\
\text { correto de EPI }\end{array}$ & $\begin{array}{c}\text { Teste de Qui- } \\
\text { quadrado }\end{array}$ & $P$-valor \\
\hline \multicolumn{6}{|l|}{ EPI - Indicado } \\
\hline Luvas & 432 & 410 & $94,91 \%$ & 226,07 & $<0,0001$ \\
\hline Avental & 292 & 267 & $91,43 \%$ & & \\
\hline Máscara & 155 & 124 & $80,00 \%$ & & \\
\hline Óculos & 57 & 14 & $24,56 \%$ & & \\
\hline \multicolumn{6}{|l|}{ EPI - Não Indicado } \\
\hline Luvas & 13 & 4 & $30,77 \%$ & 175,69 & $<0,0001$ \\
\hline Avental & 153 & 134 & $87,58 \%$ & & \\
\hline Máscara & 290 & 167 & $57,58 \%$ & & \\
\hline Óculos & 388 & 373 & $96,13 \%$ & & \\
\hline \multicolumn{6}{|l|}{ Profissional } \\
\hline Enfermeiro & 68 & 33 & $48,53 \%$ & 6,84 & 0,0772 \\
\hline Fisioterapeuta & 47 & 14 & $29,79 \%$ & & \\
\hline Médico & 69 & 31 & $44,93 \%$ & & \\
\hline Técnico de enfermagem & 261 & 131 & $50,19 \%$ & & \\
\hline \multicolumn{6}{|l|}{ Turno } \\
\hline Matutino & 149 & 67 & $44,97 \%$ & 0,36 & 0,8345 \\
\hline Vespertino & 133 & 64 & $48,12 \%$ & & \\
\hline Noturno & 163 & 78 & $47,85 \%$ & & \\
\hline
\end{tabular}

A média da taxa de acerto no uso de EPI quando indicado foi de $72,72 \%$. Destaca-se que os óculos foram o EPI com a menor taxa de uso correto $24,56 \%$, valor esse muito abaixo da média. Quanto à falta de uso do EPI quando não indicado, a média da taxa de acerto foi de 68,01\%. Destaca-se que as luvas apresentaram menor taxa de acerto, porém, esse EPI costuma ser indicado para maioria dos procedimentos. Além disso, em números absolutos, a máscara foi o EPI mais usado desnecessariamente.

O teste Qui-quadrado de independência foi aplicado para avaliar o uso de EPI entre os profissionais por turno de trabalho. Para realizar esse teste, foi necessário aplicar a correção de Yates, pois a tabela continha células com valores menores que cinco. Pode-se notar, pela 
TABELA 23, que a taxa de acerto de uso é significativamente diferente $(p<0,01)$ entre os profissionais do turno noturno. Entretanto, entre os profissionais dos outros turnos a diferença não é significativa.

\begin{tabular}{|c|c|c|c|c|c|}
\hline $\begin{array}{l}\text { Categoria profissional } \\
\text { por turno }\end{array}$ & $\begin{array}{c}\mathrm{N}^{\circ} \text { de } \\
\text { Observações }\end{array}$ & $\begin{array}{c}\mathrm{N}^{\circ} \text { de uso } \\
\text { correto de EPI }\end{array}$ & $\begin{array}{l}\text { Taxa de uso } \\
\text { correto de EPI }\end{array}$ & $\begin{array}{c}\text { Teste } \\
\text { Qui-quadrado }\end{array}$ & $P$-valor \\
\hline \multicolumn{6}{|l|}{ Matutino } \\
\hline Enfermeiro & 15 & 9 & $60,00 \%$ & $1,01 *$ & 0,7985 \\
\hline Fisioterapeuta & 20 & 8 & $40,00 \%$ & & \\
\hline Médico & 23 & 9 & $39,13 \%$ & & \\
\hline Técnico de enfermagem & 91 & 41 & $45,05 \%$ & & \\
\hline \multicolumn{6}{|l|}{ Vespertino } \\
\hline Enfermeiro & 34 & 17 & $50,00 \%$ & $3,17^{*}$ & 0,3659 \\
\hline Fisioterapeuta & 13 & 6 & $46,15 \%$ & & \\
\hline Médico & 11 & 2 & $18,18 \%$ & & \\
\hline Técnico de enfermagem & 75 & 39 & $52,00 \%$ & & \\
\hline \multicolumn{6}{|l|}{ Noturno } \\
\hline Enfermeiro & 19 & 7 & $36,84 \%$ & $13,47 *$ & 0,0037 \\
\hline Fisioterapeuta & 14 & 0 & $0,00 \%$ & & \\
\hline Médico & 35 & 20 & $57,14 \%$ & & \\
\hline Técnico em Enfermagem & 95 & 51 & $53,68 \%$ & & \\
\hline
\end{tabular}

FONTE: A autora (2016).

NOTA: *Qui-quadrado com correção de Yates por conter células menores que 5

O teste Qui-quadrado de independência com a correção de Yates foi aplicado para avaliar o uso de EPI entre os turnos de trabalho por profissionais. Observa-se, pela TABELA 24 , que a taxa de acerto de uso é significativamente diferente $(p<0,05)$ entre os turnos para os profissionais de fisioterapia. Todavia, para os profissionais dos outros turnos a diferença não foi significativa. 
TABELA 24 - TESTE QUI-QUADRADO DE INDEPENDÊNCIA DO USO DE EPI ENTRE OS TURNOS DE TRABALHO POR PROFISSIONAIS, NA UTI DO HOSPITAL DE ENSINO. BRASÍLIA, DF, BRASIL, 2015

\begin{tabular}{lrrrrr}
\hline $\begin{array}{l}\text { Turno por categoria } \\
\text { profissional }\end{array}$ & $\begin{array}{c}\mathbf{N}^{\mathbf{o}} \text { de } \\
\text { Observações }\end{array}$ & $\begin{array}{c}\mathbf{N}^{\mathbf{0}} \text { de uso } \\
\text { correto de EPI }\end{array}$ & $\begin{array}{c}\text { Taxa de uso } \\
\text { correto de EPI }\end{array}$ & $\begin{array}{c}\text { Teste } \\
\text { Qui-quadrado }\end{array}$ & $P$-valor \\
\hline Enfermeiro & & & & & \\
$\quad$ Matutino & 15 & 9 & $60,00 \%$ & $1,02^{*}$ & 0,6001 \\
$\quad$ Vespertino & 34 & 17 & $50,00 \%$ & & \\
$\quad$ Noturno & 19 & 7 & $36,84 \%$ & & \\
Fisioterapeuta & & & & & \\
$\quad$ Matutino & 20 & 8 & $40,00 \%$ & $6,14^{*}$ & 0,0463 \\
$\quad$ Vespertino & 13 & 6 & $46,15 \%$ & & \\
$\quad$ Noturno & 14 & 0 & $0 \%$ & & \\
Médico & & & & & \\
$\quad$ Matutino & 23 & 9 & $39,13 \%$ & $3,96^{*}$ & 0,1381 \\
$\quad$ Vespertino & 11 & 2 & $18,18 \%$ & & \\
$\quad$ Noturno & 35 & 20 & $57,14 \%$ & & \\
Técnico de enfermagem & & & & & \\
$\quad$ Matutino & 91 & 41 & $45,05 \%$ & 1,14 & 0,5657 \\
$\quad$ Vespertino & 75 & 39 & $52,00 \%$ & & \\
$\quad$ Noturno & 95 & 51 & $53,68 \%$ & & \\
\hline
\end{tabular}

FONTE: A autora (2016).

NOTA: *Qui-quadrado com correção de Yates por conter células menores que 5 


\section{DISCUSSÃO}

\subsection{LIMITAÇÕES DO ESTUDO}

Auditorias de processo de trabalho com observações diretas apresentam vantagens e desvantagens discutidas na literatura internacional e nacional por diferentes autores e instituições. (DE OLIVEIRA, DE PAULA, 2011; JCI, 2010; MARRA et al., 2010; SÃO PAULO, 2006; WALKER et al., 2014; WHO, 2006, 2009).

A observação direta da adesão à higiene das mãos é considerada o padrão ouro pela OMS, pois permite avaliar a técnica utilizada e os momentos em que a higiene das mãos realmente ocorreu. (WHO, 2006, 2009). A principal limitação ou desvantagem conhecida do método é o efeito Hawthorne, que foi a limitação apresentada por esse estudo. As demais desvantagens apontadas na literatura, que se apresentam às auditorias por observações diretas - como as relacionadas ao viés de amostra quando não avalia todos os turnos de trabalho, métodos não padronizados de avaliação, necessidade de tempo e de profissional treinado para a realização -, foram superadas nesse trabalho, tendo em vista o método adotado.

Da mesma forma que a higiene das mãos, as auditorias de observação de uso de EPI também podem ser influenciadas pelo efeito Hawthorne; e, quanto às demais limitações, acredita-se que o percurso metodológico foi resolutivo para minimizar o impacto nos resultados encontrados.

O viés de seleção do turno não ocorreu nesse trabalho porque as sessões das auditorias foram distribuídas proporcionalmente entre os diferentes turnos de trabalho, dias da semana, bem como o número de observações entre as diferentes categorias e profissionais. As sessões de observações estenderam-se aproximadamente por duas horas e o período inicialmente estabelecido de três meses para o desenvolvimento do estudo foi suficiente. Assim, o trabalho alcançou seu principal objetivo e permitiu uma avaliação detalhada da infraestrutura e das práticas de precauções da UTI de um hospital de ensino do Distrito Federal.

\subsection{CARACTERÍSTICAS DOS PROFISSIONAIS QUE ATUAM NA UTI}

Quanto às características dos profissionais que atuam na assistência ao paciente na UTI, observou-se, em relação ao gênero, a predominância de participantes do sexo feminino. Com a separação por categorias profissionais, identifica-se essa predominância somente entre 
os técnicos de enfermagem. Entre os enfermeiros e fisioterapeutas a proporção dos dois sexos foi igual e entre os médicos predominou o sexo masculino.

Esses achados estão de acordo com os de outros estudos em UTIs brasileiras e no DF sobre variáveis demográficas de técnicos de enfermagem; no entanto, são diferentes dos publicados em relação aos enfermeiros e fisioterapeutas, em que a maioria aponta a predominância do sexo feminino. (OLIVEIRA, CARDOSO, MASCARENHAS, 2010; GONÇALVES et al., 2012, PIMENTEL et al., 2013; SHIMIZU, COUTO, MERCHANHAMANN, 2011).

A feminização da força de trabalho no setor saúde é um fenômeno estudado e acompanhado no Brasil por pesquisadores que evidenciam crescente aumento dela na área médica desde a década de 1970, quando era de somente $11,6 \%$ e passou a 35,9\% em 2000. Wermelinger et al. (2010), em estudos sobre o tema, identificaram que na maioria das profissões da área da saúde estudadas existia o predomínio do sexo feminino, exceto entre os médicos veterinários, médicos e cirurgiões dentistas. A profissão mais feminizada era a dos nutricionistas, seguida pelos enfermeiros e psicólogos/psicanalistas. Também encontraram predomínio do sexo feminino entre os fisioterapeutas. (WERMELINGER et al., 2010; MACHADO, DE OLIVEIRA, MOYSES, 2011).

Em relação à faixa etária, a maioria encontrada nos participantes desse estudo estava entre 30 a 40 anos, e mais de $80 \%$ dos profissionais tinha de 30 a 50, o que sugere se tratarem de pessoas experientes. Esses achados são concordantes aos de outro estudo feito em UTIs brasileiras. (OLIVEIRA, CARDOSO, MASCARENHAS, 2010; GONÇALVES et al., 2012, PIMENTEL et al., 2013).

Com a análise do tempo de atuação na profissão, distribuído por categorias profissionais, identifica-se que a maioria dos médicos e enfermeiros tem mais de 11 anos de experiência na área. Já entre os fisioterapeutas, todos têm até 10 anos e a maioria dos técnicos de enfermagem também tem até 10 anos de atuação.

Tal questão deve-se ao fato de que a instituição, cenário do estudo, passou por total reestruturação de seu quadro de recursos humanos no ano anterior, quando mais de $60 \%$ de seus trabalhadores foram substituídos por outros que ingressaram por concurso público. Entre esses profissionais recém-admitidos (com período de contratação variável entre um a 20 meses) estavam os quatro fisioterapeutas, 27 técnicos de enfermagem, seis enfermeiros e quatro médicos da UTI, o que representou $78,84 \%$ da equipe de profissionais da assistência que participou do presente estudo. 
Em geral, a maioria dos participantes afirmou estar em atuação na profissão por mais de cinco anos, o que é um resultado relativamente equivalente ao de outro estudo realizado no Brasil por Gonçalves et al. (2012) e diferente dos estudos de Oliveira, Cardoso, Mascarenhas (2010) e Pimentel et al. (2013), que identificaram equipes com tempos de atuação na profissão menores.

Procurou-se, também, avaliar possíveis situações de múltiplos vínculos ou excesso de trabalho que podem ser motivo de cansaço ou fadiga, fatores de risco que predispõem à ocorrência de deslizes, lapsos de memória ou enganos que podem influenciar diretamente na execução de boas práticas assistenciais. Para tanto, questionou-se sobre a carga horária semanal total de trabalho dos profissionais. Identificou-se que na equipe a maioria atuava em apenas um vínculo empregatício, principalmente os técnicos de enfermagem, porque 79\% afirmaram trabalhar até $40 \mathrm{~h}$ semanais. Os profissionais com maior carga horária de trabalho na unidade eram quatro enfermeiros, dois médicos e um fisioterapeuta, que afirmaram trabalhar entre 61 a $80 \mathrm{~h}$, representando $13 \%$ da equipe.

Em uma revisão de literatura, Garret (2008) avaliou os efeitos da Síndrome do Esgotamento Profissional - também conhecida como Burnout - na enfermagem, sobre a ocorrência de eventos adversos na assistência perioperatória. Considerando como normal carga horária de até $40 \mathrm{~h}$ semanais, identificou que as horas extras obrigatórias frequentemente eram utilizadas para cobrir falta de pessoal na assistência perioperatória, o que resultava em fadiga e Burnout na enfermagem. Levantou estudos que indicavam que os efeitos da fadiga extrema podiam ser comparados à influência de efeitos de ingestão de álcool e ressaltou uma vasta quantidade de pesquisas que apontam para uma associação entre menores taxas de presença de enfermeiros e taxas mais elevadas de eventos adversos em pacientes. Concluiu que, ao invés de colocar a culpa em enfermeiros por falhas na assistência ao paciente, os administradores deveriam garantir segurança ao paciente oferecendo instalações de saúde seguras, número de profissionais suficientes e condições de trabalho adequadas.

Em um estudo desenvolvido por Magalhães e Glina (2006) para avaliar Burnout entre médicos de um hospital em São Paulo, identificou-se que 47\% deles trabalhavam entre 61 a 90 horas semanais e a incidência de $11 \%$ de Burnout. Os autores concluíram que a grande realização pessoal com a profissão funcionava como fator protetor contra a doença e que, embora os médicos estivessem submetidos a vários estressores como sobretrabalho, muitos empregos e rotina desgastante, eles gostavam do seu trabalho e dele auferiam grande autorrealização. 
Segundo a OMS, o desconhecimento sobre o assunto ou acreditar que o uso de luvas dispensa a higiene das mãos também são outras barreiras que dificultam a adesão dos profissionais de saúde à higiene das mãos; assim, questionou-se sobre capacitações na formação acadêmica e treinamento em serviço na instituição sobre os temas estudados. (WHO, 2006, 2009).

Neste estudo, toda a equipe de enfermagem que atua na UTI afirmou ter recebido capacitação sobre higiene das mãos, uso de EPI (avental, luvas, máscara e óculos de proteção) e tipos de precauções (padrão e isolamentos). Entre todos os participantes do estudo, somente três profissionais (um fisioterapeuta e dois médicos) informaram não ter recebido algum tipo de capacitação sobre esses temas na formação profissional.

Os treinamentos em serviço com periodicidades regulares são importantes ferramentas para manter as boas práticas de adesão às precauções. De acordo com a OMS, equipes bem treinadas conseguem manter taxas de adesão à higiene das mãos acima de 60\%, e muitas chegam a ultrapassar 80\%. (WHO, 2006, 2009).

$\mathrm{Na}$ UTI, cenário do estudo, a maioria dos profissionais, exceto os médicos, informou ter recebido treinamento em serviço sobre higiene das mãos, uso de EPI (avental, luvas, máscara e óculos de proteção) e tipos de precauções (padrão e isolamentos) no último ano. Como supracitado, muitos desses profissionais eram recém-admitidos e passaram por programas de treinamentos admissionais que incluíram os temas, como constavam nos PCIRAS do hospital dos anos de 2014 e 2015. (HUB, 2014a, 2015c).

Esses achados corroboram outros levantamentos feitos sobre o assunto em equipes de UTI, em que a maioria dos profissionais de enfermagem afirma ter recebido, e os médicos, não terem recebido treinamento sobre tais temas. (DE VITA et al., 2014, BATHKE et al., 2013, DO PRADO, HARTMANN, TEIXEIRA FILHO, 2013).

O conjunto de informações reunidas sobre as características da equipe multiprofissional da UTI do hospital de ensino do DF, em relação à idade, tempo de experiência na profissão, profissionais que atuam em sua maioria em somente um ou dois vínculos empregatícios e conhecimento sobre precauções, são positivas no sentido de favorecer melhor desempenho em termos de adesão às boas práticas das precauções. No entanto, a análise da estrutura física da unidade permitiu identificar pontos importantes para melhorias. 


\subsection{INFRAESTRUTURA DISPONÍVEL PARA EXECUÇÃO DAS PRÁTICAS DE PRECAUÇÕES}

Quanto aos lavatórios para higiene das mãos, o número é suficiente e atende às exigências da RDC n..$^{\circ} 50$ e da RDC n. ${ }^{\circ}$ 7. O acesso às áreas de localização dos lavatórios esteve livre de objetos no trajeto aos mesmos durante o período estudado.

A profundidade das pias era pequena, mas suficiente para realização da técnica da higiene das mãos. As torneiras das pias eram de acionamento por pressão e, portanto, dispensavam o contato das mãos para acionamento ou fechamento. As cubas laterais não apresentavam o problema da profundidade, mas o acionamento e fechamento manual das torneiras não atendiam às exigências da regulamentação.

Ainda em relação às pias, uma pia interna no quarto individual usado para isolamento, que não dispunha de dispensadores de sabonete ou papel-toalha, tal questão não se justificava porque existiam dispensadores disponíveis no hospital.

As preparações alcoólicas estavam disponíveis em somente cinco dispensadores fixados nas paredes. Somente um desses dispensadores estava localizado no ponto de assistência, ou seja, com relação a esse item somente um leito estava em conformidade com a RDC n. ${ }^{\circ} 42$.

A estrutura física dos leitos em forma de boxes, separados por cortinas, não permite a instalação de dispensadores nas paredes. Nas UTIs, os equipamentos de assistência ventilatória, monitorização, suportes de soro e outros ficam localizados próximo à cabeceira do leito, o que não permite que os dispensadores sejam instalados nas paredes junto às mesmas. Para as unidades com esse tipo de estrutura, as outras apresentações de preparações alcoólicas são indicadas, como as apresentações em frascos móveis, que podem ser colocados sob carrinhos, bancadas ou no bolso, ou, ainda, fixados aos pés das camas.

Uma das cinco regras de ouro da higiene das mãos é que ela deve ser feita no ponto de assistência. O ponto de assistência é o local onde se encontra o paciente, o profissional, e o cuidado está se realizando. Para tanto, todos os leitos devem dispor de preparações alcoólicas ao alcance das mãos do profissional. (WHO, 2006, 2009). Falhas na estrutura física são barreiras que dificultam a correta realização das práticas de higiene das mãos; embora as condições ideais sejam importantes, nem sempre resultam em maior adesão a elas. (ANVISA, 2009).

Os lembretes no local de trabalho da importância da higiene das mãos, bem como orientações sobre as técnicas e os momentos indicados, são apontados como importantes para 
as estratégias de melhorias. (WHO, 2006, 2009). Na unidade estudada essas sinalizações apresentavam-se insuficientes.

Áreas críticas como as UTIs não devem possuir papéis fixados em paredes ou cartazes, porque não são passíveis de limpeza. Para essas áreas, sugere-se que essas sinalizações sejam feitas com materiais que possibilitem limpeza, por exemplo, as placas em acrílico ou plástico.

O Protocolo e os POPs da CCIRAS que orientam as precauções estavam atualizados e acessíveis para fácil consulta. Esses achados evidenciam a execução do PCIRAS na UTI. E sobre esses documentos, cabe nesse momento destaque quanto à comparação do que é recomendado neles e o que foi encontrado no estudo em relação à higiene das mãos.

Nos supracitados documentos, e também nas recomendações dos CDC, da OMS e da Anvisa, existe a recomendação de que, na assistência aos pacientes submetidos às precauções de contato por microrganismos multirresistentes, a higiene das mãos seja realizada com antissépticos. No entanto, identificou-se que na UTI estudada a higiene simples das mãos com água e sabonete líquido comum foi a prática predominante, e que a grande maioria dos pacientes estava sob precauções de contato por suspeita ou já confirmada colonização ou infecção por microrganismos multirresistentes. Portanto, foram descumpridas as recomendações da CCIRAS, em relação ao uso de antissépticos, na prática de higiene das mãos, nesse contexto.

Em seus estudos, Menegueti et al. (2015) avaliaram indicadores de estrutura e processo do Programa de Controle de Prevenção de Infecção Hospitalar de 13 hospitais do interior paulista, e, dentre as instituições avaliadas, mais de 30\% delas não possuíam recomendações em conformidade para higiene das mãos e isolamento de pacientes com doenças infectocontagiosas; além disso, todos os profissionais enfermeiros entrevistados que atuavam nas comissões não tinham recebido capacitação específica para atuação no serviço, nem possuíam especialização na área. Os autores concluíram que, apesar de muito conhecimento produzido na área, ainda existe grande hiato entre prática e recomendações.

Outro aspecto deveras negativo encontrado na UTI foi o de que não se identificou rotina sistematizada de conferência e reabastecimento dos dispensadores de sabonete líquido, papel-toalha ou preparações alcoólicas, o que resultou em frequente desabastecimento desses produtos nos locais de uso.

Problemas estruturais relacionados à quantidade e qualidade dos lavatórios e produtos para a higiene das mãos são frequentemente citados na literatura nacional. Esses trabalhos avaliam essas condições em todas as áreas de estabelecimentos de saúde e, algumas vezes, 
referem-se à baixa adesão à prática. (BATHKE et al., 2013; DO PRADO, HARTMANN, TEIXEIRA FILHO, 2013; NEVES et al., 2006).

A qualidade da higiene das mãos é comprometida quando existe a presença de adornos como aneis, pulseiras, relógios ou unhas artificiais nas mãos. Não há como realizar higiene correta das mãos quando elas estão com adornos. Na UTI, objeto deste estudo, verificou-se que, na maioria das sessões de observação, existiam profissionais de saúde com algum tipo de adorno nas mãos. Os mais comumente encontrados foram alianças e anéis entre os profissionais de todas as categorias.

No presente estudo, durante a avaliação da adesão à higiene das mãos, higiene esta foi considerada realizada, quando o profissional de saúde efetuou a técnica completa. Porém, a presença de adorno nas mãos dos profissionais comprometeu a qualidade de todas as ações de higiene das mãos realizadas por eles.

Também se identificou outro aspecto negativo, embora em baixa frequência e por curto período: a falta de EPI para as atividades assistenciais. Tal situação gerou grande stress, com muitas reclamações da equipe de saúde. Reclamações justas, por não ter o EPI disponível para a execução de procedimentos que envolvem risco de contato com secreções e excreções orgânicas de pacientes, alguns deles, sabidamente portadores de infecções. Tal situação também aumenta o risco de transmissão cruzada desses microrganismos entre os pacientes, o que compromete a qualidade e a segurança do cuidado.

Quanto aos recursos humanos, a principal inadequação identificada foi a falta de médico diarista/rotineiro. A carência de recursos humanos em quantidade e qualificação adequadas é apontada como um dos principais limitadores da adesão às boas práticas e protocolos de cuidados específicos.

Entre as demais categorias profissionais não ocorreu défice de profissional, tomandose como referências a RDC n. 7 e RDC n. ${ }^{\circ} 26$. Identificou-se que os enfermeiros e técnicos de enfermagem estavam em número maior do que o mínimo necessário e a distribuição dos profissionais entre os turnos e dias de trabalho não foi proporcional ao número de leitos ocupados, o que levou ao défice de fisioterapeutas em uma sessão de observação.

A redistribuição dos profissionais nas escalas de trabalho deve ser realizada priorizando-se a necessidade do serviço. Essa medida evita sobrecarga de trabalho aos profissionais que estiverem nos turnos com maior número de pacientes internados, devido ao risco de comprometer a adesão às precauções. 


\subsection{ADESÃO À HIGIENE DAS MÃOS}

Segundo a OMS, a adesão à higiene das mãos pelos profissionais de saúde ainda é baixa. Nas UTIs, devido à alta presença das síndromes infecciosas e dos microrganismos multirresistentes e por serem alvo mais constante das ações dos PCIH, identificam-se taxas de adesão um pouco mais elevadas do que em outras áreas hospitalares. (WHO, 2006).

Para conhecer as publicações Latino-Americanas e do Caribe sobre a adesão à higiene das mãos em UTI, realizou-se uma revisão integrativa da literatura em busca de estudos publicados nos últimos dez anos, após a divulgação da Estratégia Multimodal da OMS. Identificaram-se 16 trabalhos, agrupados e categorizados em estudos que avaliaram a mensuração da adesão e a qualidade da técnica, a infraestrutura e a relação entre conhecimento dos profissionais e adesão. A maioria dos estudos avaliou a adesão de forma quantitativa em observações diretas. Na média, as taxas encontradas ficaram abaixo de 50\%, porém com grande variação entre 18,9 e 90,1\%, sendo maior entre os pacientes em precauções de contato. Não foram apresentados resultados em relação à qualidade das técnicas (COSTA, 2015).

A infraestrutura em termos de disponibilidade e qualidade de produtos usados e a sobrecarga de trabalho influenciaram nas taxas de adesão. Aumento significativo das taxas foi evidenciado após a realização de capacitações. Conclui-se que as taxas de adesão à higiene das mãos em UTI ainda são baixas. Por outro lado, poucos estudos apresentaram os resultados da estratégia multimodal da OMS de forma completa, conforme preconizado na metodologia. Além disso, as observações diretas da adesão são complexas, difíceis, dispendem tempo e recursos financeiros altos. (COSTA, 2015).

Na UTI em estudo, a média da adesão à higiene das mãos encontrada foi de $65,31 \%$, há que se ressaltar que a maioria dos pacientes estava em precauções de contato. Essa taxa de adesão é maior que a média geral encontrada em demais áreas hospitalares, e é compatível ou menor do que as taxas encontradas em outros estudos que avaliaram a adesão à higiene das mãos em UTI, ao lidar com pacientes que estavam sob precauções de contato. (ALMAGUERLEVYA et al., 2013; FRANCA et al., 2013).

A taxa de adesão encontrada foi significativamente diferente $(p<0,01)$ entre os profissionais e as indicações (cinco momentos) de higiene das mãos. Entretanto, os dias da semana e o turno de serviço não diferiram significativamente.

Entre todas as categorias profissionais, os médicos apresentaram a maior taxa de adesão, seguidos dos fisioterapeutas e enfermeiros. Os técnicos de enfermagem apresentaram 
a menor taxa de adesão e muito abaixo da média. Esses achados são diferentes da maioria dos outros estudos realizados em UTI que identificaram as menores taxas de adesão entre os médicos. (ALSUBAIE et al.; ALMAGUER-LEVYA et al.; MAHFOUZ, EL GAMAL, ALAZRAQI; ROSENTHAL et al.; SALAMA et al., 2013; GUANCHE-GARCELL et al., 2011).

No Brasil, Bathke et al. (2013), avaliando a taxa de adesão à higiene das mãos em UTI no Paraná, encontraram adesão geral de 26,5\%, o que é uma taxa extremamente baixa. Também identificaram maior taxa de adesão entre os médicos e entre equipes de auxiliares de enfermagem e menor taxa de adesão entre os fisioterapeutas. Já outro estudo mais recente, também realizado em UTI da Região Sul, feito por Souza et al. (2015), encontrou taxa de adesão à higiene das mãos muito baixa, com média de 43,7\%, mas com a maior adesão entre os fisioterapeutas e menor entre os técnicos de enfermagem.

Neste estudo analisou-se separadamente a adesão das categorias profissionais por turno de trabalho. Identificou-se significância na correlação nos turnos da tarde e noite, devido à muito baixa adesão dos técnicos de enfermagem. Já na análise dos turnos de trabalho individualmente, por categoria profissional, identificou-se significância também, com $p<0,05$ entre os enfermeiros do turno da tarde que apresentaram taxa de adesão à higiene das mãos bem menor que os enfermeiros dos demais turnos. Alsubaie et al. (2013) e Souza et al. (2015) encontraram maior adesão entre os profissionais no turno da tarde.

Quanto ao tipo de higiene das mãos realizada pelos profissionais na UTI do hospital de ensino, esta foi predominantemente feita com água e sabonete. Esse achado é igual aos encontrados em outras UTIs, no Brasil, por Bathke et al. (2013) e Souza et al. (2015).

A higiene simples das mãos com água e sabonete ou higiene antisséptica das mãos com água e antisséptico degermante eram os tipos de higiene das mãos que predominavam na prática assistencial até o ano de 2002, quando começaram a aparecer as publicações sobre a superioridade das preparações alcoólicas para a higiene das mãos. Posteriormente, em 2005, com o lançamento da Estratégia Multimodal da OMS que prioriza a higiene das mãos na assistência à saúde com as preparações alcoólicas, foi que o uso desses produtos começou a ser incorporado nos serviços de saúde. Somente no ano de 2010, com a RDC n. ${ }^{\circ} 42$, tornou-se obrigatório o uso das preparações alcoólicas para a higiene das mãos nos serviços de saúde. Essa pode ser uma das razões da preferência dos profissionais de saúde para usarem a técnica da higiene simples das mãos, por terem maior experiência com ela e estarem mais acostumados a usar a água e sabonete.

Um segundo motivo apontado para a preferência dos profissionais para a higiene das mãos com água e sabonete é o tipo de luvas de procedimentos que era usado no serviço de 
saúde em estudo. As luvas de procedimento usadas eram de látex e possuíam talco, em pequena quantidade. A presença de talco nas mãos após a remoção das luvas não possibilita o uso da preparação alcoólica e faz com que o profissional precise usar a água para higienizar as mãos. No entanto, os antissépticos deveriam estar disponíveis em todas as pias porque a unidade possuía a maioria dos pacientes em precauções de contato.

Outro motivo para a baixa adesão ao uso das preparações alcoólicas é a pouca disponibilidade desses produtos na unidade. Além de estarem disponíveis em dispensadores fixos de parede, em geral fora do ponto de assistência, também estavam localizadas próximas às pias e muitas vezes com os dispensadores desabastecidos.

Esse estudo não avaliou a tolerância ou a aceitação dos produtos usados para higiene das mãos na UTI. No entanto, foram identificadas queixas da equipe de enfermagem sobre o ressecamento da pele das mãos, atribuído ao sabonete líquido em uso. Esse desconforto também pode ser resultado do uso mais constante da técnica da higiene simples das mãos pela equipe.

O consumo mensal de sabonete líquido e de preparações alcoólicas para higiene das mãos nas áreas de internação do hospital é monitorado pela CCIRAS. Nos registros constam que a UTI, durante o período de estudo, consumiu média de $76 \mathrm{ml} /$ paciente dia de sabonete líquido e 19,09 ml/paciente dia de preparações alcoólicas.

A OMS preconiza que o consumo mínimo de preparações alcoólicas para a higiene das mãos deve ser de $20 \mathrm{ml} /$ paciente-dia. No Estado de São Paulo, o Centro de Vigilância Epidemiológica implantou o Projeto "Mãos limpas são mãos mais seguras", referente ao período de julho de 2013 a agosto de 2014. Esse projeto forneceu capacitação para profissionais de hospitais públicos e privados aplicarem as metodologias de melhorias, monitoramento e avaliação da adesão à higiene das mãos. Segundo relatório, conseguiram bons resultados referentes a vários pontos do sistema, inclusive no que se refere ao aumento do consumo de preparações alcoólicas em enfermarias e UTIs. Nas UTIs a mediana do consumo ficou em 27,67 ml/paciente dia após as capacitações. (SÃO PAULO, 2014).

A avaliação da adesão à higiene das mãos por observação da prática permite identificar os momentos em que esta ocorreu e os momentos em que não aconteceu. Essa avaliação é de muita importância para identificar os pontos falhos na execução das técnicas e para traçar as estratégias de abordagens nas capacitações.

São indicados cinco momentos para a higiene das mãos. Os dois primeiros são os momentos do "antes" e estão diretamente ligados à proteção do paciente. Na UTI estudada, esses dois momentos tiveram as menores taxas de adesão encontradas e com significância 
estatística quando comparados aos demais três momentos, que são os do "após", diretamente ligados à proteção dos profissionais ou a contaminação do ambiente. Isso sugere que os profissionais têm maior comprometimento com a sua própria proteção.

Esses achados vão ao encontro de resultados de vários outros estudos de adesão à higiene das mãos em UTI, que também identificaram maior adesão aos momentos após a realização de procedimentos que se relacionam à proteção dos profissionais. (ALSUBAIE et al.; BATHKE et al.; MAHFOUZ, EL GAMAL, AL-AZRAQI, 2013; SOUZA et al., 2015; WHO, 2006).

Ressalta-se que, na UTI, a adesão ao segundo momento, antes da realização de procedimentos assépticos, evidenciou-se extremamente abaixo da média. Na maioria das vezes, essa indicação surge durante o cuidado ao paciente e quando não se tem o produto alcoólico ao alcance das mãos para realizar-lhes a higiene. Sendo assim, a adesão a esse momento é extremamente prejudicada.

Outro fato que pode ter diminuído a adesão à higiene das mãos imediatamente antes da realização de procedimentos assépticos pode ser atribuído ao uso contínuo de luvas de procedimentos pelos profissionais, devido às precauções de contato a que os pacientes estavam submetidos. Para realizar a higiene das mãos, nesses casos, os profissionais teriam que remover as luvas, sair do local onde estavam, realizar a higiene, retornar para o ponto de assistência, calçar outro par de luvas e dar continuidade ao procedimento, já que não possuíam as preparações alcoólicas no ponto de assistência e também usavam luvas com talco.

\subsection{ADEQUAÇÃO DAS INDICAÇÕES DE PRECAUÇÕES}

Devido à alta prevalência de microrganismos multirresistentes entre os pacientes hospitalizados nos diferentes serviços de saúde, alguns grupos específicos de pacientes que possuem maior risco de colonização ou infecção por esses microrganismos, ao serem admitidos em hospitais, são submetidos às precauções de contato na admissão e coletadas amostras para pesquisa de microrganismo. Essa prática é usada pela CCIRAS do hospital, que orienta para a UTI. Na admissão, os novos pacientes com determinadas características - tais como os provenientes de outros serviços com permanência maior que $48 \mathrm{~h}$, provenientes de atenção domiciliar, readmitidos ou pacientes com histórico de colonização ou infecção por microrganismos multirresistentes - devem ser submetidos às precauções de contato. Concomitantemente, são coletadas amostras microbiológicas para análise e pesquisa de 
colonização por alguns agentes específicos de interesse. O POP institucional que orienta as condutas admissionais é extenso e contém detalhamento de informações em forma de texto. (HUB, 2013a).

Durante o período do estudo, foi frequente a colocação de pacientes em precauções de contato sem que eles se enquadrassem nos critérios de indicações estabelecidos pela CCIRAS no documento supracitado. Diante disso, pode-se depreender que a equipe apresenta dificuldades em aplicar os critérios estabelecidos, desconhece ou recusa-se a segui-los. Além de treinamentos em serviço e constante supervisão, um fluxograma para tomada de decisão sobre instituir ou não precauções de contato na admissão e coleta de amostras para pesquisa de colonizados ou um checklist com tais informações facilita a rápida tomada de decisão pela equipe. Essas medidas podem diminuir a aplicação equivocada dos critérios, contribuindo também para evitar o consumo exagerado de avental, luvas e tempo dos profissionais.

\subsection{ADESÃO AO USO DE EPI}

Quanto ao uso dos EPIs quando indicado, na análise de 445 procedimentos evidenciou-se que os profissionais usaram luvas e avental em mais de $91 \%$ das vezes em que estes estavam indicados; no entanto, os óculos foi o EPI mais negligenciado. Os óculos foram usados somente em $24,56 \%$ das vezes, quando estavam indicados, principalmente nos procedimentos de instalação de cateter venoso central e aspiração endotraqueal. A média da taxa de acerto no uso do EPI individualmente foi de $72,72 \%$.

O uso desnecessário de EPI também pode ser avaliado; proporcionalmente, as luvas foram o EPI com menor taxa de acerto quanto à não utilização quando não indicadas. Cabe destacar que ocorreram somente 13 procedimentos em que estas não estavam indicadas e, por terem sido usadas em apenas quatro vezes, a taxa de acerto ao não uso desse EPI foi a menor. Esse fato pode ser justificado pelo contexto local, em que a maioria dos pacientes estava submetida às precauções de contato e os profissionais usavam luvas na maioria dos procedimentos.

Em números absolutos, as máscaras foram o EPI mais usado desnecessariamente, totalizando 123 usos desnecessários, em 290. Ressalta-se que, para a avaliação neste trabalho, usou-se como parâmetro para indicação ou não de máscara e outros EPIs, as precauções padrão e as precauções específicas, nas quais as máscaras são indicadas dependendo do risco que o procedimento oferece de respingar secreções e líquidos orgânicos nas mucosas oral e nasal do profissional, ou quando o paciente está em precaução respiratória. (SIEGEL et al., 
2007). A CCIRAS da instituição em estudo também usa a mesma literatura de referência em seus documentos de recomendações. (HUB 2014b, 2014c).

A literatura específica sobre procedimentos de enfermagem, que muitas vezes relaciona os EPIs necessários para cada procedimento, também foi usada para consulta e definição das indicações. Tal literatura é diversificada, nela encontram-se diferentes recomendações, e, para este estudo, foram usadas as publicações de De Jesus et al. (2014), porque são autoras da Universidade de Brasília à qual o hospital em estudo pertence, e os clássicos da literatura de enfermagem Brunner e Suddarth (2006) e Potter e Perry (2008).

Ao se analisar conjuntamente o percentual de uso correto dos quatro EPIs, conforme a precaução a que o paciente estava submetido e o tipo de procedimento que estava sendo realizado no paciente, a média geral de acertos foi muito baixa, somente 46,97\%. Ressalta-se que a máscara e os óculos foram os EPIs que mais contribuíram para isso. A máscara, devido a ter sido usada desnecessariamente em variados procedimentos, e os óculos, por não terem sido usados em procedimentos como a aspiração traqueal.

Avaliou-se a taxa de acerto de uso de EPI entre os profissionais por turno de trabalho e identificou-se significância estatística $(p<0,01)$ entre os profissionais do noturno. Na análise da taxa de acerto por turno entre os profissionais, também se identificou significância estatística $(p<0,05)$ entre os fisioterapeutas. Ressalta-se que os fisioterapeutas do noturno apresentaram $100 \%$ de taxa de erro no uso de EPI, também devido ao não uso dos óculos.

A adesão ao uso dos EPIs nas precauções padrão e nas precauções especiais, principalmente nas precauções de contato, também é extremamente variável. Diferenças na adesão têm sido relatadas nas unidades de saúde entre grupos de profissionais experientes e inexperientes, entre enfermeiros e médicos. O tempo de experiência pode contribuir negativamente para a aderência. Em pesquisas com profissionais de saúde, com questionários de autoavaliação, a adesão foi geralmente mais elevada do que a relatada em estudos observacionais. (SIEGEL et al., 2007).

Em estudo anteriormente realizado pela pesquisadora para avaliar a adesão às práticas de precaução padrão em UTI, identificou-se que a adesão à higiene das mãos antes e após os procedimentos variou de 0 a $100 \%$ entre os médicos, de 40 a $100 \%$ entre os enfermeiros, de $67 \%$ a $100 \%$ entre os fisioterapeutas e de $50 \%$ a $100 \%$ entre os técnicos/auxiliares de enfermagem. A utilização de avental e luvas variou entre $71 \%$ e $100 \%$ entre todas as categorias profissionais, mas o uso desnecessário foi alto entre os médicos e os fisioterapeutas. A máscara foi usada quando indicada; no entanto, este também foi o EPI mais usado desnecessariamente, com variação de $46 \%$ a $67 \%$ entre todas as categorias 
profissionais. Os óculos só foram usados uma única vez em um procedimento em que era desnecessário. Todos os recursos materiais estavam disponíveis para a execução das práticas no momento das auditorias. (DE CASTRO, 2010).

A baixa adesão ao uso de óculos e máscara em situação de risco também foi encontrada em estudo que avaliou as precauções padrão em 30 hospitais de 19 cidades na Turquia. (HOSOGLU et al., 2011).

Em trabalhos desenvolvidos em países de baixa renda sobre as práticas de precauções padrão na assistência, evidencia-se a oferta restrita de EPI para essas práticas e, em geral, a maior adesão ao uso pelos profissionais de saúde ocorre em atendimento aos pacientes sabidamente portadores de HIV ou Hepatite. (NDERITU, MILL, RICHTER, 2015; NUGMANOVA et al., 2015).

Em outro trabalho brasileiro, de Lopes et al. (2008), os pesquisadores avaliaram a adesão às precauções padrão entre os profissionais do Serviço de Atendimento Pré-hospitalar de Belo Horizonte utilizando questionários autoaplicáveis, e concluíram que os médicos apresentaram maior grau de conhecimento, se comparado às demais categorias profissionais envolvidas. No relato das suas próprias atitudes, os profissionais não alcançaram adequação para o uso de máscara facial, óculos e EPI, e os condutores das ambulâncias relataram atitude inadequada.

Estudos avaliando a adesão à higiene das mãos e uso de EPI mostraram que a irritação da pele ou a dor nas mãos, a partir do uso de luvas, também são fatores que influenciam negativamente a adesão às práticas de precaução. (KIM et al. 1999; OLIVEIRA, CARDOSO, MASCARENHAS, 2010)

O impacto de medidas de intervenção no controle do Enterococcus spp. resistente a vancomicina em UTI foi avaliado em um estudo. Os resultados demonstraram que a adesão à higiene das mãos antes do contato com o paciente no período pré-intervenção educacional foi de 39\%, e no período pós-intervenção foi de 32\%. Já a adesão à higiene das mãos após o contato com o paciente no período pré-intervenção educacional foi de 59\%, e no período pósintervenção foi de $62,5 \%$. A adesão ao uso de luvas, que era $61 \%$ no período pré-intervenção, caiu para $41 \%$, e o uso de avental no período pré-intervenção foi de $43 \%$ e $53 \%$ no pósintervenção. (PERUGINI, 2008).

Pesquisa com abordagem qualitativa realizada no Chipre (EFSTATHIOU et al., 2011a, 2011b), com grupos focais de profissionais de enfermagem para identificar os fatores que influenciam os mesmos ao cumprimento às precauções padrão, evidenciaram aspectos que dificultam e contribuem para a adesão do pessoal. Os fatores apontados pelos 
participantes como dificultadores da adesão foram: as situações de emergência; a não disponibilidade de EPIs; o armazenamento de EPIs em locais distantes do ponto de assistência; EPIs fornecidos em tamanhos diferentes do usado pelo profissional; a inabilidade para realizar procedimentos com luvas devido à perda do tato; o impacto negativo do EPI na aparência das mulheres; irritação das mãos causada pelas luvas; o temor de que o uso de EPI possa causar algum tipo de impacto negativo ao paciente ou seus familiares, os quais podem sentir-se agredidos; excesso de trabalho e falta de tempo para vestir o EPI; prestação de cuidados às crianças, porque essas são inocentes e seriam incapazes de transmitir doenças; profissionais mais experientes, chefes, médicos ou professores que não realizam adequadamente as precauções e podem influenciar os demais profissionais; a crença de que é um indivíduo saudável e forte não o predispõe à aquisição de infecções; a maior experiência e habilidade profissional; e dificuldade de mudança de hábitos.

Os fatores contribuintes foram: a suscetibilidade e vulnerabilidade às doenças; o temor e ansiedade em não comprometer a vida pessoal por ter adquirido infecção e de transmitir para os familiares; o cuidado à pacientes adultos; exposição ocupacional anterior; cartazes e lembretes no local de trabalho alertando sobre as práticas; a educação continuada de profissionais; a aparência de debilidade do paciente; o uso de tatuagens; baixa higiene pessoal e ser estrangeiro são características do paciente que são levantadas como sendo possíveis fatores de risco para doenças infecciosas e que alertam para a necessidade do uso de EPI; e a exigência do cumprimento das precauções por parte dos chefes. (EFSTATHIOU et al., 2011a, 2011b).

A indisponibilidade ou o armazenamento em local distante dos EPIs foram relatados em outros estudos como fatores que dificultam a adesão às precauções. (BATHKE et al., 2013; HENRY et al., 1994; NAING, NORDIN, MUSA, 2001;).

Em publicações internacionais têm sido frequentes a presença de estudos que comparam desfechos entre aumento ou não de colonização ou infecções por microrganismos multirresistentes. Pode-se citar o ensaio randomizado de Harris et al. (2014), que comparou, em 20 UTIs médico-cirúrgicas de hospitais nos EUA, o uso universal de luvas e avental com o uso de cuidados comuns de precauções quanto ao desfecho de aquisição de MRSA e Enterococcus resistente à vancomicina (VRE). O estudo não encontrou diferenças significativas entre os dois grupos, mas os autores sugerem mais estudos para decisões definitivas.

Bearman et al. (2007) desenvolveram estudo controlado em UTI clínica para comparar o uso universal de luvas em substituição às precauções de contato das diretrizes do CDC para 
pacientes com microrganismos multirresistentes. O cumprimento do enluvamento universal foi maior que o das precauções de contato e foi apontada como a prática de maior preferência da equipe assistencial. No entanto, ocorreu aumento considerável das taxas de infecções relacionadas à assistência à saúde no período do enluvamento universal. Observou-se menor adesão à higiene das mãos, não teve diferença significativa na incidência de MRSA e VRE nos dois períodos e a maioria das conversões de MRSA e VRE foi clonal.

Um ensaio clínico randomizado, conduzido nos EUA por Dohar et al. (2014), traz questões importantes para serem avaliadas nas políticas das CCIRAS de indicações de precauções de contato em serviços de saúde. O trabalho identificou queda acentuada no cumprimento das práticas de precauções como higiene das mãos e uso correto dos EPIs; à medida que aumenta o percentual de pacientes sob precauções de contato na unidade. Com $40 \%$ dos pacientes em precauções de contato, identificaram-se quedas acentuadas na adesão às precauções.

Em outro ensaio clínico randomizado, Huskins et al. (2011) avaliaram o efeito da vigilância para MRSA e VRE associada às precauções de barreiras aos pacientes colonizados, em comparação ao grupo controle onde foi usada a prática já existente nas UTIs, que era a das luvas de forma universal. Não foi encontrada diferença significativa entre os dois grupos, o que sugere que a intervenção não obteve sucesso na redução de MRSA e VRE. Porém, os autores apontaram várias questões que podem ter contribuído para esse desfecho, como a demora no resultado de exames e a baixa adesão dos profissionais às práticas de precauções recomendadas, como higiene das mãos, uso de avental e luvas.

Um tipo diferenciado de luvas com emoliente foi usado também por Bearman et al. (2014) em substituição às precauções especiais para pacientes com microrganismos multirresistentes. O estudo comparou a eficácia do enluvamento universal com luvas impregnadas de emolientes na incidência de infecções e microrganismos multirresistentes e no efeito sobre a pele dos profissionais de saúde, comparados ao período anterior na mesma UTI cirúrgica em que os pacientes eram submetidos às precauções especiais, conforme determinam os CDCs. Os resultados não diferiram significativamente entre os dois períodos quanto à aquisição de microrganismos multirresistentes ou infecções. Comparado com precauções de contato, enluvamento universal com luvas impregnadas de emolientes foi associado com melhor conformidade com a higiene das mãos e saúde da pele. Os autores concluíram que o enluvamento universal pode ser uma alternativa às precauções de contato.

Em um estudo quase experimental, do tipo série temporal interrompida, Marshal, Richards e McBryde (2013) encontraram redução de 60\% na aquisição de MRSA em UTI 
com o uso de método de vigilância de rápida detecção do agente em swabs de nariz, garganta, virilha e axila de pacientes, adicionadas às precauções de contato com quarto privativo para os positivos quando comparado ao período anterior em que os pacientes não eram submetidos à vigilância para MRSA e nem às precauções de contato.

No Brasil, Dalben et al. (2013) avaliaram a pressão de colonização como um fator de risco para a colonização por Pseudomonas aeruginosa resistente a carbapenem e Acinetobacter spp multirresistente em UTI. Duas intervenções foram implementadas: a educação e a introdução de fricção com álcool. A conformidade com a higiene das mãos, pressão de colonização, a colonização na admissão e fatores de risco para a colonização foram avaliados. Ocorreu aumento da pressão de colonização devido ao aumento de pacientes já colonizados na admissão. Os autores concluíram que, quando essa pressão atinge níveis críticos, os esforços destinados principalmente à higiene das mãos podem não ser suficientes para evitar a transmissão.

Em estudo randomizado de série temporal interrompida, Derde et al. (2014) avaliaram intervenções de melhoria da higiene das mãos, banho dos pacientes com clorexidina e vigilância com pesquisa rápida ou convencional para reduzir a colonização e transmissão de bactérias resistentes a antimicrobianos (MRSA, VRE e Enterobactérias resistentes) em UTI. Os resultados foram que o maior rigor na higiene das mãos e o banho com clorexidina reduziu aquisição de MRSA. Os autores concluíram, que no contexto de um nível elevado de cumprimento sustentado, a higiene das mãos e banhos com clorexidina, triagem e isolamento de portadores não reduziram as taxas de aquisição do VRE e Enterobactérias resistentes, com ou sem triagem feita com o teste rápido ou teste convencional.

\subsection{RECOMENDAÇÕES AO LOCAL DO ESTUDO}

Apesar de todas as discussões existentes na literatura, atualmente, sobre a eficácia das precauções de contato para prevenção de transmissão de microrganismo multirresistente, vários estudos apresentam resultados de sucesso na redução da transmissão de patógenos com o aumento da adesão às práticas de precauções recomendadas.

Não existem mais dúvidas de que a correta higiene das mãos e o uso de luvas e avental possa fornecer barreiras e evitar a transmissão por contato do agente infeccioso do paciente para o profissional e do profissional para o paciente. Dessa forma, a completa adesão a essas práticas pelos profissionais de saúde deve ser foco de atuação dos programas de prevenção de IRAS. Outras medidas, também muito importantes e imprescindíveis, são as seguintes: uso 
racional de antimicrobianos, a limpeza e desinfecção de superfícies, artigos e equipamentos, metodologias de vigilância epidemiológica com identificação precoce de pacientes colonizados. Sistemas interligados para rápida comunicação de resultados entre laboratórios, controladores de IRAS e equipes assistenciais também devem fazer parte desse complexo sistema de cuidados para controlar e reduzir o risco da transmissão cruzada desses microrganismos.

Investimento e recursos devem ser disponibilizados para a adequação de estrutura física, aquisição de produtos de consumo e EPI em qualidade e quantidade suficientes, com rotinas de reabastecimento.

A quantidade de recursos humanos deve ser suficiente para o atendimento direto e indireto ao paciente e não se priorizar só o cumprimento às normas estabelecidas pela regulamentação nacional, mas também a necessidade de maior qualificação e educação permanente desses profissionais, bem como a satisfação no trabalho.

Na UTI estudada, a estrutura física apresentou importantes limitações relacionadas ao tipo de pias e torneiras usadas. A disponibilidade de preparações alcoólicas no ponto de assistência e antissépticos degermantes para higiene das mãos e o reabastecimento de dispensadores eram limitados e necessitavam de adequações importantes. O fornecimento de EPIs era irregular e o tipo de luvas não favorecia a adesão ao uso de preparações alcoólicas para fricção antisséptica das mãos. O número de médicos era insuficiente e os demais profissionais estavam distribuídos inadequadamente entre os plantões. Pacientes eram submetidos às precauções de contato desnecessariamente, o que aumenta o consumo de EPIs, tempo e demais recursos. A adesão à higiene das mãos era baixa, especialmente nos momentos referentes à proteção do paciente, e menor entre os técnicos de enfermagem dos períodos vespertino e noturno. A higiene das mãos, quando realizada, era majoritariamente com a técnica da higiene simples com água e sabonete. Ocorreu uso desnecessário de máscara cirúrgica e a não utilização de óculos de proteção em procedimentos específicos. Entre fisioterapeutas do período noturno houve total não conformidade quanto ao uso de óculos de proteção.

Este estudo não teve como objetivo avaliar os serviços de higiene e limpeza da UTI. No entanto, como é assunto que se relaciona diretamente com as precauções, fazem-se necessários comentários sobre questões importantes que foram observadas durante o período do estudo. O serviço de higiene e limpeza da UTI não possuía qualquer rotina de registro, checagem ou conferência dos procedimentos de limpeza concorrente ou terminal. Como 
agravante, não foram identificados documentos ou POPs de orientações com as técnicas de higiene e limpeza na unidade.

A padronização e sistematização minuciosas das técnicas de limpeza e desinfeção de superfícies são de extrema importância para que esses locais sejam mantidos com a menor carga microbiana possível e reduzir o risco de transmissão cruzada dos microrganismos multirresistentes. A sistematização e validação dos processos de limpeza e desinfecção terminal e concorrente de leitos são recomendadas, e o uso de checklist para registro do processo e conferência de que todos os itens foram adequadamente limpos e desinfetados são importantes ferramentas que devem fazer parte da rotina de trabalho dos serviços de higiene e limpeza hospitalares.

Com a finalização deste trabalho, foi possível conhecer os indicadores de estrutura e processos referentes às práticas de precauções na UTI do hospital de ensino do Distrito Federal, e definir metodologia de coleta de dados que possibilite o monitoramento contínuo desses indicadores na instituição. Assim, os gestores locais, de posse desses resultados e, conjuntamente, dos indicadores de resultados, poderão planejar ações que resultem em melhorias no que se refere à prevenção de IRAS e segurança do paciente. O estudo também produziu um instrumento que pode servir para outros serviços de saúde nas auditorias de práticas de precauções e uso de EPI.

A partir dos conhecimentos resultantes da presente pesquisa, reúnem-se, a seguir, recomendações para a melhoria do processo, no que tange à prática de precauções na unidade estudada:

- Instalar torneiras que dispensem o contato das mãos para abertura e fechamento nas duas cubas do posto de enfermagem;

- Disponibilizar antissépticos degermantes para higiene das mãos em todas as pias e cubas;

- Instalar dispensadores de preparações alcoólicas nas paredes ou pilastras ao lado dos leitos, quando essas existirem;

- Adquirir preparações alcoólicas em dispensadores móveis para todos os leitos;

- Instituir e supervisionar rotina de conferência e reabastecimento dos dispensadores de produtos para higiene das mãos;

- Substituir as luvas de procedimento de látex com talco por luvas de procedimento sem talco; 
- Manter o fornecimento regular de todos os EPIs. Os gestores locais devem reavaliar seu sistema de previsão e provisão desses produtos;

- Manter a mensuração do consumo de preparações alcoólicas, avaliar periodicamente em auditorias a adesão à higiene das mãos e uso de EPIs e dar feedback à equipe em painel de informações;

- Definir, em conjunto com a equipe assistencial, as metas de consumo e de adesão a serem alcançadas;

- Criar um fluxograma e um checklist para rotina admissional de precauções de contato. Manter o fluxograma visual em painel de informações e melhorar a supervisão dessa rotina;

- Melhorar e agilizar a comunicação de resultados de culturas entre laboratório, controladores de IRAS e equipes assistenciais;

- Adequar o quantitativo de profissionais médicos no quadro de pessoal da unidade, para que seja instituída a rotina do médico diarista nos períodos matutino e vespertino;

- Promover treinamentos e capacitações em serviço sobre precauções de forma contínua e sistemática e incluir a discussão nas visitas da CCIRAS na UTI para vigilância das IRAS;

- Realizar periodicamente campanhas de incentivo às boas práticas em precauções;

- Validar as rotinas de limpeza e desinfecção de leitos e equipamentos;

- Instituir checklist de limpeza e desinfecção terminal e concorrente de leitos; e

- Apresentar resultados à equipe, incluindo esclarecimento sobre os bons e maus resultados e, principalmente, valorizar melhorias com premiações dos alcances das metas.

As recomendações supracitadas foram reunidas em itens resultantes das informações levantadas no estudo; no entanto, um plano de ação deve ser elaborado em conjunto com profissionais da própria unidade, porque eles conhecem a realidade local, podem identificar ações necessárias e são as pessoas chave para o alcance das metas estabelecidas. 


\section{CONCLUSÃO}

Aumentar a adesão às práticas de higiene das mãos e o uso correto dos EPIs nos serviços de saúde têm sido o foco de atuação dos profissionais da área de prevenção e controle das IRAS, devido ao grande impacto dessas ações na redução da incidência e/ou prevenção e controle dos surtos destes eventos adversos que ameaçam a segurança do paciente.

O estudo que avaliou a infraestrutura e as práticas de precauções da UTI de um hospital de ensino do DF permitiu chegar a conclusões particulares ao local no que se refere à limitada infraestrutura para execução das práticas e à adesão às precauções pelos profissionais. Também produziu um instrumento que pode ser usado, como ferramenta auxiliar, em auditorias observacionais de uso de EPIs.

Os profissionais que atuavam na assistência direta aos pacientes na unidade estudada eram em sua maioria do gênero feminino, com tempo de atuação na profissão entre seis e 10 anos, com apenas um vínculo empregatício e estavam na faixa etária de 30 a 40 anos. Os técnicos de enfermagem representaram $55,77 \%$ da equipe multiprofissional, os enfermeiros $36,53 \%$, os médicos $32,69 \%$ e os fisioterapeutas $15,38 \%$. A grande maioria deles afirmou ter recebido capacitação na formação profissional e recente treinamento em serviço sobre higiene das mãos, uso de EPIs e precauções. Quanto ao quantitativo de recursos humanos para atendimento, foi identificada falta de médico diarista. Entre as demais categorias, o número de profissionais atendeu às exigências da regulamentação sanitária nacional, porém, com inadequações na distribuição do número de pessoas escaladas pelo número de pacientes internados.

A estrutura física e os produtos disponíveis para a execução das práticas de precauções não eram adequados ou suficientes no que se refere ao tipo de torneira usada em alguns lavatórios, a indisponibilidade de preparações alcoólicas no ponto de assistência e de antissépticos degermantes nos lavatórios. $\mathrm{O}$ reabastecimento dos dispensadores de produtos para higiene das mãos era falho e o fornecimento de EPIs apresentou irregularidade pontual.

A média da adesão à higiene das mãos foi de $65,31 \%$ e, majoritariamente, realizada com técnica da higiene simples das mãos. Existiu diferença estatisticamente significativa de adesão entre as categorias profissionais: houve maior taxa de adesão entre os médicos (77,94\%), seguido dos fisioterapeutas $(77,94 \%)$, enfermeiros $(72,11 \%)$, e a menor taxa foi observada entre os técnicos de enfermagem $(53,10 \%)$. Embora tenha sido evidenciada a 
significância estatística na taxa de adesão dos técnicos de enfermagem nos períodos da tarde e noite, não houve diferença significativa entre os dias da semana. Os momentos de antes do contato com o paciente e antes da realização de procedimentos assépticos apresentaram menor adesão significativa.

A avaliação de indicações das precauções identificou que a maioria dos pacientes foi submetida às precauções adicionais de contato ao serem admitidos na UTI, e 35\% dessas indicações foram desnecessárias. Quanto à utilização de EPI para procedimentos assistenciais, analisada individualmente, mostrou alta adesão ao uso de luvas, avental e máscara, e muito baixa adesão ao uso de óculos de proteção. A não utilização de EPI quando não indicado mostrou menor taxa de acerto, quando se tratava de luvas; porém, em números absolutos, a máscara foi o EPI mais usado desnecessariamente. A média da taxa de acerto do uso de EPI quando indicado foi de $72,72 \%$ e do não uso quando não indicado foi $68,01 \%$, ambas com diferença significativa entre os EPIs. Dentre as categorias profissionais, evidenciou-se diferença estatisticamente significativa entre os fisioterapeutas, no período noturno, devido ao não uso dos óculos nos procedimentos de aspiração traqueal.

Conclui-se que a UTI do hospital de ensino do DF, para otimizar as práticas de precauções, necessita de adequações na estrutura física, melhora no fornecimento de recursos materiais, aumento dos recursos humanos na área médica e otimização da gestão nas demais áreas, além de organização dos processos e fluxos de trabalho assistenciais e de serviços de apoio, tais com laboratório, controle de IRAS e higiene e limpeza hospitalar.

O efeito Hawthorne, que é a mudança de atitude do sujeito por saber que está sendo observado, pode ter interferido nos resultados e pode ser citado como a principal limitação deste estudo, apesar de todo o cuidado que foi dispensado para diminuir o impacto desse efeito. O reduzido número de procedimentos observados quando estratificado por tipo de procedimento, também não permite generalizações dessas informações para outras instituições.

Finalizando, sugere-se que programas contínuos de melhorias de adesão às práticas de precauções sejam mantidos em serviços de saúde. O monitoramento da adesão à higiene das mãos e uso de EPIs, bem como os respectivos indicadores de estrutura e processo, são fundamentais. Isoladamente, um indicador de consumo de produtos não é suficiente para avaliar as práticas de precauções. As auditorias por observação direta são limitadas devido ao efeito Hawthorne; no entanto, fornecem um retrato do comportamento e da qualidade das práticas. Entretanto, sua execução requer profissionais treinados e métodos padronizados. Uma alternativa substitutiva aos observadores humanos pode ser a instalação de 
monitoramento por câmera de vídeo, mas que também implicará em necessidade de profissional para assistir às filmagens e avaliar a adesão. 


\section{REFERÊNCIAS}

AGÊNCIA NACIONAL DE VIGILÂNCIA SANITÁRIA (BR). Boletim Informativo: segurança do paciente e qualidade em serviços de saúde $n^{\circ}$ 05, Ano II. Brasília: Agência Nacional de Vigilância Sanitária, 2012a. Disponível em:

<http://www20.anvisa.gov.br/segurancadopaciente/index.php/publicacoes/category/boletinsestatisticos>. Acesso em: 22 fev. 2015.

AGÊNCIA NACIONAL DE VIGILÂNCIA SANITÁRIA (BR). Boletim Informativo: segurança do paciente e qualidade em serviços de saúde $n^{\circ}$ 06, Ano III. Brasília: Agência Nacional de Vigilância Sanitária, 2013a. Disponível em:

<http://portal.anvisa.gov.br/wps/content/Anvisa+Portal/Anvisa/Inicio/Servicos+de+Saude/As sunto+de+Interesse/Boletim+Seguranca+do+Paciente>. Acesso em: 24 mai. 2014.

AGÊNCIA NACIONAL DE VIGILÂNCIA SANITÁRIA (BR). Boletim Informativo: segurança do paciente e qualidade em serviços de saúde n 08 , Ano IV. Brasília: Agência Nacional de Vigilância Sanitária, 2014. Disponível em:

$<$ http://www20.anvisa.gov.br/segurancadopaciente/index.php/publicacoes/category/boletinsestatisticos>. Acesso em: 23 fev. 2015.

AGÊNCIA NACIONAL DE VIGILÂNCIA SANITÁRIA (BR). Boletim Informativo: Segurança do paciente e qualidade em serviços de saúde no ${ }^{\circ 1}$, Ano VI. Brasília: Agência Nacional de Vigilância Sanitária, 2015a. Disponível em:

$<$ http://www20.anvisa.gov.br/segurancadopaciente/index.php/publicacoes/category/boletinsestatisticos>. Acesso em: 26 jan. 2016.

AGÊNCIA NACIONAL DE VIGILÂNCIA SANITÁRIA (BR). Critérios diagnósticos de infecção relacionada à assistência à saúde. Série Segurança do Paciente e Qualidade em Serviços de Saúde. Brasília: Agência Nacional de Vigilância Sanitária, 2013a. 80p.

AGÊNCIA NACIONAL DE VIGILÂNCIA SANITÁRIA (BR). Medidas de prevenção de infecção relacionada à assistência à saúde. Série Segurança do Paciente e Qualidade em Serviços de Saúde. Brasília: Agência Nacional de Vigilância Sanitária, 2013c. 92p.

AGÊNCIA NACIONAL DE VIGILÂNCIA SANITÁRIA (BR). Normas para projetos físicos de estabelecimentos de saúde. Agência Nacional de Vigilância Sanitária. 2. ed. Brasília: ANVISA, 2004. 160p.

AGÊNCIA NACIONAL DE VIGILÂNCIA SANITÁRIA (BR). RDC n 07, de 24 de fevereiro de 2010. Dispõe sobre os requisitos mínimos para funcionamento de Unidade de 
Terapia Intensiva e dá outras providências. Brasília: ANVISA, 2010a. Disponível em: <http://bvsms.saude.gov.br/bvs/saudelegis/anvisa/2010/res0007_24_02_2010.html>. Acesso em: 07 fev. 2015.

AGÊNCIA NACIONAL DE VIGILÂNCIA SANITÁRIA (BR). RDC n 26 , de 11 de maio de 2012. Altera a Resolução RDC $n^{\circ}$. 07, de 24 de fevereiro de 2010, que dispõe sobre os requisitos mínimos para funcionamento de Unidades de Terapia Intensiva e dá outras providências. Brasília: ANVISA, 2012b. Disponível em: <http://bvsms.saude.gov.br/bvs/saudelegis/anvisa/2012/rdc0026_11_05_2012.html>. Acesso em: 13 mai. 2016.

AGÊNCIA NACIONAL DE VIGILÂNCIA SANITÁRIA (BR). RDC n 36, de 25 de julho de 2013. Institui ações para a segurança do paciente em serviços de saúde e dá outras providências. Brasília, ANVISA, 2013. Disponível em: <http://bvsms.saude.gov.br/bvs/saudelegis/anvisa/2013/rdc0036_25_07_2013.html>. Acesso em: 27 mai. 2014.

AGÊNCIA NACIONAL DE VIGILÂNCIA SANITÁRIA (BR). RDC nº 42, de 25 de outubro de 2010. Dispõe sobre a obrigatoriedade de disponibilização de preparação alcoólica para fricção antisséptica das mãos, pelos serviços de saúde do País, e dá outras providências. Brasília: ANVISA, 2010b. Disponível em:

$<$ http://www.anvisa.gov.br/hotsite/segurancadopaciente/documentos/rdcs/RDC\%20N\%C2\%B A\%2042-2010.pdf>. Acesso em: 27 mai. 2014.

AGÊNCIA NACIONAL DE VIGILÂNCIA SANITÁRIA (BR). RDC n ${ }^{\circ} \mathbf{6 3}$, de 25 de novembro de 2011. Dispõe sobre os Requisitos de Boas Práticas de Funcionamento para os Serviços de Saúde. Brasília: ANVISA, 2011. Disponível em: http://www.anvisa.gov.br/hotsite/segurancadopaciente/documentos/rdcs/RDC $\% 20 \mathrm{~N} \% \mathrm{C} 2 \% \mathrm{~B}$ A\%2063-2011.pdf>. Acesso em: 27 mai. 2014.

AGÊNCIA NACIONAL DE VIGILÂNCIA SANITÁRIA (BR). Relatório da resistência microbiana em infecções primárias de corrente sanguínea confirmadas laboratorialmente associadas ao uso de cateter venoso central, em unidades de terapia intensiva (2014). Brasília: Agência Nacional de Vigilância Sanitária, 2015b. Disponível em: <http://www20.anvisa.gov.br/segurancadopaciente/index.php/publicacoes/category/boletinsestatisticos>. Acesso em: 26 jan. 2016.

AGÊNCIA NACIONAL DE VIGILÂNCIA SANITÁRIA (BR). Segurança do paciente em serviços de saúde: higiene das mãos. Brasília: Agência Nacional de Vigilância Sanitária, 2009. 105p. 
AGÊNCIA NACIONAL DE VIGILÂNCIA SANITÁRIA (BR). Segurança do paciente em serviços de saúde: limpeza e desinfecção de superfícies. Brasília: Agência Nacional de Vigilância Sanitária, 2010c. 116p.

ALMAGUER-LEYVA, M. et al. Hand hygiene compliance in patients under contact precautions and in the general hospital population. American Journal of Infection Control, v. 41, n. 11, p. 976-978, 2013. Disponível em: 〈http://dx.doi.org/10.1016/j.ajic.2013.05.003〉. Acesso em: 10 jul. 2015.

ALSUBAIE, S. et al. Determinants of hand hygiene noncompliance in intensive care units. American Journal of Infection Control, v. 41, n. 2, p. 131-135, 2013. Disponível em: <doi:10.1016/j.ajic.2012.02.035>. Acesso em: 19 jan. 2015.

ARANAZ-ANDRE'S, J.M. et al. Prevalence of adverse events in the hospitals of five Latin American countries: results of the 'Iberoamerican study of adverse events' (IBEAS). BMJ Quality and Safety, v. 20, n. 12, p. 1043-1051, jun., 2011. Disponível em: <doi:10.1136/bmjqs.2011.051284>. Acesso em: 15 ago. 2015.

ASSOCIAÇÃO PAULISTA DE ESTUDOS E CONTROLE DE INFECÇÃO HOSPITALAR (BR). Precauções e isolamentos. São Paulo: APECIH; 1999. 51p.

BATHKE, J. et al. Infraestrutura e adesão à higiene das mãos: desafios à segurança do paciente. Revista Gaúcha de Enfermagem, v. 34, n. 2, p. 78-85, 2013. Disponível em: <http://www.scielo.br/scielo.php?script=sci_serial\&pid=1983-1447\&lng=pt\&nrm=iso>. Acesso em: 19 jan. 2015.

BEARMAN, G.M.L. et al. A controlled trial of universal gloving versus contact precautions for preventing the transmission of multidrug-resistant organisms. American Journal of Infection Control Online, v.35, n.10, p. 650-655, dec., 2007. Disponível em: <doi:10.1016/j.ajic.2007.02.011>. Acesso em: 20 jun. 2015.

BEARMAN, G.M.L. et al. Trial of Universal Gloving with Emollient-Impregnated Gloves to Promote Skin Health and Prevent the Transmission of Multidrug-Resistant Organisms in a Surgical Intensive Care Unit. Infection Control and Hospital Epidemiology, v. 31, n. 5, p. 491-497, mai., 2010. Disponível em: < http://www.jstor.org/stable/10.1086/651671>. Acesso em: 24 mar. 2014.

BRASIL. Lei $\mathbf{n}^{\circ}$ 9.431, de 6 de janeiro de 1997. Diário Oficial da União de 07 de janeiro de 1997. Disponível em: <http://www.planalto.gov.br/ccivil_03/Leis/L9431.htm>. Acesso em: 28 mai. 2014. 
BREVIDELLI, M.M.; CIANCIARULLO, T. I. Fatores psicossociais e organizacionais na adesão às precauções-padrão. Revista de Saúde Pública, v. 43, n. 6, p. 907-916, 2009. Disponível em: 〈http://www.scielo.br/pdf/rsp/v43n6/01.pdf>. Acesso em: 14 fev. 2016.

BRUNNER, L. S. \& SUDDARTH, D. S. Tratado de Enfermagem Médico-Cirúrgica. 9. ed. Rio de Janeiro: Guanabara Koogan S.A, 2006.

BUSSAB, W.O.; MORETTIN, P.A. Estatística Básica. 6. ed. São Paulo: Saraiva, 2010.

CENTER FOR DISEASE CONTROL AND PREVENTION (CDC). Guidelines for hand hygiene in healthcare settings: recommendations of the Healthcare Infection Control Practices Advisory Committee and the HICPAC/SHEA/APIC/IDSA Hand Hygiene Task Force. MMWR Recomm Rep, Atlanta, 2002, v. 51, p. 1-44. Disponível em: <http://www.cdc.gov/mmwr/PDF/rr/rr5116.pdf >. Acesso em: 28 mai. 2014.

CENTERS FOR DISEASE CONTROL. Isolation Techniques for Use in Hospitals. US Government Printing Office, CDC, Washington, 2 ed., 1975. 80-8314.

CENTERS FOR DISEASE CONTROL. Recommendations for preventing Transmission of infection with human T-lymphotropic virus type III/lymphadenopathy-associated virus in the workplace. Morbidity and Mortality Weekly Report, v. 34, n45, p. 682/6-691/5, 1985. Disponível em: <http://www.cdc.gov/mmwr/preview/mmwrhtml/00033093.htm>. Acesso em: 28 mai. 2014.

CUNHA A.F.A.; JOHNSON D.S.D. Transmissão de Microorganismos e Precauções. In: COUTO R.C. et al. Infecção hospitalar e outras complicações não-infecciosas da doença: epidemiologia, controle e tratamento. 4. ed. Rio de Janeiro: Guanabara Koogan, 2009. p. 375380.

DALBEN, M. F. et al. Colonization pressure as a risk factor for colonization by multiresistant Acinetobacter spp and carbapenem-resistant Pseudomonas aeruginosa in an intensive care unit. Clinics, v. 68, n. 8, p. 1128-1133, 2013. Disponível em: <http://www.scielo.br/pdf/clin/v68n8/1807-5932-clin-68-08-1128.pdf>. Acesso em: 15 ago. 2015.

DE CASTRO, A.F. Avaliação das práticas de precauções padrão na Unidade de Terapia Intensiva de Adultos do Hospital Universitário de Brasília. 41f. Monografia (MBA em Gestão de Saúde e Controle de Infecção), Instituto Nacional de Ensino e Pesquisa, Brasília, 2010. 
COSTA, I.I.R. Adesão à higiene das mãos em Unidade de Terapia Intensiva: revisão integrativa de estudos da América Latina e Caribe. 31 f. Trabalho de Graduação (Bacharelado em Enfermagem) - Faculdade de Ciências da Saúde, Universidade de Brasília, Brasília, 2015.

DE OLIVEIRA, A.C.; DE PAULA, A.O. Monitoração da adesão à higienização das mãos: uma revisão de literatura. Acta Paulista de Enfermagem, v. 24, n. 3, p. 407-13, 2011. Disponível em: < http://www.scielo.br/pdf/ape/v24n3/16.pdf>. Acesso em: 15 ago. 2015.

DE OLIVEIRA, M.S. et al. Guia de utilização de anti-infecciosos e recomendações para prevenção de infecções relacionadas à assistência à saúde 2015-2017. Fundação Faculdade de Medicina da USP, 2014, 222p. E-book. Disponível em:

<http://livraria.folha.com.br/ebooks/medicina-e-saude/guia-utilizacao-anti-infecciososrecomendacoes-ebook-1283522.html>. Acesso em: 19 jan. 2015.

DE VITA, V. et al. Conocimiento, actitudes y prácticas del personal de salud relacionados con el lavado de manos clínico en una unidad de cuidados intensivos. Revista Médica de Rosario, v. 80, n. 3, p. 105-16, 2014. Disponível em: <

http://pesquisa.bvsalud.org/portal/resource/pt/lil-740636>. Acesso em: 10 jul. 2015.

DERDE, L.P.G. et al. Interventions to reduce colonisation and transmission of antimicrobialresistant bacteria in intensive care units: an interrupted time series study and cluster randomised trial. The Lancet Infectious Diseases, v. 14, n. 1, p 31-39, 2014. Disponível em: <http://dx.doi.org/10.1016/S1473-3099(13)70295-0>. Acesso em: 15 ago. 2015.

DISTRITO FEDERAL (BR). Manual de prevenção e controle de infecção relacionada à assistência à saúde. Brasília: Secretaria de Estado de Saúde do Distrito Federal, 2014. 91p.

DISTRITO FEDERAL (BR). Manual de recomendações de prevenção e controle das infecções em estabelecimentos de saúde. Brasília: Secretaria de Estado de Saúde do Distrito Federal, 2005. 67p.

DISTRITO FEDERAL (BR). Plano de enfrentamento da resistência bacteriana nas áreas críticas dos hospitais públicos do GDF 2015. Brasília: Secretaria de Estado de Saúde do Distrito Federal, 2015b. 17p.

DISTRITO FEDERAL (BR). Relatório dos indicadores de infecções relacionadas à assistência à saúde nos hospitais do Distrito Federal: ano 2014. Brasília: Secretaria de Estado de Saúde do Distrito Federal, 2015a. 34p. 
DO PRADO, M.F.; HARTMANN, T.P.S.; TEIXEIRA FILHO, L.A. Acessibilidade da estrutura física hospitalar para a prática da higienização das mãos. Escola Anna Nery Revista de Enfermagem, v. 17, n. 2, p. 220-226, 2013. Disponível em: <http://www.scielo.br/pdf/ean/v17n2/v17n2a03.pdf>. Acesso em: 10 jul. 2015.

DOHAR, S. et al. Contact precautions: more is not necessarily better. Infection Control and Hospital Epidemiology, v. 35, n. 3, p. 213-221, mar., 2014. Disponível em: <http://www.ncbi.nlm.nih.gov/pubmed/24521583>. Acesso em: 20 jun. 2015.

EDWARDS, J.R. et al. National Healthcare Safety Network (NHSN) report: Data summary for 2006 through 2008, issued December 2009. American Journal Infection Control, v. 37, n. 10, p. 783-805, dez, 2009. Disponível em:

<http://www.cdc.gov/nhsn/PDFs/dataStat/2009NHSNReport.PDF>. Acesso em: 30 jan. 2010.

EFSTATHIOU, G. et al. Factors influencing nurses' compliance with standard precautions in order to avoid occupation exposure to microorganisms: a focus group study. BioMed Central Nursing, v. 10, n. 1, p 1-12, 2011a. Disponível em:

<http://www.biomedcentral.com/content/pdf/1472-6955-10-1.pdf >. Acesso em: 01 jan. 2012.

EFSTATHIOU, G. et al. Compliance of Cypryot nurses with standard precautions to avoid to pathogens. Nursing and Health Sciences, v. 13, n. 1, p. 53-59, 2011b. Disponível em: <doi: 10.1111/j.1442-2018.2011.00576.x>. Acesso em: 15 ago. 2015.

EMPRESA BRASILEIRA DE SERVIÇOS HOSPITALARES. Diretrizes Para Implantação dos Núcleos de Segurança do Paciente nas Filiais da EBSERH. Brasília: Empresa Brasileira de Serviços Hospitalares, 2014. 35p.

EUROPEAN CENTRE FOR DISEASE PREVENTION AND CONTROL. Annual Epidemiological Report 2013. Reporting on 2011 surveillance data and 2012 epidemic intelligence data. Stockholm, 2013. Disponível em:

$<$ http://ecdc.europa.eu/en/publications/publications/0812_sur_annual_epidemiological_repor t_2008.pdf>. Acesso em: 24 mai. 2014.

FRANCA, S.R. et al. The effect of contact precautions on hand hygiene compliance. American journal of infection control, v. 41, n. 6, p. 558-559, 2013.

Disponível em: <http://dx.doi.org/10.1016/j.ajic.2012.08.010>. Acesso em: 10 jul. 2015.

GAGE, N. D.; LANDON, J. F.; SIDER, M.T. Communicable Disease. Philadelphia, PA, FA Davis, 1959. 
GALES, A.C. et al. Antimicrobial resistance among Gram-negative bacilli isolated from Latin America: results from SENTRY Antimicrobial Surveillance ProGram (Latin America, 20082010). Diagnostic Microbiology and Infectious Disease. v. 73, n. 4, p. 354-360, aug., 2012. Disponível em: < http://ac.els-cdn.com.ez54.periodicos.capes.gov.br/S0732889312001563/1s2.0-S0732889312001563-main.pdf?_tid=7c3fdfcc-0014-11e6-af17-

00000aab0f6b\&acdnat=1460400046_5bac2c244408c55c9226eca79d6f7845>. Acesso em: 22 fev. 2016.

GARNER, J. S.; SIMMONS, B. P. CDC Guideline for Isolation Precautions in Hospitals. Department of Health and Human Services, Public Health Service, Centers for Disease Control. HHS publication no. (CDC) 83-8314. Infect Control, v.4, n.4, p 247-325, 1983. Disponível em: <http://www.jstor.org/stable/30142564>. Acesso em: 24 mai. 2014.

GARNER, Julia S.; THE HOSPITAL INFECTION CONTROL PRATICES ADVISORY COMMITTEE. Guideline for isolation precautions in hospitals control advisory committee. Infection Control and Hospital Epidemiology, v. 17, n. 1, p. 53-80, 1996. Disponível em: <http://dx.doi.org/10.1017/S0195941700006123>. Acesso em: 24 mai. 2014.

GARRET, C. The effect of nurse staffing patterns on medical errors and nurse burnout. AORN Journal, v. 87, n. 6, p. 1191-1204, jun., 2008. Disponível em: <http://web.a-bscohostcom.ez54.periodicos.capes.gov.br/ehost/Pdfviewer/pdfviewer?sid=701ff801-77be-4b6a-954663398b913102\%40sessionmgr4005\&vid=1\&hid=4204>. Acesso em: 19 mar. 2016

GONÇALVES, F.A.F. et al. Ações de enfermagem na profilaxia da pneumonia associada à ventilação mecânica. Acta Paulista de Enfermagem, v.25, n. esp. 1, p. 101-107, 2012. Disponível em: <http://www.scielo.br/pdf/ape/v25nspe1/pt_16.pdf>. Acesso em: 19 jan. 2015.

GOUVÊA, C.S.D. Desenvolvimento de indicadores de segurança do paciente para hospitais de pacientes agudos. 270f. Tese (Doutorado em Ciências na área de Saúde Pública) - Escola Nacional de Saúde Pública Sérgio Arouca, Rio de Janeiro, 2011.

GUANCHE-GARCELL, H. et al. Device-associated infection rates in adult intensive care units of Cuban university hospitals: International Nosocomial Infection Control Consortium (INICC) findings. International Journal of Infectious Diseases, v. 15, n. 5, p. e357-e362, 2011. Disponível em: <doi:10.1016/j.ijid.2011.02.001>. Acesso em: 19 jan. 2015.

HARRIS, A.D. et al. Universal glove and gown use and acquisition of antibiotic-resistant bacteria in the ICU: a randomized trial. JAMA, v. 310, n. 15, p.1571-1580, out., 2013. Disponível em: <doi:10.1001/jama.2013.277815>. Acesso em: 20 jun. 2015. 
HENRY. K. et al. Compliance with universal precautions and needle handling and disposal practices among emergency department staff at two community hospitals. American Journal of Infection Control, v. 22, n. 3, p. 129-137, 1994. Disponível em:

<http://www.ajicjournal.org/article/0196-6553(94)90001-9/pdf>. Acesso em: 30 jan. 2010.

HOSOGLU, S. et al. Healthcare workers' compliance with universal precautions in Turkey. Medical Hypotheses, v. 77, n. 6, p. 1079-1082, 2011. Disponível em: < http://www.medicalhypotheses.com/article/S0306-9877(11)00460-9/pdf> Acesso em: 03 fev. 2016.

HOSPITAL UNIVERSITÁRIO DE BRASÍLIA. Planta baixa com layout: hub_utiadulto_pe_ar01_layout_rev02. Arquivo DWG. Brasília: HUB, fev., 2013.

HOSPITAL UNIVERSITÁRIO DE BRASÍLIA. Programa de controle de infecções relacionadas à assistência à saúde 2014. Brasília: HUB, jun., 2014a. 21p.

HOSPITAL UNIVERSITÁRIO DE BRASÍLIA. Programa de controle de infecções relacionadas à assistência à saúde 2015. Brasília: HUB, abr., 2015c. 16p.

HOSPITAL UNIVERSITÁRIO DE BRASÍLIA. Procedimento operacional padrão no 2: precauções padrão. Brasília: HUB, fev., 2014b. 16p.

HOSPITAL UNIVERSITÁRIO DE BRASÍLIA. Procedimento operacional padrão no 3 : precauções adicionais ou isolamentos. Brasília: HUB, fev., 2014c. 19p.

HOSPITAL UNIVERSITÁRIO DE BRASÍLIA. Procedimento operacional padrão $\mathbf{n}^{0} 4$ : prevenção de microorganismos multirresistentes. Brasília: HUB, jul., 2013a. 7p.

HOSPITAL UNIVERSITÁRIO DE BRASÍLIA. Protocolo de higiene das mãos. Brasília: HUB, fev., 2015a. 16p.

HOSPITAL UNIVERSITÁRIO DE BRASÍLIA. Relatório epidemiológico das infecções relacionadas à assistência à saúde (IRAS) no Hospital Universitário de Brasília de janeiro a setembro do ano de 2015. Brasília: HUB, dez., 2015b. 19p.

HULLEY, S.B. et al. Delineando a Pesquisa Clínica: uma abordagem epidemiológica. Tradução Duncan MS. 3. ed. Porto Alegre: Artmed, 2008. 384 p. 
HUSKINS, W.C. et al. Intervention to reduce transmission of resistant bacteria in intensive care. The New England Journal of Medicine, v. 364, n. 15., p. 1407-1418, abr., 2011. Disponível em: <http://www.nejm.org.ez54.periodicos.capes.gov.br/doi/pdf/10.1056 /NEJMoa1000373>. Acesso em: 17 mar. 2014.

HUSNI, R.N. et al. Risk factors for an outbreak of multi-drug-resistant Acinetobacter nosocomial pneumonia among intubated patients. Chest Journal, v. 115, n. 5, p. 1378-1382, 1999. Disponível em:

<http://journal.publications.chestnet.org/article.aspx?articleid=1077239>. Acesso em: 30 jan. 2010.

JOINT COMMISSION INTERNATIONAL. Padrões de acreditação da Joint Commission International para Hospitais. Rio de Janeiro: CBA, 2010, 288p.

KAWAGOE J.Y.; GONÇALVES P. Prevenção e Controle de Infecção para a Segurança do paciente e qualidade em Serviços de Saúde. In: AGÊNCIA NACIONAL DE VIGILÂNCIA SANITÁRIA. Série Segurança do Paciente e Qualidade em Serviços de Saúde. Assistência Segura: Uma reflexão teórica à prática. Brasília: Agência Nacional de Vigilância Sanitária, 2013. p. 141-153.

KAWAGOE, J.Y. et al. Racional teórico das precauções para evitar a transmissão dos agentes infeciosos no ambiente de assistência à saúde. In: CORREAA, L.; SILVA, A.A.; FERNANDES, M.V.L. (Organizadores). Precauções e Isolamentos. 2. ed. São Paulo: Associação Paulista de Estudos e Controle de Infecção Hospitalar, 2012. p. 25-44.

KIM, L.E. et al. Compliance with Universal Precautions among emergency department personnel: implications for prevention programs. American Journal of Infection Control, v. 27, n. 5, p. 453-455, 1999. Disponível em:

<http://www.sciencedirect.com/science/article/pii/S0196655399700143>. Acesso em: 30 jan. 2010 .

KNAUS, W.A. et al. Variations in mortality and length of stay in intensive care units. Annals of Internal Medicine, v. 118, n. 10, p. 753-761, 1993. Disponível em: <http://annals.org/article.aspx?articleid=706367\#>. Acesso em: 30 jan. 2010.

KOHN, L.Y.; CORRIGAN, J.M.; DONALDSON, M.S; COMMITTEE ON QUALITY OF HEALTH CARE IN AMERICA. To err is human: building a safer health system. Washington DC: National Academy Press, 1999. Disponível em: <http://www.iom.edu/ /media/Files/Report\%20Files/1999/To-Err-isHuman/To\%20Err\%20is\%20Human\%201999\%20\%20report\%20brief.pdf >. Acesso 25 set. 2014. 
LEVIN A.S.S. et al. Guia de utilização de anti-infecciosos e recomendações para prevenção de infecções hospitalares. 4. ed. São Paulo: FMUSP, 2009. 222p.

LEVIN A.S.S. et al. Guia de utilização de anti-infecciosos e recomendações para prevenção de infecções hospitalares. 5. ed. São Paulo: Hospital das Clínicas, 2011. 192p. Disponível em: <http://www.sbp.com.br/pdfs/Anti-Infecciosos_Infec_Hospitalar.pdf>. Acesso em: 19 jan. 2015.

LOPES, A.C.S. et al. Adesão às precauções padrão pela equipe de atendimento pré-hospitalar móvel de Belo Horizonte. Caderno de Saúde Pública, Rio de Janeiro, v. 24, n. 6, p. 1387 1396, 2008. Disponível em: <http://www.scielo.br/pdf/csp/v24n6/19>. Acesso em: 30 jan. 2010 .

$\mathrm{LYNCH}$, P. et al. Rethinking the role of isolation practices in the prevention of nosocomial infections. Annals of Internal Medicine, v. 107, n. 2, p. 245-246, 1987. Disponível em: <doi:10.7326/0003-4819-107-2-243>. Acesso em: 24 mai. 2014.

LYNCH, T. Communicable Disease Nursing. St. Louis, MO: Mosby; 1949.

MACEDO, RDCR et al. Positive deviance: Using a nurse call system to evaluate hand hygiene practices. American Journal of Infection Control, v. 40, n. 10. p. 946-950, 2012. Disponível em: <http://dx.doi.org/10.1016/j.ajic.2011.11.015>. Acesso em: 22 fev. 2016.

MACHADO, M.H.; OLIVEIRA, E.S.; MOYSES, N.M.N. Tendências no mercado de trabalho em saúde no Brasil. In: PIERANTONI, C; POZ, M.R.D.; FRANÇA, T. (ORG.). O trabalho em saúde: abordagens quantitativas e qualitativas. $1^{a}$ ed. Rio de Janeiro: CEPESC, UERJ, 2011, v. 1, p. 103-116. Disponível em:

<http://www.ensp.fiocruz.br/observarh/arquivos/Tendencias\%2520de\%2520Mercado\%2520d e\%2520Trabalho.pdf >. Acesso em: 19 mar. 2016.

MAGAlHÃES, R.A.C.; GLINA, D.M.R. Prevalência de Burnout em médicos de um Hospital Público de São Paulo. Saúde, Ética \& Justiça. v. 11, n. 1/2, p. 29-35, 2006. Disponível em: <http://dx.doi.org/10.11606/issn.2317-2770.v11i1-2p29-35>. Acesso em: 19 mar. 2016.

MAHFOUZ, A.A.; EL GAMAL, M.; AL-AZRAQUI, T.A. Hand hygiene non-compliance among intensive care unit health care workers in Aseer Central Hospital, south-western Saudi Arabia. International Journal of Infectious Diseases, v. 17, n. 9, p. e729-e732, 2013. Disponível em: < http://dx.doi.org/10.1016/j.ijid.2013.02.025>. Acesso em: 19 jan. 2015. 
MALAGUTI-TOFFANO, S. E. et al. Adesão às precauções-padrão de profissionais de enfermagem de um hospital universitário. Acta Paulista de Enfermagem, v. 25, n. 3, p. 401407, 2012. Disponível em: <http://www.scielo.br/pdf/ape/v25n3/v25n3a13.pdf>. Acesso em: 19 jan. 2015.

MARRA, A.R. et al. Measuring Rates of Hand Hygiene Adherence in the Intensive Care Setting A Comparative Study of Direct Observation, Product Usage, and Electronic Counting Devices. Infection Control, v. 31, n. 8, p. 796-801, 2010. Disponível em: < http://www.jstor.org/stable/10.1086/653999>. Acesso em: 22 fev. 2016.

MARSHALL, C.; RICHARDS, M.; MCBRYDE, E. Do active surveillance and contact precautions reduce MRSA acquisition? A prospective interrupted time series. PLOS ONE, v. 8, n. 3, p. e58112, 2013. Disponível em: <doi:10.1371/journal.pone.0058112>. Acesso em: 20 jun. 2015.

MENDES W. Taxonomia em segurança do paciente. In: SOUZA P, MENDES W (Organizadores). Segurança do paciente: conhecendo os riscos nas organizações de saúde. Rio de Janeiro: EAD/ENSP, 2014, p. 57-71.

MENDES, W. et al. Características de eventos adversos evitáveis em hospitais do Rio de Janeiro. Revista da Associação Médica Brasileira, v. 59, n. 5, p 421-428, 2013. Disponível em: <http://dx.doi.org/10.1016/j.ramb.2013.03.002>. Acesso em: 15 ago. 2015.

MENEGUETI, M. G. et al. Avaliação dos programas de controle de infecção hospitalar em serviços de saúde. Revista Latino-Americana de Enfermagem, v. 23, n. 1, p. 98-105, jan., 2015. Disponível em: <http://www.scielo.br/pdf/rlae/v23n1/pt_0104-1169-rlae-23-0100098.pdf $>$. Acesso em: 21 abr. 2015.

MINISTÉRIO DA SAÚDE (BR). Anexo 03: Protocolo de segurança na prescrição, uso e administração de medicamentos. Brasília: MS/ANVISA/FIOCRUZ, 2013b, 16p. Disponível em: 〈http://proqualis.net/sites/proqualis.net/files/000002490IQmwD8.pdf>. Acesso em: 05 mai. 2016.

MINISTÉRIO DA SAÚDE (BR). Anexo 01: Protocolo para a prática de higiene das mãos em serviços de saúde. Brasília: MS/ANVISA/FIOCRUZ, 2013b, 16p. Disponível em: $<$ http://proqualis.net/sites/proqualis.net/files/000002428z8pha4.pdf >. Acesso em: 24 jul. 2013.

MINISTÉRIO DA SAÚDE (BR). Portaria GM/MS nº 2.616, de 12 de maio de 1998. Brasília: MS, 1998. Disponível em:

<http://portal.anvisa.gov.br/wps/wcm/connect/8c6cac8047457a6886d6d63fbc4c6735/PORTA 
$\mathrm{RIA}+\mathrm{N} \% \mathrm{C} 2 \% \mathrm{~B} 0+2.616,+\mathrm{DE}+12+\mathrm{DE}+\mathrm{MAIO}+\mathrm{DE}+1998 . \mathrm{pdf}$ ?MOD=AJPERES $>$. Acesso em: 28 mai. 2014.

MINISTÉRIO DA SAÚDE (BR). Portaria GM/MS n ${ }^{\circ}$ 529, de $1^{\circ}$ de abril de 2013. Brasília: MS, 2013a. Disponível em:

<http://bvsms.saude.gov.br/bvs/saudelegis/gm/2013/prt0529_01_04_2013.html>. Acesso em: 28 mai. 2014.

MISTÉRIO DA SAÚDE (BR). Resolução CNS n 466, de 12 de dezembro de 2012. Brasília: MS, 2012. Disponível em:

<http://bvsms.saude.gov.br/bvs/saudelegis/cns/2013/res0466_12_12_2012.html>. Acesso em: 20 jun. 2015.

MINISTÉRIO DO TRABALHO E EMPREGO (BR). Portaria GM/MS n 485, de 11 de novembro de 2005. Brasília: MTE, 2005. Disponível em:

<http://www.anvisa.gov.br/servicosaude/avalia/saude_do_trabalhador_portaria_485_aprova_ NR32.pdf >. Acesso em: 10 fev. 2016.

NAING, L.; NORDIN, R.; MUSA, R. The prevalence of, and factors related to, compliance with glove utilization among nurses in Hospital Universiti Sains Malaysia. Southeast Asian Journal of Tropical Medicine and Public Health, v. 32, n. 3, p. 636-642, 2001. Disponível em: < http://www.tm.mahidol.ac.th/seameo/2001_32_3/34-2701.pdf >. Acesso em: 30 jan. 2010 .

NATIONAL COMMUNICABLE DISEASE CENTER. Isolation Techniques for Use in Hospitals. US Government Printing Office, Washington, 1970. PHS publication, n. 2054.

NDERITU, E.W.; MILL, J.; RICHTER, S. The experience of ugandan nurses in the practice of universal precautions. Journal of the Association of Nurses in AIDS Care, v. 26, n.5, p. 625-638, set., 2015. Disponível em: <http://dx.doi.org/10.1016/j.jana.2014.10.003>. Acesso em: 03 fev. 2016.

NEVES, Z.C.P. et al. Higienização das mãos: o impacto de estratégias de incentivo à adesão entre profissionais de saúde de uma unidade de terapia intensiva neonatal. Revista LatinoAmericana de Enfermagem, v. 14, n. 4, p. 546-552, 2006. Disponível em: <http://www.scielo.br/pdf/rlae/v14n4/pt_v14n4a12.pdf >. Acesso em: 24 mai. 2014.

NOGMANOVA, Z. et al. Universal precautions in Central Asia: the need for multiple strategies in this window of opportunity. Journal of Hospital Infection, v. 89, n. 3, p. 197 201, 2015. Disponível em: <http://dx.doi.org/10.1016/j.jhin.2014.11.011>. Acesso em: 03 fev. 2016. 
OLIVEIRA, A.C.; CARDOSO, C.S.; MASCARENHAS, D. Contact precautions in intensive care units: facilitating and inhibiting factors for professionals' adherence. Revista da Escola de Enfermagem da USP, v. 44, n. 1, p. 161-65, 2010. Disponível em: <

http://www.scielo.br/pdf/reeusp/v44n1/en_a23v44n1.pdf>. Acesso em: 19 jan. 2015.

ORGANIZAÇÃO MUNDIAL DA SAÚDE. A crescente ameaça da resistência antimicrobiana. Genebra, 2012. Disponível em: < http://apps.who.int/iris/bitstream/ 10665/75389/3/OMS_IER_PSP_2012.2_por.pdf>. Acesso em: 07 fev. 2015.

ORGANIZAÇÃO PAN-AMERICANA DA SAÚDE; AGÊNCIA NACIONAL DE VIGILÂNCIA SANITÁRIA (BR). Guia para implantação: estratégia multimodal da OMS para melhoria da higienização das mãos. Desafio: uma assistência limpa é uma assistência mais segura/Aliança mundial para segurança do paciente/Organização Mundial da Saúde. Brasília: OPAS, 2008a. 59p.

ORGANIZAÇÃO PAN-AMERICANA DA SAÚDE; AGÊNCIA NACIONAL DE VIGILÂNCIA SANITÁRIA (BR). Manual para observadores: estratégia multimodal da OMS para melhoria da higienização das mãos. Desafio: Uma assistência limpa é uma assistência mais segura/Organização Mundial da Saúde. Brasília: OPAS, 2008b. 56p.

PÉREZ, E.R.; ZAMBRAMO, P.; AMADO, P. Adherencia a las guías de higiene de manos en cuidado intensivo: el caso de una clínica privada. Medicina Universidad Pontificia Bolivariana, v. 31, n. 2, p. 127-134, 2012. Disponível em: <http://revistas.upb.edu.co/index.php/Medicina/article/view/1760/pdf >. Acesso em: 19 jan. 2015.

PERUGINI, M.R. Avaliação do impacto de medidas de intervenção no controle de Enterococcus spp. resistente a vancomicina em unidade de terapia intensiva. 168f. Tese (Doutorado em Doenças Infecciosas e Parasitárias) - Faculdade de Medicina, Universidade de São Paulo, São Paulo, 2008.

PIMENTEL, T.S. et al. Processo de trabalho de enfermeiros de Unidades de Terapia Intensiva: desafios da formação acadêmica. Revista de Enfermagem da UFPE on line, Recife, v. 7, n. 10, p. 5915-5922, out., 2013. Disponível em:

$<$ https://www.google.com.br/\#q=Processo+de+trabalho+de+enfermeiros+de+Unidades+de+T erapia+Intensiva:+desafios+da+forma\%C3\%A7\%C3\%A3o+acad\%C3\%AAmica $>$. Acesso em 07 mar. 2016.

PINA E.; FERREIRA E.; UVA M. S. Infecções associadas aos cuidados de saúde. In: SOUZA P.; MENDES W. Segurança do paciente: conhecendo os riscos nas organizações de saúde. Rio de Janeiro: EAD/ENSP; 2014, p. 137-158. 
POTTER, P. A.; PERRY, A.G. Fundamentos de enfermagem: conceitos, processo e prática. 6. ed. São Paulo: Elsevier, 2006.

ROSENTHAL, V.D. et al. Impact of the International Nosocomial Infection Control Consortium (INICC) Multidimensional Hand Hygiene Approach over 13 Years in 51 Cities of 19 Limited-Resource Countries from Latin America, Asia, the Middle East, and Europe.

Infection Control and Hospital Epidemiology, v. 34, n. 4, p. 415-423, 2013. Disponível em: <http://www.jstor.org/stable/10.1086/669860>. Acesso em: 19 jan. 2015.

SALAMA, M. F. et al. The effect of hand hygiene compliance on hospital-acquired infections in an ICU setting in a Kuwaiti teaching hospital. Journal of Infection and Public Health, v. 6, n. 1, p. 27-34, 2013. Disponível em: <http://dx.doi.org/10.1016/j.jiph.2012.09.014>. Acesso em: 19 jan. 2015.

SAN MIGUEL, L.G. et al. Secular trends of candidemia in a large tertiary-care hospital from 1988 to 2000: emergence of Candida parapsilosis. Infection Control and Hospital Epidemiology, v. 26, n.6, p. 548-552, 2005. Disponível em:

<http://www.jstor.org/stable/pdf/10.1086/502582.pdf>. Acesso em: 30 jan. 2010.

SANCHEZ, V. et al. Nosocomial acquisition of Candida parapsilosis: an epidemiologic study. American Journal of Medicine, v. 94, n. 6, p. 577-582, 1993. Disponível em: < http://www.amjmed.com/article/0002-9343(93)90207-6/pdf>. Acesso em: 30 jan. 2010.

SÃO PAULO (BR). Centro de Vigilância Epidemiológica. Manual de avaliação da qualidade de práticas de controle de infecção hospitalar. São Paulo: Secretaria de Estado de Saúde de São Paulo, 2006. 237p. Disponível em:

<http://www.cve.saude.sp.gov.br/htm/ih/IH_MANUALFAPESP06.pdf >. Acesso em: 28 mai. 2014.

SÃO PAULO. Avaliação do Projeto Estadual "Mãos limpas são mãos mais seguras" fase 2013-2014. Power point. Centro de Vigilância Epidemiológica, Divisão de Infecção Hospitalar. Disponível em: $<$ https://www.google.com.br/\#q=cve+apresenta\%C3\%A7\%C3\%A3o +do+projeto+estadual+higiene+das+m\%C3\%A3os>. Acesso em: 15 ago. 2015.

SAX, H, et al. The World Health Organization hand hygiene observation method. American Journal of Infection Control, v. 37, n. 10, p 827-834, 2009. Disponível em: < doi: 10.1016 / j.ajic.2009.07.003>. Acesso em: 19 jun 16. 
SCHAFFNER, W. Infection control: old myths and new realities. Infection Control, v. 1, n. 5, p. 330-334, 1980. Disponível em: <http://dx.doi.org/10.1017/S0195941700053285>. Acesso em: 19 fev. 2015.

SHIMIZU, H.E.; COUTO, D.T.; MERCHAN-HAMANN, E. Prazer e sofrimento em trabalhadores de enfermagem de unidade de terapia intensiva. Revista Latino-Americana de Enfermagem, v. 19, n. 3, p. 9, mai., 2011. Disponível em: <http://www.scielo.br/pdf/rlae/v19n3/pt_16.pdf>. Acesso em: 19 jan. 2016.

SIEGEL J.D. et al. 2007 Guideline for Isolation Precautions: Preventing Transmission of Infections Agents in Healthcare Settings. Healthcare Infection Control Practices Advisory Committee (HICPAC). Atlanta, 2007. Disponível em:

<http://www.cdc.gov/ncidod/dhqp/pdf/isolation2007.pdf>. Acesso em: 24 out. 2009.

SILVA A.M.C. et al. Precauções e Isolamento. In: FERNANDES A. T. Infecção hospitalar e suas interfaces na área de saúde. $1^{a}$ ed. São Paulo: Atheneu; 2000. Volume 2. p. 1008-1019.

SILVA, A. M. C. et al. Componentes das precauções: o passo a passo. In: CORRÊA, L.; SILVA, A.A.; FERNANDES, M.V.L. (Organizadores). Precauções e Isolamentos. 2. ed. São Paulo: Associação Paulista de Estudos e Controle de Infecção Hospitalar, 2012. p. 45-68.

SONG, X. et al. Improving hand hygiene compliance in health care workers: strategies and impact on patient outcomes. American Journal of Infection Control, v. 41, n. 10, p e101e105, 2013. Disponível em: <http://dx.doi.org/10.1016/j.ajic.2013.01.031>. Acessado em: 19 jan. 2015.

SOUZA, L.M. et al. Adherence to the five moments for hand hygiene among intensive care professionals. Revista Gaúcha de Enfermagem, v. 36, n. 4, p. 21-28, dez., 2015. Disponível em: <http://dx.doi.org/10.1590/1983-1447.2015.04.49090>. Acesso em: 03 fev. 2016.

SRIGLEY, J.A. et al. Hand hygiene monitoring technology: a systematic review of efficacy. Journal of Hospital Infection, v. 89, n. 10, p. 51-60, 2015. Disponível em: <http://dx.doi.org/10.1016/j.jhin.2014.10.005>. Acesso em: 22 fev. 2016.

SUNKESULA, V.C.K. et al. Comparison of hand hygiene monitoring using the 5 Moments for hand hygiene method versus a wash inewash out method. American Journal of Infection Control, v. 43, n.10, p 16-19, 2015. Disponível em: <http://dx.doi.org/10.1016/j.ajic.2014.10.003>. Acesso em: 22 fev. 2016.

TACCONELLI, E. et al. Diretrizes da ESCMID para o gerenciamento de medidas de controle de infecção a fim de reduzir a transmissão de bactérias Gram-negativas multidroga-resistentes 
em pacientes hospitalizados. The Journal of Infection Control (JIC) the official journal of the Brazilian Association of Infection Control and Hospital Epidemiology Professionals. v. 3, n.3, p. 1-42, 2014. Disponível em: <http://jic.abih.net.br/index.php/jic/article/view/99>. Acesso em: 20 jun. 2015

UNIÃO EUROPÉIA. Recomendação do Conselho de 9 de julho de 2009 sobre a segurança dos pacientes, incluindo a prevenção e o controlo de infecções associadas aos cuidados de saúde. Jornal da União Europeia, 2009. Disponível em: <http://ec.europa.eu/health/patient_safety/docs/council_2009_pt.pdf>. Acesso em: 07 fev. 2015.

VAIDOTAS, M. et al. Measuring hand hygiene compliance rates at hospital entrances. American Journal of Infection Control, v. 43, n. 3, p. 694-696, 2015. Disponível em: <http://dx.doi.org/10.1016/j.ajic.2015.03.008>. Acesso em: 22 fev. 2016.

VILLARINO, M.E. et al. Risk factors for epidemic Xanthomonas maltophilia infection/colonization in intensive care unit patients. Infection Control and Hospital Epidemiology, v. 13, n. 4, p. 201-206, 1992. Disponível em: <http://journals.cambridge.org/abstract_S0195941700014090>. Acesso em: 30 jan. 2010.

WALKER, J.L. et al, 2014. Hospital hand hygiene compliance improves with increased monitoring and immediate feedback. American Journal of Infection Control, v. 42, n. , p. 1074-1078, 2014. Disponível em: <http://dx.doi.org/10.1016/j.ajic.2014.06.018>. Acesso em: 19 jan. 2016.

WENZEL, R.P.; GENNINGS, C. Bloodstream infections due to Candida species in the intensive care unit: identifying especially high-risk patients to determine prevention strategies. Clinical Infectious Diseases, Oxford, v. 41, n. suppl 6, p. S389-393, 2005. Disponível em: <http://cid.oxfordjournals.org/content/41/Supplement_6/S389.full.pdf+html>. Acesso em: 30 jan. 2010.

WERMELINGER, M. et al. A força de trabalho do setor de saúde no Brasil: focalizando a feminização. Revista Divulgação em Saúde para Debate, Rio de Janeiro, n. 45, p. 54-70, mai., 2010. Disponível em:

<http://www.ensp.fiocruz.br/observarh/arquivos/A\%20Forca\%20de\%20Trabalho\%20do\%20 Setor\%20de\%20Saude\%20no\%20Brasil\%20.pdf>. Acesso em: 19 mar. 2016

WORLD HEALTH ORGANIZATION (WHO). Report on the Burden of Endemic Health Care Associated Infection Worldwide. A systematic review of the literature. Geneva, 2011. Disponível em: 〈http://whqlibdoc.who.int/publications/2011/9789241501507eng.pdf>. Acesso em: 24 abr. 2014. 
WORLD HEALTH ORGANIZATION (WHO). WHO best practices for injections and related procedures toolkit. Geneva: World Health Organization, mar., 2010, 55p. Disponível em: <http://apps.who.int/iris/bitstream/10665/44298/1/9789241599252_eng.pdf>. Acesso 10 fev. 2016.

WORLD HEALTH ORGANIZATION (WHO). WHO guidelines on hand hygiene in health care. First Global Patient Safety Challenge Clean Care is Safer Care. WHO, Geneva, 2009. 270p. Disponível em:

<http://www.who.int/gpsc/5may/tools/9789241597906/en/>. Acesso em: 08 fev. 2015.

WORLD HEALTH ORGANIZATION (WHO). World Alliance for Patient Safety: Clean care is safer care - global patient safety challenge. Geneva, 2005-2006. Disponível em: <http://www.who.int/patientsafety/events/05/GPSC_Launch_ENGLISH_FINAL.pdf>. Acesso em: 24 mai. 2014.

YAWSON, A.E.; HESSE, A.A.J. Hand hygiene practices and resources in a teaching hospital in Ghana. Journal of Infection in Developing Countries, v. 7, n. 4, p. 338-347, 2013.

Disponível em: <http://www.jidc.org/index.php/journal/article/view/23592644/863>. Acesso em: 19 jan. 2015.

YOKOE, D.S. et al. A Compendium of Strategies to Prevent Healthcare-Associated Infections in Acute Care Hospitals: 2014 Updates. Infection Control and Hospital Epidemiology. v. 35, n. 8, p. 967-977, ago., 2014. Disponível em: <http://www.jstor.org/stable/pdf/10.1086/677216.pdf?_=1460475677735>. Acesso em: 15 ago. 2015.

YAWSON, A.E.; HESSE, A.A.J. Hand hygiene practices and resources in a teaching hospital in Ghana. The Journal of Infection in Developing Countries, v. 7, n. 4, p. 338-347, 2013. Disponível em: <doi:10.3855/jidc.2422>. Acesso em: 19 jan. 2015. 


\title{
APÊNDICE A - TERMO DE CONSENTIMENTO LIVRE E ESCLARECIDO
}

\author{
$\checkmark$ \\ Universidade de Brasília \\ Faculdade de Ciências da Saúde \\ Programa de Pós-Graduação em Enfermagem
}

$\mathrm{O}$ (a) Senhor(a) está sendo convidado(a) a participar, como voluntário(a), do projeto de pesquisa "Práticas de Precauções em Unidade de Terapia Intensiva de um Hospital de Ensino do Distrito Federal", sob a responsabilidade da pesquisadora Alaíde Francisca de Castro. O objetivo do estudo é avaliar as práticas de precauções e a infraestrutura da UTI de um hospital de ensino do Distrito Federal.

Trata-se de um estudo que destinará a elaboração de dissertação de mestrado a ser apresentado ao Programa de Pós-Graduação em Enfermagem, da Universidade de Brasília (UnB). Está garantido o sigilo e o anonimato do pesquisado e da instituição de origem.

Solicitamos a sua colaboração em participar deste estudo respondendo a um questionário com suas características profissionais, com duração prevista de cinco minutos, e autorizando que sua rotina de trabalho seja observada e registrada por um pesquisador, com duração prevista de duas horas diárias, no que se refere às práticas das precauções que envolvem a higiene das mãos, uso de equipamentos de proteção individual e indicações de tipos de precauções. A pesquisa se realizará no período de agosto a outubro de 2015.

Sua participação no estudo poderá representar risco mínimo, de natureza psíquica, decorrente de possível desconforto ou ansiedade ao responder perguntas que envolvem informações de si, assim como a observação direta pela pesquisadora das suas práticas de precauções, mas que será minimizado com esclarecimentos necessários antes e no decorrer da pesquisa, referente ao seu objetivo e procedimentos de coleta de dados. No entanto, a sua reflexão sobre o assunto transforma-se em um grande benefício indireto desta pesquisa para seu local de trabalho, porque a abordagem do tema serve para divulgar e estimular a melhoria da adesão às práticas recomendadas. Caso haja algum dano direto ou indireto decorrente de sua participação na pesquisa, você poderá ser indenizado, obedecendo às disposições legais vigentes no Brasil.

A participação na pesquisa não gera quaisquer despesas que acarretem ressarcimento pelas pesquisadoras. $\mathrm{O}$ (a) senhor(a) receberá todos os esclarecimentos necessários antes e no decorrer da pesquisa, sendo assegurado o mais rigoroso sigilo pela omissão total de quaisquer informações que permitam identificá-lo(a). 
Informamos que o(a) Senhor(a) poderá se recusar a responder questões que lhe tragam constrangimentos, assim como poderá desistir de participar da pesquisa sem riscos de ser penalizado(a) na instituição local do estudo ou no âmbito da sua profissão. A participação no estudo é livre, não acarretará custos para você, não cabendo qualquer benefício ou remuneração.

Este estudo contribuirá para se redefinir estratégias gerenciais, de modo a melhorar a gestão do Programa de Controle de Infecção Relacionada à Assistência à Saúde no hospital.

Os resultados da pesquisa serão divulgados em congressos científicos, aos gestores e profissionais da UTI do hospital, podendo ser publicados posteriormente. Os dados e materiais serão utilizados somente para esta pesquisa e ficarão sob a guarda do pesquisador por um período de cinco anos, após isso serão destruídos.

Qualquer dúvida em relação à pesquisa, por favor, telefone para Alaíde Francisca de Castro, na Universidade de Brasília, telefones (61) 3448-5278 e (61) 8104-1210, no horário das $8 \mathrm{~h}$ às 18h, ou pelo e-mail: castroalaide@gmail.com, ou para Maria Cristina Soares Rodrigues, na Universidade de Brasília, telefones (61) 3107-1976 e (61) 8237-8710, no horário de $8 \mathrm{~h}$ às $17 \mathrm{~h}$, ou pelo e-mail: mcsoares@unb.br .

Este projeto foi Aprovado pelo Comitê de Ética em Pesquisa da Faculdade de Ciências da Saúde (CEP/FS) da Universidade de Brasília. O CEP é composto por profissionais de diferentes áreas, cuja função é defender os interesses dos participantes da pesquisa em sua integridade e dignidade e contribuir no desenvolvimento da pesquisa dentro de padrões éticos. As dúvidas com relação à assinatura do TCLE ou aos direitos do participante da pesquisa podem ser obtidos pelo telefone: (61) 3107-1947 ou pelo e-mail cepfs@unb.br ou cepfsunb@gmail.com, horário de atendimento de 10h às 12h e de 13:30h às 15:30h, de segunda a sexta-feira.

Este documento foi elaborado em duas vias, uma ficará com o(a) participante da pesquisa e a outra com a pesquisadora responsável.

Assinatura do participante da pesquisa ou representante legal.

Profa. Dr. ${ }^{\text {a }}$ Maria Cristina Soares Rodrigues

Pesquisadora Orientadora Mat. FUB147559
Alaíde Francisca de Castro

Pesquisadora Responsável Mat. FUB1016067

Brasília, de de 


\section{APÊNDICE B - QUESTIONÁRIO DE PESQUISA: PERFIL DOS PROFISSIONAIS}

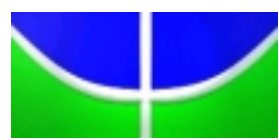

Universidade de Brasília

Faculdade de Ciências da Saúde

Programa de Pós-Graduação em Enfermagem

\section{QUESTIONÁRIO DE PESQUISA}

Práticas de precauções em Unidade de Terapia Intensiva de um hospital de ensino do

\section{Distrito Federal}

\section{Orientação:}

Marque somente uma alternativa para responder às perguntas abaixo.

1. Qual é o seu gênero?

$\square$ Masculino $\square$ Feminino

2. Qual é a sua idade?

$\square 20$ a 29 anos $\square 30$ a 40 anos $\square 41$ a 50 anos $\square 51$ ou mais

3. Qual é a sua profissão?

$\square$ médico $\square$ enfermeiro $\square$ fisioterapeuta $\square$ técnico de enfermagem

$\square$ auxiliar de enfermagem

4. Há quanto anos você atua nessa sua profissão?

$\square 0$ a 5 anos $\square 6$ a 10 anos $\square 11$ a 15 anos $\square 16$ a 20 anos $\square$ mais de 20 anos

5. Qual é a sua carga horária semanal total de trabalho? Somando-se todos os seus empregos?

$\square$ até $40 \mathrm{~h} \quad \square$ até $60 \mathrm{~h} \quad \square$ até $80 \mathrm{~h} \quad \square$ mais de $80 \mathrm{~h}$

6. Você recebeu capacitação na sua formação profisssional sobre?

Higiene das Mãos: $\square \operatorname{sim} \quad \square$ não

Uso de EPI (avental, luvas, máscara e óculos de proteção): $\square \operatorname{sim} \quad \square$ não

Tipos de precauções (padrão e isolamentos): $\square \operatorname{sim} \quad \square$ não

7. Você recebeu treinamento em serviço nesse hospital sobre?

Higiene das Mãos: $\square \operatorname{sim} \quad \square$ não

Uso de EPI (avental, luvas, máscara e óculos de proteção): $\square \operatorname{sim} \quad \square$ não

Tipos de precauções (padrão e isolamentos): $\square \operatorname{sim} \quad \square$ não

Esse(s) treinamento(s) foi(ram) no último ano? $\square \operatorname{sim} \quad \square$ não 


\section{APÊNDICE C - INSTRUMENTO DE COLETA DE DADOS 2: AVALIAÇÃO DE ESTRUTURA, PRECAUÇÕES E USO DE EPI}

\section{INSTRUMENTO DE COLETA DE DADOS 2}

DATA: _ _ _ _ PERÍODO: ( ) MATUTINO ( ) VESPERTINO ( ) NOTURNO Nº DE LEITOS OCUPADOS:

REGISTRO DOS INSUMOS DISPONÍVEIS

№ LEITOS COM ÁLCOOL GEL DISPONÍVEL: $\quad \mathrm{N}^{\circ}$ DE PIAS COM SABÃO LÍQUIDO: $\quad \mathrm{N}^{\circ}$ DE DISPENSADORES COM PAPEL-TOALHA: No DE PLANTONISTAS: MÉDICO ( ) ENFERMEIRO ( ) FISIOTERAPEUTA ( ) TÉCNICO E AUX. DE ENF ( ).

AVENTAL: ( ) sim ( ) Não LUVAS: ( ) sim ( ) Não MÁSCARA: ( ) sim ( ) Não ÓCULOS: ( ) $\operatorname{sim}$ ( ) Não

PLANTONISTA COM ADORNO NAS MÃOS? ( ) sim ( ) não Qual categoria profissional?

$\mathrm{N}^{\mathrm{O}}$ $\mathrm{N}^{\circ}$ $\mathrm{N}^{\mathrm{o}}$

OBSERVAÇÕES INDIVIDUAIS:

\begin{tabular}{|c|c|c|c|c|c|c|}
\hline Descrição & \multicolumn{2}{|c|}{ Observação 1 Leito: } & \multicolumn{2}{|c|}{ Observação 2 Leito: } & \multicolumn{2}{|l|}{ Observação 3 Leito: } \\
\hline $\begin{array}{ll}\text { Tipo de } \\
\text { precaução }\end{array}$ & \multicolumn{2}{|c|}{$\begin{array}{l}\text { ( ) padrão ( ) contato ( ) respiratório } \\
\text { ( ) Adequada ( ) Inadequada }\end{array}$} & \multicolumn{2}{|c|}{$\begin{array}{l}\text { ( ) padrão ( ) contato ( ) respiratório } \\
\text { ( ) Adequada ( ) Inadequada }\end{array}$} & \multicolumn{2}{|c|}{$\begin{array}{l}\text { ( ) padrão ( ) contato ( ) respiratório } \\
\text { ( ) Adequada ( ) Inadequada }\end{array}$} \\
\hline $\begin{array}{l}\text { Categoria } \\
\text { profissional }\end{array}$ & \multicolumn{2}{|c|}{$\begin{array}{l}\text { ( ) médico } \\
\text { ( ) enfermeiro } \\
\text { ( ) fisioterapeuta } \\
\text { ( ) tec/aux enfermagem }\end{array}$} & \multicolumn{2}{|c|}{$\begin{array}{l}\text { ( ) médico } \\
\text { ( ) enfermeiro } \\
\text { ( ) fisioterapeuta } \\
\text { ( ) tec/aux enfermagem }\end{array}$} & \multicolumn{2}{|c|}{$\begin{array}{l}\text { ( ) médico } \\
\text { ( ) enfermeiro } \\
\text { ( ) fisioterapeuta } \\
\text { ( ) tec/aux enfermagem }\end{array}$} \\
\hline Procedimento & $\begin{array}{l}\text { ( ) aspirar traqueia } \\
\text { ( ) higiene oral } \\
\text { ( ) trocar equipo } \\
\text { ( ) instalar CVC } \\
\text { ( ) instalar cat. periférico } \\
\text { ( ) medicação endovenosa } \\
\text { ( ) curativo de cateter } \\
\text { ( ) coletar sangue } \\
\text { ( ) instalar SVD } \\
\text { ( ) esvaziar diurese } \\
\text { ( ) banho no leito } \\
\text { ( ) glicemia }\end{array}$ & $\begin{array}{l}\text { ( ) mudar decúbito } \\
\text { ( ) trocar fralda } \\
\text { ( ) curativo } \\
\text { ( ) cuidar de estomias } \\
\text { ( ) instalar SNG/NE } \\
\text { ( ) adm. dieta } \\
\text { ( ) débito de dieta } \\
\text { ( ) transporte } \\
\text { ( ) exame físico } \\
\text { ( ) traqueostomia } \\
\text { ( ) drenar tórax } \\
\text { ( ) equipamentos }\end{array}$ & $\begin{array}{l}\text { ( ) aspirar traqueia } \\
\text { ( ) higiene oral } \\
\text { ( ) trocar equipo } \\
\text { ( ) instalar CVC } \\
\text { ( ) instalar cat. periférico } \\
\text { ( ) medicação endovenosa } \\
\text { ( ) curativo de cateter } \\
\text { ( ) coletar sangue } \\
\text { ( ) instalar SVD } \\
\text { ( ) esvaziar diurese } \\
\text { ( ) banho no leito } \\
\text { ( ) glicemia }\end{array}$ & $\begin{array}{l}\text { ( ) mudar decúbito } \\
\text { ( ) trocar fralda } \\
\text { ( ) curativo } \\
\text { ( ) cuidar de estomias } \\
\text { ( ) instalar SNG/NE } \\
\text { ( ) adm. dieta } \\
\text { ( ) débito de dieta } \\
\text { ( ) transporte } \\
\text { ( ) exame físico } \\
\text { ( ) traqueostomia } \\
\text { ( ) drenar tórax } \\
\text { ( ) equipamentos }\end{array}$ & $\begin{array}{l}\text { ( ) aspirar traqueia } \\
\text { ( ) higiene oral } \\
\text { ( ) trocar equipo } \\
\text { ( ) instalar CVC } \\
\text { ( ) instalar cat. periférico } \\
\text { ( ) medicação endovenosa } \\
\text { ( ) curativo de cateter } \\
\text { ( ) coletar sangue } \\
\text { ( ) instalar SVD } \\
\text { ( ) esvaziar diurese } \\
\text { ( ) banho no leito } \\
\text { ( ) glicemia }\end{array}$ & $\begin{array}{l}\text { ( ) mudar decúbito } \\
\text { ( ) trocar fralda } \\
\text { ( ) curativo } \\
\text { ( ) cuidar de estomias } \\
\text { ( ) instalar SNG/NE } \\
\text { ( ) adm. dieta } \\
\text { ( ) débito de dieta } \\
\text { ( ) transporte } \\
\text { ( ) exame físico } \\
\text { ( ) traqueostomia } \\
\text { ( ) drenar tórax } \\
\text { ( ) equipamentos }\end{array}$ \\
\hline Luvas & Indicado ( ) Sim ( ) Não & Usou ( ) sim ( ) Não & Indicado ( ) Sim ( ) Não & Usou ( ) $\operatorname{sim}($ ) Não & Indicado ( ) Sim ( ) Não & Usou ( ) sim ( ) Não \\
\hline Avental & Indicado ( ) Sim ( ) Não & Usou ( ) sim ( ) Não & Indicado ( ) Sim ( ) Não & Usou ( ) sim ( ) Não & Indicado ( ) Sim ( ) Não & Usou ( ) $\operatorname{sim}($ ) Não \\
\hline Máscara & Indicado ( ) Sim ( ) Não & Usou ( ) sim ( ) Não & Indicado ( ) Sim ( ) Não & Usou ( ) $\operatorname{sim}($ ) Não & Indicado ( ) Sim ( ) Não & Usou ( ) sim ( ) Não \\
\hline Óculos & Indicado ( ) Sim ( ) Não & Usou ( ) sim ( ) Não & Indicado ( ) Sim ( ) Não & Usou ( ) sim ( ) Não & Indicado ( ) Sim ( ) Não & Usou ( ) sim ( ) Não \\
\hline
\end{tabular}




\section{APÊNDICE D - EPI INDICADO PARA OS PROCEDIMENTOS POR TIPO DE PRECAUÇÃO}

\begin{tabular}{|c|c|c|c|c|c|c|c|c|c|c|c|c|}
\hline \multirow[b]{2}{*}{ Procedimentos } & \multicolumn{4}{|c|}{ Precaução Padrão } & \multicolumn{4}{|c|}{ Precaução de contato } & \multicolumn{4}{|c|}{ Precaução Respiratória } \\
\hline & Avental & Luvas & Máscara & Óculos & Avental & Luvas & Máscara & Óculos & Avental & Luvas & Máscara & Óculos \\
\hline Adm. Dieta & & $\mathrm{X}$ & & & $\mathrm{X}^{*}$ & \begin{tabular}{|l|}
$\mathrm{X}$ \\
\end{tabular} & & & & $\mathrm{X}$ & $\mathrm{X}$ & \\
\hline Aspiração de traqueia & $X$ & $\mathrm{X}$ & $\mathrm{X}$ & $\mathrm{X}$ & $\mathrm{X}$ & $\mathrm{X}$ & $X$ & $\mathrm{X}$ & $\mathrm{X}$ & $\mathrm{X}$ & $\mathrm{X}$ & $\mathrm{X}$ \\
\hline Banho no leito & $\mathrm{X}$ & $\mathrm{X}$ & $\mathrm{X}$ & & $\mathrm{X}$ & $\mathrm{X}$ & $\mathrm{X}$ & & $\mathrm{X}$ & $\mathrm{X}$ & $\mathrm{X}$ & \\
\hline Coletar sangue & & $\mathrm{X}$ & & & $\mathrm{X}$ & $\mathrm{X}$ & & & & $\mathrm{X}$ & $\mathrm{X}$ & \\
\hline Cuidar de estomias & & $\mathrm{X}$ & $\mathrm{X}$ & & $\mathrm{X}$ & $\mathrm{X}$ & $X$ & & & $\mathrm{X}$ & $\mathrm{X}$ & \\
\hline Curativo & & $\mathrm{X}$ & $\mathrm{X}$ & $\mathrm{X} * *$ & $\mathrm{X}$ & $\mathrm{X}$ & $\mathrm{X}$ & $\mathrm{X}^{* *}$ & & $\mathrm{X}$ & $\mathrm{X}$ & $\mathrm{X} * *$ \\
\hline Curativo de cateter & & $\mathrm{X}$ & $\mathrm{X}$ & & $\mathrm{X}$ & $\mathrm{X}$ & $\mathrm{X}$ & & & $\mathrm{X}$ & $\mathrm{X}$ & \\
\hline Débito de dieta & & $\mathrm{X}$ & & & $\mathrm{X}^{*}$ & $X$ & & & & $\mathrm{X}$ & $\mathrm{X}$ & \\
\hline Dreno de tórax & $\mathrm{X}$ & $\mathrm{X}$ & $\mathrm{X}$ & $\mathrm{X}$ & $\mathrm{X}$ & $\mathrm{X}$ & $X$ & $\mathrm{X}$ & $\mathrm{X}$ & $\mathrm{X}$ & $\mathrm{X}$ & $\mathrm{X}$ \\
\hline Esvaziar diurese & & $\mathrm{X}$ & & & $\mathrm{X}^{*}$ & $\mathrm{X}$ & & & & $\mathrm{X}$ & $\mathrm{X}$ & \\
\hline Exame físico & & $\mathrm{X}$ & & & $\mathrm{X}$ & $\mathrm{X}$ & & & & $\mathrm{X}$ & $\mathrm{X}$ & \\
\hline Glicemia & & $\mathrm{X}$ & & & $\mathrm{X}^{*}$ & $X$ & & & & $\mathrm{X}$ & $\mathrm{X}$ & \\
\hline Higiene oral & & $\mathrm{X}$ & $\mathrm{X}$ & & $\mathrm{X}$ & $\mathrm{X}$ & $\mathrm{X}$ & & & $\mathrm{X}$ & $\mathrm{X}$ & \\
\hline Instalar cat. Periférico & & $\mathrm{X}$ & & & $\mathrm{X}$ & $\mathrm{X}$ & & & & $\mathrm{X}$ & $\mathrm{X}$ & \\
\hline Instalar CVC & $X$ & $\mathrm{X}$ & $\mathrm{X}$ & $\mathrm{X}$ & $\mathrm{X}$ & $\mathrm{X}$ & $\mathrm{X}$ & $\mathrm{X}$ & $\mathrm{X}$ & $\mathrm{X}$ & $\mathrm{X}$ & $\mathrm{X}$ \\
\hline Instalar SNG/NE & & $\mathrm{X}$ & $\mathrm{X}$ & $\mathrm{X}$ & $\mathrm{X}$ & $\mathrm{X}$ & $\mathrm{X}$ & $\mathrm{X}$ & & $\mathrm{X}$ & $\mathrm{X}$ & $\mathrm{X}$ \\
\hline Instalar SVD & & $\mathrm{X}$ & $\mathrm{X}$ & $\mathrm{X}$ & $\mathrm{X}$ & $X$ & $\mathrm{X}$ & $\mathrm{X}$ & & $\mathrm{X}$ & $\mathrm{X}$ & $\mathrm{X}$ \\
\hline Manuseio de equipamento & & & & & $\mathrm{X}^{*}$ & $\mathrm{X}$ & & & & & $\mathrm{X}$ & \\
\hline Medição endovenosa & & $\mathrm{X}$ & & & $\mathrm{X}^{*}$ & $\mathrm{X}$ & & & & $\mathrm{X}$ & $\mathrm{X}$ & \\
\hline Mudar decúbito & & & & & $\mathrm{X}$ & $\mathrm{X}$ & & & & & $\mathrm{X}$ & \\
\hline Transporte & & & & & $\mathrm{X}$ & $\mathrm{X}$ & & & & & $\mathrm{X}$ & \\
\hline Troca de equipo & & $\mathrm{X}$ & & & $\mathrm{X}^{*}$ & $\mathrm{X}$ & & & & $\mathrm{X}$ & $\mathrm{X}$ & \\
\hline Trocar fralda & & $\mathrm{X}$ & $\mathrm{X}$ & & $\mathrm{X}$ & $\mathrm{X}$ & $\mathrm{X}$ & & & $\mathrm{X}$ & $\mathrm{X}$ & \\
\hline Outros & Variável & Variável & Variável & Variável & $\mathrm{X}^{*}$ & $\mathrm{X}$ & Variável & Variável & Variável & Variável & $\mathrm{X}$ & Variável \\
\hline
\end{tabular}




\section{APÊNDICE E - AUTORIZAÇÃO E CONCORDÂNCIA DA INSTITUIÇÃO}

\section{TERMO DE CONCORDÂNCIA}

O Prof. Dr. Hervaldo Sampaio Carvalho, Superintendente do Hospital Universitário de Brasilia está de acordo com a realização, neste Setor, da pesquisa "Práticas de precauções em Unidade de Terapia Intensiva de um hospital de ensino do Distrito Federal", de responsabilidade da pesquisadora Alaíde Francisca de Castro, para Mestrado do Programa de Pós-Graduação em Enfermagem, após aprovação pelo Comitê de Ética em Pesquisa da com Seres Humanos do(a) CEP da Faculdade de Ciências da Saúde da Universidade de Brasília.

$O$ estudo envolve realizaçấo de entrevistas e auditorias observacionais não participantes da rotina de trabalho em colaboradores. Tem duração de quatro meses, com previsão de início para julho de 2015.

Brasília, 19 de março de 2015.

Diretor responsável do Hospital/ Faculdade:

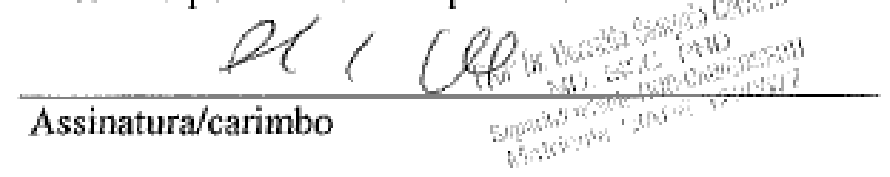

Chefe do setor de pesquisa e inovação tecnológica:

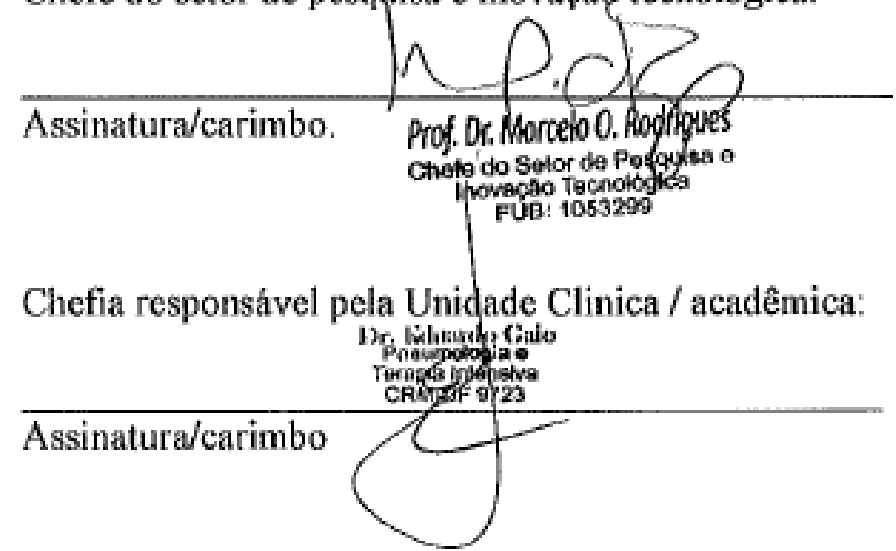

Pesquisador Responsável pelo protocolo de pesquisa:

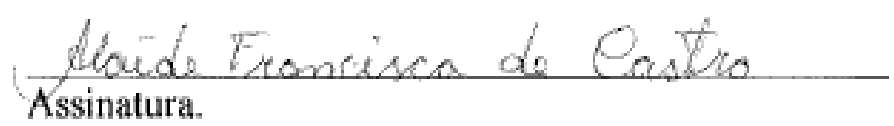




\section{ANEXOS A - TÉCNICA DE HIGIENE SIMPLES DAS MÃOS DA OMS}

\section{Como Higienizar as Mãos com Água e Sabonete?}

Higienize as mãos com água e sabonete apenas quando estiverem visivelmente sujas! Senão, friccione as mãos com preparações alcoólicas!

(7) Duração de todo o procedimento: 40-60 seg.
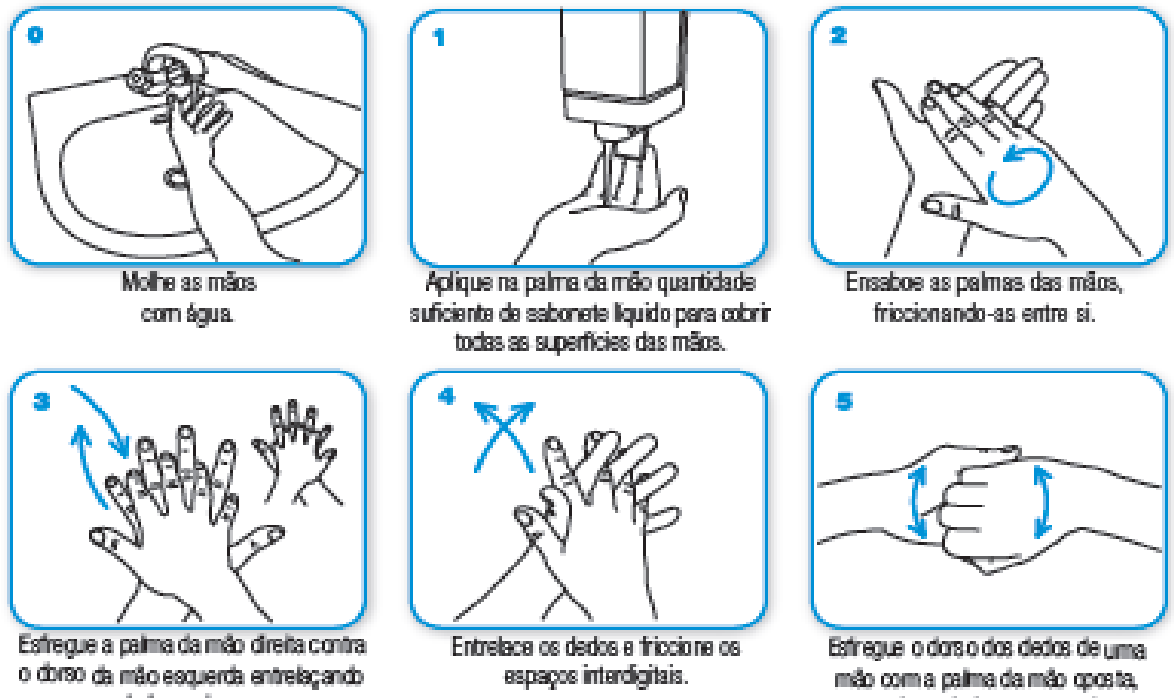

todas 39 superficies das
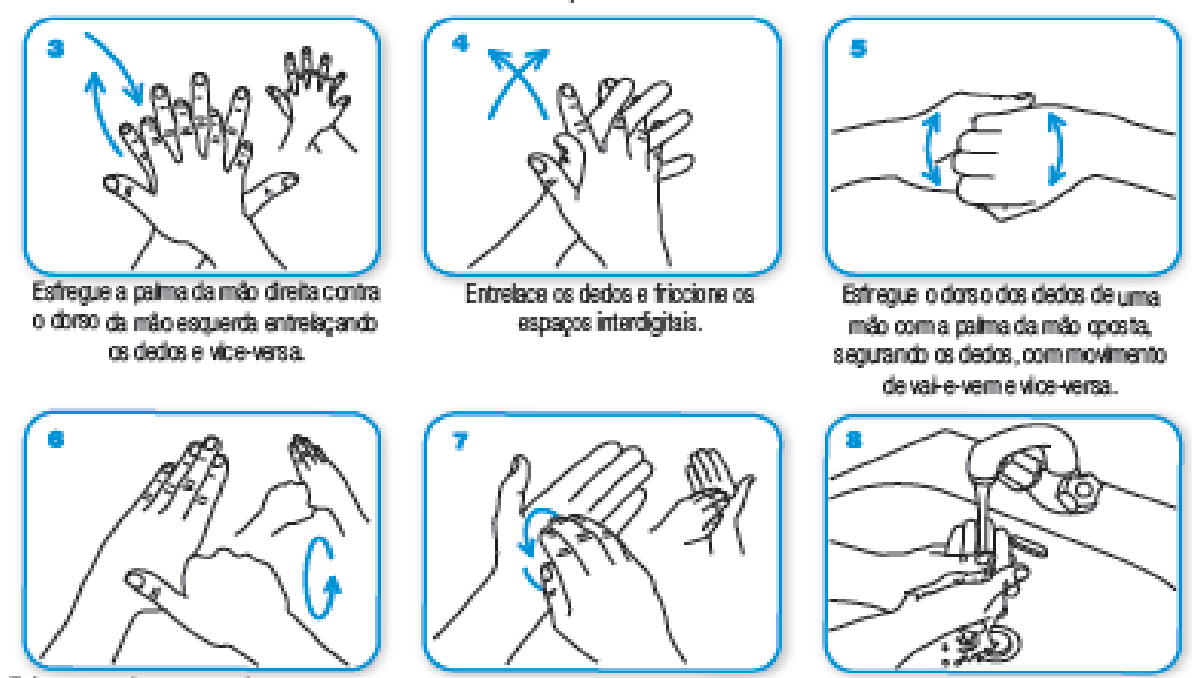

Estreque o polecar equado con oaudio dapatra de milo dreba, unlandb-sede novinerto cicula e vos-versa.
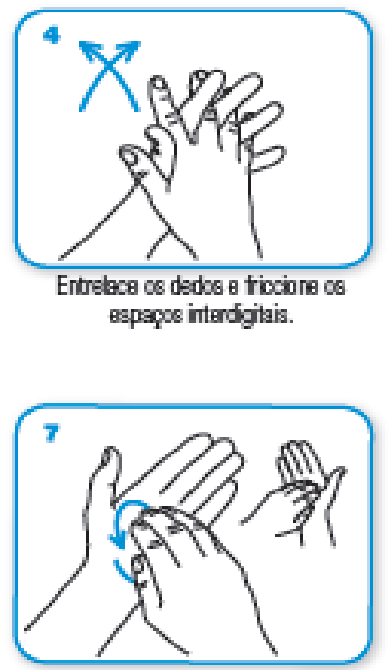

Fibione as popas dgtaise urhas da mâ

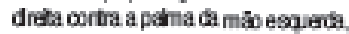
fagando moviment crula e viceversa.
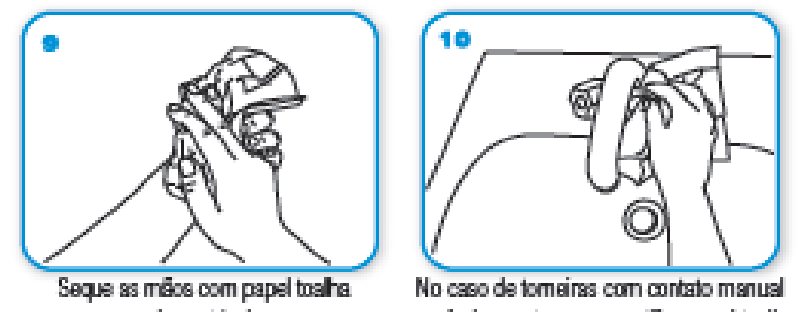

No caso ds tomeiras com contaio menual descartivel para fechamento, ampre utilise papel bel ha

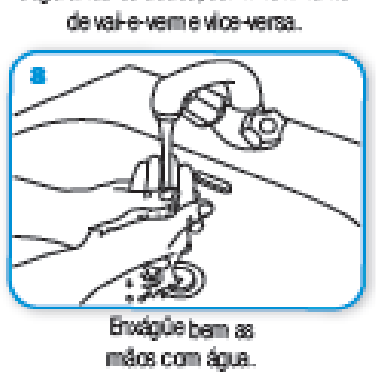

WORLD ALLLANCE

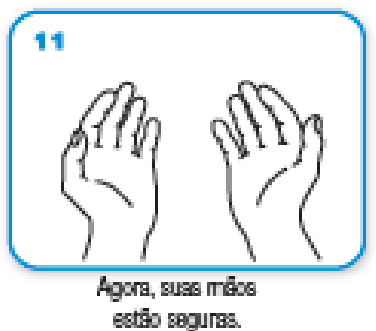




\section{Como Fazer a Fricção Anti-Séptica das Mãos com Preparações Alcoólicas?}

Friccione as mãos com Proparações Alcoólicas! Higionize as mãos com água e sabonote apenas quando estiverem visivelmente sujas!

(1) Duração de todo o procedimento: 20 a $30 \mathrm{seg}$

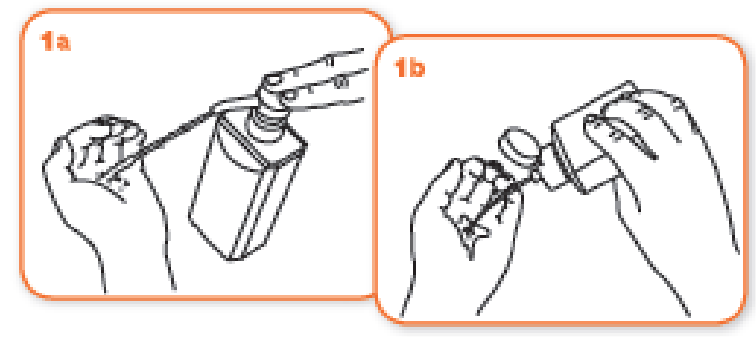

Aplique uma quantidade suficiente de preparaçāo alcoólica em uma mão em forma de concha para cobrir todas as superficies das mãos.

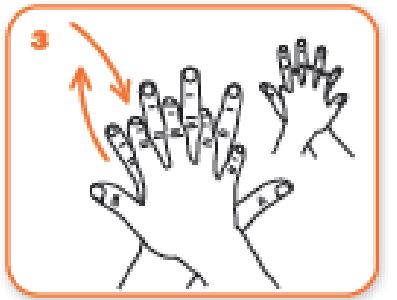

Friccione a palma dreita contra 0

dorso da mâo esquerda entrelaçando os dedos e vice-versa.

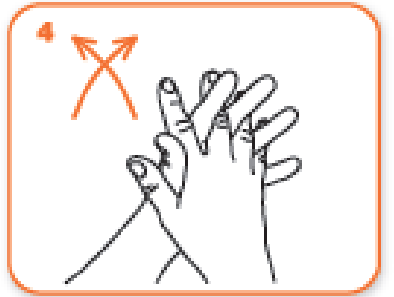

Friocione a palma das mãos entre si com os dedos entrelaçados.

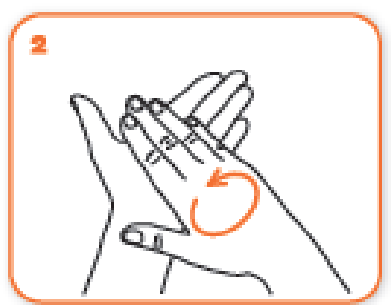

Friccione as palmas das māos entre si.

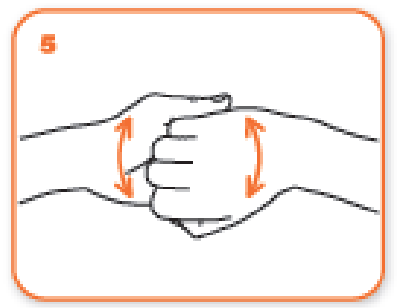

Friocione o dorso dos dedos de uma māo com a palma da māo oposta, segurando os dedos, com movimento de vai-e-vem e vice-versa.

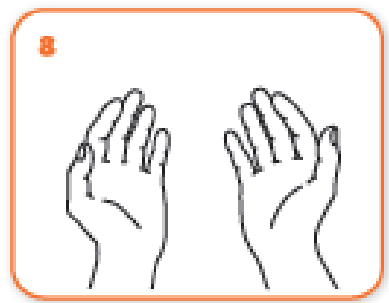

Quando estiverem secas, suas māos estarāo seguras.

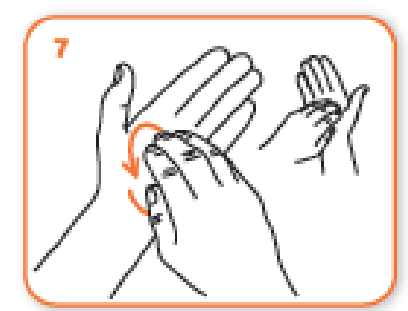

Friccione as popas digitais e unhas da māo dreita contra a palma da mäo esquerda, fazendo um movimento circular e vice-versa.
Friccione o polegar esquerdo, com o auxilib da palma da mäo direita, utilizando-se de movimento circular e vice-versa.

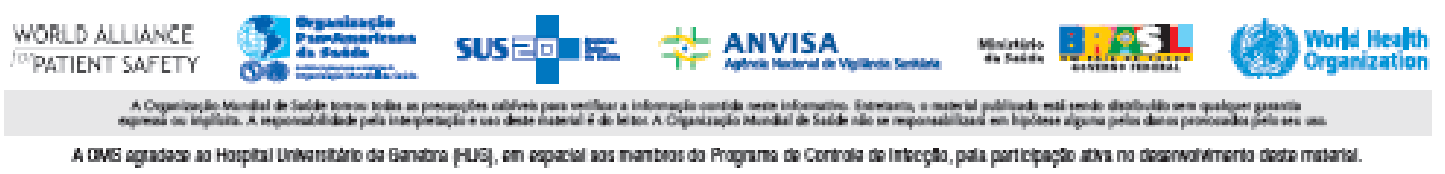


ANEXO C - TÉCNICA DE ANTISSEPSIA CIRÚRGICA DAS MÃOS DA ANVISA

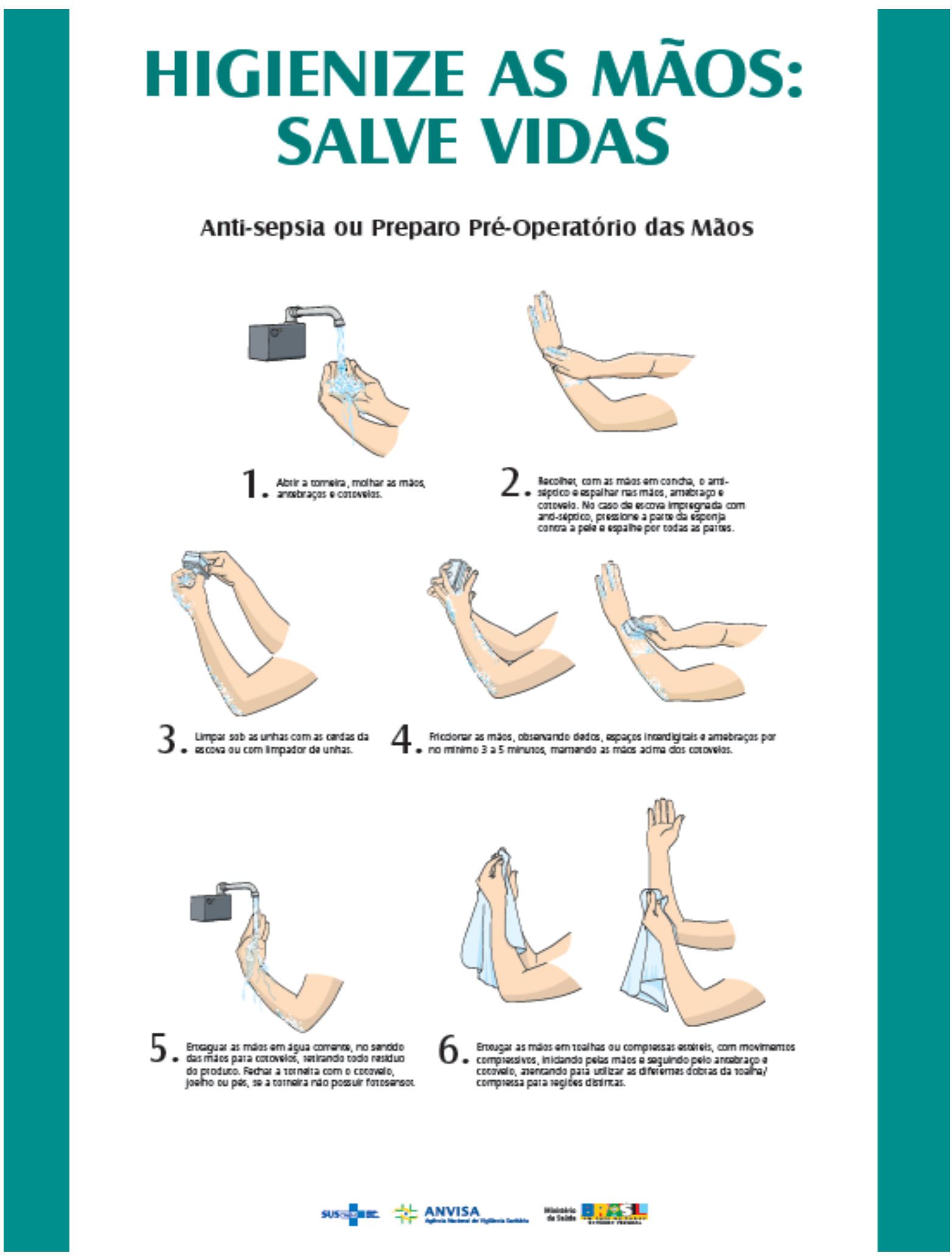




\section{ANEXO D - PIRÂMIDE DE ORIENTAÇÕES AO USO DE LUVAS DA OMS}

A Pirâmide das Luvas - para apoiar a tomada de decisaào sobre quando usar (ou nāo usar) luvas

As luvas devem ser usadas de acordo com as precauçoes PADRÃO $\theta$ de CONTATO. A pirâmide detalha alguns exemplos clínicos em que as luvas nă sato indicadas, $\theta$ outros em que as luvas de procedimento ou estéreis să indicadas. A higiene das mass deve ser realizada quando for o caso, independentemente de indicaçoes para o uso de luvas.

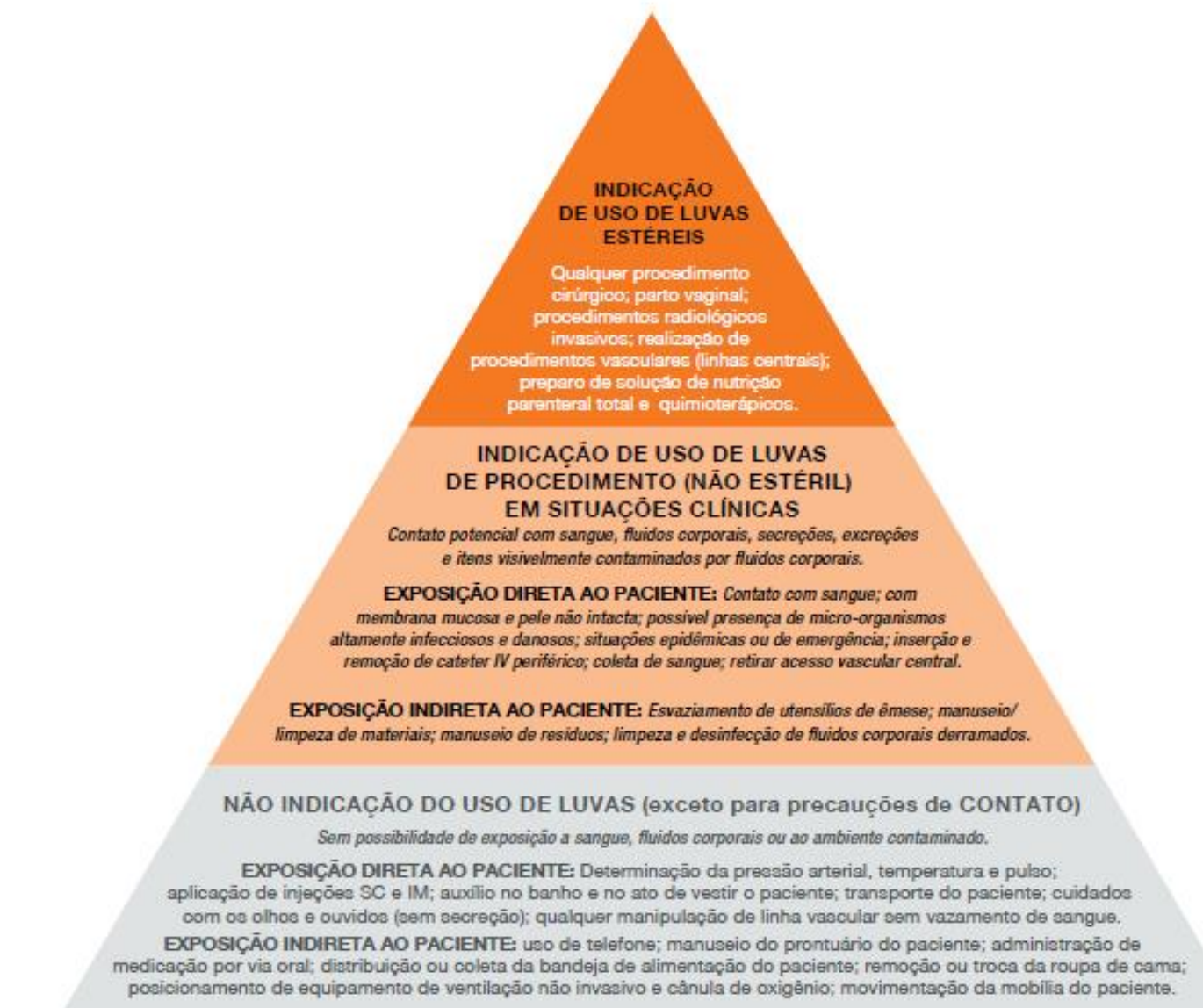




\section{ANEXO E - TÉCNICA DE COLOCAÇÃO E RETIRADA DE LUVAS DA OMS}

Quando a higiene das mács coconer antas de um contalo que exja o uso de luvss, reelias-a com preparaça alcoólica ou com água e saboneb.

I COMO CALÇAR AS LUVAS:

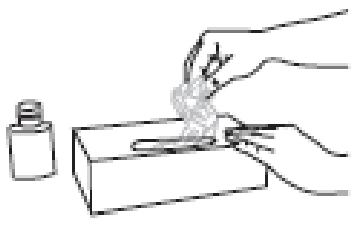

1. Retire uma lva de sua caixa original

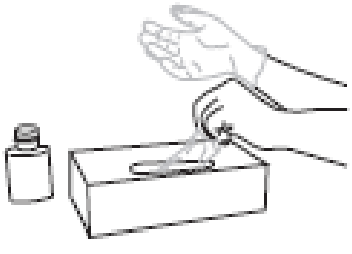

4. Retire a segunda luva com a mso sem liva e toqua apenas una área restrta da supericie conrespondente as pulso

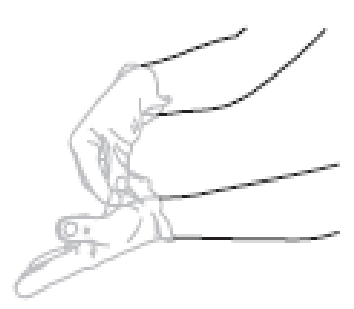

1. Toqua a parte irterna da luva na alura do pulso para removè la, sem tocar na pele do antecracpo, e retre-a da más, permitindo assim qua a luva vire do avesso

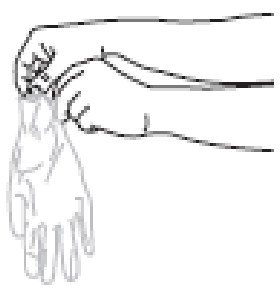

2. Toque apenas uma área restrita de supericie da luva corrasondente ao pulso (na extrenidade superior do purho)

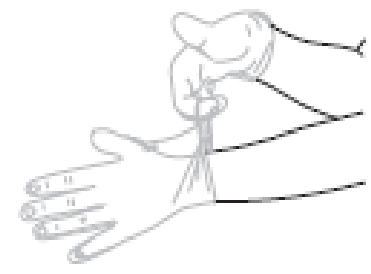

5. Para evitar o contato com a pela do antebrapo com a mso calçada dobre a perte externa da liva a ser calcada nos dedos dobrados da máo calçada, permìindo assim 0 calçamento da segunda uva

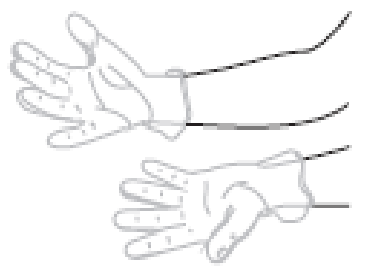

6. Uma ver calpadas, as mbos nto devem tocar nada que nకso estieja defínido pelas indicaçbes e condíptes de uso das livas

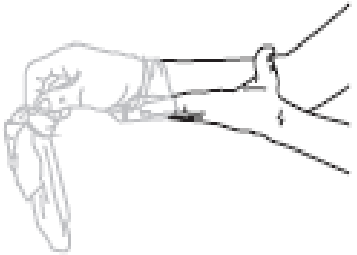

2. Segure a luva refirada com a mato enluvada e dasize os dedos da mán sem tiva na perte interna entre a luva e o pubo. Remova a segunda luva, rolando-a para baixo sobre a máo e dobrando-a na primera lva

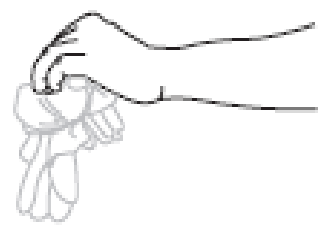

3. Descarte as luvas refiradss

Em seguida efetue a higiene das mács com preparaçao alcoólica ou com água e sabonete liquido 
ANEXO F - PLANTA FÍSICA DA

UTI

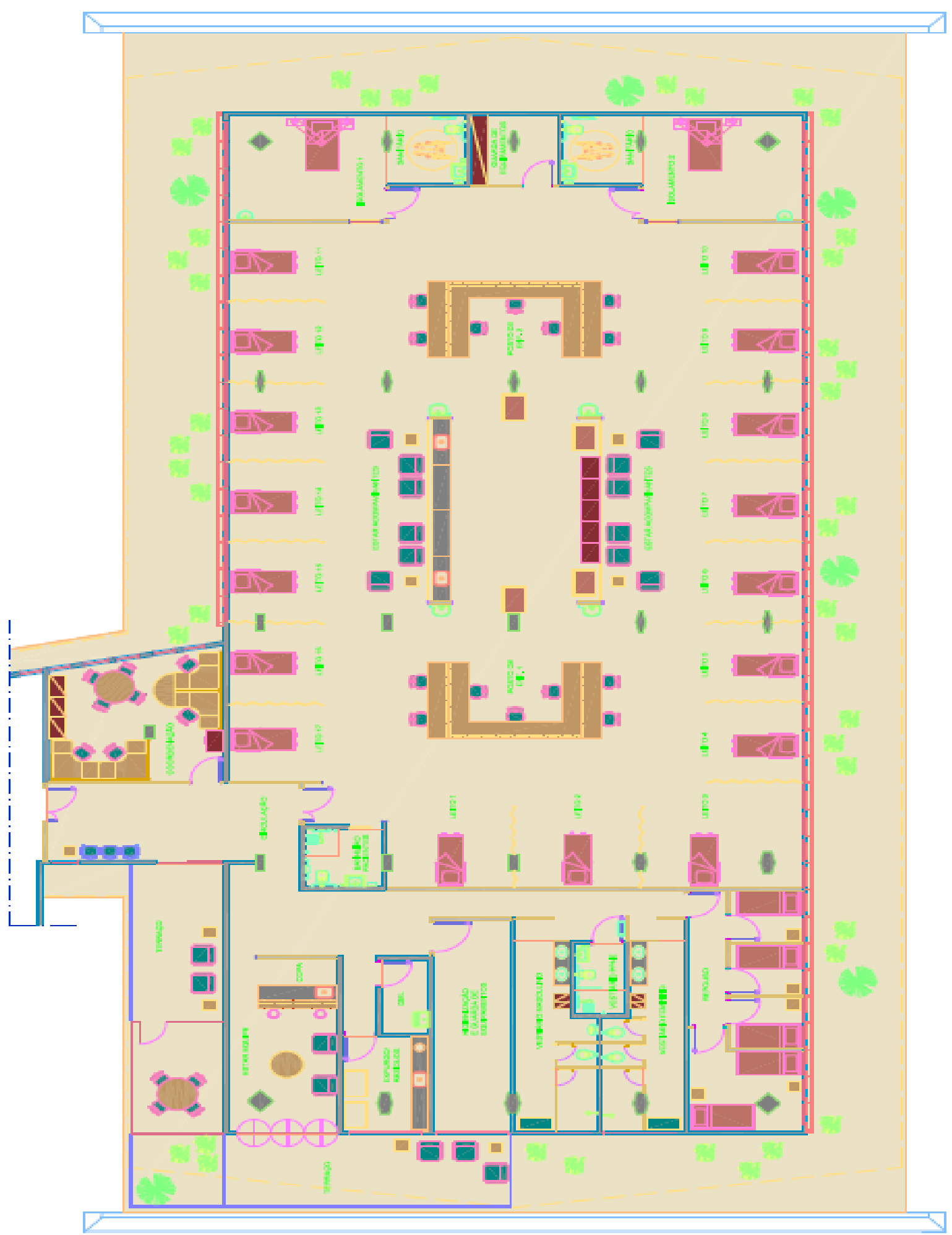

FONTE: Planta baixa com layout da UTI Adulto (HUB, 2013b). 


\section{ANEXO G - INSTRUMENTO DE COLETA DE DADOS 1: AVALIAÇÃO DE HIGIENE DAS MÃOS DA OMS}

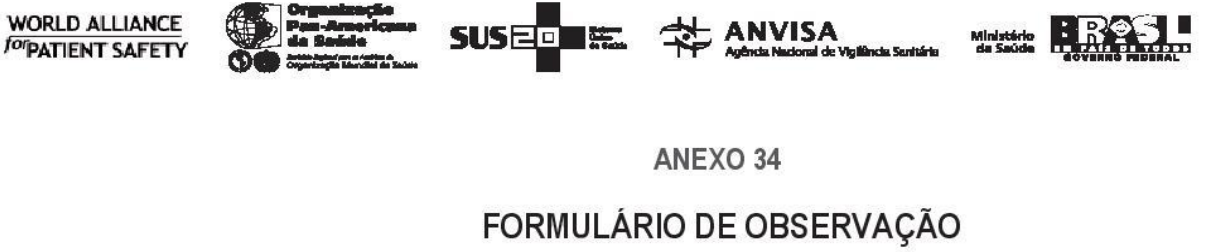
SUSED nastons

ANEXO 34

FORMULÁRIO DE OBSERVAÇÃO

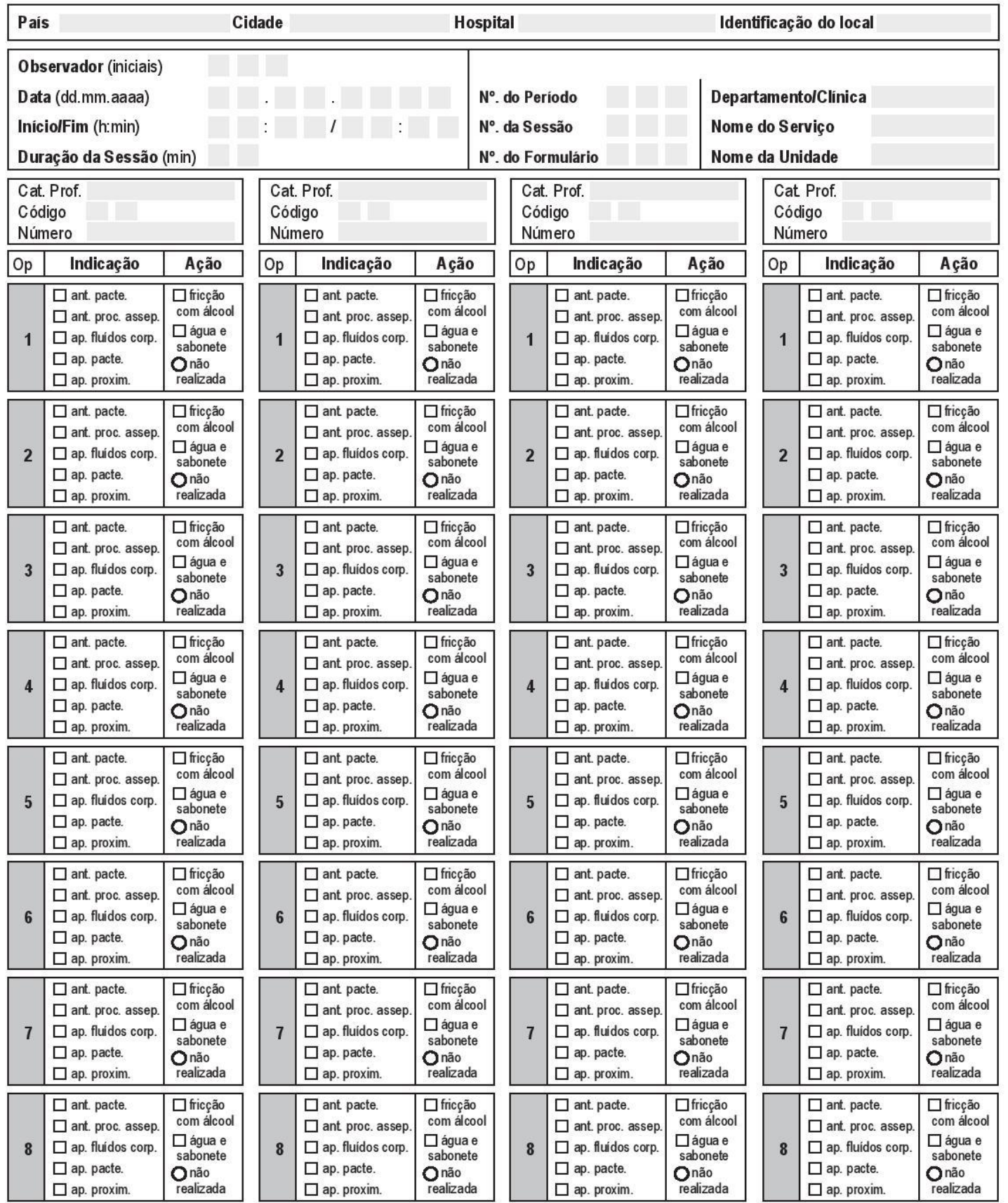




\title{
ANEXO H - APROVAÇÃO DO COMITÊ DE ÉTICA DA FACULDADE DE CIÊNCIAS DA SAÚDE, DA UNIVERSIDADE DE BRASÍLIA
}

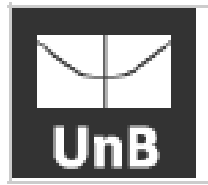

\author{
FACULDADE DE CIÊNCIAS DA \\ SAÚDE DA UNIVERSIDADE DE \\ BRASILIA - CEP/FS-UNB
}

\section{PARECER CONSUBSTANCIADO DO CEP}

\section{DADOS DO PROJETO DE PESQUISA}

Título da Pesquisa: Práticas de precauçōes em Unidade de Terapia Intensiva em um hospital de ensino no Distrito Federal.

Pesquisador: Alaide Francisca de Castro

Área Temática:

Versäo: 2

CAAE: 44389815.8 .0000 .0030

Instituiçäo Proponente:Programa de Pós Graduação em Enfermagem - Mestrado - Universidade de

Patrocinador Principal: Financiamento Próprio

\section{DADOS DO PARECER}

Número do Parecer: 1.188 .047

Data da Relatoria: $12 / 08 / 2015$

Apresentaçäo do Projeto:

"Introdução: As infecções relacionadas à assistência à saúde (IRAS) săo um grave problema de saúde pública ameaçando a segurança dos pacientes, profissionais e usuários em todo o mundo. As instituições têm dedicado grandes esforços para melhorar a adesăo às medidas de prevençäo, principalmente as precauçốes para evitar a transmissão de microrganismos entre os pacientes e entre pacientes e profissionais. Na avaliaçăo dessas práticas é cada vez mais frequente a utilizaçăo de indicadores clínicos de estrutura e processo e năo somente os indicadores de resultado, como é o caso das taxas de infeç̧ão. Objetivo: Avaliar as práticas de precauções e a infraestrutura da UTI de um hospital de ensino do Distrito Federal. Método: Serão aplicados três instrumentos. 0 primeiro será um questionário estruturado autoaplicável aos profissionais que atuam na unidade; os outros dois instrumentos säo para auditorias em observação direta näo participante com questionários estruturados. A primeira auditoria avaliará a adesão à higiene das mãos e a segunda auditoria registrará as condiçöes físicas, a disponibilidade de insumos para as práticas de precauçōes, o uso de equipamentos de proteção individual e a adequaçäo das indicaçöes de precauçôes na rotina de trabalho dos médicos, enfermeiros, fisioterapeutas, técnicos e auxiliares de enfermagem. Resultados esperados: Espera-se alcançar diagnóstico da infraestrutura para aplicação das precauçôes e a adesão às práticas pelos profissionais da UTI para oferecer dados que

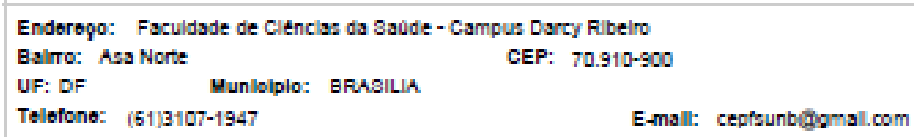




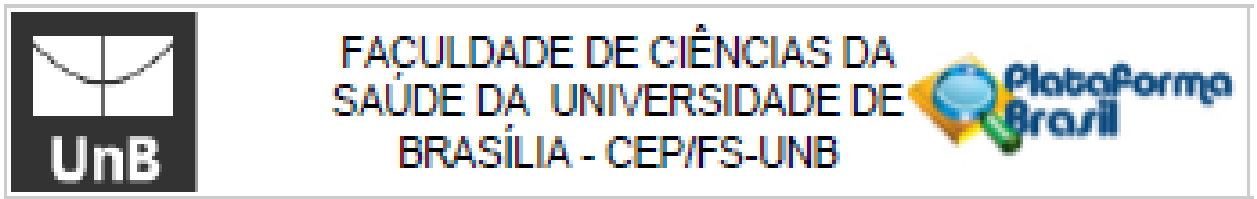

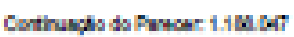

contrbusm so piane|smento do Fropams de Controle de RAB do horplal".

Metodologla:

- Exhdo observalons|, transueral e prosettho

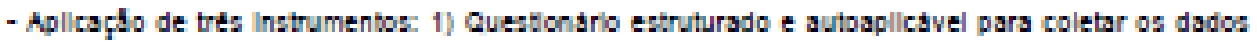
referentes as carcteristicas dos profselonals lotnero, ldade, profsabo, tempo de atuapas na profasto,

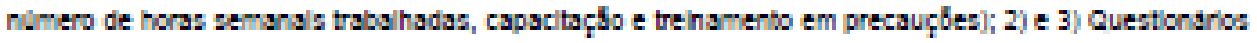

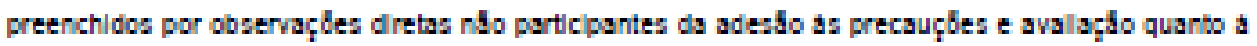

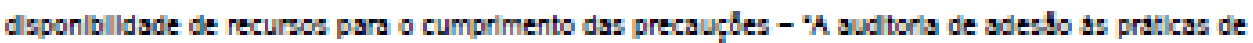

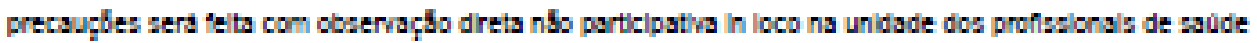

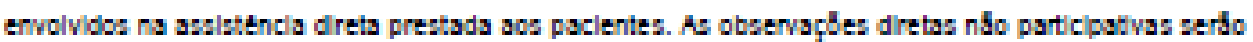
teltas a datacls, porem sem ocultar a presenca do observador que flcara locslindo no ponto de

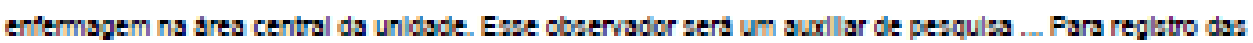
observages da sdesdo a hlplene das mos sera usado o formularlo de observages da Estratepla

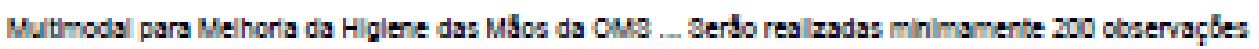
de oportunldades de hlene das mboa". "O nümero de observacles sera dletribuldo proporclonalmente

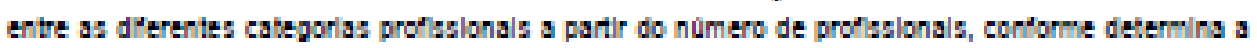

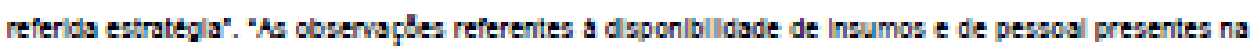

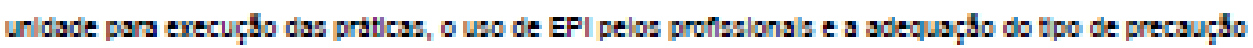
Indlcads, serto replatas em outro questlonario eatruturado que fol construldo e adsphado a partr dos Instrumentos waldados, do Manus de Avallagho de Quallade das Frafcas de controle de Infecflo

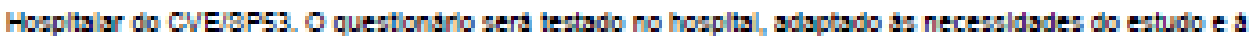
resliade local".

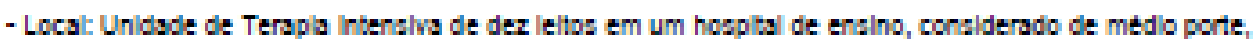
com 234 leltas atvo:

critrio de linchso:

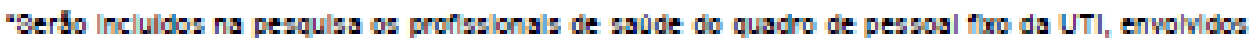

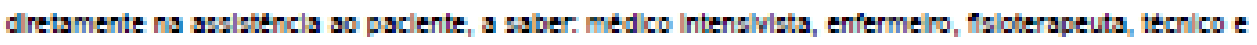
aullar de enermspem, que aceltarem ao convite para partclpar do estudo e asainarem o Termo de

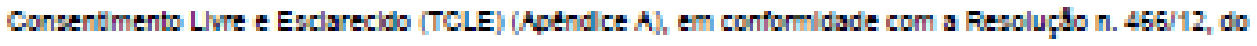
Conetho Hachal de asude (CNa)".

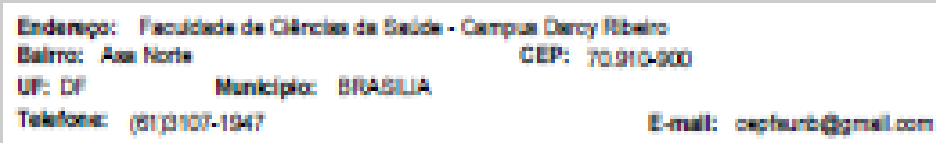




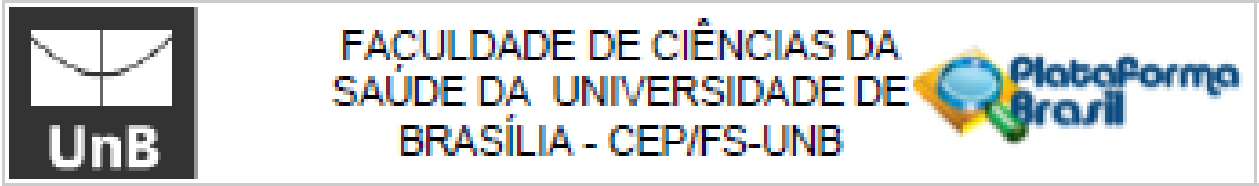

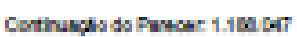

Crterio de Exclus foc

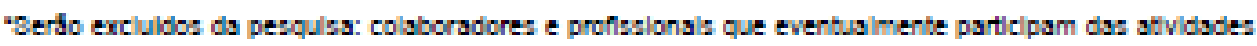
assistenclals na unidade como os alunos de gradusç5o e pos-graduaç5o, tecnicos de laboratorlo ou radiologla, nutricionistas, paicologos, odontologos, farmactuticos e medicos de outras especialidades. Tambem serdo excluldoa os colsborsdores da ares de higlene e limpezs, sdminlstrativoa, famillares, vialtantes e oa profasionals que se recusarem a particlosr do estudo ou que eativerem em Icença medica ou terisa no periodo da coleta de dados".

Hpotese:

"N5o se aplica".

Objettvo da Pocqulca:

Objetvo Primario:

"Avalar as pratcas de precauçbes e a intraestrutura da UTI de um hospital de enaino do Dlatrito Federa".

Objetivo aecundario:

"Descrever as caracteristicas dos proflesionals que atuam na assistencla direta aos pacientes. Medr a adesfo as praticas de higlene das mfos e uso de equipamentos de proteçlo indlvidus doa proflasionals que prestam asalestencia direta aoa pacientez. Avalar a adequaç\$o das indlcaçbes de precauçbea. Identificar a estrutura flaica e recursos materiala dlspontvels para a execuç5o das pratcas de precauçbez".

\section{Avallogso doc Rileoec o Benefioloc:}

Rlacos: "A pesquisa pode acarretar acs participantes, risco minimo de natureza palquica, decorrente de poasivel deaconforto ou ansiedsde ao reaponder

perguntas que envolvam informaçbes sobre sl, assim como, a observaçlo direta pela pesapulasdora das praticas de trabalho dos participantes, mas

que serd minimizado com eaciarecimentos necesatrios antes e no decorrer da pesquas referente ao objetivo da pesquasa e procedimentoa de coleta

de dadoa. No entanto, a refexdo doa participantes sobre o assunto e um grande bene'icio indireto desas pesqulsa para seu local de trabaino, porque

a abordspem do tema serve para dlvulgar e eatimular a mehoria da adeafo as praticas recomendadas." Beneficios: "Conforme devermina a RDC n"35, de 25 de Juho de 2013, o hospltal eata implantando

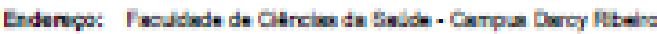

Balrna: Ase Norte CEP: Rogrosoo

UT: DF Munkipio Bluasua

CEP: 70.910200

Tekloes: (ot)anot-1947 E-malt: cesturtagnel xem 


\begin{tabular}{|c|c|}
\hline MnR & $\begin{array}{c}\text { FACULDADE DE CIËNCIAS DA } \\
\text { SAUUDE DA UNIVERSIDADE DE } \\
\text { BRASÍLIA - CEPIFS-UNB }\end{array}$ \\
\hline
\end{tabular}

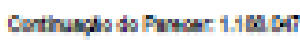

o seu 'Plano de aepuranpa do Faclente' que contempla a

amplagdo do Proprams de Controle de Infectio Relacionada a Assisthcla a Salde (PCIRAS) na busca da wallaço dos Indladores de proceses

relaclonsdos as princlpals recomendaçdes para prevençbo das IFAB. Portanto, sto primordala os dlagnosticos corretos da eltuaçbo encontrada na

Insthulço referente a sdesto as orientaçles de precauples e extutura ofereclids para o cumprimento deasa orlentagdes. Expera-se wallar a

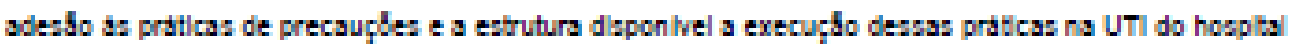
para orieriar a bomada de dechbo do

pestores no plane|amenio do FC FAB. Fara a aplapho deses probcolos e proced mentos operaclonals de precayples so necerearlos pastos

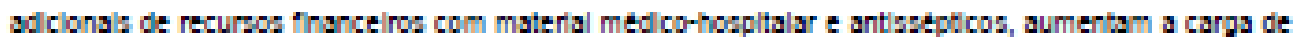
trabalho dos profleslonals na aselatencla e

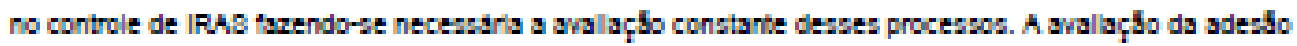
ace protocolos do PCIRAS Ira contribulr

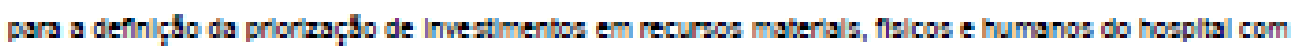
vatsa a busca de me horls em seus

proceses de trabalho intemos para a sepuranpa dos pacientes, colsboradores e usuarios."

Comentarloc o Concidarapose cobre a Pocqulca:

Os pesquasores responderam adequadamente s solletaçto deste CEF conforme elencado no utimo porto do parecer potado em 13 de malo de 2015 icons/deragdea finals a criterio do cafin envando cata

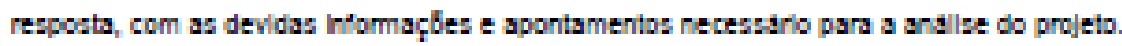

Otservarse sdequacto do risca ds pesqulsa, aselm como doa pontos elencados pela comlsebo no TCLE Tambem se verfica que os peaquasdores adequaram o cronograma do eatudo, Informando que a realzaço da "bolets de dado" tera lniclo em aposto de 2015 e termino em outubro do mesmo ano

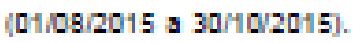

Conelderagec cobro os Tomoc de aprecentapjo obripatorla:

Documentse que complem o processo

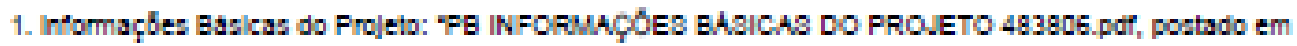
$17 / 04 / 2015$

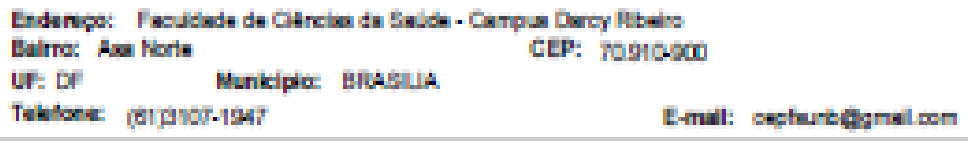




FACULDADE DE CIÊNCIAS DA
SAÚDE DA UNIVERSIDADE DE
BnB BrasiliA - CEP/FS-UNB

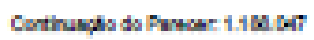

2. Outroa: "Cumiculum Maria Criatina pd", poetado em 17/04/15. Curriculo do orientador, gerado em arqulvo pdt. por meio da plataforma Lattea. Documento adequado as normas deste CEP;

3. Vinculo Inattulg̨les Farticipantes: "Termo de clencla co-participante.pd", postado em 31/03/2015. Documento devidamente redigido, carimbado e asainado pelo dretor e pelo chefe do setor de pesquias do HuB;

4. TCLE-Modelo de Termo de Consentimento Livre e Eaclarecido: "Apendice A- TCLE.doc", postado em 31/03/2015;

5. Projeto Detainado: "PROJETO DE PEsQUisA Praticas de Precauçdes em UTI.doc, postado em 31/03/2015;

6. Folha de rosto: "Folha de roato.pdi, postado em 31/03/2015. Documento devidamente presnchido e assinado peio pesquisador responstvel, e devidamente asainado e carimbado pela diretora da Faculdade de Clencias da aaude;

7. Outroe: "Cumiculo Lattes Alaide.pdr, postado em 17/04/15. Curriculo do pesqulasdor reaponatvel, gerado em arquivo pdf. por melo da plataforma Lattea. Documento adequado as normas deste CEP;

8) Informaçbes Bdaicas do Projeto: "Pg INFORMAÇÓES BAsiCA3 DO PROJETO 483806.pd", poatado em 31/03/2015;

9) Outros: "Termo de responaablidade e compromisso.pdi, postado em 31/03/2015. Documento adequado as normas desse CEF;

10) Vinculo Insttulçbes Participantea: "Termo de concordsncia.pd", postado em 31/03/2015. Documento devidamente redigido, carimbado e asainado pelo dretor, chefe do setor de pesqulas e chefa direta (Terapla intenalva) do HuB, assim como da pesquisadora;

10) Vinculo insthulçbes Participantes: 'Termo de concordsncia co-participante.pdr, poatado em 31/03/2015. Primeira versfo do documento. O meamo fol adequado posteriormente;

11) Outroa: "Carta de encaminhamento do projeto ao CEP.pdr", postado em 31/03/2015. Documento contempla criterios exigldos pelo CEP;

12) Outroa: "Formulario de observaçlo.pdr, postado em 31/03/2014. Documento que compde o eatudo anexos/apendices;

13) Outros: "Mpendice C - Instrumento de coleta de dsdoa 2.doc", postado em 20/03/2014. Documento que comple o eatudo - anexos/apendices;

14) Outroa: "Anero - Instrumento de coleta de dadoa 1.doc", postado em 20103/2014. Documento que comple o estudo - anexos/apendices;

15) Cutroa: "Apendice B - Cuestionario de pesquias.doc", postado em 20103/2014. Documento

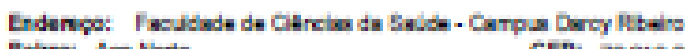
Balrna: Asa Norte

UF: Df Munkipio: BILABUA

Tekloes: (E) ginou-1947

E-mall: esteurtegnel xom 


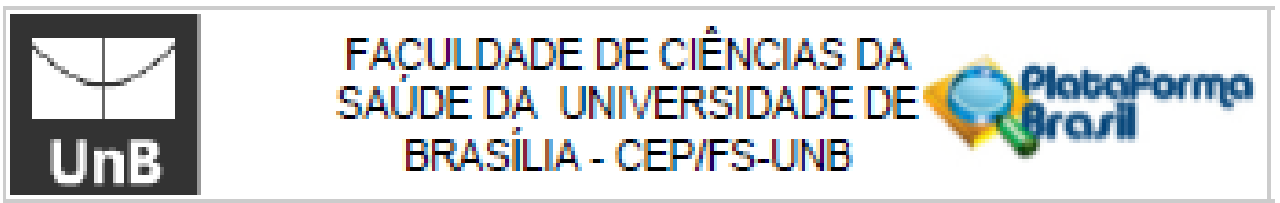

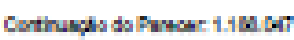

que comple o thodo - anzwaptandlaes:

Documentos acresertados ao proceso apde emlesbo de parecer - 13052015

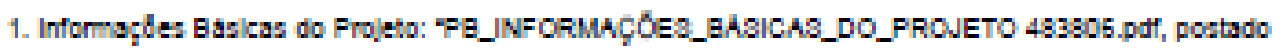
e-m 0472015:

2. TCLE - Modelo de Termo de Coneentmento Lvre E Esclarecldo: "Apthdice A- TCLE alteradodoc",

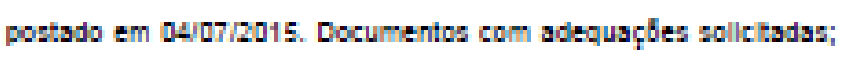

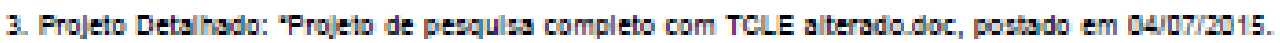
Documentos com adequagtes solleltadas;

4. Outros: "Carta de respota pendenclas.puf, poatado em 04/07/2015. Fiedlalda contome golletapho deste CEP.

Recomondapglec:

No se aples

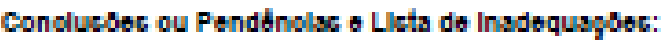

ANALISE DAS RESPOSTAB AB PENDENCIAS APONTADOS NO PARECER NO DE 11.120.113, 13/05/20+15:

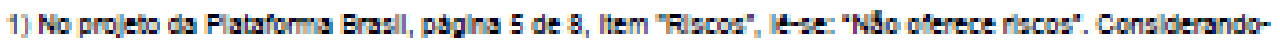

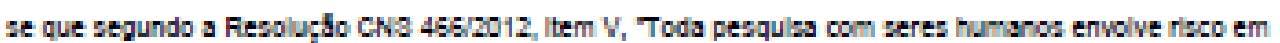

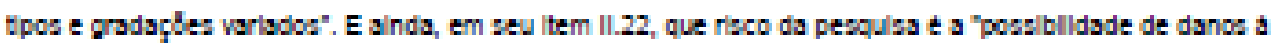

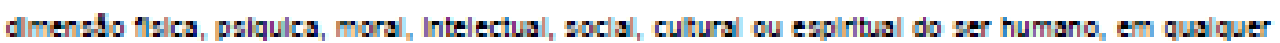
perqulss e dela decontente", solleita-se explcitar riscos e beneflelos, bem como formas de minimlzar os

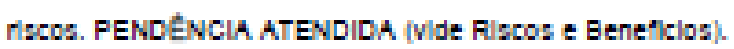

2) Cuanto ao TCLE - sollch-se Infomaçlee/adequap̧o quanto as:

211 tempo de durapho do(s) proced mento(or). FENDENCLATENDIDA.

2.2) Frevlslo de rocos: PENDENCHATENDIDA.

23) Frevlsbo de resorclmento de degesas: FENDENCMATEND DA.

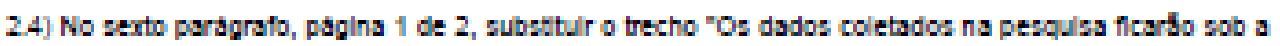
guarda da pesquladora responebvel por um periodo de no minimo clnoo anoa, apta leso serdo dastruldo ou mantidos na Inettulçbo" por "os dsdos e materisla serbo utllzadoa

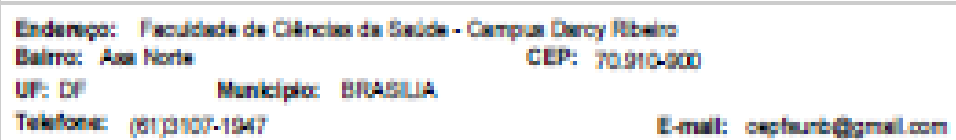




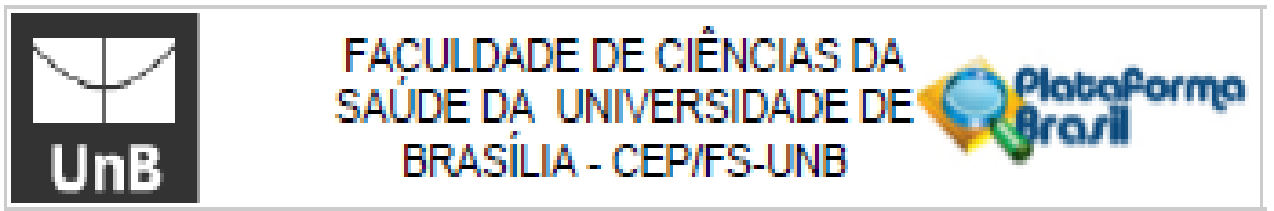

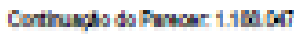

amente para esta peaqula e flcarbo wb a quarda do pesulasdor por um periodo de cinco anos, apde laso seribo destruldos." PENDENCIAATENDIDA

2.5) sollciose suprimir o ultimo paragrato do TCLE: "Eu, full Informads (s) do: objethos da perqua aclma de manelra clara e detalhada e esclarecl dúvidas. Bel que em qualquer momenib poderel solledtar nowas Informaçles e mothar minha declabo se o aselm dese|gr. Desta forms, declaro, de forma llyre e expontinea, que concordo em particlpar dese estudo. Recebl uma copla daste Termo de consentimento Lure e Esclarecldo e me fol dada a opoturldade de ler e exclarecer as mirha dVidas." FENDENCIA ATENDIDA

Fol apresentado TCLE com as adequaple wolchads:

SItuaplo do Parsos:

Aprovado

Nescelta Aproolaplo da cowEP:

No

Concldara, pes FInale a ortbirlo do CEF:

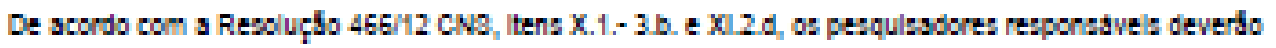
apresentar relatorlos parclal semesiral e final do proleco de pegoulsa, contados a partir da dats de aprovecto do protocolo de pequles.

ERABLIA, 17 de Apoto de 2015

Auslnado por:

Kalla Ellasteth Fontans

(Coordenador)

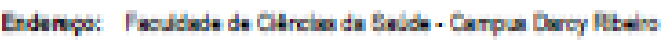

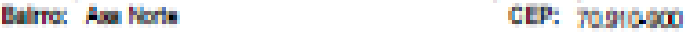

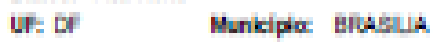

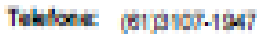

E-mil: betetefinal an 